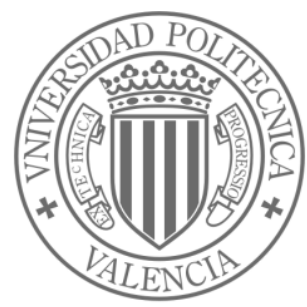

UNIVERSITAT

POLITÈCNICA

DE VALÈNCIA

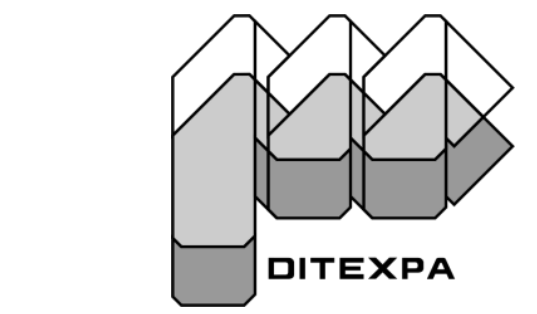

DEPARTAMENTO DE INGENIERÍA

TEXTIL Y PAPELERA

\title{
LA INFLUENCIA DE LAS TECNOLOGÍAS DE LA INFORMACIÓN Y LAS COMUNICACIONES EN LAS PYMES DEL SECTOR TEXTIL. EFECTO DE LA IMPLANTACIÓN DEL COMERCIO ELECTRÓNICO.
}

TESIS DOCTORAL

AUTOR:

F. Javier Muñoz Giner

DIRIGIDA POR:

Roberto García Paya

Alcoy, junio de 2004 

1.INTRODUCCIÓN

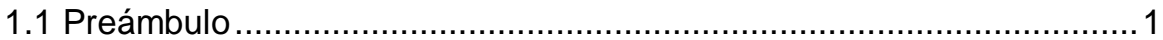

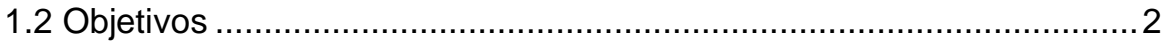

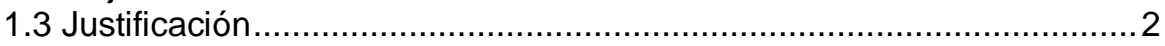

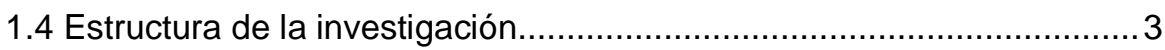

2. MARCO TEÓRICO.................................................................................

2.1 Gestión de intangibles: Capital tecnológico. ....................................... 5

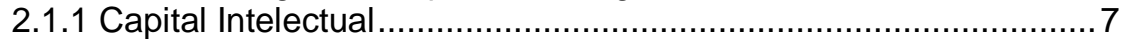

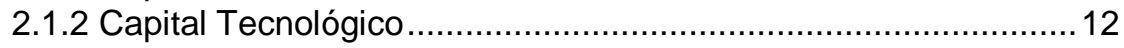

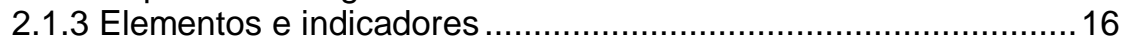

2.1.4 Gestión de la información....................................................... 16

2.1.5 Impacto de las TICs en la Innovación Tecnológica ......................17

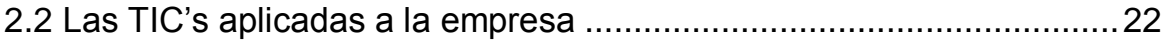

2.2.1 Delimitación de un Sistema Avanzado de Gestión .......................22

2.2.2 Características y estructura técnica. .........................................28

2.2.3 Subsistemas de información. ................................................... 34

2.2.4 Comercio electrónico y Sistemas CRM / SCM ............................35

3. MODELO E HIPÓTESIS DE LA INVESTIGACIÓN. ......................................47

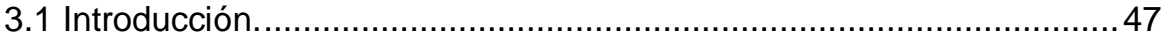

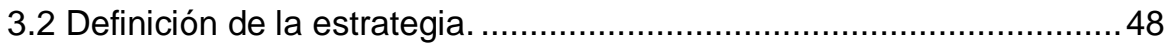

3.3 Implantación de un ERP.......................................................... 49

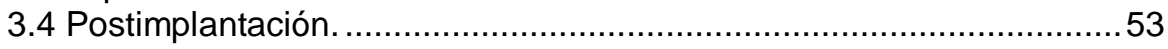

3.5 Factores críticos en la implantación de Sistemas ERP. .......................55

4. SITUACIÓN DE LAS TICS EN EL SECTOR TEXTIL...................................61

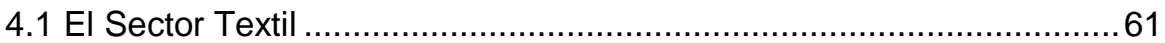

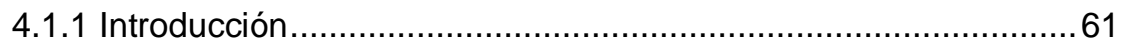

4.1.2 Descripción de la cadena de valor ...........................................64

4.2 Las TIC's en el sector Textil ........................................................... 72

4.2.1 Situación actual .............................................................. 72

4.2.2 Hardware Informático-Telemático. ............................................ 73

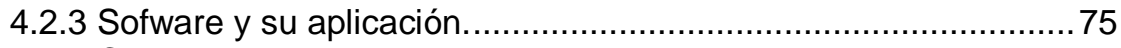

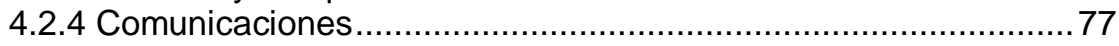

4.2.5 Formación en el entorno de las TICs ........................................ 83

4.3 Perspectivas de las TICs en el Sector Textil. .....................................87

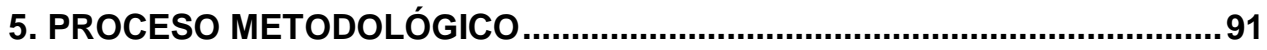

5.1 Introducción............................................................................91

5.2 Concepto y características de la investigación cualitativa...................91

5.3 Características metodológicas .......................................................92

5.3.1 Planteamiento general de los estudios cualitativos ...................... 92

5.3.2 Principales técnicas cualitativas ................................................93 
5.3.3 Muestreo y Trabajo de campo ................................................. 93

5.3.4 Análisis de los Resultados e Informe final ................................94

5.4 El estudio de casos .................................................................94

5.4.1 Concepto y tipología del estudio de casos ................................95

5.4.2 El estudio de casos como estrategia de investigación .................96

5.4.3 Evaluación científica de los estudios de casos. ...........................99

5.5 Diseño e implantación del estudio de casos.........................................98

5.5.1 El objetivo de la investigación. ................................................99

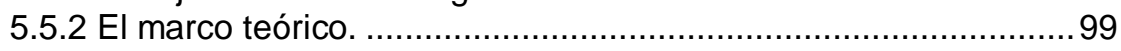

5.5.3 La unidad y el nivel de análisis............................................. 102

5.5.4 La selección de los casos. Caso piloto.................................... 113

5.5.5 El protocolo de cada caso. ..................................................... 104

5.5.6 El informe general y la generalización de los resultados...........104

5.6 Diseño específico de la investigación................................................. 105

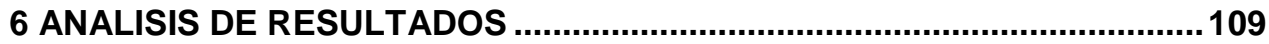

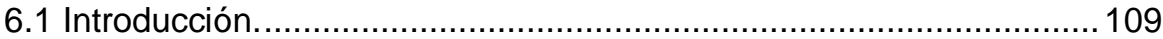

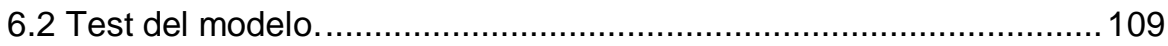

6.3 Análisis de la estrategia de selección: un prototipo..........................110

6.3.1 Metodología de trabajo.........................................................111

6.3.2 Descripción de las Fases .................................................... 112

6.3.2.1 Plan de acción...............................................................112

6.3.2.2 Equipo de gestión del proyecto ……………………......115

6.3.2.3 Análisis de necesidades de la empresa ...........................116

6.3.2.4 Selección de la Solución ERP y contratación....................121

6.3.2.5 Modelo mejorado para la estrategia de selección..............126

6.4 Análisis de casos prácticos y contraste de los Factores

Criticos de Éxito según el modelo de la investigación.............................128

6.4.1 CASO A: Textiles albaida S.A. .......................................... 128

6.4.1.1 El pasado: causas y antecedentes del sistema ERP. .......129

6.4.1.2 El presente: proceso de implantación del ERP. ................130

6.4.1.3 El futuro: la evolución de los sistemas de información......131

6.4.1.4 Lecciones aprendidas. .................................................... 132

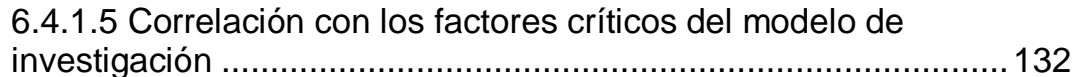

6.4.2 CASO B: Textiles Valencia S.A........................................... 134

6.4.2.1 El pasado: causas y antecedentes del sistema ERP ........135

6.4.2.2 El Presente: selección e implantación del ERP.................136

6.4.2.3 El futuro: la evolución de los sistemas de información......139

6.4.2.4 Lecciones aprendidas. ................................................. 139

6.4.2.5 Correlación con los factores críticos del modelo de

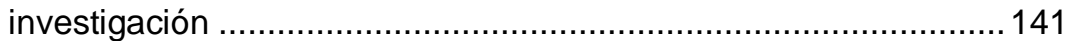

6.4.3 CASO C: Textiles Alcoi S.A................................................ 143

6.4.3.1 El pasado: causas y antecedentes del sistema ERP .........144

6.4.3.2 El presente: desarrollo e implantación del ERP. ................146

6.4.3.3 El futuro: la evolución de los sistemas de información. .....150 
6.4.3.4 Lecciones aprendidas.

6.4.3.5 Correlación con los factores críticos del modelo de investigación

6.4.4CASO D: Textiles Ontinyent, S.A.

6.4.4.1 El pasado: causas y antecedentes del sistema ERP. ........154

6.4.4.2 El presente: proceso de implantación del ERP. ................157

6.4.4.3 El futuro: la evolución de los sistemas de información......160

6.4.4.4 Lecciones aprendidas. ................................................... 161

6.4.4.5 Correlación con los factores críticos del modelo de investigación

6.4.5 Comparativa de los casos analizados ..................................... 163

6.5 Modelo mejorado de los Factores Críticos de Éxito. ......................... 164

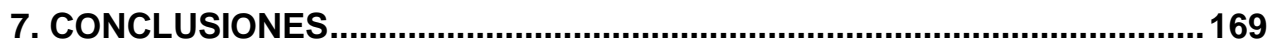

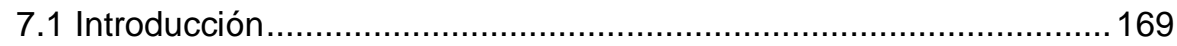

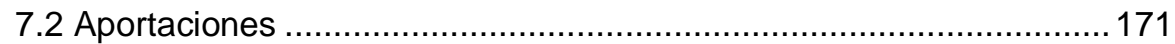

7.2.1 Aportación a la Comunidad Científica ....................................171

7.2.2 Aportación a la Comunidad Empresarial, Social y Política.........171

7.3 Limitaciones y Evolución ................................................................. 172

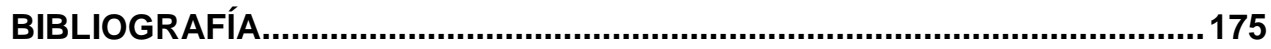

ANEXOS

ANEXO 1

ENCUESTA SOBRE TECNOLOGÍAS DE LA INFORMACIÓN Y

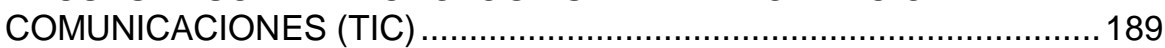

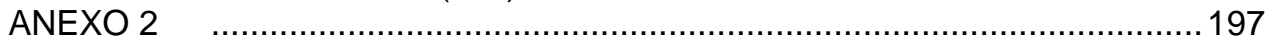

CUESTIONARIO PARA EMPRESAS TEXTILES...............................197

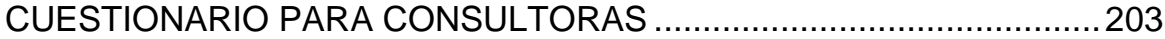

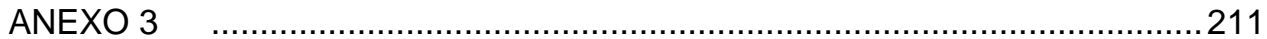

TIPIFICACIÓN DE SOLUCIONES ERPS .................................................211

CLASIFICACIÓN DE CONSULTORAS .........................................2215

FUNCIONALIDADES ESPECIFICAS PARA EL SECTOR TEXTIL..........219

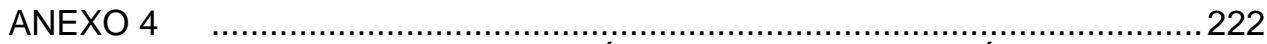

FORMATO PARA LA DEFINICIÓN DEL PLAN DE ACCIÓN..................222

FORMATO PARA LA DEFINICIÓN DEL EQUIPO DE GESTIÓN ...........225

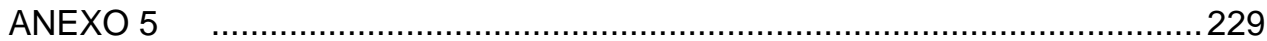

DESCRIPCIÓN DE LOS PROCESOS DE NEGOCIO .........................229

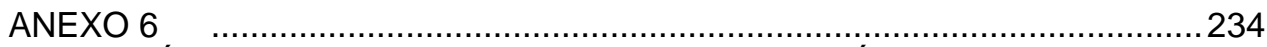

ANÁLISIS DE LOS SISTEMAS DE INFORMACIÓN..................................23

LISTA DE REQUERIMIENTOS A PROVEEDORES DE ERP.................235

ANEXO 7

236

CRITERIOS DE EVALUACIÓN DE LA SOLUCIÓN ERP ...........................236 


\section{RESUMEN}

Título: "La influencia de las Tecnologías de la Información y las Comunicaciones en las PYMES del Sector Textil. Efecto de la implantación del comercio electrónico."

Autor: F. Javier Muñoz Giner

Director: Dr. Roberto García Payá

El presente trabajo de investigación trata acerca de una temática clave en el desarrollo competitivo de las empresas y por tanto necesaria para la supervivencia de las mismas. El área de la Tesis son las Tecnologías de la Información y las Comunicaciones y la influencia de las mismas en el Capital Tecnológico de las empresas. En concreto el estudio se ha realizado dentro del Sector Textil de la Comunidad Valenciana.

En la investigación se ha propuesto un modelo específico de gestión para las empresas objeto de estudio que permita la elaboración de una estrategia tecnológica en sistemas de información coherente con la estrategia general de la empresa y que posibilite una implantación eficiente de los Sistemas Avanzados de Gestión.

El modelo planteado se ha contrastado en casos reales del sector obteniendo un modelo mejorado a través de técnicas cualitativas que permite seleccionar los sistemas de información de apoyo a los procesos de negocio atendiendo a diversos factores, entre los que destaca la oportuna identificación de los elementos críticos en la implantación de dichos sistemas y su correcta secuencia contemplando tanto factores técnicos como organizativos y haciendo especial énfasis en los aspectos y funcionalidades específicas para las pequeñas y medianas empresas del Sector Textil.

Las conclusiones de la validación del modelo en el sector productivo del textil de la Comunidad Valenciana determinan la líneas de actuación prioritarias para fortalecer los puntos débiles actuales y generar una ventaja competitiva que les permita afrontar la nueva situación del mercado con éxito y diferenciación, tomando como herramienta de mejora competitiva la implantación eficaz de los Sistemas Avanzados de Gestión y su evolución hacia el e-business. 


\section{RESUM}

Títol: "L'influència de les Tecnologies de L'Informació i les Comunicacions a les PYMES del Sector Textil. Efecte de l'implantació del comerç electrònic."

Autor: F. Javier Muñoz Giner

Director: Dr. Roberto García Payà

El present treball d'investigació tracta d'una temática clau al desenvolupament competitiu de les empreses i per tant necessaria per a la supervivència d'aquestes. El àrea de la Tesi són les Tecnologies de L'Informació i les Comunicacions i l'influència d'aquestes al Capital Tecnològic de les empreses. En concret l'estudi que s'ha realitzat dins del Sector Textil de la Comunitat Valenciana.

A l'investigació s'ha proposat un moldel específic de gestió per a les empreses tèxtils d'estudi que permeta l'elaboració d'una estratègia tecnològica als sistemes d'informació coherent amb l'estratègia general de l'empresa i que faja possible una implantació eficient dels Sistemes Avançats de Gestió.

El model plantejat s'ha possat a prova a casos reials del sector obtenint un model millorat gràcies a tècniques qualificatives que permet seleccionar els sistemes d'informació de suport als procesos de negoci tenint en compte diversos factors, entre els quals destaca l'oportuna identificació dels elements crítics a l'implantació d'aquestos sistemes i la seva correcta seqüència tenint en compte tant factors tècnics com organitzatius i mostrant especial interés als aspectes i funcionalitats específiques per a les petites i mitjanes empreses del Sector Textil.

Les conclusions de la validació del model al sector productiu del textil de la Comunitat Valenciana determinen les línies d'actuació prioritaries per tal d’enfortir els punt dèbils actuals i generar una ventatja competitiva que els permeta afrontar la nova situació del mercat amb èxit i diferenciació, tenint com a eina de millora competitiva l'implantació eficaç dels Sistemes Avançats de Gestió i la seva evolució cap al e-business. 


\section{SUMMARY}

Title: "The influence of communication and information technologies on textile sector small and medium sized companies. The effect of the implementation of e-commerce."

Author: F. Javier Muñoz Giner

Director: Dr. Roberto García Payá

This research work deals with a topic which is crucial for the competitive development of companies and which is therefore necessary for their very survival. The subject area is communication and information technologies and the influence these exercise on the technological capital of companies. In particular, the study was carried out within the Valencian Community textile sector.

In the research, a specific management model for the companies which are the object of study has been proposed. Such model facilitates the elaboration of a technological strategy for information systems which is coherent with the general company strategy and which enables an efficient implementation of advanced management systems.

The model established has been contrasted with real cases from the sector and an improved model has been obtained by means of qualitative techniques that facilitate selecting information systems that support business processes by dealing with various factors. Among these, the appropriate identification of elements critical to the implementation of these systems and their correct sequence are notable. Both technical and organisational factors are considered and special emphasis is made on specific aspects and functions for small and medium sized textile companies.

The conclusions from the validation of the model in the Valencian Community textile production sector determine the priorities in order to strengthen current weak points and generate a competitive advantage that facilitates confronting the new market situation successfully and innovatively. The efficient implementation of advanced management systems and their evolution towards e-business is being used as a tool for competitive improvement. 


\section{TESIS DOCTORAL}

LA INFLUENCIA DE LAS TECNOLOGÍAS DE LA INFORMACIÓN Y LAS COMUNICACIONES EN LAS PYMES DEL SECTOR TEXTIL. EFECTO DE LA IMPLANTACIÓN DEL COMERCIO ELECTRÓNICO. 


\section{INTRODUCCIÓN}

\section{$1.1 \quad$ Preámbulo}

El modelo económico actual de la industria textil y de la confección se debe enmarcar en un entorco caracterizado por la globalización de los mercados, la reducción del ciclo de vida de los productos, el cambio continuo en las preferencias de los clientes, los requisitos medioambientales, el surgimientos de nuevos negocios, la emergencia de nuevas tecnologías, la mutación y la desaparición de ciertos mercados, la deslocalización geográfica de las empresas, la sobrecapacidad de la producción y en definitiva en la complejidad, la incertidumbre, la hipercompetición y el cambio continuo y a veces radical. Todo ello, esta dando lugar a una estructura productiva e industrial mucho más amenazada y vulnerable donde las empresas se ven obligadas a rediseñar continuamente sus estrategias de negocios, a la reorganización y flexibilización de sus procesos productivos, a la renovación continua del catálogo y la calidad de sus productos, al desarrollo de nuevas capacidades competitivas y a la gestión del conocimiento y específicamente al fomento de la innovación como elemento clave de competitividad. Esto pasa necesariamente por integrar la gestión de la innovación en su estrategia de negocio, impulsar los procesos de aprendizaje y la mejora continua, en fortalecer y proteger sus activos intangibles, en reducir los tiempos de desarrollo y en fomentar la cooperación y el trabajo en equipo como elemento sinérgico, de creatividad y mejora de la competitividad.

La situación supone que se debe plantear la necesidad de un cambio de paradigma para fortalecer la competitividad del sector. De esta forma, a través de esta investigación se pretende analizar la necesidad del uso de las Tecnologías de la Información y proponer nuevos modelos que permitan incrementar el valor de las empresas del sector textil fortaleciendo su posición competitiva dentro del mercado global.

Encontramos precedentes en el presente trabajo en proyectos como "el cambio en la PYME ante la sociedad de la información. Aplicación a empresas del sector textil de la Comunidad Valenciana. Desarrollo de herramientas de análisis, diagnostico e intervención en las organizaciones" ( Plan Nacional I+D ref.: 1FD972251-C02-01) en el que el autor de esta tesis trabajo como investigador y en otros estudios (J. Muñoz, 1999; Gonzalez, 2001; Miñana, 2001; Rodenes, 2002; Gil, 2003).

Así mismo, la necesidad de esta investigación esta de manifiesto en gran cantidad de trabajos entre ellos los presentados más recientemente en el congreso APLIMATEC 2004 "innovaciones en los materiales y los productos y su incidencia en los procesos textiles" (Libert Coll 2004) e "innovación en la gestión de empresas" (Isidre Marimón 2004). 


\subsection{Objetivos}

Los objetivos que persigue la presente investigación son los siguientes:

Objetivo General:

Contribuir al desarrollo de un modelo para el fortalecimiento de la competitividad en el sector textil por medio la correcta utilización de sistemas y tecnologías de la información.

Objetivos Específicos:

- Analizar la situación tecnológica en lo referente a sistemas de información del sector textil.

- Determinar los riesgos que las empresas de este sector soportan al gestionar sistemas y tecnologías de la información.

- Elaborar una metodología en base al trabajo de campo realizado que permita entre otras cosas:

1. Seleccionar los sistemas de información de apoyo a los procesos de negocio adecuados atendiendo a diversos factores, entre los que cabe citar: sistemas heredados, recursos de toda índole y la propia naturaleza y estrategia empresarial.

2. Definir los elementos de la implantación de dichos sistemas y su correcta secuencia contemplando tanto factores técnicos como organizativos.

- Proponer un modelo específico de gestión para las empresas objeto de estudio que permita la elaboración de una estrategia tecnológica en sistemas de información coherente con la estrategia general de la empresa y que posibilite una implantación eficiente.

- Aportar una sistemática que permita a las empresas disminuir los riesgos existentes, tanto los que se derivan de la reducción de la complejidad como de la ambigüedad

\subsection{Justificación}

Las razones que me han llevado al desarrollo de este trabajo de investigación son las siguientes: Tal y como se comenta en el preámbulo de este capítulo, la situación del sector precisa el incremento de la productividad por medio de, entre otras vías, las innovaciones tecnológicas y de procesos, a través de la implantación de Sistemas Avanzados de Gestión. Hay que mencionar también, el elevado número de fracasos existentes a la hora de implantar sistemas de información de apoyo a las operaciones. 
Estas realidades justifican la investigación, en tanto que se puedan reducir los riesgos que se dan en esos procesos, disminuyendo los costes tanto de índole económica como organizativa, de forma que al difundirse los resultados en la comunidad empresarial se disponga de un conjunto de experiencias que convenientemente procesadas y tratadas constituyan una suerte de cuaderno de bitácora que guíe en el proceso de selección e implantación de estos sistemas a las empresas del sector.

\subsection{Estructura de la investigación}

El trabajo de investigación que se presenta, consta de los apartados que se muestran en la siguiente tabla:

\begin{tabular}{|l|l|}
\hline Capítulo 1 & Introducción \\
\hline Capítulo 2 & Marco Teórico \\
\hline Capítulo 3 & Modelo e Hipótesis de trabajo \\
\hline Capítulo 4 & Situación de las TIC en el sector Textil. \\
\hline Capítulo 5 & Proceso metodológico \\
\hline Capítulo 6 & Análisis de Resultados \\
\hline Capítulo 7 & Conclusiones \\
\hline ANEXOS & \\
\hline BIBLIOGRAFÍA & \\
\hline
\end{tabular}

Tabla 1.1: Organización de la Investigación.

En el capítulo 1 INTRODUCCIÓN se realiza una breve introducción que pretende situar la temática de esta investigación, presentar los objetivos del estudio y justificar el mismo indicando las motivaciones y realidades que son causa del mismo.

El capítulo 2 MARCO TÉORICO recoge los antecedentes teóricos que sirven de base para definir el marco y entorno del objeto de estudio. Son abordados entre otros los siguientes elementos:

- Gestión de intangibles: capital tecnológico.

- Las tecnologías de la información y las comunicaciones TIC's aplicadas a la empresa. Gestión y comercio electrónico.

El capítulo 3 MODELO E HIPÓTESIS DE TRABAJO define las hipótesis de partida y se crea un MODELO para contrastarlo partiendo de la investigación previa.

El capítulo 4 SITUACIÓN DE LAS TIC's EN EL SECTOR TEXTIL hace referencia la situación previa en la que se encuentra la población donde se ha aplicado el modelo anterior: el sector textil de la Comunidad Valenciana. 
El capítulo 5 PROCESO METODOLÓGICO describe la metodología empleada en la investigación.

El capítulo 6 ANÁLISIS DE RESULTADOS presenta los resultados obtenidos como fruto de la investigación empírica y su discusión. Así como, la determinación de los modelos mejorados fruto de las investigaciones llevadas a cado en la Tesis.

Finalmente, en el capítulo 7 CONCLUSIONES se recogen las conclusiones obtenidas tras el proceso investigador en relación al modelo propuesto, las hipótesis de partida y a su vez se reflexionará sobre la potencial implicación que supone este estudio para las diferentes comunidades: social, académica, empresarial y política. Finalmente se proponen futuras líneas de investigación que puedan derivarse del trabajo actual.

La memoria concluirá con la parte correspondiente a los Anexos y la Bibliografía usada para la elaboración de la presente Tesis Doctoral. 


\section{MARCO TEÓRICO}

\subsection{Gestión de intangibles: Capital tecnológico.}

Existe una incuestionable e imparable tendencia hacia la globalización de la economía. Las empresas se encuentran ante un entorno condicionado por esa globalidad donde la variedad o multiplicidad de factores da lugar a la complejidad, aspecto del entorno que nos conduce a una segunda característica del mismo que se ha de considerar: la incertidumbre. A estas dos características se les une una tercera, el dinamismo del entorno, que implica que los cambios que se producen sean intensos, frecuentes y muy rápidos.

Las anteriores características generales del entorno con que se encuentran las empresas, suponen un endurecimiento de la competencia para las mismas, lo que comprometerá en gran medida su rentabilidad actual y futura, así como su capacidad de supervivencia. Lo que determina la rentabilidad de una empresa es su competitividad (Porter, 1990), y esta, a su vez, será el resultado de ocupar una posición ventajosa en lo referente a productos y servicios, sistemas de producción, servicios al cliente, recursos humanos, etc. Por lo tanto, partiendo de la idea de que el cambio preside el entorno actual y, lógicamente, el futuro, para asegurar una posición competitiva ventajosa en estas áreas, a la empresa no le queda otra opción que la de "seguir el ritmo del progreso", es decir, le será necesario una actividad de innovación permanente que haga posible la introducción a tiempo de los cambios precisos para ir delante de la competencia.

Es evidente, entonces, que el proceso evolutivo del entorno está presidido por un fenómeno que se puede expresar con una única palabra: "cambio", que exige de las empresas y de las personas una perfecta sincronización que requiere nuevos sistemas de valores y nuevas perspectivas. Las cosas están cambiando demasiado rápido para mantenerse atados al pasado. En resumen, nos podemos manejar en el cambio, pero no podemos manejar el cambio, hay que estar preparado ante el mismo para cuando éste llegue.

El objetivo del análisis estratégico ha sido siempre explicar los motivos por los que empresas, que desarrollan su actividad en el mismo entorno competitivo y que por lo tanto estarían sujetas a los mismos factores de éxito, obtienen niveles de rentabilidad diferentes (Porter, 1982; Porter, 1990; Barney, 1991, Hamel y Parlad, 1995).

\section{Cambio de Paradigma estratégico}

Previamente a la Teoría de Recursos y Capacidades, se utilizaba el modelo de cinco fuerzas de Porter (Porter, 1982) como herramienta fundamental para entender el entorno competitivo y las fuerzas que desde el exterior influían en las empresas de un mismo sector. Estas cinco fuerzas consideradas son: 
competidores actuales, competidores potenciales, productos sustitutivos, proveedores y clientes.

La Teoría de Recursos y Capacidades supuso un cambio de paradigma en el análisis estratégico, pasando de un enfoque exterior a un enfoque interno basado en los recursos y capacidades de la empresa. Las tres ideas básicas sobre las que se sustenta esta teoría son las siguientes:

1) Las empresas son diferentes entre sí tanto por los recursos y capacidades que poseen en un momento dado, como por las diferentes características de los mismos (Barney, 1991; Ventura, 1996).

2) Los recursos y capacidades de una empresa juegan un papel cada vez más relevante en la definición de la identidad de la misma.

Como afirma Grant (1996):

"cuanto más dinámico sea el entorno de la empresa, más sentido tiene basar su estrategia en los recursos y capacidades internos frente a hacerlo sobre consideraciones de tipo externo."

3) El beneficio de una empresa es consecuencia tanto de las características competitivas del entorno, como de los recursos de que dispone. No obstante, la competitividad empresarial depende cada vez más de factores de carácter intraempresarial.

Por todo lo anterior, la Teoría de Recursos y Capacidades se convierte en un instrumento esencial para el análisis interno y la formulación de la estrategia de la empresa.

Para ello, en primer lugar, la empresa debe identificar sus propios recursos y capacidades de modo que conozca con detalle su potencial de partida para definir la estrategia. Después, será necesario evaluar el valor de su inventario de recursos y capacidades. Y por último, la empresa deberá analizar sus posibles opciones estratégicas disponibles a partir de la disponibilidad de recursos y capacidades y de su valor potencial (Grant, 1996).

En relación con esto, Prahalad y Hamel (2001) afirman:

"Los rápidos cambios en el mundo industrial hacen que sea necesario que los directivos no sólo reconozcan y gestionen las capacidades existentes en la empresa, sino que además desarrollen con rapidez otras nuevas. A veces, hay que desechar determinadas capacidades para poder adaptarse a la nueva realida

Actualmente la teoría de que los activos intangibles constituyen el principal recurso competitivo de la empresa es mantenida por numerosos autores de renombre y prestigio internacional (Kaplan y Norton, 1992; Bontis, 1996; López, 1996; Brooking, 1997; Edvinsson y Malone, 1997; Roos y Roos, 1997; Steward, 1997; Sveiby, 1997; Bueno, 1998; Drogoneti y Roos, 1998; Euroforum, 1998; Bueno, 
1999 a; Roos y Lövingsson, 1999; Bueno y Salmador, 2000; Camisón y otros, 2000; Kaplan y Norton, 2000; Ordoñez, 2000; Bueno 2001; CIC, 2002). Esto es lo que podíamos considerar como un nuevo cambio de paradigma en la realidad competitiva actual.

\subsubsection{Capital Intelectual}

Se puede definir, inicialmente, como activo intangible todo aquello que utiliza una empresa para crear valor, pero que no contabiliza (Edvinson y Malone, 1997). Este concepto es el responsable de la diferencia (normalmente positiva) entre el valor bursátil y el valor contable de una empresa.

En los últimos años ha crecido el interés del sector empresarial por la medición de los activos intangibles, ya que han visto en ellos una fuente básica para la generación de ventajas competitivas perdurables en el tiempo. Se trata pues de averiguar qué características deben cumplir estos recursos para adquirir un carácter estratégico.

Numerosos autores han escrito sobre ello, algunas aportaciones aparecen a continuación:

Grant (1991) dice que han de ser:

"duraderos, difíciles de identificar y comprender, imperfectamente transferibles, no fácilmente duplicables, y en los cuales la empresa posee clara propiedad y control"

Amit y Schoemaker (1993) exigen que:

"sean difíciles de intercambiar, imitar o sustituir, escasos, complementarios, duraderos, apropiables, y que varían con los cambios en el conjunto relevante de factores estratégicos de la industria".

En definitiva, son los activos intangibles los que gracias a su intensidad en conocimiento, se convierten en activos escasos, valiosos, difícilmente imitables por terceros, etc. y por tanto, idóneos para generar ventajas competitivas perdurables en el tiempo.

A partir de este creciente interés, los activos intangibles han sido denominados Capital Intelectual, y se ha creado toda una disciplina dedicada a ello.

Eduardo Bueno (2001), uno de los mayores exponentes españoles en este campo, afirma que:

"el Capital Intelectual representa la suma integrada de los diferentes activos intangibles, y es la 'cuenta y razón' de los intangibles de la organización. De un lado es la 'cuenta' del valor creado gracias a las actividades intangibles existentes en la empresa y de otro, sirve como 'razón' frente a propios y terceros de la creación de valor producido por los procesos de conocimiento en acción".

Edvinsson y Malone (1997), comparan a la empresa con un árbol, con su tronco, sus ramas y sus hojas, que dan fruta madura. Los estados financieros y otros 
folletos informan sobre el estado del tronco, ramas y hojas, es decir de los activos tangibles. Los frutos son los resultados, el valor de la empresa en el mercado. Pero también hay que tener en cuenta que el árbol tiene unas raíces invisibles (activos intangibles) que nos ayudan a conocer la salud del árbol en el futuro (por ejemplo, si hay un parásito en la raíz a diez metros bajo la tierra que puede acabar con la aparente salud del árbol) y van a permitir al árbol (la empresa) sobrevivir ante una sequía o helada (problemas).

Para terminar de rizar el rizo en esta maraña de conceptos, Eduardo Bueno distingue en un artículo (Bueno, 2001) entre Capital Intelectual y Capital Intangible, siendo el primero un concepto estático que representa la suma de los activos intangibles de la organización y el segundo, un concepto dinámico que engloba todas sus actividades intangibles. Por tanto el Capital Intangible es mayor que el Capital Intelectual, siendo la diferencia las actividades intangibles que todavía no se han concretado en activos intangibles (recursos). Según Eduardo Bueno, una buena gestión de las capacidades dinámicas permite disminuir esta diferencia.

Así, recurriendo de nuevo al ejemplo del árbol de Edvinsson y Malone (1997), Eduardo Bueno explica el mismo de la forma:

- Las raíces del árbol son los activos intangibles (Capital Intelectual)

- El clima, el agua, el abono, los cuidados del labrador, etc. son los elementos dinámicos que junto con el Capital Intelectual, forman el Capital Intangible.

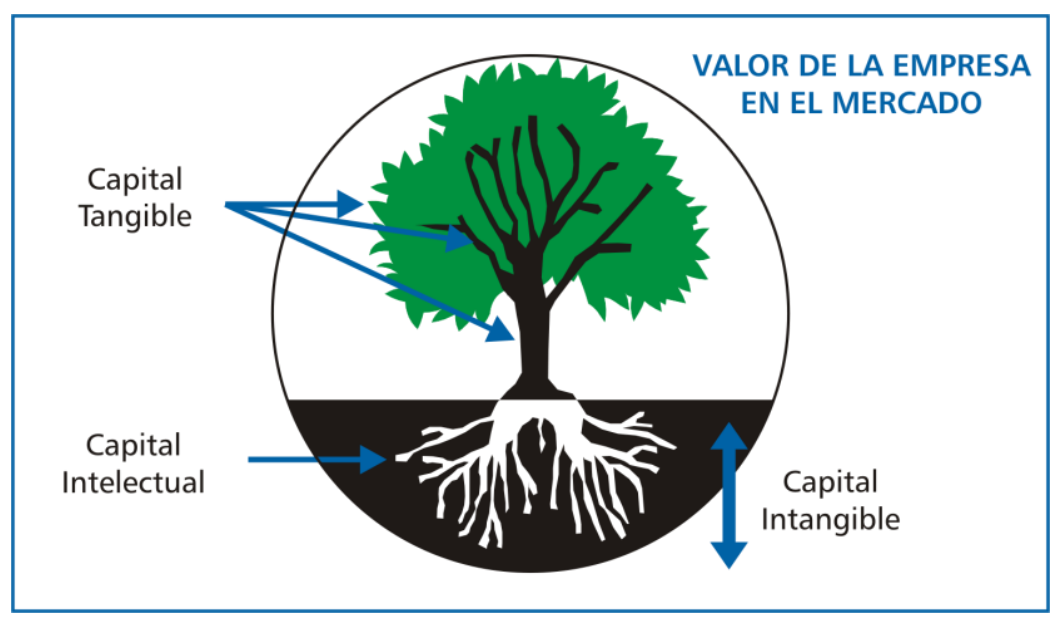

Figura 2.1 Capital Intangible frente a Capital Intelectual. Fuente: Bueno, 2001

El Capital Total de una Organización, siguiendo a Roos y Lövingsson (1999) se divide en dos grandes ramas: el Capital Financiero y el Capital Intelectual tal y como vemos en la figura siguiente. 


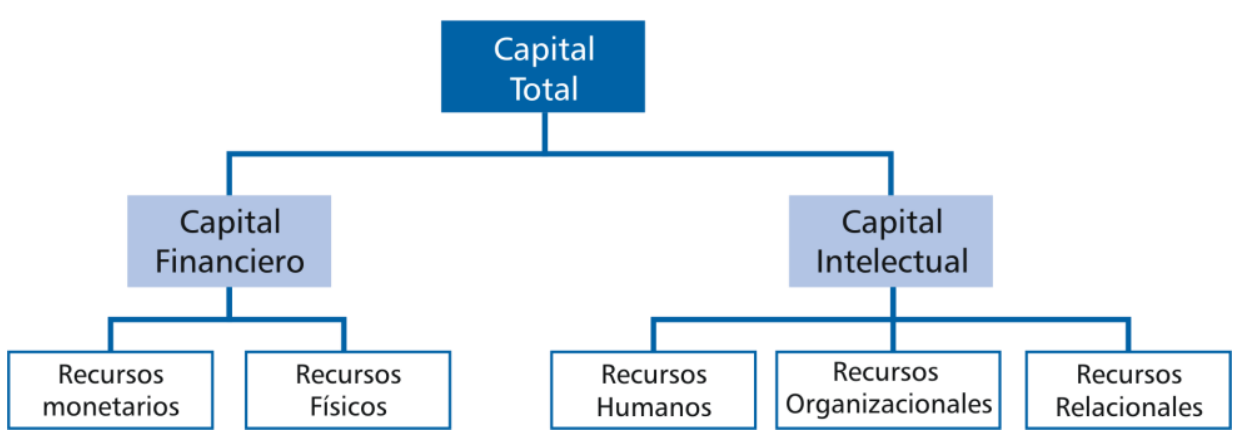

Figura 2.2 Capital Total. Fuente: Göran Ross y Fedrik Lövingsson, 1999.

Este gap representado por el Capital Intelectual entre el valor de mercado y la suma de los valores de la empresa se denomina goodwill, y representa, si es positivo, la cantidad que un posible comprador estaría dispuesto a pagar por encima del valor de los libros.

Tradicionalmente, la única forma que había de conocer los activos intangibles era en momentos de fusiones y adquisiciones, a través del fondo de comercio o goodwill, concepto financiero que expresaba la diferencia entre el valor contable de la empresa y el precio pagado por ella en el momento de la adquisición.

Según López y Vázquez (2002) el goodwill:

"hace referencia a la parte de valor de negocio que excede la suma de los valores de los activos que lo conforman; que no es una partida estable en los estados contables como pudiera serlo un activo fijo". "Su naturaleza es totalmente subjetiva, en el sentido que no sólo su cuantificación sino incluso su propia identificación dependen del modo de realizar la valoración, de la persona que la realice y del objetivo que se pretende con ella".

Por consiguiente estamos sumergiéndonos en un mundo empresarial que valora como activo el conocimiento residente en las mentes de las personas sobre el negocio.

El Capital Intelectual (Cl), como vemos en la anterior figura, está estructurado en 3 subsistemas: los Recursos Relacionales, Organizacionales y Humanos:

1. Los Recursos Relacionales: contemplan las relaciones con sus grupos de interés, clientes y proveedores.

2. Los Recursos Organizacionales ${ }^{1}$ : según Roos y Lövingsson, consisten en "todos los elementos intangibles propiedad de la compañía, como

${ }^{1}$ Esta investigación se centra precisamente en el rol que desempeña el capital tecnológico que es precisamente un recurso organizacional de la empresa. 
procesos, infraestructura, sistemas, marcas, etc.". Aquí también se incluyen la tecnología que toda empresa debe tener para guardar el conocimiento explícito y el tácito que ha podido traducirse en explícito ${ }^{2}$.

3. Recursos Humanos: no se va a establecer distinción alguna entre Recursos Humanos y el Capital Humano. A pesar de que muchas empresas tienen un departamento de RR.HH no acorde con la filosofía el empleado como inversor. Este departamento es la base misma de los empleados, y no el enemigo al otro lado de la mesa del convenio colectivo.

Es vital que la empresa tenga herramientas de control sobre el Capital Intelectual.

Por lo tanto, el Capital Intelectual se convierte en el nuevo activo para la riqueza de las organizaciones. En la valoración de este Capital Intelectual, nos apoyamos en diversos modelos de referencia, que nos sirven para justificar el componente del Capital Tecnológico en el que se apoya nuestra investigación y el cual trataremos en un apartado independientemente y con algo más de profundidad.

Los componentes del Capital Intelectual de las Organizaciones estudiados serían:

1. Capital Humano (Kaplan y Norton, 1992; Bontis, 1996; Sveiby, 1997; Edvinson y Malone, 1997; Brooking, 1997; Roos y otros, 1997; Camisón y otros, 2000; Euroforum, 1998; Bueno, 1998; CIC, 2002). Precisamente este Intangible es la base del Capital Intelectual de la Organización.

2. Capital Estructural (Bontis, 1996; Sveiby, 1997; Edvinson y Malone, 1997; Brooking, 1997; Roos y otros, 1997; Euroforum, 1998). Siguiendo a Bueno (1998) y las investigaciones del Centro de Investigación sobre la Sociedad del Conocimiento (CIC, 2002), el Capital Estructural se puede descomponer en Tecnológico y Organizativo $^{3}$. Dentro del Capital Organizativo se considera el elemento Cultura Organizativa (Alió, 2001; CIC, 2002; Díez, 2002; Moncaleano, 2002) como indicador clave estratégico para aumentar el valor de este Capital Organizativo. Otros autores como Camisón y otros (2000), incluyen dentro del capital estructural, el Capital Social y el Capital de Innovación y Aprendizaje.

3. Capital Relacional (Bontis, 1996; Sveiby, 1997; Roos y otros, 1997; Euroforum, 1998; Bueno, 1998; CIC, 2002). Algunos autores particularizan este capital al mercado y hablan de Capital Clientes

\footnotetext{
${ }^{2}$ Nonaka cita la posible migración de: tácito a explícito, tácito a tácito, explícito a explícito y explícito a tácito.

${ }^{3}$ También comparten esta distinción de Capital Organizativo: Edvinson y Malone (1997), Roos y otros (1997) y Camisón y otros (1999).
} 
(Kaplan y Norton, 1992; Sveiby, 1997; Edvinson y Malone, 1997; Brooking, 1997).

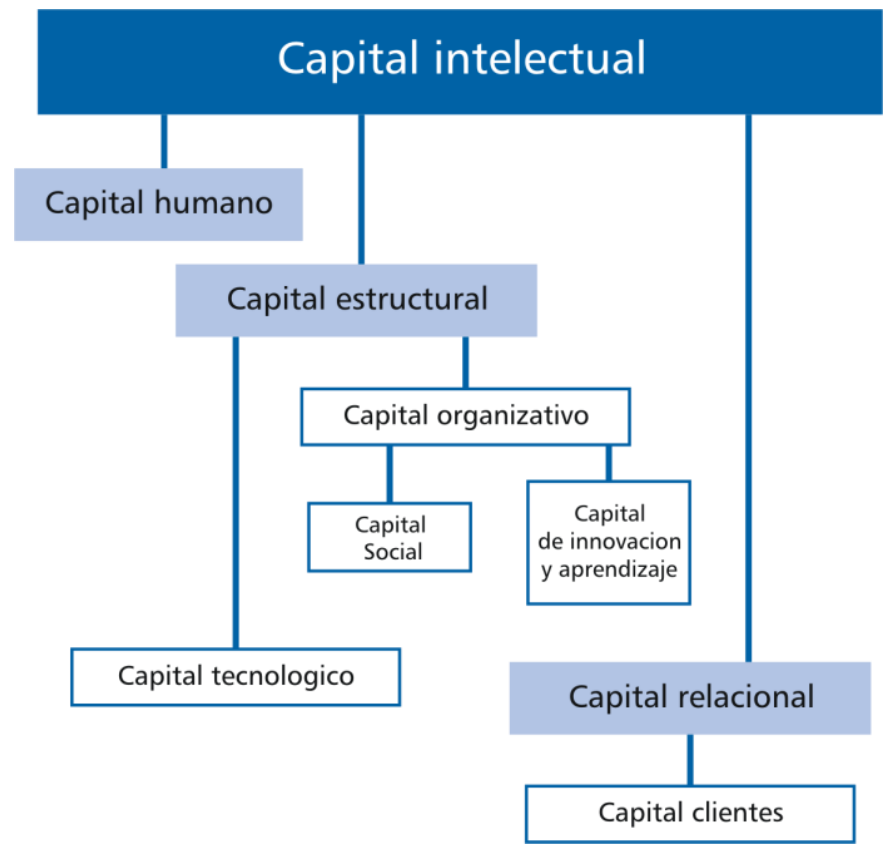

Figura 2.3 : Elementos del Capital Intelectual. Gil (2003)

La identificación del $\mathrm{Cl}$ dentro de una empresa no es inmediata. Cualquier método parte de un denominador común. En un primer momento, la empresa debe de averiguar cuales de sus factores son clave, es decir, los Factores Clave de Éxito (FCE).

Siguiendo a Roos y otros (1999) los podemos definir "como las actividades que desencadenan el mayor avance hacia el propósito estratégico elegido en el continuo coste ofrecido/ valor percibido".

Röos y Lövingson en su experiencia en Ericsson Business Consulting Norrköping (EBCN) identificaron los siguientes FCE:

- Orientación al cliente,

- Innovación y

- Capacidad de cambio.

Los FCE son consignas generales para conseguir los objetivos de las empresas. A su vez para lograr los FCE será necesario multitud de factores relacionados y operando entre si. Todos los procedimientos para conseguir los FCE serán tan clave como los mismos FCE a la hora de hacer crecer el activo del $\mathrm{Cl}$. 
Una vez identificados los FCE, las herramientas para conseguir estos y los grupos de interés tenemos la base para localizar el Cl de la empresa (Roos y otros, 1999). Además de esto, una Gestión de Competencias (Cubeiro, 2002) trata de acondicionar los equipos para que trabajen en un entorno agradable. También se encargará de la formación acerca de los aspectos de su tarea.

Uno de los FCE en las organizaciones de la época actual es la apuesta por el fortalecimiento del Capital Tecnológico con la incorporación de las Tecnologías de la Información y las Comunicaciones (TIC's) en todos los procesos de la organización (Andreu, Ricart i Valor, 2000).

Por otro lado, la cultura organizacional es parte de la filosofía de la empresa.

Según Elías y Mascaray (1998):

"modificar una cultura y orientarla en un determinado sentido, imprimiéndole el ritmo y la velocidad adecuada, no es tarea fácil".

Para ello proponen un método para llevar a cabo un cambio cultural que se basa en una serie de pasos a seguir que tiene como bases:

1. El cambio cultural debe ser promovido e impulsado por la dirección; pero no puede ser impuesto. El cambio cultural debe ser resultado de la participación activa de toda la organización. En las organizaciones actuales y de un futuro inmediato, el cambio cultural no es un hecho puntual que debe acometerse en momentos de crisis. El cambio cultural en la empresa de hoy debe ser permanente; ha de constituir uno de los valores más significativos de la cultura 0 , mejor aún, debe impregnar toda la cultura a convertirse en 'cultura de cambio'.

2. La comunicación es el instrumento que permite la participación activa de todos los elementos integrantes de la empresa para conseguir el cambio cultural.

Se identifica entonces, una Resistencia al cambio ante la implantación del nuevo sistema. Esta resistencia será tanto a la hora de integrar estos nuevos sistemas como en el uso, por parte de la organización de ellos.

\subsubsection{Capital Tecnológico}

La inexistencia de un bloque específico referente al capital tecnológico dentro del modelo Intelect (1998), tal y como observamos en la siguiente figura, hace necesaria la definición de lo que debe entenderse por el mismo, así como los conceptos que sirven de soporte a la estructura del modelo: el proceso de innovación tecnológica y la tecnología. 


\section{CAPITAL INTELECTUAL}

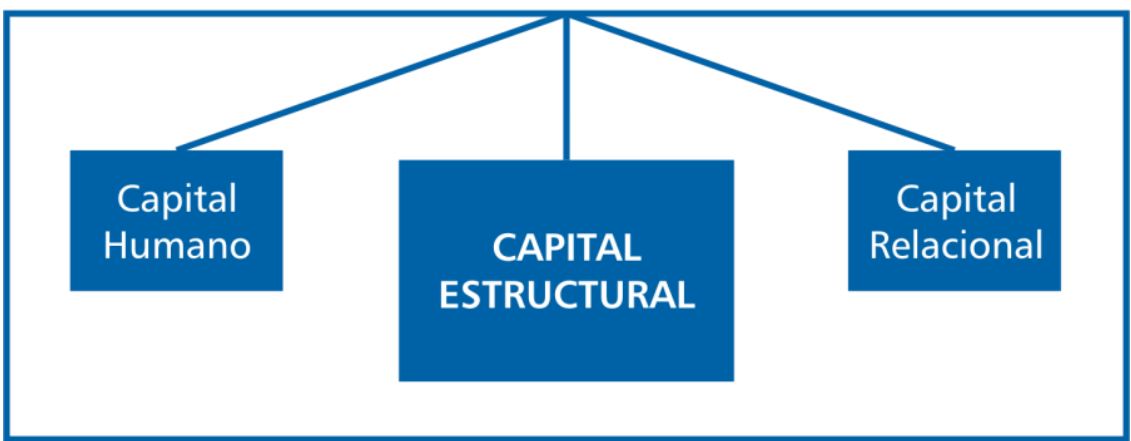

Figura 2.4 .- El capital Intelectual en el Modelo Intellectus (Intelect, 1998)

Así, en lo relativo al capital tecnológico el segundo reto planteado ha sido la definición de los principales conceptos objeto de estudio de forma que quedara justificada la necesidad de desagregar el fenómeno tecnológico respecto del componente organizativo.

La distinción entre el proceso de innovación tecnológica y tecnología resulta coherente con la dimensión temporal de la propuesta original del Modelo Intelect (1998).

\begin{tabular}{|l|}
\hline PRESENTE: \\
\hline -Propiedad Intelectual \\
-Tecnología de Proceso \\
-Tecnología de Producto \\
-Procesos de Apoyo \\
-Procesos de Captación de Conocimiento \\
-Mecanismos de Transmisión y Conocimiento \\
-Tecnología de la Información \\
\hline FUTURO: \\
\hline -Procesos de Innovación \\
\hline
\end{tabular}

Tabla 3.1 .- Proceso de innovación tecnológica, presente y futuro (Intelect, 1998)

De este modo, el proceso de innovación tecnológica se define como aquel en virtud del cual la empresa adquiere, desarrolla, integra, conserva (o abandona) los intangibles tecnológicos que, según las características de la industria y de la organización, se consideren (o no) necesarios para la creación de valor en el tiempo. Este proceso se caracterizará por ser dinámico y continuo de forma que la empresa juegue un papel esencial en la determinación de la dirección y del ritmo del mismo, mediante las distintas modalidades de aprendizaje. 
Realizando una interrupción ficticia en el proceso de innovación tecnológica podemos aproximarnos al concepto de tecnología. De este modo, queda definida como el volumen de intangibles tecnológicos que dispone la empresa en un momento determinado del tiempo en virtud del proceso de innovación tecnológica acontecido a lo largo de su evolución histórica. En este sentido, la tecnología vendría definida como la variable input/output del proceso de innovación tecnológica.

El capital tecnológico vendría a ser el elemento de soporte a estos dos anteriores. Así, podría definirse como aquel componente del capital intelectual que incluye los intangibles tecnológicos responsables de la consecución y mantenimiento de la ventaja competitiva así como de la apropiación de las rentas generadas y, por tanto, que aseguran la creación de valor empresarial, como consecuencia de su positivo comportamiento en los criterios esenciales que integran la modelización de la ventaja competitiva, teniendo en consideración la estructura de la industria y la idiosincrasia de la empresa (García Muiña; Martín de Castro; Navas López, 2001).

Según García y otros (2001):

El fenómeno tecnológico va más allá de los meros soportes físicos o de los complejos sistemas de tratamiento de la información. Este fenómeno debe entenderse en un sentido mucho más amplio como el conocimiento de la organización relativo al modo en el que las actividades básicas de operaciones son desarrolladas. Por supuesto, el desarrollo de estas actividades no es independiente del resto de la organización; esto es, las tareas esenciales son desarrolladas gracias al conocimiento que poseen determinadas personas (capital humano), el cual es integrado en virtud de una serie de rutinas, reglas, procedimientos, etcétera, que facilitan el desarrollo conjunto de diversas funciones y permite la consecución de objetivos globales (capital organizativo), teniendo en cuenta la asimilación de las oportunidades y amenazas que el entorno, cada vez más dinámico, supone (capital relacional)

Junto a la propuesta del modelo Intelect (1998) se hace necesario revisar el tratamiento que ha recibido el fenómeno tecnológico en otros modelos de capital intelectual.

La identificación y medición de las distintas manifestaciones del conocimiento (actitudes, conocimientos explícitos y capacidades) posibilitará la mejora en la gestión del capital intelectual y encontrar en él la mayor fuente de ventajas competitivas sostenibles. En la siguiente tabla recogemos de una forma resumida las principales aportaciones al capital tecnológico. 


\begin{tabular}{|c|c|c|c|}
\hline & BLOQUES & ELEMENTOS & INDICADORES \\
\hline $\begin{array}{l}\text { Kaplan y } \\
\text { Norton (1992) }\end{array}$ & $\begin{array}{l}\text { - Procesos } \\
\text { internos de } \\
\text { negocios } \\
\text { - Aprendizaje y } \\
\text { crecimiento }\end{array}$ & $\begin{array}{l}\text { - Procesos de innovación } \\
\text { - Procesos de operaciones } \\
\text { - Sistemas de información }\end{array}$ & $\begin{array}{l}\text { - \% productos nuevos } \\
\text { - \% productos patentados } \\
\text { - Introducción de nuevos } \\
\text { productos / competencia } \\
\text { - Bases de datos } \\
\text { - Software } \\
\text { - Copyrights }\end{array}$ \\
\hline Sveiby (1997) & $\begin{array}{l}\text { - Estructura } \\
\text { interna }\end{array}$ & - Crecimiento e innovación & $\begin{array}{l}\text { - Nuevos métodos y sistemas } \\
\text { - Inversión en TICs }\end{array}$ \\
\hline $\begin{array}{l}\text { Edvinsson } \\
\text { (1996) }\end{array}$ & $\begin{array}{l}\text { - Capital } \\
\text { estructural }\end{array}$ & - Tecnología de la información & $\begin{array}{l}\text { - \% teletrabajo } \\
\text { - Formación tecnológica } \\
\text { - Calidad } \\
\text { - Horas desarrollo } \\
\text { - Gastos en investigación }\end{array}$ \\
\hline $\begin{array}{l}\text { Brooking } \\
\text { (1996) }\end{array}$ & $\begin{array}{l}\text { - Activos de } \\
\text { propiedad } \\
\text { intelectual } \\
\text { - Infraestructuras }\end{array}$ & $\begin{array}{l}\text { - Patentes } \\
\text { - Copyrights } \\
\text { - Derechos de diseños } \\
\text { - Secretos comerciales } \\
\text { - Sistemas de información y } \\
\text { bases de datos }\end{array}$ & $\begin{array}{l}\text { - No propone indicadores } \\
\text { cuantitativos concretos }\end{array}$ \\
\hline Bueno (1998) & $\begin{array}{l}\text { - Capital } \\
\text { tecnológico }\end{array}$ & $\begin{array}{l}\text { - Actitudes tecnológicas } \\
\text { - Conocimientos explícitos } \\
\text { tecnológicos } \\
\text { - Capacidades tecnológicas } \\
\text { - Competencias tecnológicas }\end{array}$ & $\begin{array}{l}\text { - No propone indicadores } \\
\text { cuantitativos concretos }\end{array}$ \\
\hline $\begin{array}{l}\text { Roos y Roos } \\
\text { (1997) }\end{array}$ & $\begin{array}{l}\text { - Capital } \\
\text { organizativo }\end{array}$ & $\begin{array}{l}\text { - Desarrollo de productos } \\
\text { - Capacidad de producción } \\
\text { - Control de la calidad }\end{array}$ & $\begin{array}{l}\text { - \% nuevos productos } \\
\text { - \% nuevos productos } \\
\text { desarroll. en cooperación } \\
\text { - Gasto en I+D } \\
\text { - Tasa de éxito desarrollo de } \\
\text { nuevos productos } \\
\text { - Inversión en TICs }\end{array}$ \\
\hline Bontis (1996) & $\begin{array}{l}\text { - Capital } \\
\text { estructural }\end{array}$ & $\begin{array}{l}\text { - Tecnología de la Información } \\
\text { - Nuevas ideas } \\
\text { - Soporte a la innovación }\end{array}$ & $\begin{array}{l}\text { - Facilidad de acceso a } \\
\text { sistemas de información } \\
\text { - № nuevas ideas } \\
\text { - № nuevas ideas implan. } \\
\text { - Existencia de procesos de } \\
\text { apoyo a la innovación }\end{array}$ \\
\hline $\begin{array}{l}\text { Modelo } \\
\text { Intelect (1998) }\end{array}$ & $\begin{array}{l}\text { - Capital } \\
\text { estructural }\end{array}$ & $\begin{array}{l}\text { - Propiedad intelectual } \\
\text { - Tecnología de proceso } \\
\text { - Tecnología de producto } \\
\text { - Procesos de apoyo } \\
\text { - Captación del conocimiento } \\
\text { - Transmisión del conocimiento } \\
\text { - Tecnología de la } \\
\text { información } \\
\text { - Procesos innovación }\end{array}$ & $\begin{array}{l}\text { - № patentes } \\
\text { - Reducción tiempo de proceso } \\
\text { - № procesos documen. } \\
\text { - № líneas de producto } \\
\text { - № promociones } \\
\text { - Movilidad del personal } \\
\text { - № referencias aportadas } \\
\text { - № PC's / empleados } \\
\text { - Tiempo de desarrollo } \\
\text { de los procesos } \\
\text { - № Lanzamientos / año } \\
\text {-Reducción errores en } \\
\text { los procesos }\end{array}$ \\
\hline
\end{tabular}

Tabla 2.2 - Principales aportaciones al estudio del capital tecnológico. Fuente: García Muiña; Martín de Castro (2001) 


\subsubsection{Elementos e indicadores}

Tomando como criterio de estructuración del capital tecnológico la dimensión temporal (elementos de presente y elementos de futuro), en la siguiente figura reflejamos la propuesta mejorada del modelo Intelect (CIC, 2002).

\section{CAPITAL INTELECTUAL}

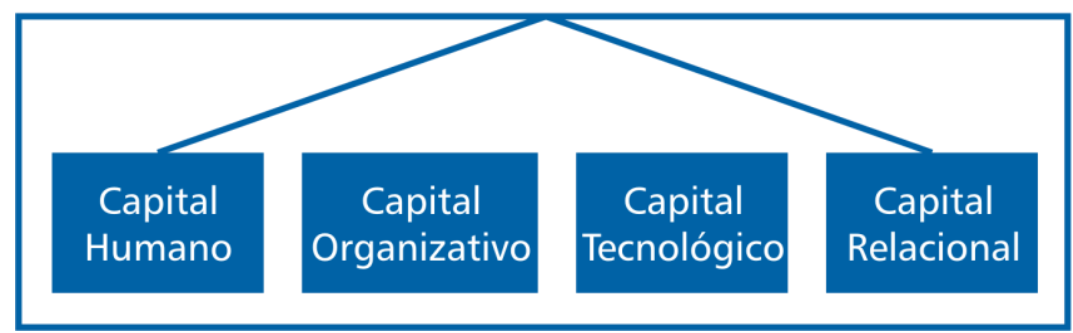

Figura 2.5 .- Propuesta de elementos del capital tecnológico

\section{PRESENTE:}

- Esfuerzo en I+D

- Esfuerzo en Innovación

- Compra de Tecnología

- Propiedad Intelectual Disponible

- Dotación de Tecnologías de la Información y las

Telecomunicaciones

- Dotación de Tecnologías de la Producción

- Procesos documentados

\section{FUTURO:}

- Innovación Tecnológica

- Propiedad Intelectual Conseguida Internamente

- Venta de Tecnología

- Nueva Documentación

Tabla 2.3 - Fuente: CIC (2002).

\subsubsection{Gestión de la información}

Isabel Medrano y Luis Suárez (2001) establecen un modelo de organización genérico, que debe cumplir con una serie de condiciones en su sistema de trabajo y de información, sobre la cual proponen la adopción de medidas encaminadas a documentar el conocimiento que las personas que la componen poseen y que no es compartido por el común. 
Estas condiciones a las que se refieren son las siguientes:

- Las actividades de la organización han de realizarse conforme a procedimientos normalizados, que estén regulados por escrito, bien sea conformando un Manual de Calidad, o con normas de procedimiento. Por tanto, los procesos administrativos y de negocio han debido ser analizados, redactados y son conocidos por los miembros de la organización, que en el ejercicio de su actividad comprueban la viabilidad de los mismos y proponen posibles modificaciones o mejoras.

- La gestión de la organización debe estar soportada por un Sistema de Información que integre datos y procesos y los haga visible a través de una tecnología tipo intranet.

- Debe reconocerse como línea estratégica de la organización la cultura corporativa, impulsada desde la dirección e interiorizada por los miembros. La percepción por parte de todos de que el fomento del conocimiento compartido es una ventaja competitiva para la organización es un elemento clave a la hora de emprender cualquier actuación encaminada a gestionar el conocimiento.

En el marco del programa para la gestión del conocimiento, Isabel Medrano y Luis Suárez (2001) se centran en su vertiente de gestión de la información, y más concretamente en el diseño de una metodología para documentar el conocimiento. En el proceso distinguen las siguientes fases:

\begin{tabular}{|l|l|}
\hline \multicolumn{1}{|c|}{ FASE } & \multicolumn{1}{c|}{ PRODUCTO } \\
\hline 1-Identificación del conocimiento clave & $\begin{array}{l}\text { Documento programático de gestión del } \\
\text { conocimiento }\end{array}$ \\
\hline $\begin{array}{l}\text { 2-Selección de las fuentes de } \\
\text { información }\end{array}$ & $\begin{array}{l}\text { Elaboración de un repositorio de } \\
\text { objetos }\end{array}$ \\
\hline $\begin{array}{l}\text { 3-Implantación de la solución } \\
\text { tecnológica }\end{array}$ & Desarrollo de la herramienta \\
\hline 4-Exteriorización del conocimiento & Creación y clasificación de documentos \\
\hline 5-Interiorización del conocimiento & Acceso a los documentos \\
\hline
\end{tabular}

Tabla 2.4 - metodología para documentar el conocimiento. Medrano y Suarez (2001).

\subsubsection{Impacto de las TICs en la Innovación Tecnológica}

Podemos definir la innovación ${ }^{4}$ como la "renovación y ampliación de la gama de productos y servicios y de los mercados asociados; el establecimiento de nuevos métodos de producción, suministro y distribución; la introducción de cambios en la

4 “La innovación en una economía del conocimiento", C. E., Bruselas, 2000. 
gestión, la organización del trabajo y las condiciones laborales y la preparación de los trabajadores".

Hemos visto como el cambio es hoy la única certeza en el mundo de los negocios, en este contexto la innovación representa la mejor y, posiblemente, la única solución para salvar a las empresas dentro de un entorno en constante evolución, donde los mercados ya no pueden ser controlados y gestionados eficazmente, resultando esencial que las empresas sean capaces de responder de forma rápida y flexible a los cambios de las condiciones del mercado, de tal forma que ese potencial de respuesta vendrá determinado por la capacidad de innovar que presenten. (Escorsa y Valls, 1997; Drucker, 2002))

De esta forma, se hace evidente que la empresa que no sepa entrar en el mundo de la innovación tecnológica, ya sea para mejorar aquellos de sus productos que han llegado a la madurez, como para emprender nuevas actividades y realizar nuevos productos, tiene una perspectiva a medio y largo plazo bastante insegura.

Las empresas son cada día más sensibles a la importancia que tiene la introducción de innovaciones, bien a través de modificaciones o mejoras, de sus procesos productivos o del producto final, y están realizando un gran esfuerzo para poner en marcha medidas dirigidas a potenciar el desarrollo tecnológico y, por tanto, su capacidad de ser competitivas.

Como conclusión, cabe resaltar que estas exigencias del entorno en materia de innovación en un sentido amplio, o de innovación tecnológica en una acepción más restringida, obliga a las empresas a considerar este factor como determinante de su competitividad, tanto a corto como a medio y largo plazo, y al incluirlo, por tanto, en su planteamiento estratégico, llegando a formular estrategias de innovación integradas necesariamente en la estrategia general de la empresa.

La innovación nos proporciona nuevo conocimiento. El nuevo conocimiento es el que se crea continuamente en una organización fruto de la creatividad continua de las personas, mientras que el 'viejo', se creó en su día y permanece en ella, bien en una o un grupo de personas.

Será tan fundamental crear ideas, conocimiento nuevo en la empresa, como transmitir e integrar el ya existente. Aquí entraría en juego el tema siempre considerable del Aprendizaje y la Comunicación.

\section{Aprendizaje y Comunicación empresarial}

La organización debe ser capaz de crear, adquirir y transmitir conocimiento, y de modificar su conducta para adaptarse a esas nuevas ideas para de esta forma aumentar su Capital Intelectual y por tanto su valor competitivo. 
Precisamente una característica fundamental de las empresas innovadoras es que en su estructura organizativa sigan el modelo de organización abierta al aprendizaje. Respecto a esto encontramos algunas consideraciones interesantes.

David A. Garvin (1993) sostiene que:

"Una organización que aprende es aquella que es hábil en generar, adquirir y transferir conocimiento, así como en modificar su comportamiento a partir de esta nueva percepción"

Muchas definiciones se han propuesto para definir una organización que aprende. Marlene y Marjorie (1985) nos dicen que una "organización que aprende es el proceso de perfeccionar las actividades mediante un mejor conocimiento y comprensión".

Ray Stata (1989) opina que :

"el aprendizaje de empresa se produce mediante el intercambio de ideas, conocimiento y la experiencia anterior - es decir, la memoria".

George P. Huber (1991) considera que

"una entidad que aprende si, mediante el procesamiento de la información, cambia la gama de sus potenciales conductas"

Barbara Levit y James G. March (1988) piensan que

"una organización aprende cuando traduce las enseñanzas obtenidas de su pasado en normas que orientarán su conducta".

En este mar de ideas acerca del aprendizaje es especialmente interesante la amplia literatura de Peter M.Senge (1990): "El verdadero aprendizaje llega del corazón de lo que significa humano. A través del aprendizaje re-creamos a nosotros mismos. A través del aprendizaje nos capacitamos para hacer algo que antes no podíamos. A través del aprendizaje ampliamos nuestra capacidad para crear, para formar parte del proceso generativo de vida. Dentro de cada uno de nosotros hay un hambre profunda de aprendizaje".

Y añade haciendo referencia a la comunicación entre las personas: "La disciplina del aprendizaje en equipo", extrapolable al organizativo "comienza con el diálogo, la capacidad de los miembros del equipo para 'suspender los supuestos' e ingresar en un auténtico 'pensamiento conjunto'".

Por tanto debe existir una Comunicación tanto externa e interna entre los participes la empresa para que surja el aprendizaje. Compartimos con Gonzalo (2002) la visión sobre el papel de la comunicación: "La comunicación interna no es una moda o un beneficio social para que los empleados dejen de quejarse de que no hay comunicación: la comunicación interna es una herramienta de management" etc. "Si una empresa necesita empleados comprometidos -que uno no sólo quiera hacer bien lo que se le pide sino que además quieran hacerlo mejor cada día- entonces es necesario que se influya sobre ellos para que ellos quieran".

O en palabras de Senge,

"la gente no sobresale ni aprende porque se lo ordenen, sino porque lo desea". 
La Comunicación interna la veremos por tanto como:

- Un elemento facilitador de la integración del personal en el proyecto de empresa y de su participación en la concepción, diseño y desarrollo de la visión compartida.

- Un agente de cambio que posibilite la adecuación de la empresa a las cambiantes exigencias del entorno y de la evolución técnica y social.

- Como elemento de cohesión, que le permite a la organización dirigir todas sus acciones a la consecución del objetivo general y orientarla a través del aparente caos.

- Como herramienta para el aprendizaje organizativo.

La comunicación interna no sería de gran ayuda sino hubiera también otra hacia el exterior la empresa: la Comunicación externa.

Lo externo a la empresa comprende su entorno. Dentro de él destacan los proveedores, los clientes, los accionistas, la competencia, las instituciones, etc.

Todos ellos son importantes, los clientes "como principal activo de la empresa" (Uroz, 2003), exigirá un buen diálogo con nosotros. Igual pasará con los proveedores y accionistas.

El significado etimológico de la palabra comunicación es compartir. Es por eso que es crucial en la compartición de conocimiento de cualquier red de personas o de organizaciones.

\section{Las TIC's}

En la situación actual en la que el entorno es cada vez más cambiante, hostil y competitivo, surge la llamada Nueva Economía. Se trata de una economía global, basada en el conocimiento, donde la globalización y la tecnología actúan como causa y efecto del proceso del desarrollo mundial; basada en la innovación; digital debido al impacto de las TIC's (Tecnologías de la Información y las Comunicaciones) y como consecuencia de todo esto, es una economía en red.

Las ideas de los individuos, el conocimiento y la tecnología pasan a ser de vital importancia y la competitividad de las organizaciones pasa a estar en su capacidad para aprender más rápido que sus competidores.

La tecnología es la base que capacitará a las empresas para poder crear y explotar sus ventajas competitivas.

Si definimos ventaja competitiva ${ }^{5}$ como "el dominio y control por parte de una empresa de una característica, habilidad, recurso o conocimiento que incrementa su eficiencia y le permite distanciarse de la competencia", detectamos que su

5 “ La decisión de cooperar", Dirección General de Política de la PYME, Ministerio de Economía, 2000. 
consecución requiere prestar atención a los movimientos del mercado, a las tendencias tecnológicas y los competidores, formular una estrategia viable, es decir encontrar esa ventaja competitiva que haga que la empresa sobreviva, en cierto modo es comparable a la teoría de la evolución de las especies de Darwin donde: "...sólo los animales que mejor se adaptan al entorno sobreviven...". De esta forma presenta una relevancia particular el tema tecnológico en cuanto a ser una ventaja competitiva crítica (Drucker, 2002). Además la empresa deberá adquirir y asimilar el conocimiento tecnológico necesario e implantar las tecnologías elegidas para su permanencia en el mundo empresarial. En definitiva, el éxito o el fracaso dependerá del modo en que las empresas gestionen la tecnología y, en particular su evolución y transformación: la innovación tecnológica (Escorsa y Valls, 1997).

La innovación tecnológica es por tanto, la que surge tras el uso de la tecnología como medio de introducir cambios en la empresa (Escorsa y Valls, 1997). Tradicionalmente se asocia a la innovación de proceso (nuevos métodos productivos que mejorarán la productividad, la racionalización de la fabricación y, en consecuencia la estructura de costes) y de producto/servicio (fabricación y comercialización de nuevos productos/servicios o bien, mejorar los ya existentes). Lejos de ser un proceso aleatorio, ésta conlleva una importante labor de gestión que podemos dividir en un conjunto de actividades que podrán desarrollarse bien de forma secuencial o de forma simultánea (Idipyme, 2001):

- Vigilar: observar la situación del entorno de modo que sepa reconocer oportunidades en los mercados, las tendencias tecnológicas y los competidores.

- Focalizar: interpretar esta situación para a partir de ella definir una estrategia viable.

- Capacitarse: adquirir o generar los conocimientos o recursos tecnológicos que necesite para estar en condiciones de aplicar el cambio.

- Implantar las tecnologías elegidas.

- Aprender de la experiencia.

Por tanto, se puede afirmar que el desarrollo tecnológico ocupa una posición central en el proceso de acumulación de capital intangible y, por ello, los sectores y las empresas más competitivos en la economía moderna son también aquellos que dedican mayores recursos a los procesos de innovación tecnológica. (Escorsa y Valls, 1997; Drucker, 2002).

En los últimos años se ha constatado, un cambio significativo en los sistemas organizativos de las empresas del sector textil, hacia modelos mucho más estructurados basados en la adopción de sistemas de gestión de la calidad y mejora continua, que necesitan de sistemas avanzados de gestión que abarquen todos los procesos de la empresa y sean capaces de generar información precisa en tiempo real. 
A su vez, los sistemas de información de planificación de recursos empresariales, ERP (Enterprise Resource Planning), que antes eran patrimonio exclusivo de las grandes empresas, también han evolucionado flexibilizando la definición de los modelos de negocio.

En la actualidad se ha producido la convergencia entre las necesidades en los sistemas de información y gestión de las empresas del sector textil y la oferta de las funcionalidades de los sistemas ERP que permite augurar un gran auge en la implantación de los sistemas ERP en las empresas del sector textil.

\subsection{Las TIC's aplicadas a la empresa}

\subsubsection{Delimitación de un Sistema Avanzado de Gestión}

Una de las innovaciones tecnológicas que mayor impacto están teniendo en la vida de las organizaciones al facilitar su posición competitiva son los Sistemas de información y su componente tecnológico las Tecnologías de la Información y las Comunicaciones (TIC). Se consideran como aquel conjunto de tecnologías destinadas al procesamiento y a la transmisión de información por medios electrónicos, siendo información los datos, el sonido, la voz o la imagen. Estas tecnologías han tenido un alto impacto en la productividad, tanto la productividad laboral como la multifactorial (Brynjolfsson y Hitt, 1996).

Según Andreu, Ricart y Valor, pueden definirse los Sistemas de Información como (Cf. Andreu, Ricart y Valor, 2000):

"Conjunto integrado de procesos, principalmente formales, desarrollados en un entorno usuario-ordenador, que operando sobre un conjunto de datos estructurados (Bases de Datos) de una organización, recopilan, procesan y distribuyen selectivamente la información necesaria para la operatividad habitual de la organización y las actividades propias de la dirección de la misma." 


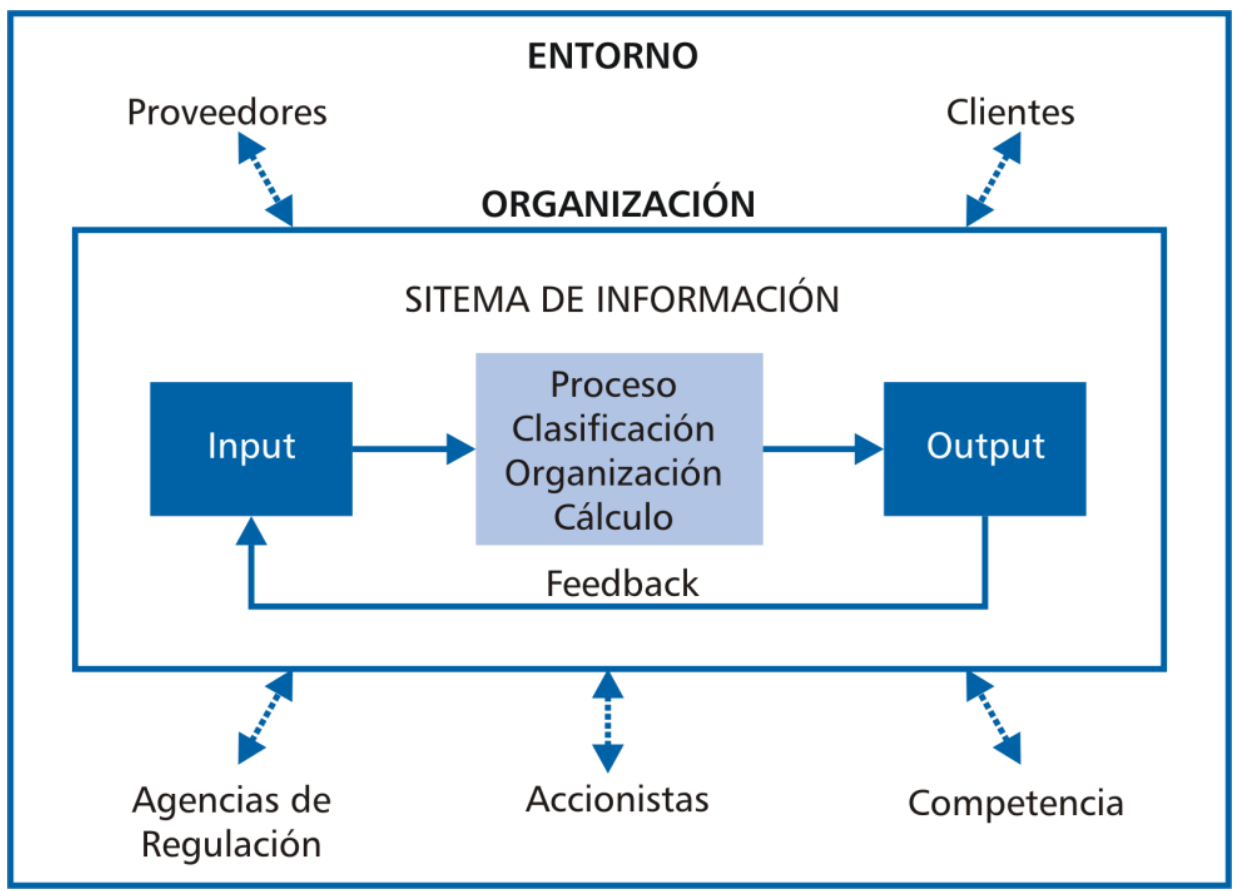

Figura. 2.6.- Funciones de los Sistemas de información.

Los sistemas de información permiten a la empresa interactuar con los agentes del entorno. Hasta no hace mucho, los sistemas de información de las empresas se limitaban a ejercer un papel pasivo, organizando la información y optimizando los circuitos de gestión. Es decir, eran sistemas orientados a mejorar la productividad y la eficiencia en la gestión pero que apenas participaban a la hora de innovar o servir de apoyo en la Dirección Estratégica de la empresa, salvo para aquellas que por su dimensión pudiesen permitirse unas dotaciones presupuestarias de mayor nivel. Esta era una de las razones por las que las empresas, excluyendo las grandes corporaciones, no consideraban las inversiones en Sistemas de Información tan importantes como las inversiones en sus circuitos de producción.

Se ha pasado de disponer de unas aplicaciones, que soportaban procesos de negocio departamentales, con escasa interconexión, lo que provocaba problemas de redundancia, falta de fiabilidad y oportunidad (en muchos casos estos sistemas todavía estaban enfocados a tratamiento de ficheros), a unas soluciones que representan una mejora notable en la integración de la información (Davenport, $\left.1998^{6}\right)$.

\footnotetext{
${ }^{6}$ Este autor presenta una visión general de los sistemas ERP, sus funciones principales, sus ventajas y desventajas, así como los problemas que surgen durante el proceso de implantación.
} 
Actualmente la situación ha cambiado, los fabricantes de hardware y software, así como los proveedores de servicios (consultoría, etc.) han evolucionado sus ofertas, tanto en prestaciones como en coste, para poner al alcance de cualquier empresa herramientas y servicios concebidos para colaborar no solo en la gestión administrativa del negocio, sino en aspectos que afectan directamente a la competitividad empresarial (Esteves y Pastor, 2002).

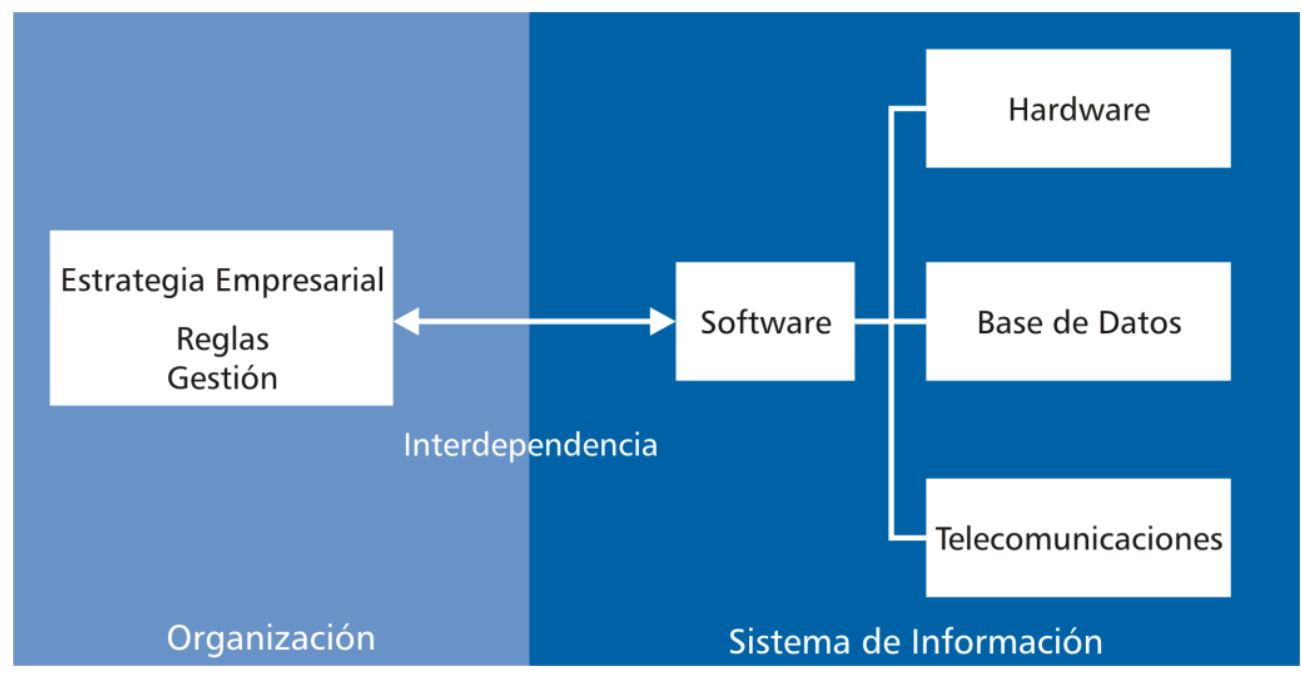

Fig. 2.7.- Sistemas de información y estrategia empresarial

Entre los numerosos beneficios que aportan a la empresa las actuales TICs, lo más destacable no es la realización de nuevas tareas, sino el hecho de abrir un amplio espectro de ideas y oportunidades, que, adecuadamente aprovechadas, constituyen una herramienta excepcional para mejorar la calidad de los bienes y servicios de la empresa, aumentando su competitividad. Pasan de tener una repercusión "interna de gestión" a una repercusión "externa de negocio", por todo ello, la implantación de nuevos sistemas de información no es algo a realizar únicamente por el personal informático, sino que debe ser objeto de un pequeño grupo, principalmente de gestores, que incorporen una orientación básicamente hacia el cliente, y en el que el personal informático aporte su conocimiento sobre las oportunidades que las TICs ofrecen. Los sistemas de información, tal y como muestra la figura siguiente, deben estar estrechamente relacionados con la estrategia empresarial y tener en cuenta factores organizativos como el entorno, la cultura, la estructura, los procedimientos y normas, así como el estilo de gestión. 


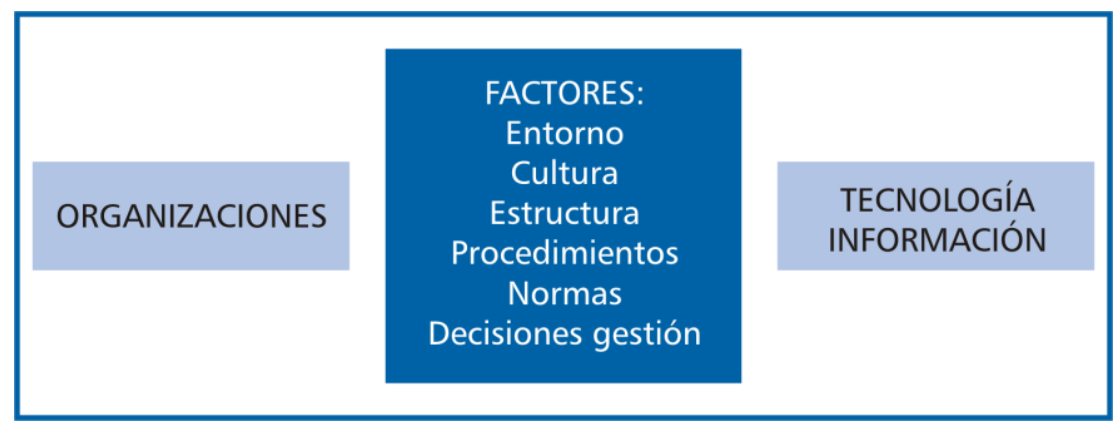

Fig. 2.8.- Factores organizativos y tecnológicos

Un sistema de información que muchas empresas pequeñas y medianas están implantando es de carácter interfuncional, e integrado que se suele conocer como ERP (Enterprise Resource Planning, Planificación de recursos de la empresa). Se dispone de una arquitectura de hard y soft que facilite el flujo de información entre las distintas funciones de la empresa y que permita el acceso a la información en tiempo real, y se dispone también, de algunas prestaciones características de los enfoques de sistema de información gerencial (Holsapple y Sena, 1999).

\section{¿Cómo se ha llegado a los sistemas ERP?}

En la década de 1960, las grandes empresas comenzaron a usar los primeros paquetes informáticos empresariales en logística y producción, que estaban destinados al manejo de inventarios. A partir de 1970, se empezó a utilizar el software MRP (Material Requirement Planning, Planificación de Necesidades de Materiales) que estaba dirigido a determinar las necesidades de materiales (materia prima, componentes, etc.) para producir lo que se demandaba en un pronóstico de ventas dado y también cuánto costaría esa producción.

Este concepto fue evolucionando hasta llegar al concepto de MRP II en la década de 1980, ampliando su ámbito de planificación al trabajo personal, maquinaria, costes, etc. y no solo a los materiales como en el MRPI. El MRPII permite planificar la producción a partir de las demandas directas de los clientes, brindando además pronósticos, a fin de reducir los niveles de inventario, la fabricación contra stocks teniendo en cuenta las limitaciones de los recursos y los costes involucrados.

El concepto ERP fue creado por el Gartner Group a principios de la década de 1990 para identificar una nueva generación de sistemas de software empresarial. Desde entonces el objetivo de los ERP ha sido la integración de las diferentes funciones de una empresa, tanto las administrativas como las propias de producción, estando basados en el dato único, en la fiabilidad y en poder disponer de la información en tiempo real. 
Desde finales de los 90 se están haciendo grandes esfuerzos para adaptar estos sistemas avanzados de gestión a las necesidades de las pequeñas y medianas empresas que están dando sus frutos en la actualidad.

De igual forma, los sistemas de tipo ERP presentan algunas desventajas que es conveniente tener en cuenta:

- Inversión de inicio importante. Hay que tener en cuenta todos los costes hasta que esté en funcionamiento efectivo.

- La empresa tiene que adaptar en cierto grado sus procesos, como mínimo a la parte del ERP que es común a todas las empresas en las que se implanta.

- La implantación es compleja porque involucra a toda la organización. El coste de la implantación va más allá del coste del software (licencia, parametrización, programas que se realicen, etc.) y el hardware, ya que hay que tener en cuenta otros aspectos (formación de los recursos humanos, asignación de recursos humanos al proyecto, etc.).

- Necesidad de establecer las condiciones de la implantación contractualmente con los consultores de forma clara y detallada, para evitar posteriores problemas debido a las diferentes interpretaciones.

- Se crea la dependencia del producto ERP y en gran medida también del proveedor.

Un sistema ERP no es:

- Un paquete que no permita cubrir las necesidades informáticas de cada una de las áreas de la empresa, ya sea mediante módulos propios del ERP o interactuando con paquetes estándar del mercado.

- Una aplicación informática funcionando de forma aislada en un solo departamento de la empresa, dando solución a las tareas propias de ese departamento.

- Una herramienta fija que no se pueda adaptar a la evolución razonable del negocio.

- Un sistema que no se alimenta de una base de datos única para todos los departamentos.

- Una aplicación que no sea capaz de proporcionar información en tiempo real.

La investigación realizada hasta la fecha sobre los sistemas ERP no es muy amplia, y debería ser realizada con una sistemática que permita identificar los patrones subyacentes comunes en este tipo de sistemas, a nivel funcional, de arquitectura de soporte y de organización (David, Dunn y McCarthy, 1999)

La incorporación de un sistema ERP puede contribuir a la mejora de los procesos empresariales debido a la tecnología de gestión de procesos que proporciona la 
solución ERP y la incorporación de métodos contrastados en otras empresas (Ross y Vitale, 1998). Cabe señalar, que la implantación de un sistema ERP suele precisar también una revisión de los procesos de la empresa, lo que conlleva mejoras sustanciales; de igual modo, es necesario que el ERP contemple las particularidades de la empresa.

Otras ventajas están asociadas, principalmente, con el enfoque interfuncional e integrado , así como en su enfoque de sistema de información gerencial y no solo de procesamiento de transacciones:

- Almacenamiento de la información de la empresa en una única base de datos disponible para todos los departamentos.

- Disponibilidad de información actualizada en tiempo real, siempre que sea necesaria.

- Permite reducir los costes administrativos y de operación, muchas veces asociados a actividades que tal vez estaban duplicadas 0 no suficientemente automatizadas, reduciendo los tiempos de operación, etc. posibilitando mejores precios de venta y por tanto productos más competitivos.

- La capacidad de proporcionar a la Gerencia información fiable, precisa y oportuna de cada una de las áreas de la empresa para una mejor toma de decisiones.

- En relación con las operaciones:

- La planificación de los recursos de producción permite establecer fechas de entrega de pedidos más realistas, lo que contribuye a que los clientes estén más satisfechos y permite la atención a un mayor número de clientes.

- Reducción del tiempo de ciclo de producción de productos, lo que supone más expediciones en menor tiempo, menores costes de personal permitiendo la realización de otras actividades y una mayor eficiencia en el uso de los recursos productivos.

- En relación con el mantenimiento (adaptativo, perfectivo y evolutivo):

- Los proveedores del ERP ofrecen a la empresa la incorporación de nuevas mejoras que se van detectando en posteriores versiones del producto y que son de interés para el subsector al que la empresa pertenece.

- Disponibilidad de herramientas de desarrollo de software compatibles con el producto ERP instalado.

- Mejora del mantenimiento de las aplicaciones informáticas.

- Interfaces amigables, sencillas, con ayuda en línea (online) y aplicaciones convenientemente documentadas. 
En definitiva, las aportaciones más destacables de los sistemas ERP son:

- Organización de la Empresa: Los sistemas avanzados de gestión son herramientas para la definición de los modelos de negocio y sus flujos de trabajo, permitiendo planificar y controlar todos los procesos y contribuyendo a la mejor gestión de la empresa.

- Integración de la información: Las empresas necesitan una solución de la información que garantice el principio de dato único y lo mantenga actualizado en tiempo real.

- Ayuda a la Toma de Decisiones: La información de calidad en un sistema avanzado de gestión resulta vital para la ayuda a la toma de decisiones. De esta forma, gerencia puede comprobar fácilmente que los indicadores más representativos de funcionamiento de la empresa se encuentran dentro de los márgenes preestablecidos, a través de la elaboración de cuadros de mando.

Estas y otras ventajas son aportadas por un sistema ERP pero siempre y cuando, la solución esté tecnológicamente bien concebida (desde las perspectivas técnica, organizativa y estratégica). Para que un sistema interfuncional integrado, ERP, sea considerado "bueno", debe tener algunas características que le hagan capaz de soportar los esfuerzos relacionados con la mejora continua y el rediseño de los procesos de negocios orientados al cliente.

\subsubsection{Características y estructura técnica.}

A continuación se cita un conjunto de características técnicas que colaboran en la consecución de los objetivos anteriores:

Modelos de configuración del sistema informático.

- Modelo Cliente-Servidor.

- Modelo de Intranet.

- Modelo ASP (Proveedor de servicios de aplicaciones).

Multiplataforma

Se denomina así la característica del ERP que describe la posibilidad de funcionamiento en distintos sistemas informáticos y no solo en los de la marca del proveedor. Se pretende que el esfuerzo necesario para transferir la solución informática de un entorno hardware/software a otro entorno diferente, sea lo más pequeño posible.

Conectividad

El ERP debe permitir interactuar compartiendo datos y "comunicándose" con otros sistemas, tanto en su configuración actual como en su evolución de futuro.

$\underline{\text { Configuración interfuncional progresiva }}$ 
Los módulos que integran la solución ERP pueden funcionar de forma autónoma, dando el servicio solicitado por el área o función correspondiente. De esta forma se pueden implantar no todos a la vez, sino que puede hacerse de forma progresiva.

\section{Integración con otras aplicaciones externas}

El ERP permite exportación o importación de datos con productos de software utilizados como estándares de mercado. De esta forma el sistema va cubriendo las distintas necesidades de información, sin tener que hacerlo exclusivamente con otros módulos del mismo ERP.

\section{Parametrización}

El ERP trata de adaptarse a las características particulares de diferentes empresas; no es por tanto un programa estándar cerrado, que obligue necesariamente a la empresa a adaptarse a él, sino que es adaptable el ERP a la empresa. Esta adaptación se realiza en buena parte mediante lo que se denomina "parametrización" (por ejemplo, se pueden añadir campos nuevos a los registros existentes) lo cual no tiene nada que ver con hacer programas nuevos.

¿Como llega el ERP a adaptarse a las necesidades de una empresa concreta? El primer paso es la parametrización (particularización para esa empresa) del ERP, sin necesidad de hacer programación, con lo que ya se puede resolver buena parte de sus necesidades de algunas áreas. Lo que no se consigue con la parametrización, se puede enfocar mediante dos alternativas:

- Crecimiento Vertical: se hacen adaptaciones del ERP mediante programación para resolver una problemática funcional de un proceso concreto para cumplir con las características propias de la empresa.

- Crecimiento Horizontal: se refiere a la incorporación de módulos adicionales o paquetes externos, como EDI, correo electrónico, acceso a Internet y otros que van surgiendo de acuerdo con la evolución de los negocios.

Con esto obtenemos una total adaptación del sistema a las necesidades específicas de la empresa.

Facilidad de operación y manejo (Usabilidad)

- Interfaz Gráfica de Usuario (GUI): Es la parte de un sistema de información que permite a los usuarios finales interactuar con el sistema. Se trata de las pantallas y los formularios de edición de datos fundamentalmente. Debe ser clara, de fácil uso, consistente en todo el conjunto de la aplicación, de forma que se facilite su aprendizaje.

- Consultas y generación de informes: El ERP provee a los usuarios las herramientas adecuadas para la elaboración sencilla de consultas y la generación de informes así como de la adaptación (personalización) de éstos al entorno de la empresa.

- Asistentes: Los asistentes son herramientas que proporcionan al usuario una guía para la generación automática, rápida y sencilla de tablas, consultas, documentos, informes, etc., facilitando las tareas básicas de 
implantación, explotación de la información o modificación de las reglas de gestión por parte de los usuarios.

Facilidad de Mantenimiento

La calidad del servicio posventa (también llamado soporte de mantenimiento y servicio de asistencia técnica SAT) que proporciona el proveedor del ERP a la empresa, es un elemento fundamental en cuanto a la satisfacción final de la empresa.

\section{Garantías de Futuro}

Es fundamental asegurarse que el fabricante de la solución ERP seguirá proporcionando nuevas versiones, y que la empresa proveedora del ERP tenga una sólida política de mantenimiento del sistema que prolongue la vida útil de la inversión el mayor tiempo posible. En definitiva puede decirse que:

Garantías de Futuro = Nuevas versiones ERP + Servicio de mantenimiento + Servicio de consulta + Adaptabilidad a los cambios previsibles de futuro.

\section{Seguridad}

Involucra dos aspectos: A) El de confidencialidad de los datos, se soluciona con claves de usuarios, restringiendo así el acceso a la información que se considere oportuno. B) El de integridad de los datos, se asegura con sistemas de gestión de bases de datos que proporcionan una interfaz entre la base de datos y el programa de aplicación que la está usando.

\section{Simulación}

Empecemos por un ejemplo. Cuando se está realizando un presupuesto financiero, es deseable poder determinar los efectos de diferentes enfoques sobre la situación de tesorería, con el fin de elegir finalmente el presupuesto más conveniente. Las herramientas de simulación del ERP permiten realizar estas pruebas que ayudan en la importante tarea de hacer planes y presupuestos. La simulación es una herramienta muy importante ya que mediante un adecuado nivel de detalle, con definición de elementos, recorridos y reglas de operación, se pueden ver los efectos probables asociados directamente $\mathrm{o}$ indirectamente a una acción determinada.

\section{Trazabilidad}

La trazabilidad del sistema permite controlar cada lote de bienes o servicios de manera que, para cada uno de estos lotes, se puede saber qué materias primas y componentes han participado en su obtención, así como el origen, las máquinas, y el personal que han intervenido.

Además, esta misma característica nos proporciona un seguimiento de cada uno de los procesos de gestión comercial, administración, etc., no solo de los de producción. 
Por ejemplo, esta característica de la trazabilidad es especialmente útil en el seguimiento de partidas defectuosas, de manera que es posible identificar con seguridad:

- Qué partida de materia prima (bala de fibra, partida de tejido, etc.) se ha utilizado y, por tanto, qué proveedor.

- Qué proceso (con la información del telar que ha intervenido, así como el personal), de los que componen la producción de la partida de tela, ha sido el causante de los defectos.

- si por el contrario, se ha tratado de un error en la confección del pedido generador de la orden de producción, podremos saber cuando y quién ha sido el comercial o administrativo responsable.

\section{Formación y Documentación.}

El aprendizaje del usuario ha de venir facilitado por cursos de formación. La documentación, tanto la orientada al usuario, como la de tipo técnico dirigida al administrador del sistema, y la ayuda en línea, son otros medios que facilitan el aprendizaje del ERP.

Al comentar los tipos de configuración del sistema informático se mencionó que los principales modelos utilizados son los siguientes:

- Modelo Cliente-Servidor.

El Modelo Cliente-Servidor se basa en un servidor central donde se ejecuta la mayor parte del procesamiento de información y el acceso a la base de datos, y en ordenadores denominados clientes, que son los equipos de usuario, de capacidad más reducida, que se limitan a interrogar al servidor, procesando una pequeña parte de la aplicación y además, proporcionando la interfaz de usuario.

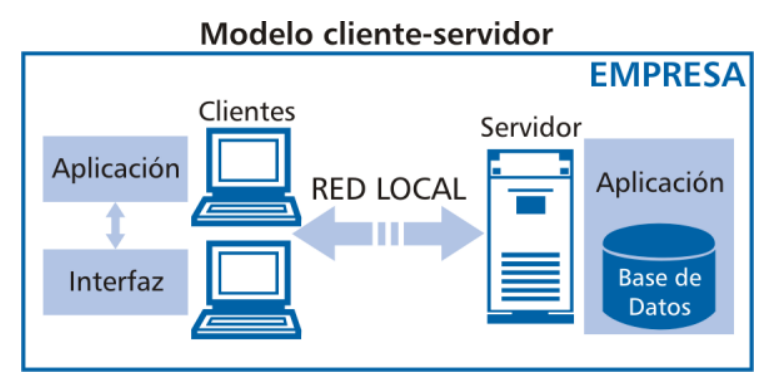

Fig. 2.9.- Modelo cliente-servidor.

- Modelo de Intranet.

Se basa en el acceso de los usuarios al servidor mediante un simple navegador (Internet Explorer, Netscape Navigator, etc.). La conexión se realiza mediante el protocolo IP, cumpliendo así con los estándares de Internet, y se puede acceder a través de Internet o a través de la red local. 
Los ordenadores del usuario no procesan nada, tan sólo muestran por pantalla el resultado que le envía el Servidor, con lo que cuentan con la totalidad de las prestaciones de su ordenador para otras tareas.

Modelo intranet

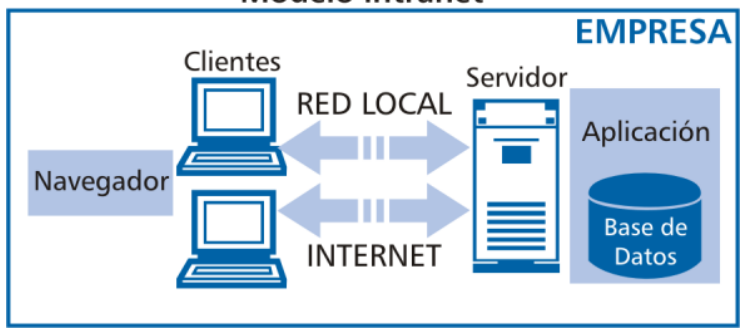

Fig. 2.10.- Modelo de Intranet

- Modelo ASP (Proveedor de servicios de aplicaciones).

Para facilitar la exposición, nos referiremos a una empresa del sector textil. Como cualquier empresa, presenta semejanzas y diferencias con otras empresas de su mismo sector que la hacen genuina. Estos "rasgos", fruto del quehacer operativo y del estilo de dirección, pueden clasificarse según la siguiente tipología:

- Características singulares de la empresa.

- Características que se dan en las empresas del subsector del sector textil al que pertenece la empresa (por ejemplo, subsector de tejeduría, subsector de confección de moda, etc.).

- Aspectos que se dan en las empresas de todo el sector textil.

- Elementos que comparten todas las empresas del mismo estado o país.

Esto ha llevado a los proveedores de soluciones ERP a tener en cuenta esta tipología de diferencias entre las empresas, de forma que los ERP puedan organizarse con una parte común (que es igual en todos los países y estados en que ofertan el ERP. Realmente, esta parte sería estándar, en el sentido de que es igual para todos. Pero como cada estado o país tiene ciertas diferencias con respecto a otros, en cada uno se añade lo específico de dicho país o estado que servirá para todas las empresas de un estado recogiendo las características diferenciales de éste: fiscales, contables, normas medioambientales, impuestos, etc.

Adicionalmente, para las empresas de un mismo sector (por ejemplo, el sector textil), se añade lo específico de dicho sector. De igual forma se procede con cada subsector al añadir lo específico del subsector (por ejemplo, en el subsector de confección de prendas de vestir personales, la posibilidad de trabajar con tallas, colores, etc.). Y así sucesivamente, se puede añadir también lo diferencial de un grupo de empresas, para llegar finalmente a lo peculiar y propio de cada empresa, que se incorpora al producto ERP solo para ella, con lo que se consigue una adaptación eficiente. 
La terminología que se utiliza es la de núcleo central o estándar para indicar lo que sirve en todos los países; y para las diferencias referidas a distintos niveles, se utiliza la denominación de capa. Así, hay una capa que contempla cada una de las diferencias que se van incorporando hasta llegar al ámbito de la empresa particular, pasando por lo tanto por la capa país, capa del sector, capa del subsector, capa del grupo de empresas en su caso, como muestra la figura 2.11.

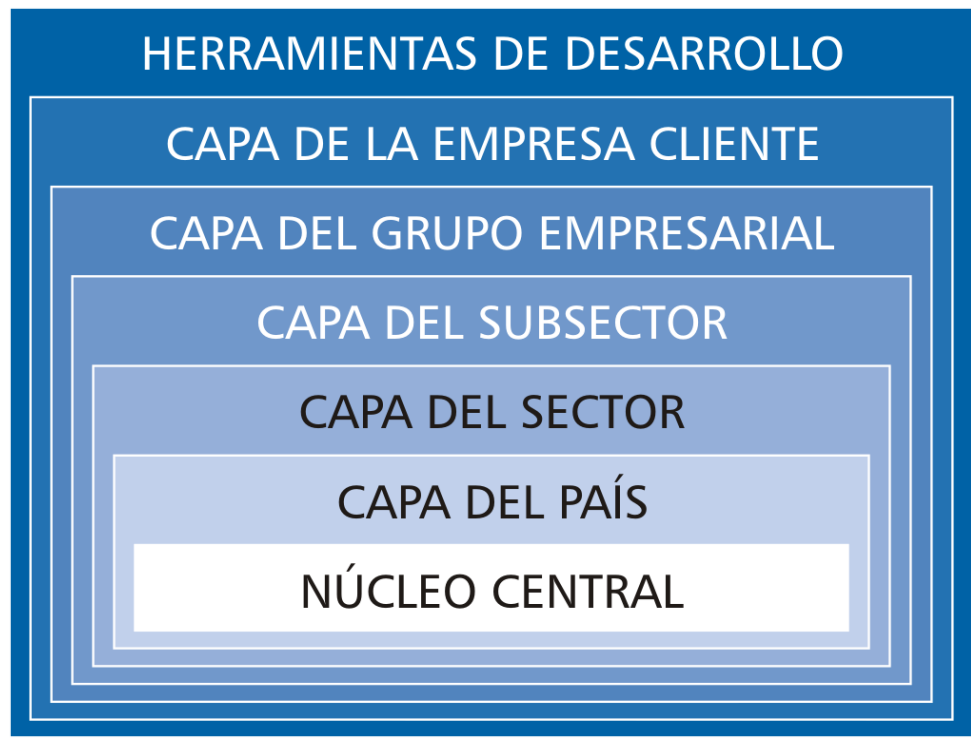

Figura 2.11.- Modelo de Arquitectura de Estructura en Capas del ERP. (Basado en Open Solutions y Navision, 2002)

La parte estándar (que se ha indicado que es igual para todos los países) será el núcleo de la solución ERP, contendrá todas aquellas funcionalidades básicas para el funcionamiento y normalmente no será modificado, salvo por la empresa fabricante del software, mediante actualizaciones de la versión. Por otro lado, los bloques adicionales (para adaptarse a las diferencias de cada país, sector, subsector, grupo de empresas y empresa) estarán formados por las aplicaciones y funcionalidades específicas de cada país, sector, subsector, grupo o empresa. Esta forma de organizar el ERP se denomina arquitectura en capas o distribuida.

El modelo de división en capas permite:

- Desarrollos paralelos (esto es, se puede trabajar en más de una capa a la vez).

- Aplicaciones más robustas.

- Mantenimiento y soporte más sencillo (es más fácil actuar sobre una de las capas que modificar una aplicación monolítica). 
- Alta escalabilidad. Escalabilidad es la característica de poder adaptarse con relativa facilidad a la evolución de la empresa, siendo adecuados a las necesidades de pequeñas, medianas y grandes empresas.

- Mayor flexibilidad (se pueden añadir nuevos módulos para dotar al sistema de nueva funcionalidad).

Dada la importancia de este planteamiento técnico, debe ser un aspecto digno de ser tenido en cuenta en el momento de la selección del ERP, puesto que no todas las soluciones existentes en el mercado contemplan la utilización de esta estructura.

\subsubsection{Subsistemas de información.}

La empresa precisa de una intensa coordinación entre sus departamentos para lograr sus objetivos. Los sistemas de información ERP actuales están compuestos por una serie de subsistemas, también denominados módulos, que abarcan las funciones principales de la empresa. No todas las soluciones ERP disponen de los mismos módulos, ni reciben la misma denominación, y adicionalmente, las funcionalidades de cada módulo difieren entre marcas. No obstante, todos ellos contienen aquellos que son básicos o fundamentales para la gestión de una empresa, como:

- Módulo de Gestión de Compraventa o Comercial.

- Módulo de Contabilidad y Finanzas.

- Módulo de Logística.

- Módulo de Producción.

- Módulo de Recursos Humanos

Hay otras funcionalidades que afectan a Gestión de Proyectos, Servicio y Soporte, Comunicación, etc. que suelen formar parte de módulos más generales, pudiendo incluso tener distinta denominación. Estos módulos se adquieren de acuerdo con las necesidades de la empresa y el grado de integración que se quiera lograr.

En general, estos sistemas tienden a incluir un mayor número de módulos, fruto de la competencia entre los distintos proveedores informáticos. Esto produce que las diferencias entre un ERP y otro sean cada vez más escasas, en cuanto a funciones o aspectos que incorporan, aunque no en cuanto a la forma de llevarlos a cabo.

Es preciso destacar que cada módulo tiene autonomía propia y se puede implantar con la secuencia que se desee en el departamento que más se necesite, como por ejemplo en almacén o en el departamento comercial, etc. No obstante, hay que subrayar también, que es el funcionamiento conjunto e integrado de todos estos módulos el que aporta la verdadera ventaja cualitativa frente a los sistemas de información tradicionales (en los que cada función era soportada por un paquete informático independiente). 


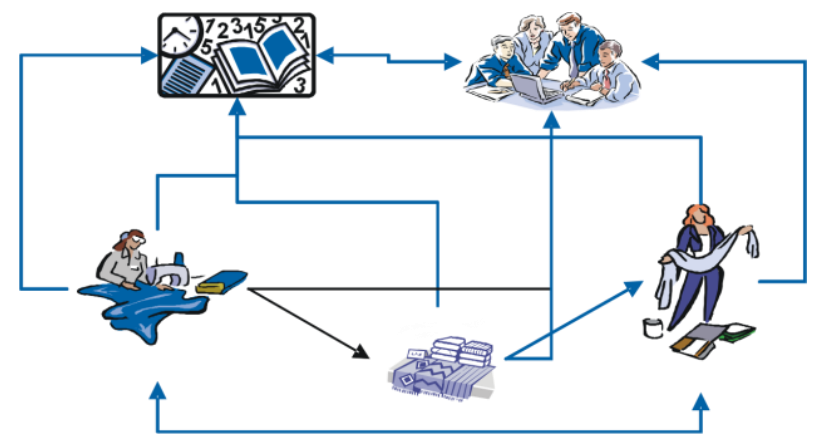

Figura. 2.12.- Diagrama de los diferentes módulos de los ERP de PYMES textiles y sus relaciones.

Hay otras funcionalidades que afectan a los departamentos de Recursos Humanos, Gestión de Proyectos, Servicio y Soporte, Comunicación, Gestión documental, etc. que suelen formar parte de módulos más generales, pudiendo incluso tener distinta denominación.

En general, estos sistemas tienden a incluir un mayor número de módulos, fruto de la competencia entre los distintos proveedores. Esto produce que las diferencias entre un ERP y otro sean cada vez más escasas, en cuanto a funciones o aspectos que incorporan, aunque no en cuanto a la forma de llevarlos a cabo.

\subsubsection{Comercio electrónico y Sistemas CRM / SCM}

Los sistemas ERP están incorporando funcionalidades que permiten gestionar las relaciones con los clientes por una parte, sistemas CRM y por otra lograr mayores ventajas en la administración de la cadena de suministro.

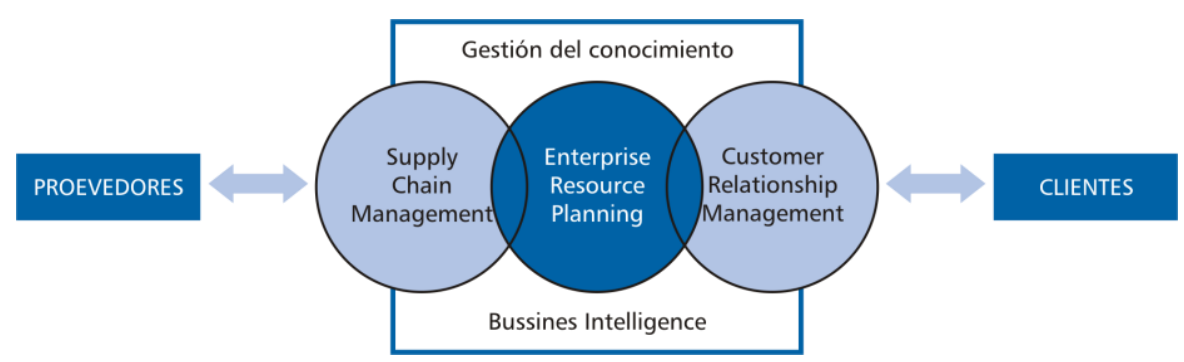

Figura 2.13.- Sistemas ERP y su relación con sistemas CRM y SCM.

La empresa puede integrar con un sistema ERP todas las actividades de todas las áreas de su organización. Pero es fundamental para el progreso de la organización relacionarse con otras organizaciones e intercambiar información y mercancías con el exterior (clientes y proveedores). Para gestionar estas 
relaciones con el exterior de la organización existen una serie de herramientas, que pueden integrarse con el sistema ERP para dar una solución global.

En estas relaciones externas encontramos a los proveedores y a los clientes en ambos extremos de la cadena de suministro. Para gestionar esta cadena de suministros, principalmente de los proveedores, pero también los suministros intermedios internos, existen los sistemas SCM (Supply Chain Management), y para gestionar las relaciones con los clientes, y poderles ofrecer un servicio cada vez más personalizado se tienen los sistemas CRM (Customer Relationship Management).

Además, es importante resaltar el concepto de empresa extendida o "extended enterprise" a una organización que dispone de un sistema de información que integra un sistema SCM y un sistema CRM, en torno a un ERP, situado en el núcleo de esa red.

\section{Sistemas CRM}

La gestión de las relaciones con los clientes ha sufrido una transformación durante las últimas décadas, como se muestra en la tabla siguiente:

\begin{tabular}{cl}
\hline Año & Concepto \\
\hline 1960 & El cliente siempre tiene la razón \\
1980 & El cliente es el principal activo de la empresa \\
1990 & Hay clientes internos y externos \\
2000 & Clientes como creadores de valor \\
Tabla 25 - Evolución histórica de la concepción de cliente
\end{tabular}

El concepto de cliente ha evolucionado en gran medida de su concepto tradicional al que se concibe en la actualidad. Se ha pasado de la visión tradicional de cliente, es decir, entidades o individuos a las que se vende una serie de productos, a la visión contemporánea de cliente, el individuo o grupo con el que la empresa intercambia valor.

Las empresas han evolucionado de una filosofía orientada al producto a otro enfoque orientado hacia el cliente, según muestra la figura siguiente. 


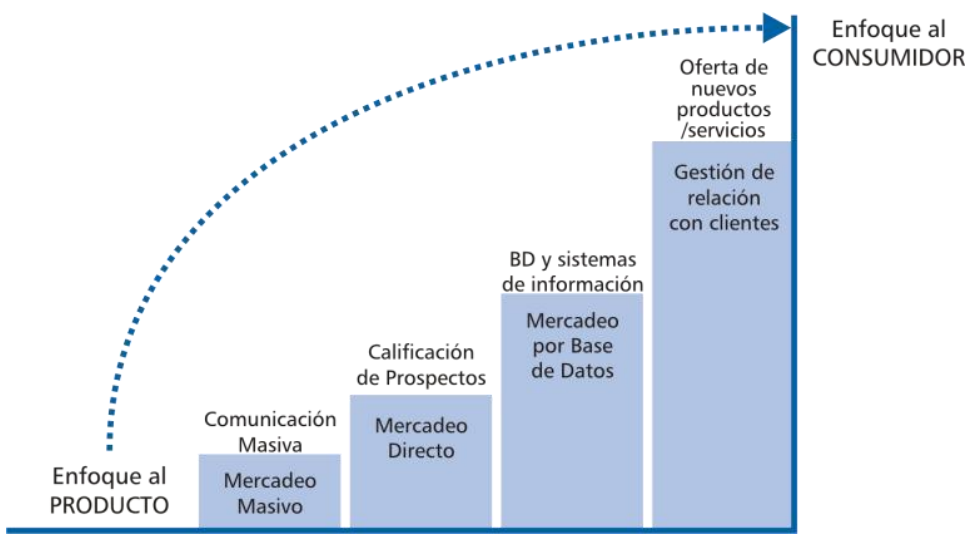

Figura 2.14.- Evolución de un enfoque al producto a un enfoque hacia el cliente

Por tanto, se puede llegar a la conclusión de que el concepto de gestión de las relaciones con los clientes no es una teoría moderna, sino que obedece a una evolución natural de una filosofía a través del tiempo.

En este sentido, el uso de las herramientas tecnológicas adecuadas ha permitido a las organizaciones desarrollar un profundo conocimiento de sus clientes mediante la captura, el almacenamiento, el análisis y la utilización de la información más relevante. Pero también ha permitido desarrollar otro de los pilares fundamentales en el que se basan las relaciones con los clientes, las interacciones con los mismos, coordinando y proporcionando una visión de conjunto de todos los canales de relación y contacto que la empresa mantiene con sus clientes, tales como: su fuerza de ventas, campañas, participación en ferias, centros de soporte, servicios web, listas de correo, etc.

CRM (Customer Relationship Management) o la gestión de las relaciones con los clientes, es ante todo, una filosofía empresarial, que orienta y encamina las estrategias de las organizaciones a reforzar y mantener las relaciones de la empresa con los clientes, especialmente con los "clientes más rentables".

El auge de Internet para la realización de transacciones comerciales, los anchos de banda cada vez mayores y a un menor coste, y los avances en la capacidad de proceso están, todos ellos, impulsando los sistemas CRM, y dando lugar a una gran variedad de ofertas tecnológicas para ayudar a las empresas a implementar la filosofía CRM. Estas ofertas CRM consisten básicamente en un software para automatización de las redes de ventas, marketing, servicio y atención al cliente.

A grandes rasgos, un sistema integrado CRM obtiene los datos de diferentes puntos de interacción con los clientes y los consolida en una base de datos central. Una vez recolectados, almacenados y organizados, esta información puede ser analizada y 
accedida de un gran número de formas diferentes y por varios usuarios de acuerdo al objetivo que se pretenda conseguir.

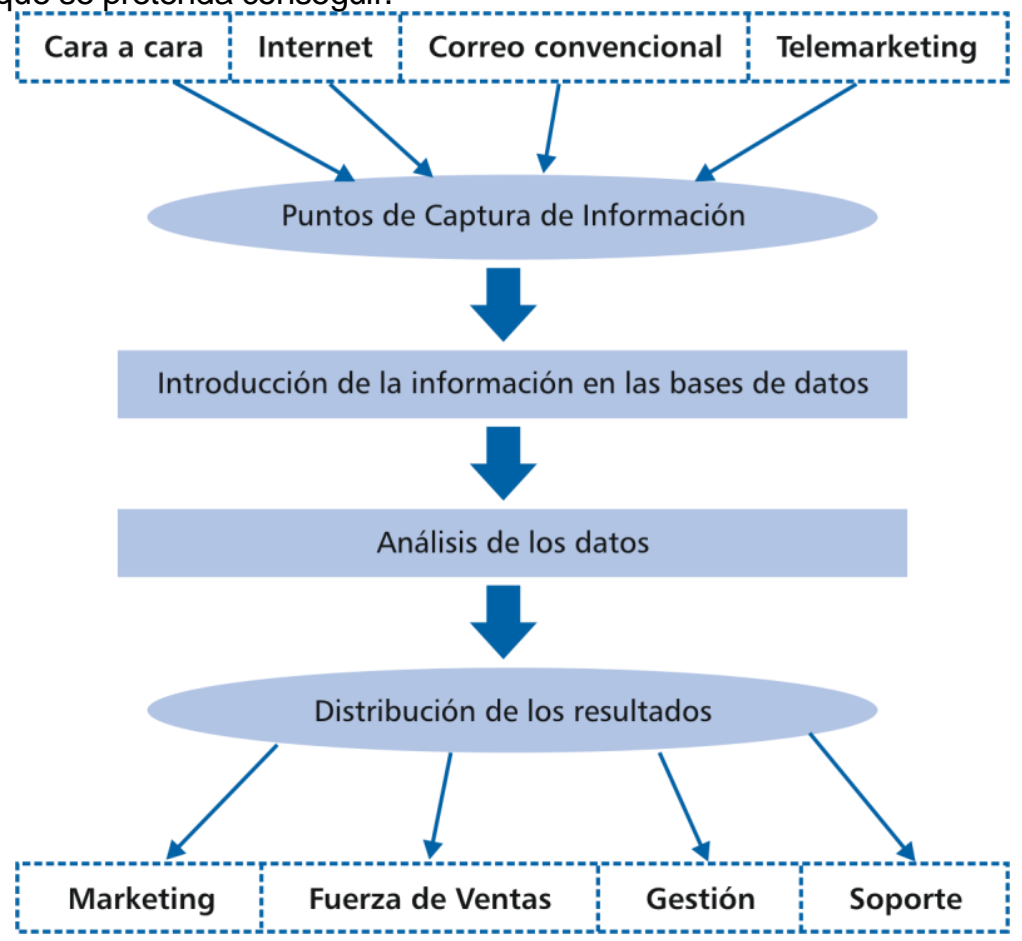

Figura 2.15.- Desarrollo del proceso CRM

Los objetivos de un proyecto más CRM, aunque son muchos y variados, se pueden integrar en tres conceptos:

- Cambio del concepto de relaciones con los clientes, adquiriendo una visión integrada y única de los clientes, potenciales y actuales, pudiendo emplear herramientas de análisis y desarrollando así, acciones más inteligentes.

- Gestionar las relaciones con los clientes de una manera única e independientemente del canal de contacto, ya sea vía telefónica, por medio de accesos a sitio web, o incluso visita personal.

- Mejora de la eficacia y eficiencia de los procesos implicados en las relaciones con los clientes.

Así pues, CRM es, básicamente, la respuesta a la creciente necesidad de las empresas de fortalecer las relaciones con sus clientes, en un entorno cada vez más globalizado, pero no sólo basándose en la tecnología, sino implicando a la empresa en su conjunto, mediante el uso de las herramientas tecnológicas adecuadas. 
Las posibilidades de Internet y las Nuevas Tecnologías en el área de relaciones con los clientes son infinitas.

En este contexto, es importante destacar que Internet, sin lugar a dudas, ha sido la tecnología que más ha contribuido sobre los sistemas de gestión CRM, sobre todo en los siguientes aspectos:

- Importante disminución de los costes de interacción.

- Incremento de las ventas, tanto por incremento de ventas a clientes actuales, como por ventas cruzadas.

- Mayor eficacia y eficiencia de las acciones de comunicación.

- Capacidad de comunicar con cualquier sitio desde cualquier lugar.

- Mejora de la atención al cliente.

- Mejora de los procesos comerciales.

- Posibilidad de interacción los 365 días del año y 24 horas al día.

Sin embargo, y aunque la tecnología sea la herramienta para el desarrollo de la filosofía, no puede dejarse un proyecto CRM en manos de ella, ya que la misma es sólo el facilitador que permite desarrollar el proyecto. Es muy importante destacar que para alcanzar el éxito en este tipo de proyectos se han de tener en cuenta los cuatro pilares básicos en una empresa: estrategia, personas, procesos y tecnología. Estos conceptos se desarrollan a continuación:

- Estrategia: Obviamente, la implantación de herramientas CRM debe estar alineado con la estrategia corporativa y estar en consonancia de las necesidades tácticas y operativas de la misma. El proceso correcto es que CRM sea la respuesta a los requerimientos de la estrategia en cuanto a la relaciones con los clientes y nunca, que se implante sin que sea demasiado coherente con ella.

- Personas: La implantación de la tecnología no es suficiente. Al final, los resultados llegan con su correcta utilización. Se ha de gestionar el cambio en la cultura de la organización buscando el total enfoque al cliente por parte de todos sus integrantes. En este campo, la tecnología es totalmente secundaria, y elementos como la cultura, la formación y la comunicación interna son las herramientas clave.

- Procesos: Es necesaria la redefinición de los procesos para optimizar las relaciones con los clientes, consiguiendo procesos más eficientes y eficaces.

- Tecnología: También es importante destacar que existen soluciones CRM al alcance de organizaciones según el tamaño o sector, aunque la solución necesaria en cada caso será diferente en función de sus necesidades y recursos.

En definitiva, antes de iniciar un proyecto CRM es importante tener claro los objetivos empresariales se pretenden conseguir. Tras aclarar este punto, la 
empresa debe comenzar a analizar diferentes soluciones tecnológicas. Además, se debe hacer un análisis previo de la inversión y un seguimiento de los resultados de la misma.

Conceptualmente, dentro de CRM, se distinguen tres grandes segmentos o componentes del CRM:

- CRM Operativo(Operacional): Engloba el conjunto de aplicaciones CRM responsables de la gestión de las diferentes funciones de ventas, marketing y servicio al cliente.

- CRM Analítico: es una herramienta para la explotación y análisis de la información sobre el cliente.

- CRM Colaborativo: tiene como finalidad gestionar los diferentes canales de relación con los clientes.

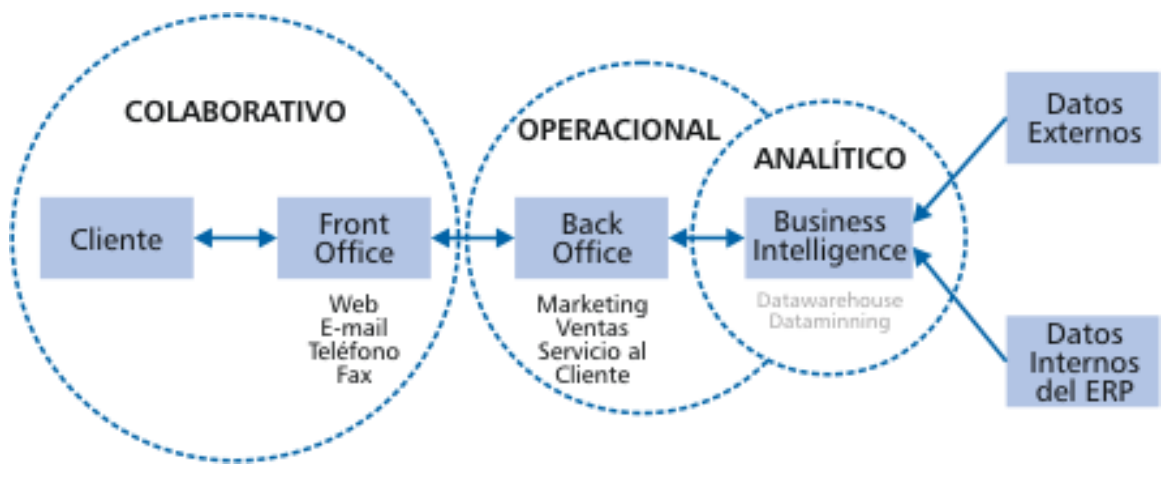

Figura 2.16.- Bloques que componen el CRM

\section{Sistemas SCM}

Los Sistemas SCM consisten en la planificación y la ejecución de las actividades de la cadena de suministro, asegurando un flujo coordinado dentro de la empresa, e incluso entre las diferentes compañías integradas en la cadena de valor, desde los proveedores de las materias primas, hasta los distribuidores del producto acabado. 

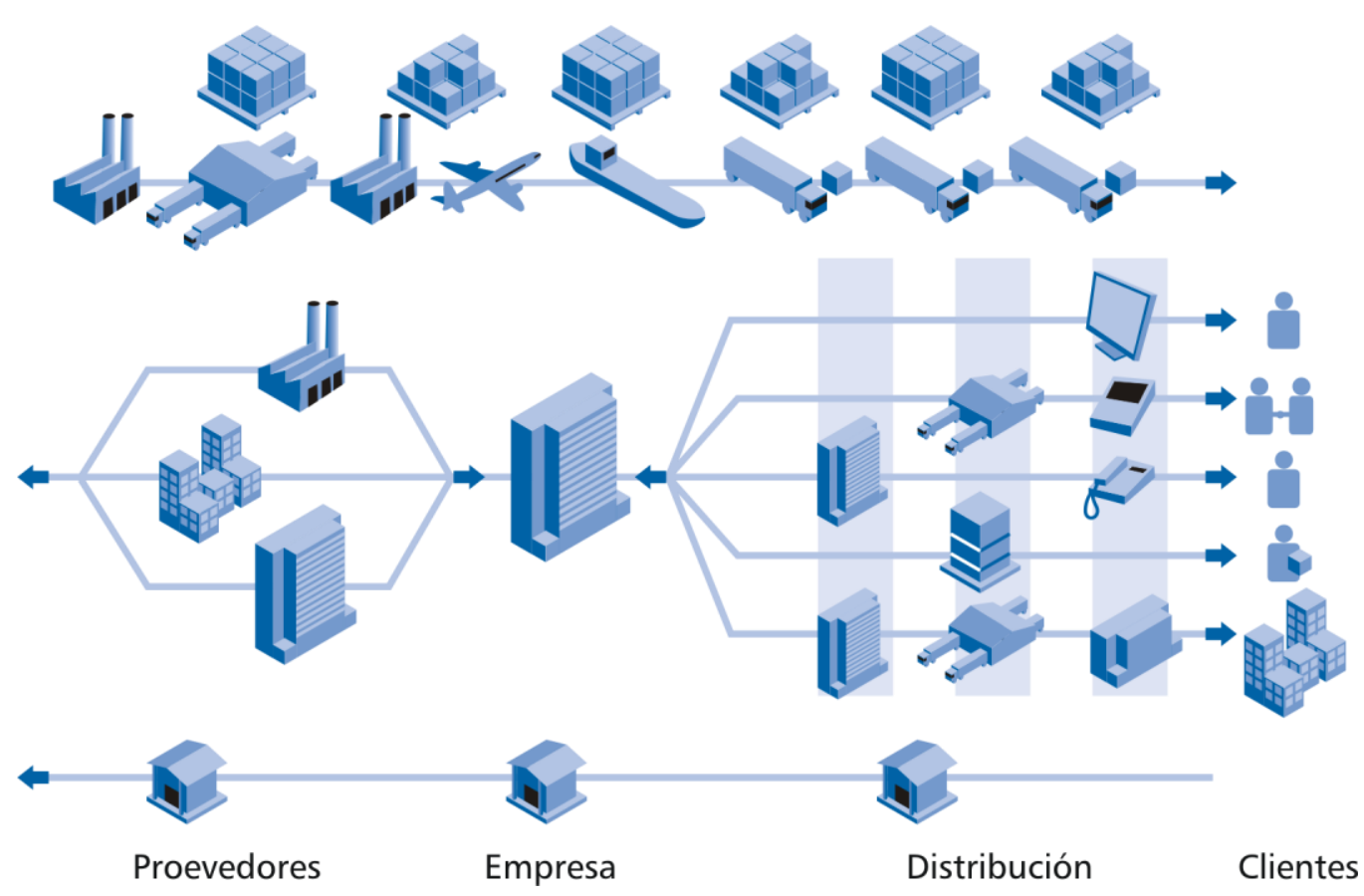

Figura 2.17.- Cadena de suministro

Estas actividades incluyen la selección, compra, programación de producción, procesamiento de órdenes, control de inventarios, transporte, almacenamiento y servicio al cliente. Además, incluye los sistemas de información requeridos para monitorizar todas estas actividades.

Las herramientas SCM permiten la sincronización de las etapas: compra, producción, almacén y distribución, de tal forma que se puedan enlazar proveedores, producción, subcontratas, distribuidores, en una red de producción y distribución cohesionada, y centrada en torno al cliente, como se puede observar en la figura 2.16.

En general, las soluciones de software para SCM se dividen en los siguientes componentes:

- El desarrollo del producto incluye los requisitos, el diseño y las pruebas del producto, además del diseño de la producción. Las soluciones para el desarrollo del producto permiten a la empresa diseñar de la forma más rápida mejores productos y servicios, ya que sus desarrolladores pueden trabajar con una información directa y puntual de las necesidades y exigencias de los clientes y de la capacidad de los proveedores. Estas herramientas reducen el periodo de comercialización, los costes del producto y los problemas de comunicación entre los grupos de ingeniería. 
- La planificación incluye las predicciones de ventas y pedidos, la planificación de la fabricación y la distribución, para satisfacer la futura demanda de los clientes en función de los suministros disponibles. Estos procesos pueden optimizar las operaciones de producción y envío, y permitir cumplir con la mayoría de los pedidos de los clientes a tiempo y al coste más bajo.

- La distribución y logística incluye la gestión de inventarios y almacenamiento, el transporte interior y exterior, la gestión de pedidos, la distribución física y la gestión de socios externos. Una solución de distribución y logística ayuda a garantizar que se dispone del número de productos adecuado, en el lugar preciso de la cadena de suministro, en el momento apropiado, y a los costes más bajos posibles. Esto mejora el movimiento y almacenamiento de los bienes, y garantiza una provisión adecuada de activos líquidos de inicio a fin de la cadena de suministro. Puede realizar un seguimiento de los clientes, los proveedores y los pedidos, así como controlar y gestionar sus compras, los transportes y las necesidades del cliente.

- Las soluciones de compras incluyen la adquisición de componentes del producto, las materias primas estándar y los suministros especializados necesarios para la fabricación del producto final. A través de Internet se puede optimizar el proceso de compra y reducir los gastos de dinero y tiempo en estas actividades.

- La producción incluye la fabricación, el ensamblaje y la subcontratación, todo de forma automatizada. Puede hacer un seguimiento, generar informes y analizar en tiempo real la información del proceso de fabricación, desde la planta de fabricación, hasta sus almacenes de servicio. Se puede determinar y eliminar con facilidad la sobreproducción, el movimiento de material, los inventarios excesivos y los cuellos de botella.

- La integración de socios de negocio permite concentrarse en aquello que hace mejor la empresa. Estas soluciones ayudan a desarrollar estrategias de asociación a través de la identificación de las ventajas en las relaciones con los socios y los proveedores. También ayudan a definir los procesos asociados con estas relaciones, así como a utilizar la tecnología de redes para intercambiar información y ampliar su red de socios y proveedores.

Los beneficios, más generales, que se pueden obtener de la implantación de una solución de gestión de la cadena de suministro son:

- Disminución de los precios de adquisición de las compras debido a negociaciones más eficaces y acceso a mayor número de proveedores.

- Disminución de los costes de procesos debido a la mejora de la eficiencia de los mismos.

- Reducción de los costes de compras debido a la eliminación de intermediarios. 
- Ampliación del número de proveedores potenciales y disminución del tiempo de localización.

- Disminución del tiempo de aprovisionamiento.

- Mejoras en la gestión de stocks y disminución de los niveles de inventarios.

- Mayor aprovechamiento de los recursos humanos del área de compras y logística.

- Información precisa sobre el estado del proceso de compra y logística.

- Mejora en la satisfacción del cliente al ofrecer un incremento de velocidad y adaptabilidad. Reducción de los tiempos muertos e incremento de la calidad, mejorando las relaciones con el cliente y propiciando su retención.

El SCM representa el esfuerzo de integración de los procesos de negocio interconectando sus diversos participantes, y teniendo como único objetivo conseguir la máxima satisfacción del cliente.

Las mejores soluciones de SCM presentan una serie de características comunes, la primera y más destacada es una extrema preocupación en la demanda de los clientes. En vez de intentar forzar los productos al mercado, con el riesgo que esto supone, pudiendo vender estos productos rápidamente o convirtiéndose en completos fracasos financieros, para este tipo de iniciativas de gestión de la cadena de suministro se trazan objetivos de desarrollo y producción de productos que sean demandados por los clientes, minimizando así, el flujo de materias primas, de productos terminados, de materiales de embalaje, el dinero y la información en cada punto del ciclo del producto.

Estos objetivos han sido perseguidos por las empresas industriales desde hace varias décadas. En este proceso de búsqueda, se han experimentado e implementado con éxito técnicas modernas como Just in Time (JIT), Respuestas Rápidas (QR), Respuesta Eficiente al Cliente (ECR), Inventarios Manejados por el Proveedor (VMI) y otras. Estas son las herramientas que ayudan a construir una estructura de cadena de suministros robusta y fiable.

Una de las tecnologías que se utilizan para comunicar y procesar transacciones de negocios electrónicamente es EDI (Electronic Data Interchange), que es también un estándar ANSI X.12. Otra tecnología utilizada es XML (Extensible Markup Language), recomendada por el World Wide Web Consortium desde Febrero de 1998. XML es un formato flexible para suministrar información a través de Internet, intranets y otros canales de distribución de información, donde no existe ninguna plataforma común compartida.

Los sistemas de gestión de la cadena de suministro, Supply Chain Management (SCM), constituyen uno de los motores principales para la rápida y eficaz incorporación de la empresa a la economía digital, que requiere un cambio fundamental: pasar de una cadena de suministro lineal y secuencial clásica a una red adaptable de cadenas de suministro. 
En la siguiente tabla se puede encontrar una diferenciación entre las características principales que presenta una cadena de suministro tradicional frente a las de una red de cadenas de suministro.

\begin{tabular}{|l|l|}
\hline $\begin{array}{c}\text { Concepción clásica de la cadena } \\
\text { de suministro }\end{array}$ & $\begin{array}{c}\text { Concepción actual de una Red } \\
\text { adaptable de cadenas de } \\
\text { suministro }\end{array}$ \\
\hline - Centralizada & - Distribuida \\
- Tamaño & - Valor \\
- Posición & - Información \\
- Fábrica & - Cliente \\
- Cuatro paredes & - Fábrica virtual \\
- Integración vertical & - Competencia esencial \\
- Personal/Dirección & - Empleados/Partners \\
- Previsibilidad & - Capacidad de \\
\end{tabular}

Tabla 2.6 - Cadena de suministro clásica vs. en red

Conceptualmente se puede encontrar dos tipos de aplicaciones que cubren la gestión de la cadena de suministro, que son:

\section{Supply Chain Planning: SCP}

Son aplicaciones utilizadas para acceder y analizar información almacenada en las bases de datos de la empresa, para pronosticar la demanda y planificar la producción de forma adecuada. Pueden ser utilizadas en decisiones operacionales (a corto plazo, schedule de fabricación) o en decisiones estratégicas (a largo plazo, como la construcción de una fábrica).

Sus principales funcionalidades son:

- Planificación de la distribución. 
- Planificación y schedule (especificar que es, se puede perder la gente en el concepto) de la producción.

- Planificación del suministro.

- Planificación de la demanda.

\section{Supply Chain Execution: SCE}

La información generada por SCE se utiliza para guiar la producción física, el almacenaje, el flujo de materiales, los productos semiterminados y el producto terminado. Estas aplicaciones se basan en interfaces con SCP y otros sistemas de gestión para determinar la capacidad de producción, incluyendo restricciones de tiempo y costes, y para calcular un plan de producción que satisfaga todos los requerimientos y que pueda adaptarse rápidamente a cualquier cambio en las variables.

Sus funcionalidades son:

- Gestión de órdenes.

- Gestión de Inventarios.

- Logística.

- Gestión de transporte.

- Gestión de almacenes. 


\section{MODELO E HIPÓTESIS DE LA INVESTIGACIÓN.}

\subsection{Introducción.}

En este capítulo se define el modelo que, a partir de la definición del estado del arte, Marco Teórico (Capítulo 2), he considerado como marco de referencia para la investigación, también se mencionan las diferentes hipótesis de trabajo, que están estrechamente relacionadas con los objetivos y que permitirán definir las estrategias metodológicas de la investigación (Capítulo 5).

A lo largo de la pasada década muchas compañías han tratado de reestructurarse para convertirse en empresas mucho más competitivas. En ésta relación se encuentran tanto grandes organizaciones como otras pequeñas, corporaciones en mala situación económica, y también compañías en situación económica boyante. Sus proyectos se han llevado a cabo bajo distintas etiquetas: gestión en calidad total, reingeniería, rightsizing, reestructuración, cambio cultural y reflotación. Pero, prácticamente en todos los casos, el objetivo básico ha sido siempre el mismo, realizar cambios fundamentales en el modo de manejar los negocios para tener éxito en el nuevo y cambiante entorno de mercado, con la inevitable incorporación de las nuevas tecnologías y su efecto positivo en la productividad (López Sánchez, 2004).

La ejecución de un proyecto ERP va más allá de la simple implantación de un sistema informático, algunos autores incluso plantean que la empresa se encuentra frente a la definición de un nuevo modelo de negocio (Al-Mashari, 2000; Ronca, 1999 ${ }^{1}$ ). Es ineludible tener presente el concepto de "organización" como sistema sociotécnico, que va a verse afectado en un proceso de cambio que debe ser adecuadamente gestionado; es por tanto imprescindible considerar el factor humano, los usuarios del sistema: finales, paramétricos, personal técnico, etc. En muchos casos la adopción del sistema puede suponer el rediseño de la institución (Laudon y Laudon, 1996 pp. 8-27, 382-391, 527-535).

El desarrollo de una solución ERP se realiza de forma claramente diferenciada de un proyecto de Sistemas de Información tradicional. La principal diferencia es que cuando una organización adopta un sistema ERP, no se desarrolla un sistema para satisfacer plenamente sus procedimientos de trabajo (Parr y Shanks, 2000). Por el contrario, la organización tendrá que adaptar parte de su modelo de negocio a las funcionalidades genéricas del sistema, a través del análisis de sus principales procesos; las adaptaciones que se deben hacer en algunas ocasiones, llegan hasta el Rediseño de Procesos (Gable, Scott J.E y Davenport, 1998).

\footnotetext{
${ }^{1}$ Este autor plantea también la conveniencia de llevar a cambio procesos de cambio y aprendizaje organizativo deforma que se facilite el éxito en la implantación de un sistema ERP. Este planteamiento es también considerado en Taxen, 1999.
} 
El modelo propio planteado en este investigación para la adecuada gestión de un proyecto ERP consta de una serie de etapas: la definición de la estrategia, la implantación del ERP y la fase de post-implantación (Gable, Scott J.E, y Davenport, 1998; Mabert, Soni y Venkataramanan, 2002; Ross y Vitale, 1998)

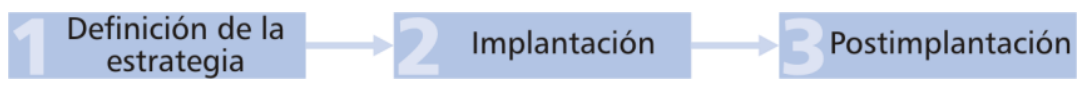

Figura 3.1.- Fases de un proyecto ERP.

La fase definición de la estrategia incluye el proceso que debe seguir una empresa desde que se plantea la necesidad de un sistema ERP hasta que elige un producto y contrata a un proveedor. La etapa denominada implantación del ERP contempla las actividades propias de su nombre así como las diferentes alternativas que existen. Por último, en la fase de postimplantación se incluyen aquellas actividades posteriores a la puesta en marcha del sistema, necesarias para completar con éxito la ejecución del proyecto. En los apartados siguientes se comentan cada una de estas etapas.

\subsection{Definición de la estrategia.}

Durante esta fase la empresa se prepara y organiza para llevar a cabo la Implantación de la solución ERP, identificando las necesidades de mejora de los procesos y analizando las características de los sistemas de información actuales. El modelo considera también necesario la organización de un equipo que se encargue de la gestión del proyecto. Se trata en definitiva de pergeñar una estrategia que permita al equipo del proyecto la definición de los objetivos a conseguir. Durante esta fase el modelo considera como factor clave de éxito el compromiso y liderazgo de la dirección de la empresa.

Las actividades que deben realizarse en esta fase son:

a) Definición de un plan de acción por parte de la Dirección de la empresa.

Los sistemas de información deben ser coherentes con la estrategia general de la organización. Por ello es importante definir un plan que a partir del análisis DAFO ${ }^{2}$ correspondiente, contemple los potenciales cambios internos de la empresa (estructura organizativa, modelo de negocio, situación económico-financiera, objetivos comerciales, nuevos productos, cultura, etc.) y las exigencias provenientes del exterior (nuevos mercados, alianzas estratégicas, cambio en la demanda, leyes, etc.)

\footnotetext{
${ }^{2}$ El análisis DAFO considera las amenazas, y oportunidades que afectan a la organización provenientes del entorno y las fortalezas y debilidades que son intrínsecas a su propia naturaleza y estructura (Domínguez Machuca et al., 1998)
} 
b) Selección y establecimiento del equipo de Gestión del Proyecto.

Es necesario establecer un equipo interdepartamental para llevar a cabo el proceso de gestión del proyecto ERP y es imprescindible que tengan el apoyo y la dirección de la gerencia durante todo el proyecto, así como de los máximos responsables de las diferentes áreas.

\section{c) Identificación de las necesidades de la empresa: Procesos y Sistemas de Información actuales.}

Una vez se ha constituido el equipo de gestión del proyecto, su primera tarea es realizar una revisión de todos los procesos de la empresa, las tareas y dificultades asociadas a cada uno de ellos, y la forma en la que los actuales sistemas de información soportan dichos procesos. Este análisis permite obtener las necesidades existentes y potenciales en cuanto a procesos y Sistemas de Información que servirán como base para la generación de un cuestionario de formato general, que pueda ser utilizado para la comparación de las soluciones ERP de los diferentes proveedores (Esteves y Pastor, 2001).

\section{d) Selección de la solución ERP a implantar.}

A partir del análisis de necesidades y los requerimientos y especificaciones obtenidas, acerca del nuevo sistema de información. El equipo de gestión de proyecto debe seleccionar la solución idónea entre el amplio abanico de soluciones existentes en el mercado. Deben tenerse en cuenta los siguientes aspectos:

- El análisis de sus necesidades.

- Una lista de criterios debidamente ponderados que permita valorar las ofertas de las consultoras y proveedores de ERP.

- Información sobre las características técnicas y funcionales de las soluciones ERP y las consultoras existentes en el mercado.

e) Contratación, aprobación del presupuesto y del plan de implantación.

Una vez seleccionada la solución, la empresa debe conocer en profundidad la opción elegida; para ello, se llevarán a cabo varias sesiones con la consultora en cuestión, en las que se tratarán con detalle todos los aspectos anteriores, para asegurarse que la opción elegida es la correcta. Es necesario elaborar un presupuesto exhaustivo, que incluya tanto los costes directos (personal, equipamiento hard y soft) como los indirectos atribuibles al proyecto y su secuencia temporal. Finalmente, debe estimarse el retorno de la inversión del proyecto $(\mathrm{ROI})$.

\subsection{Implantación de un ERP.}

La fase de implantación implica la correcta utilización de un método de trabajo sistemático que garantice cumplir con el proyecto en cuanto a: calidad, especificaciones, tiempo y costes. 
Para lograrlo existen diferentes Metodologías de Implantación utilizadas por expertos en consultoría, cada una presenta variantes de acuerdo con las características y dimensiones de la empresa que va a implantar el sistema.

La Metodología es el aspecto más importante y complejo del proyecto, ya que a través de ella se relacionan todos los factores que intervienen, como son: personal (empresa y consultora), recursos físicos, tecnología (hardware, software), procesos, conocimiento, etc. Es decir, se debe hacer una planificación que incluya la organización, disposición y utilización de estos recursos en el tiempo y en el espacio, para cumplir con el objetivo del proyecto tanto en requerimientos como en costes y calidad.

En esta fase uno de los factores clave de éxito es la comunicación entre todos los participantes del proyecto tanto internos como externos.

La implantación de una solución ERP en el momento de puesta en marcha se puede realizar de varias formas cuya conveniencia varía dependiendo de las características del proyecto. Las alternativas disponibles son las siguientes (Taxen, 1999; Esteves J., Pastor J. y Casanovas J., 2002; Parr y Shanks, 2000; Slevin y Pinto, 1987):

- Paralela: enfoque en el que tanto el sistema antiguo como el nuevo operan juntos durante un tiempo hasta que se verifica el correcto funcionamiento del nuevo sistema. Se trata de la opción más utilizada.

- "Big Bang": el nuevo sistema sustituye totalmente al antiguo en una fecha determinada.

- Estudio Piloto: introduce el sistema nuevo sólo en un área limitada de la organización, que puede ser un único departamento o unidad operativa, hasta que demuestre ser plenamente funcional; entonces pueden abordarse el resto de los departamentos de la organización, ya sea simultáneamente o por etapas.

- Método de fases: introduce el nuevo sistema ya sea por funciones o por unidades de organización.

Una vez definido el método de implantación entre la empresa y la consultora, analizadas convenientemente las ventajas y desventajas de cada alternativa, y seleccionando la que más se ajuste a las condiciones de la empresa, se da inicio al desarrollo del proyecto con base en la propuesta por la consultora y aprobada por la empresa.

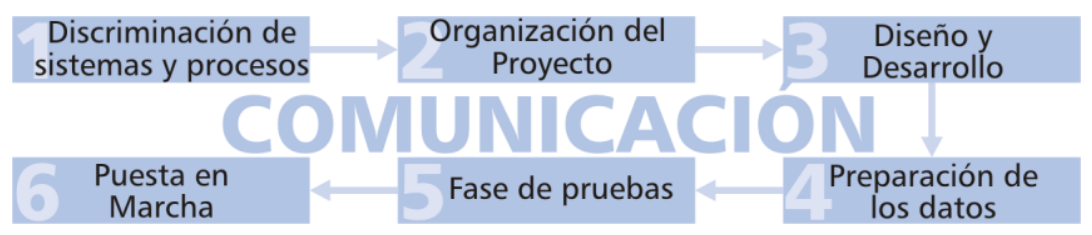

Fig. 3.2.- Etapas en el proceso de implantación de una solución ERP. 
El modelo considera las siguientes etapas:

\section{a) Descripción de sistemas y procesos}

Se lleva a cabo un estudio de empresa por parte de la consultora para tener claro e identificar totalmente los objetivos y los motivos del cambio. Se hace un exhaustivo análisis de sistemas de información heredados, previos a la implantación del ERP: Procesos, Sistemas, Formación necesaria y Cultura Organizacional de la empresa (Dianne Galloway, 1998; John Pallatto, 2002; Pallatto, 2002).

\section{b) Organización del Proyecto}

Esta etapa proporciona a la empresa y consultora una perspectiva previa global del proyecto de implantación, determinando su ámbito de aplicación, expectativas, dimensión y evolución, enmarcándolo dentro de una metodología global debidamente organizada. Se seleccionan las personas que van a participar en el proceso de implantación, las tareas a realizar, la secuenciación, los plazos y la asignación de responsabilidades. Además, se crean los instrumentos de control adecuados (Somers y Nelson, 2001b).

\section{c) Diseño y desarrollo}

Es la parte más técnica del proceso, partiendo de la etapa 1 "Descripción de sistemas y procesos", se realiza la adaptación del sistema a las necesidades de la empresa, tanto mediante parametrización del paquete estándar, como con la programación de funciones o incluso módulos específicos para el cliente. A su vez, se genera la documentación necesaria para que el conocimiento obtenido por todos esos análisis quede registrado.

Un aspecto importante en el registro y difusión del conocimiento es la formación de los usuarios "clave" entre el personal de la empresa, que participan en este periodo de diseño de la aplicación, y que después servirán de nexo entre la consultora y la formación del resto de usuarios de la empresa. Así como la creación de los procedimientos necesarios para éstos (Esteves J., Pastor J., y Casanovas J., 2002).

\section{d) Preparación de los datos}

Consiste en la valoración de los datos contenidos en el antiguo sistema de información para decidir cuáles de ellos son realmente válidos y de utilidad en el nuevo sistema y se establece la operativa de traslado de datos. Esta fase se hace paralelamente desde la etapa 1, porque se va notificando los datos necesarios en cada proceso.

\section{e) Fase de pruebas}

Etapa previa a la puesta en marcha dónde se procede a la integración y aceptación del sistema, comprobando que los procesos definidos funcionan correctamente (se realizan también pruebas de programas durante el proceso de 
desarrollo) y que cumplen con lo establecido en las fases previas, antes de dejar de utilizar definitivamente el sistema antiguo en la fase siguiente.

\section{f) Puesta en marcha}

Se valida el trabajo realizado durante todo el proceso de implantación. En este punto se realiza la formación final, donde se reduce la incertidumbre de los usuarios ante el nuevo sistema y los nuevos conceptos.

Es muy importante que cuando empiece a funcionar el ERP, se asegure el funcionamiento del sistema considerando las contingencias de fallo, parada y revisión de alguno de los módulos. Deben preveerse las actuaciones ante las diferentes situaciones posibles, que incluyen diferentes medidas de seguridad y procedimientos de control manual. 


\subsection{Postimplantación.}

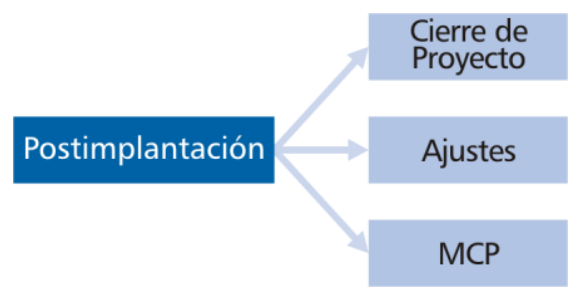

Fig. 3.3.- Etapas de la fase de Postimplantación.

Tras la puesta en marcha del sistema es necesario el cierre formal del proyecto, ajustes pequeños de adaptación de la operativa del nuevo sistema y establecer los mecanismos de evolución y mejoramiento continuo de procesos y del sistema ERP. Aspectos que se consideran a continuación:

\section{a) Cierre formal del proyecto.}

Consiste en finiquitar económicamente el proyecto, entregar los manuales, actas, licencias y garantías, verificar el correcto funcionamiento de la solución y el cumplimiento de los objetivos de la empresa. Es conveniente la elaboración de un informe de cierre del proyecto.

\section{b) Ajustes Iniciales.}

Es la fase donde la organización comienza a vivir con el sistema, presentándose los lógicos altibajos y problemas debido al proceso de aprendizaje por el cual la organización debe pasar. Se precisa un tunning por medio de una serie de ajustes relativos a la parametrización, seguridad y documentación del sistema.

\section{c) Mejora Continua de Procesos.}

Finalmente, una vez la organización ha alcanzado la estabilidad en sus operaciones con el sistema y los usuarios han incrementado sus conocimientos del mismo, se presentan oportunidades de mejora. Estas pueden estar provocadas por cambios en el entorno, cambios tecnológicos, nuevas necesidades de información por parte del personal de la empresa, o por la aparición de cambios en la plataforma tecnológica o en el software (nuevas versiones) de la solución elegida (Dianne Galloway, 1998).

El modelo, constatado por la realidad de las empresas, considera la adopción de nuevas funcionalidades que abarcan la cadena de valor de las empresas: CRM, datamining (minería de datos), e-business, SCM gestión de la cadena de suministro, sistemas EIS (Executive Information Systems), etc.

El gráfico siguiente representa el modelo planteado para la gestión de la implantación de los sistemas ERP en la empresa. 


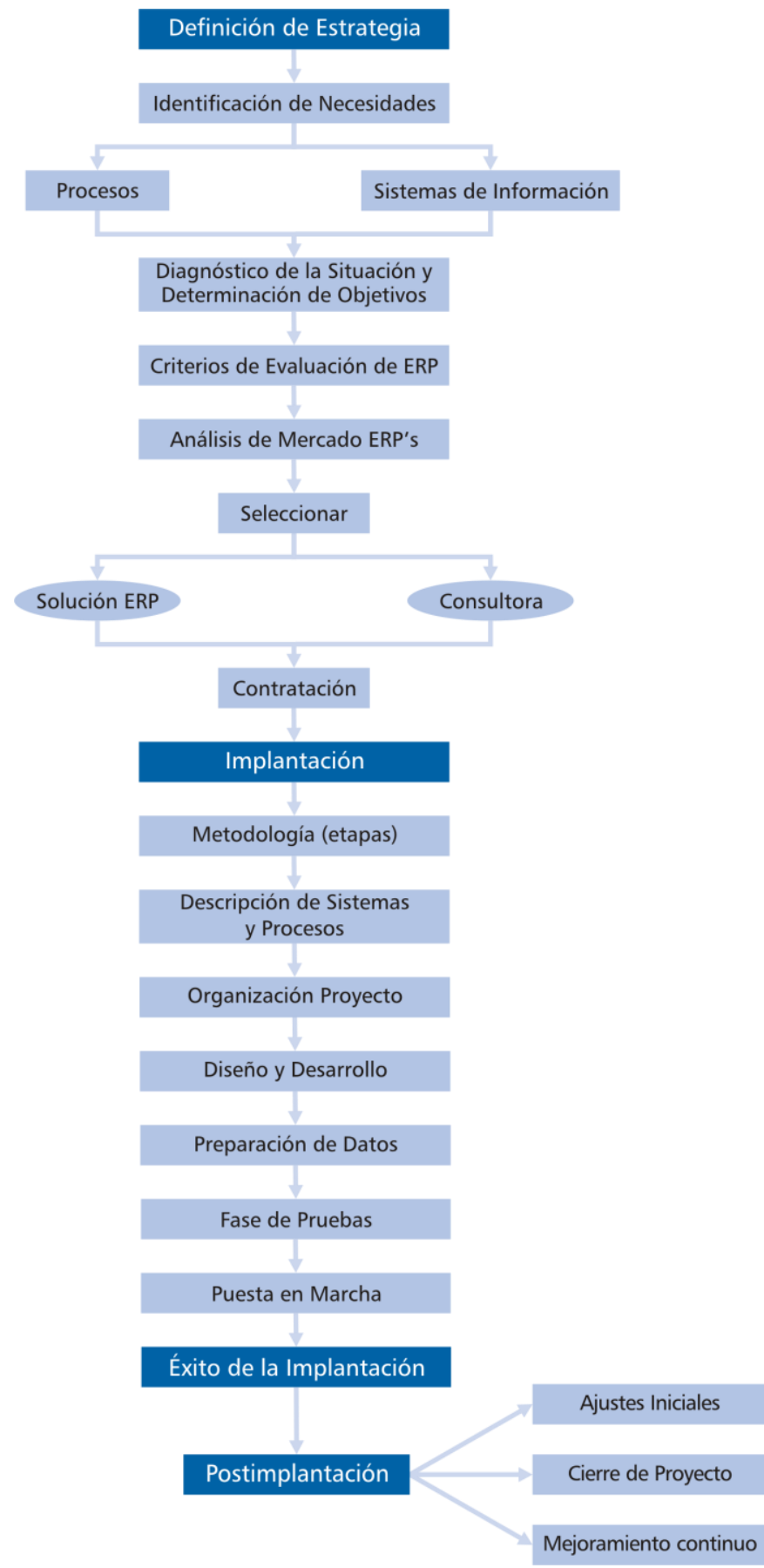

Figura 3.4.- El proceso de desarrollo de un proyecto ERP. 


\subsection{Factores críticos en la implantación de Sistemas ERP.}

Al considerar los proyectos de cambio, entre los que se cuentan la incorporación de sistemas ERP, algunos de éstos han sido muy satisfactorios. Otros pocos han sido fracasos completos. La mayoría se encuentran en algún lugar intermedio con tendencia hacia la parte más baja de la escala. Circunstancias como una tasa mantenida de innovación del producto, nuevos proveedores y opciones tecnológicas plantean importantes retos organizativos cuando estas empresas equilibran la necesidad de realizar adecuadamente las operaciones diarias con la de investigación y asimilación de las nuevas tecnologías.

Para abordar este problema deben tomarse dos medidas clave. En primer lugar, la dirección de la empresa necesita adoptar un planteamiento contingente respecto a los sistemas administrativos para gestionar la asimilación de la tecnología (Andreu, Ricart y Valor, 2000). Cada tecnología requiere diferentes tipos de gestión en las diversas etapas de su ciclo de vida. La introducción de tecnologías en una empresa requiere una perspectiva estratégica y de aprendizaje organizativo, en lugar de considerar únicamente el coste y la eficiencia ${ }^{3}$. El segundo paso es el posible establecimiento de una nueva unidad en la estructura denominada "nuevas tecnologías". Esta unidad, instalada con éxito en diferentes marcos, gestiona la detección e introducción de tecnología nueva que tenga un elevado potencial de rentabilidad, aportartando apoyo complementario en favor de la eficacia posible de esta unidad ${ }^{4}$.

La lección más general que hay que aprender de los casos de mayor éxito consiste en que el proceso de cambio atraviesa una serie de pasos que, en conjunto, requieren normalmente una considerable duración en el tiempo. Eliminar pasos sirve únicamente para crear la ilusión de velocidad y nunca conduce a resultados satisfactorios. Un segundo aprendizaje es que fallos críticos en cualquiera de las fases pueden ralentizar el ímpetu y anular avances costosamente obtenidos. Quizás, por ser relativamente pequeña la experiencia en renovación de organizaciones, incluso gente muy preparada comete, a menudo, al menos un error importante.

Las investigaciones sobre los factores de éxito en la implantación de ERP, sus operaciones y su impacto en las empresas son muy limitadas, debido a que estos sistemas son relativamente nuevos, la gran mayoría de las implantaciones datan de los últimos cinco años (Mabert, Soni, y Venkataramanan, 2002:74-82) y generalmente en organizaciones de un tamaño considerable, donde la complejidad de sus procesos les obligó a buscar una solución que integrara eficientemente los departamentos de la empresa. Desde otra perspectiva, aparece la situación de las Pequeñas y Medianas Empresas, que han comenzado la

\footnotetext{
3. C. Argyris and D.A.Schon, Organizational Learning: A. Theory of Action Perspective (Reading, Mass,: Addison- Wesley publishing, 1978).

4. T.Burns and G.M.Stalker, The Mangement of Innovation . (London: Tavistock Publishing, 1979).
} 
integración de los sistemas ERP; para estas organizaciones la información disponible es todavía menor.

La literatura científica recoje aspectos relativos al éxito en la gestión de los proyectos de implantación, definiciones de fallos y problemas, factores críticos de éxito y gestión del riesgo.

Diferentes autores han identificado factores de éxito en la implantación de ERP, (Sumner, 1999) incluye los siguientes: apoyo de la dirección, rediseño de los procesos del negocio para adecuarlo con el software, inversión en la formación de usuarios, evitar la customización y el uso de analistas de negocios con conocimientos en tecnologías y en organización.

Bingi, Sharma y Godla, 1999, contemplan el compromiso desde la alta gerencia, la reingeniería de los procesos existentes, la adecuada integración del ERP con los otros sistemas de información, la selección y dirección de los consultores y la formación de los empleados en el nuevos sistema son los aspectos a considerar para asegurar el éxito en la implantación. Slevin y Pinto, 1987 identifican 10 factores de éxito en la implantación de un proyecto, estos son: misión del proyecto, apoyo de la alta dirección, plan del proyecto, consulta al cliente, personal competente, disponer de la técnica necesaria, aceptación del cliente (usuarios), control y realimentación, comunicación y habilidad para resolver imprevistos. Holland y Ligth ( 1999), desarrollaron un marco para agrupar los factores de críticos de éxito del proceso de implantación de ERP en factores estratégicos y tácticos. Sommers y Nelson ( 2001a) proponen una lista de 22 factores de éxito asociados con la implantación de un sistema o proyecto informático, derivado de un proceso de identificación y síntesis de los requerimientos en la implantación que han sido recomendados por investigadores y académicos, específicamente la literatura de implantación de tecnologías de la información, reingeniería de procesos, descripción e implantación de proyectos y el estudio de casos de implantación de ERP.

Esteves y Pastor (2000), clasifican los factores críticos según 4 perspectivas: la organizativa, la tecnológica, estratégica y táctica, obteniendo una matriz, donde organiza los factores según el número de veces que aparecen en los artículos que ha revisado. Los de mayor frecuencia son apoyo continuo de la dirección, gestión efectiva del cambio organizativo, alcance del proyecto, dedicación de los consultores y los empleados, comunicación externa e interna, planificación del proyecto.

Laudon y Laudon (1996), consideran que el resultado de la implantación puede quedar determinado por los siguientes factores: el papel de los usuarios, el grado de apoyo directivo para el esfuerzo de implantación, el nivel de riesgo y complejidad del proyecto de implantación y la calidad de la administración en el proceso de implantación. 
Mabert, Soni, y Venkataramanan (2002), consideran que la implantación de un sistema ERP es un compromiso de gran magnitud, por lo que debe ser planificada de forma apropiada y gestionada con eficacia, ellos determinaron mediante una investigación que el común denominador del éxito de las empresas era: directivos completamente implicados en el proyecto, nombramiento de un equipo de implantación mixto dirigido por un alto directivo, dedicación permanente a la planeación del proceso de implantación, directrices claras para evaluar el rendimiento, diseño del uso de los consultores y transferencia del conocimiento de los asesores externos al personal de la empresa, planificación detallada de la formación de los usuarios.

La mayoría de autores coinciden en que la implantación de una solución ERP puede ser un éxito tecnológico pero un fracaso organizacional a causa del fracaso en el proceso social y político del desarrollo del proyecto. Se debe prestar suficiente importancia a la participación, liderazgo y compromiso de los miembros claves de la empresa en cada una de las etapas de la implantación buscando la colaboración y el saber hacer de todos los participantes (stakeholders): clientes, proveedores, implantadores, subcontratistas, empleados, etc. (Gable, Scott J.E, y Davenport, 1998). Muchos investigadores han señalado que la introducción o alteración de un sistema de información tiene un poderoso impacto conductual e institucional que a menudo se dirigen a nuevos roles de autoridad y poder. La participación, motivación y compromiso de la gente son determinantes en el proceso implantación y posterior explotación del ERP (Al-Mashari, 20005).

Hong y Kim ( 2002) presentan el resultado de una investigación donde se planteó la relación existente entre las influencias organizativos y el éxito de la implantación del ERP. Verificaron el impacto de los aspectos organizativos en conjunto con las contingencias de la implantación. Los resultados de la encuesta con 34 organizaciones mostraron una significativa dependencia de los factores organizativos para el éxito del ERP.

El concepto de "mejores prácticas" es el modelo defendido por los proveedores de ERP (Lee Pender, 2001). En contraste, algunos académicos mantienen que eso es ilusorio y potencialmente prejudicial porque el ERP no provee modelos para todos los procesos de negocio y al final las industrias acaban reconfigurando el paquete y adicionando nuevas funciones para optimizar el uso en sus únicos contextos.

Generalmente, los proveedores de ERP recomiendan la adaptación del proceso y desaconsejan la adaptación del software como medida de prevención contra la aparición de problemas funcionales que atenten contra la integridad así como la aparición de futuros problemas en nuevas versiones. Un desafío crítico en la implantación del ERP es identificar las divergencias entre las generalidades

\footnotetext{
${ }^{5}$ Este autor plantea los sistemas integrados de gestión desde una perspectiva de gestión del cambio.
} 
funcionales del ERP y los requisitos específicos de la organización y así decidir como esos huecos serán manejados.

Se definen a continuación los factores tecno-organizativos que constituyen el modelo propio, y que contribuyen de manera clave al éxito del sistema. Este puede quedar definido como la desviación de los objetivos del proyecto en términos de costes, tiempo, funcionalidad del sistema y beneficios (Hong y Kim, 2002). Por lo cual parece necesario comenzar definiendo la conveniencia de definir los objetivos del proyecto.

\section{A) DEFINICIÓN DEL OBJETIVO}

Saber qué es lo que se quiere y hacerlo explícito para toda la organización y a los consultores que participaran como socios en la implantación del ERP. La etapa de fase de análisis es donde se definen los objetivos y metas, por tanto es considerada por los consultores como la más importante para el cumplimiento de las siguientes fases. Los objetivos deben ser claros, específicos y indican la dirección general del proyecto.

\section{B) PARTICIPACIÓN Y COMPROMISO}

La participación, compromiso y liderazgo de los diferentes actores de la implantación del ERP: implica contar con el apoyo total de la alta dirección, con un líder de proyecto comprometido y con usuarios involucrados que se adueñen del nuevo sistema, capacitados apropiadamente y oportunamente (Blanco, 2002, Bennis y Nanus, 2001). Es importante contar con un consultor experto, que sea capaz de transmitir a la organización positivamente los cambios que se generan con el proyecto, que tenga el respeto de todos los miembros de la organización por su conocimiento y asertividad en el lenguaje utilizado.

A continuación presentamos los actores que participan y el rol que desempeñan en el proyecto (González Ladrón de Guevara y Torres Rodríguez, 2002.)

Por parte de la empresa:

- Alta dirección: el apoyo y control del proyecto por parte de la Gerencia y asamblea directiva está bien documentados por muchos investigadores. Los directivos deben estar completamente implicados en el proyecto y establecer prioridades claras, comunicar la estrategia corporativa a todos los empleados.

- Jefe de Proyecto: es quien tomará la responsabilidad por parte del cliente. Será el interlocutor válido de cara al implantador de la solución y el portavoz de la empresa para cualquier decisión que se desee transmitir. Debe aunar capacidad de liderazgo, con conocimiento en sistemas de información, agente motivador del proyecto. Debe tener el reconocimiento y respeto de toda la empresa. 
- Usuarios clave: son usuarios que disponen de un profundo conocimiento de los procesos de negocio o de algunas de las áreas de actividades específicas de la empresa. Generalmente son los jefes de área. Sus principales responsabilidades dentro del proyecto de puesta en marcha serán las de suministrar requisitos, delimitar su alcance y verificarlos. Dirigen a nuevos roles de autoridad y poder. La participación, motivación y compromiso de la gente son determinantes en el proceso implantación y posterior explotación del ERP.

Cabe destacar que dadas las características de las PYMES, distinguiéndose por ser empresas de carácter familiar, con procesos no muy complejos y con una organización administrativa significativa (Guarch y Cuenca, 2002). El proyecto de implantación es menos complejo en una PYME que en una empresa grande: se realizan todas las fases descritas anteriormente, pero las actividades y recursos necesarios son menores, se organizan menos equipos de trabajo, el ERP se implanta en un período de seis meses a un año, dependiendo de los módulos a implantar.

En este factor también se incorpora la capacitación de la empresa consultora, su competencia a la hora de analizar las necesidades y aportar experiencia en el sector.

\section{C) MÉTODO DE TRABAJO}

Establecer y cumplir con un método sistemático de trabajo, sencillo, comprensible para todos, con objetivos claros, control de avance del proyecto, asignación de responsabilidades y roles, cumplimiento de compromisos, programación de reuniones efectivas, asignación de recursos generación de documentos de control, seguimiento del proyecto y una planificación detallada de actividades de cada una de las fases de la metodología de implantación, es otro factor de éxito. Este factor está estrechamente ligado con la gestión de la resistencia al cambio definida como: la fuerza de la respuesta negativa de la organización a implantación del ERP (Esteves J., Pastor J., y Casanovas J., 2002; Somers y Nelson, 2001b)

\section{D) IDONEIDAD DE LA SOLUCIÓN}

Es decir que cumpla con las características básicas de una solución ERP, que sea flexible y adaptable a las exigencias de la empresa, y que le permita crecer hacia nuevos planteamientos de negocio. Este factor incluye tanto el ajuste organizativo al ERP, definido como: el grado de adecuación entre el modelo ERP y las necesidades de la empresa en términos de datos, procesos e interfaces del usuario (Hong y Kim, 2002) y la adaptación del ERP a la organización receptora, definida como: los esfuerzos adicionales y tiempo preciso para el cambio de procesos para adecuación al ERP (Bingi, Sharma, y Godla, 1999;Holland y Light, 1999; Hong y Kim, 2002).

Las hipótesis planteadas en relación a este factor son las siguientes: 
- El ajuste de la organización al ERP está directamente relacionado con el suceso en la implantación del ERP.

- Existe una relación entre la resistencia de la organización frente a la implantación, la perspectiva de un ajuste organizativo necesario y el éxito en la implantación del ERP (Hong y Kim, 2002).

Así pues, durante la implantación es preciso tener en cuenta un conjunto de factores organizativos que quedan condensados en la siguiente figura y que serán analizados a lo largo del proceso investigador:

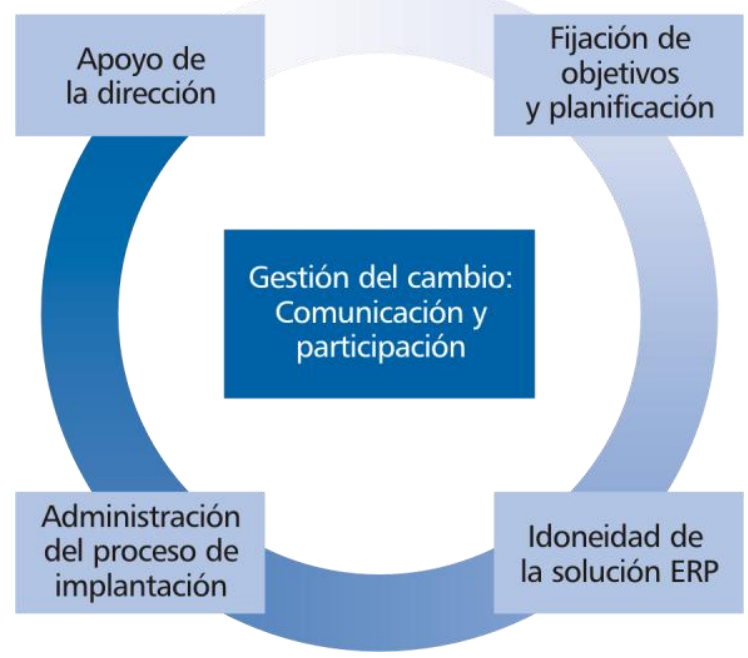

Fig. 3.5.- Factores críticos en la implantación. Gestión del cambio. 


\section{SITUACIÓN DE LAS TICS EN EL SECTOR TEXTIL}

\subsection{El Sector Textil}

\subsubsection{Introducción}

La industria textil y de la confección es una de las más globales del mundo, pues representa el $6 \%$ de la producción mundial. Es un sector generador de empleo fundamental en muchos países y constituye el 14\% del empleo mundial en industrias manufactureras. En España es uno de los sectores tradicionales de nuestra economía, representando el 15\% de las empresas españolas.

Según Canals (2003) los cambios que se van produciendo en la realidad económica internacional, derivados de la mayor intensidad de la globalización, internacionalización e interdependencia económica, unidos a procesos de mayor liberalización, provocan la transformación y adaptación de nuestro sector, así como el de los principales países desarrollados. El sector textil se considera una actividad de las denominadas maduras (ACTE, 2003), y sin embargo está demostrando una alta capacidad de innovación y de avance tanto a los cambios de temporada, como a las modificaciones funcionales y estéticas requeridas por la evolución cultural y, especialmente por la presión de consumidores exigentes y la penetración de nuevos competidores, por lo que la apuesta por la innovación continua que hace el sector tiene un carácter estable y una dimensión estratégica (Canals, 2003).

Según Fabregat (2003), el verdadero impulso a los cambios citados ha venido por la creciente liberalización de los intercambios textiles mundiales. Las sucesivas rondas del GATT ${ }^{1}$, llevadas a cabo por la $\mathrm{OMC}^{2}$, han propiciado una mayor apertura de los mercados internacionales por lo que el crecimiento mundial de los intercambios ha sido más intenso que el de la producción mundial. El paradigma de esta liberalización son los Acuerdos de Marrakech, que establecen la supresión escalonada de las limitaciones cuantitativas (cuotas) que regulan los intercambios textiles y de la confección desde 1973 bajo la cobertura legal del Acuerdo Multifibras. Actualmente nos encontramos en la fase final que culminará en 2005 con la libertad total de intercambios.

Este proceso también ha sido propiciado por las facilidades que la UE ha dado a los países en vías de desarrollo con el fin de mejorar el acceso de sus productos textiles y de la confección en el mercado europeo. Hay que destacar que la UE, además de practicar los aranceles más bajos del mundo, ha concedido numerosas exenciones a través de los acuerdos comerciales firmados con estos países y una amplia aplicación del Sistema de Preferencias Generalizadas (SPG) a los mismos.

\footnotetext{
${ }^{1}$ Acuerdo general sobre Aranceles Aduaneros y Comercio.

${ }^{2}$ Organización Mundial del Comercio.
} 
El proceso actual tiene algunas diferencias importantes que determinan la naturaleza e intensidad de competencia en curso. Entre otras pueden mencionarse cuatro (Canals, 2003):

1. Existencia de competidores instalados, por lo que se trata de entrar en un mercado cubierto y con exceso de producción, pero con elevados costes salariales, sociales y de regulación en los países desarrollados, por lo que los nuevos entrantes tienen ventajas competitivas apreciables.

2. Posibilidad de jugar con las barreras arancelarias cada vez menor y, además, asimétrica, pues los países desarrollados apenas protegen al sector, en tanto que los nuevos pueden hacerlo sin temor a represalias comerciales. Es notoria la presión de los países en vías de desarrollo exigiendo de forma unilateral y sin contrapartidas (ni siquiera en otros ámbitos) desarmes arancelarios, eliminación de contingentes y otras restricciones, al tiempo que combinan las barreras no arancelarias con fiscalidad adicional en forma de aranceles, recargos compensatorios y tasas.

3. Posible combinación, en el actual mercado global, de todos los factores productivos en su nivel más adelantado, esto es, que el desarrollo, aunque desigual en los ritmos, es combinado en sus componentes, lo que se traduce en que en Vietnam haya decenas de miles de trabajadores diligentes y hábiles trabajando en empresas de capital chino y dotadas de la mejor tecnología alemana.

4. La cuarta y última es el avance en el uso de las posibilidades derivadas del abaratamiento de los costes de comunicación y transporte y en general en los sistemas logísticos para deslocalizar actividades productivas, con lo que los países que más han avanzado pueden concentrar la gestión, el diseño, marketing, I+D y control de calidad en su país de origen y en donde se controla el acceso a los mercados relevantes mientras ubican la producción en países de menor coste laboral y regulatorio, con lo que quienes han iniciado más tarde el proceso o que, por contar con una estructura productiva formada por empresas pequeñas, no llegan a la masa crítica, que les posibilite efectuar ese tipo de actividades estratégicas.

Siguiendo a Canal (2003), la industria textil es uno de los mejores exponentes de la complejidad de la manufactura española y de respuesta a los cambios en el entorno. Aúna ejemplos de innovación continua en producto y diseño con cambios en comercialización, presencia internacional, potenciación de marcas y experiencias en deslocalización. La notoriedad visible de la moda se apoya en una industria de fibras, hilados, tejidos, estampados, acabados y artículos confeccionados que abarca todos los materiales y combinaciones que van desde el producto de vestimenta al tejido técnico. 
Hasta el momento, el reto se ha afrontado con reajustes de los que el sector ha salido renovado, con capacidad de supervivencia basada en añadir valor al producto, con una autofinanciación mayor que el promedio de los países de la UE y prestigio ganado a pulso.

Este escenario de mayor apertura ha comportado la necesidad de reestructurar la estrategia de las empresas del sector textil en el mercado mundial. La apuesta hoy se centra en productos de calidad; que incorporan más innovación, tanto en producto como en diseño y, también, en su traslación al consumidor a través de políticas de potenciación de las marcas y de diferenciación de producto, pero sin perder de vista que el precio es importante y que lo anterior ha de acompañarse por mejoras sustantivas y continuas de eficiencia productiva (Canals, 2003).

De ahí que, aunque la transformación del quehacer de las empresas textiles españolas haya sido significativa, se impongan nuevos avances en las funciones expuestas.

Trigo, J (2003) apunta algunas razones por las que se ha resentido la industria en los últimos dos años: una elevada competencia interna y externa y la caída del consumo interior, que están afectando negativamente al sector. Si en 1992 las familias españolas dedicaban un $11,5 \%$ de su presupuesto al gasto en vestido y calzado, actualmente ese porcentaje se ha reducido al 9,93\%. Las empresas tienen, además, que hacer frente a las falsificaciones y a una estricta legislación que no cumplen empresas de otros países.

En el año 2003, según datos del Centro de Información Textil y de la Confección (Cityc), se han perdido 10.700 empleos y en los últimos 3 años, desde el 2000, 20.700. La producción del sector textil español alcanzó los 13.275 millones de euros, cifra que supone un descenso del 5,4\% en relación al año anterior, a la vez que las inversiones en el sector experimentaron una disminución del $11 \%$ entre los dos años considerados. Y por lo que se refiere al saldo exterior, las importaciones del sector textil crecieron un 10,5\% (alcanzando en 2003 los 9.418 millones de euros), mientras que las exportaciones aumentaron un 3,8\% (situándose en 2003 en 6.406 millones de euros), resultando de estos flujos comerciales de compras y ventas con el exterior una tasa de cobertura del $68 \%$.

\begin{tabular}{|l|r|r|r|r|r|}
\hline \multicolumn{7}{|c|}{ Datos Sectoriales } \\
\hline & \multicolumn{1}{|c|}{1999} & \multicolumn{1}{c|}{2000} & \multicolumn{1}{l|}{2001} & \multicolumn{1}{c|}{2002} & \multicolumn{1}{c|}{2003} \\
\hline Producción & 14.180 & 14.830 & 14.800 & 14.030 & 13.275 \\
\hline Valor añadido & 6.030 & 6.220 & & 5.950 & \\
\hline Exportación & 4.780 & 5.480 & 5.991 & 6.170 & 6.406 \\
\hline Importación & 6.550 & 7.670 & 8.230 & 8.520 & 9.418 \\
\hline Ocupados (no personas) & 275.700 & 278.200 & 277.900 & 268.200 & 257.500 \\
\hline № empresas & 7.657 & 7.650 & 7.590 & 7.470 & - \\
\hline \multicolumn{6}{|c|}{ Datos monetarios en millones de euros } \\
\hline
\end{tabular}

Tabla 4.1: Datos del sector Textil. Fuente: elaboración propia a partir de datos del Centro de Información Textil y de la Confección (Cityc). 12/05/04 
Las cifras anteriores muestran la intensidad del proceso de ajuste que está realizando el sector textil español, que se ha ido especializando cada vez más en producciones que incorporan niveles crecientes de valor añadido: las posibilidades de supervivencia de nuestro sector textil en un mercado mundial completamente liberalizado pasan por añadir un valor creciente, en las diferentes producciones, a los aspectos de diseño, moda, innovación, creatividad y calidad de producto.

\subsubsection{Descripción de la cadena de valor}

El conjunto textil está formado por una serie de procesos interrelacionados que tienen como finalidad ofrecer una amplia gama de productos de vestuario, para el hogar / decoración y para usos industriales.

Las actividades del textil y la confección están configuradas por una serie de subsectores con peculiaridades específicas. Es una industria muy heterogénea si atendemos a, tres factores, como son la diversidad de fibras utilizadas, las múltiples fases del proceso de producción o los distintos usos de los productos finales. La combinación de estos tres factores da lugar a un gran número de segmentos de especialización, que se amplia cuando introducimos los múltiples nichos productivos y mercadológicos que componen cada uno de ellos.

\section{Gráfico general de la cadena de valor}

El concepto cadena de valor (Porter, 1990) abarca todos y cada uno de los procesos productivos desde que se obtiene la fibra en la industria hasta que el producto final llega al consumidor final. En el siguiente gráfico se muestra de manera muy esquemática dicha cadena de valor:

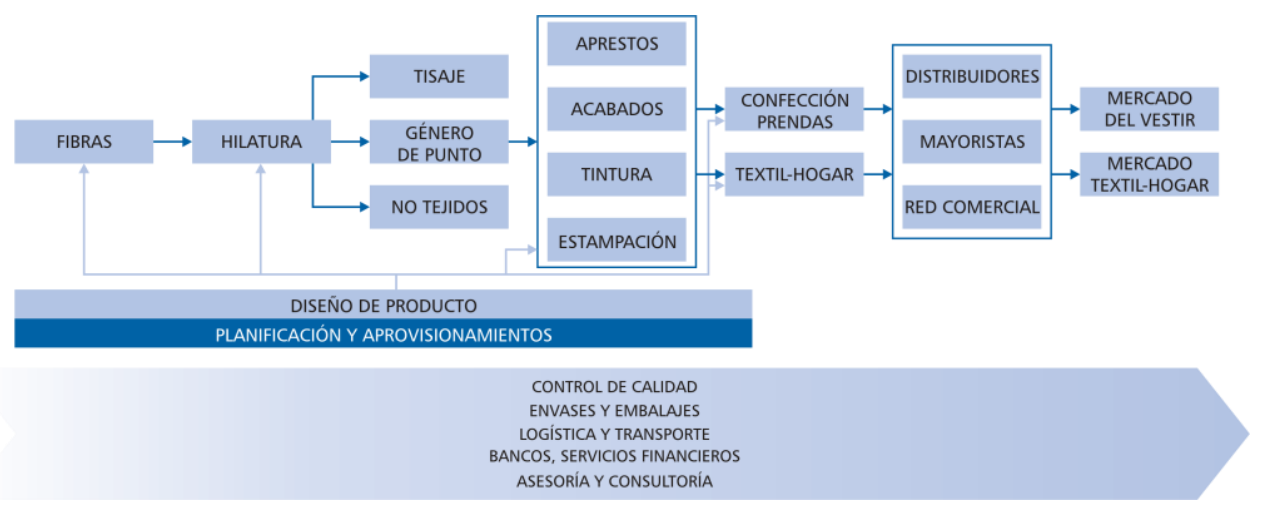

Figura 4.1: Cadena de Valor del sector Textil.

Como se ha visto el proceso de producción textil engloba una serie de operaciones claramente diferenciadas: producción de fibras, del hilo, fabricación del tejido, acabado, confección y distribución a los mercados finales tejidos. 


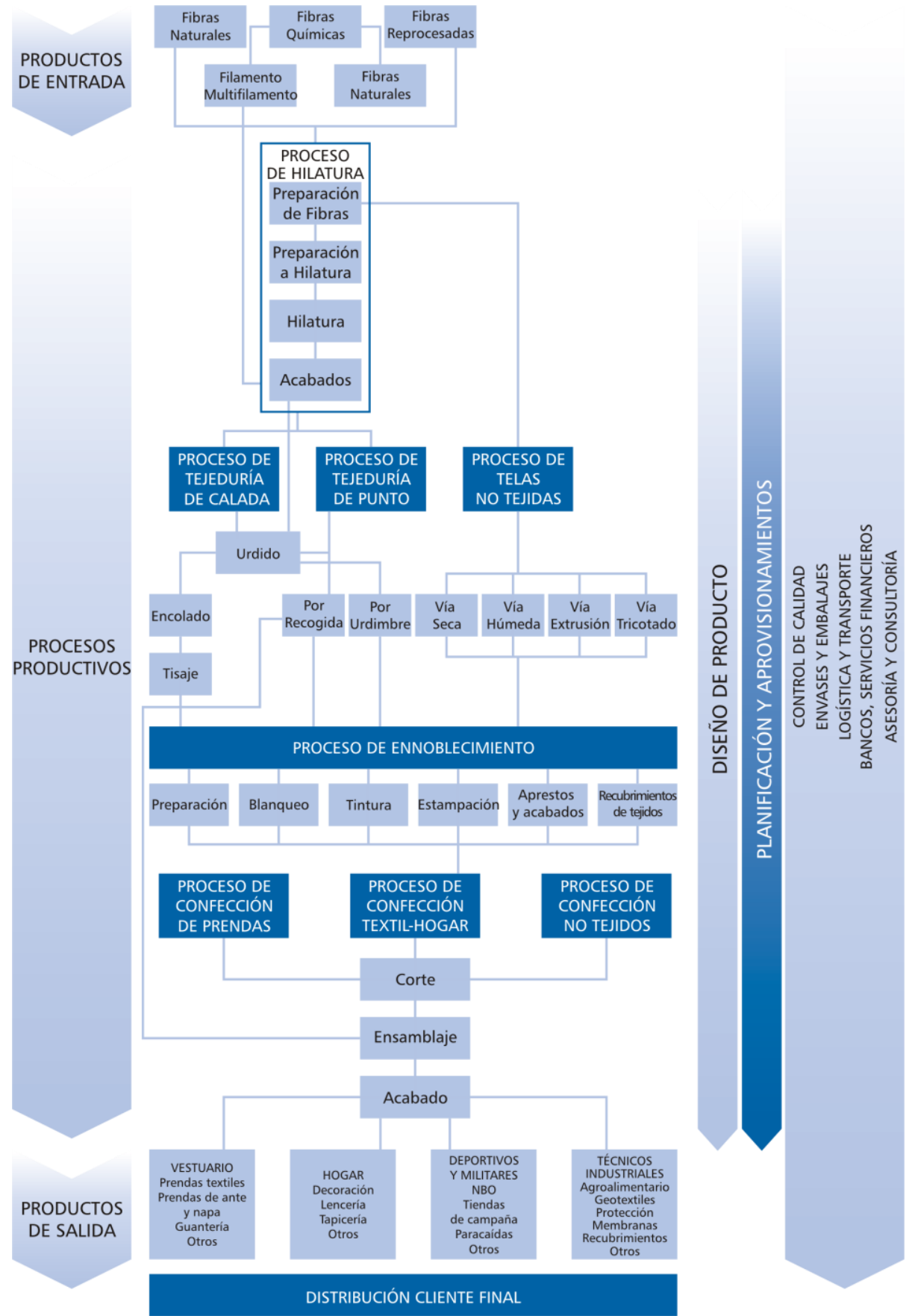

Figura 4.2: Cadena de Valor del sector Textil detallada. 
Como se puede apreciar en la figura $4.2^{3}$, el proceso textil es un proceso largo donde los productos obtenidos en cada parte del mismo son muy diversos. Además no se obtiene un producto único, sino que existe una gran diversidad de productos finales los cuales tienen mercados claramente diferenciados.

\section{Flujos de información}

En el este punto se presenta un análisis de los flujos de información que se dan en la cadena de valor del sector del textil y la confección. Por una parte se analizará de manera conjunta los subsectores de hilatura y tejeduría, y por otra los subsectores de género de punto y de la confección. Se ofrece este análisis conjunto porque, aunque sus productos finales son distintos, el proceso de intercambio de la información en cada par de casos es paralelo. Este ejemplo nos va a reforzar los planteamientos iniciales de este trabajo de investigación sobre la necesidad de la Integración de las Tecnologías de la Información y las Comunicaciones dentro de las Organizaciones.

\section{Hilatura y tejeduría}

El modelo tradicional de producción bajo pedido es el que rige el flujo de información entre la empresa de hilados y tejidos y sus proveedores y clientes, de esta manera, el proceso productivo y la compra de materia prima es consecuencia directa de un pedido en firme.

Una vez se ha recibido el pedido se genera un plan de producción, el cual determinará el volumen de compra de la materia prima, previó análisis del nivel de stock. Esta metodología, que podemos considerar estable, limita la comunicación con los proveedores a pedidos puntuales y periódicos

${ }^{3}$ basado en el publicado por Ignacio Argote en el número de Enero de la Revista Confección Española 


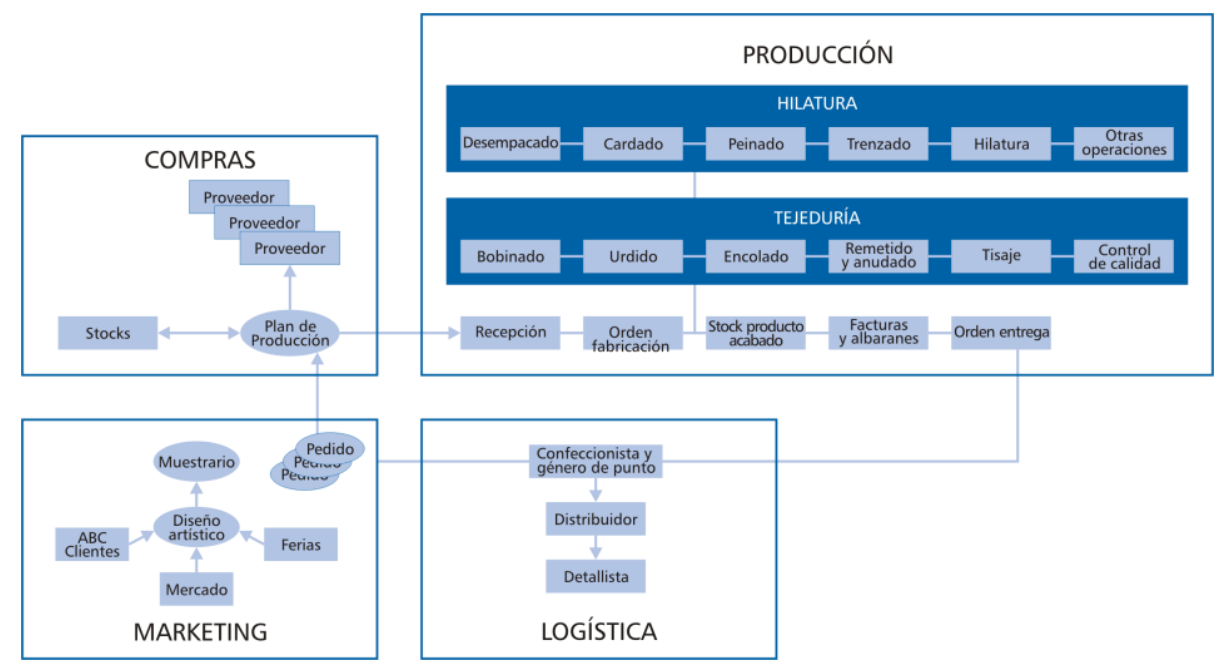

Figura 4.3: Flujos de información en hilaturas y tejedurías.

\section{Género de punto y confección}

Los flujos de información entre las empresas de estos dos sectores y sus proveedores y clientes, muestran que hay dos tipos de relaciones comerciales diferentes entre si, por un lado está la relación con los proveedores y por otro lado la relación con sus clientes.

A los proveedores se les realiza pedidos muy puntuales, los cuales son remitidos en unos plazos de entrega muy dilatados. Los proveedores, además, tienen poca flexibilidad ante repeticiones de pedidos.

En cuanto a la relación de estas industrias con sus clientes, ésta se basa en pedidos iniciales que estos clientes realizan fundamentados en el muestrario de la empresa. La producción estará supeditada, por una parte, a las previsiones de venta, pero por otro lado, también encontramos que una habrá una elevada sobreproducción a fin de servir las repeticiones que continuamente demandan los clientes a lo largo de la temporada.

Destacar que los productos de la confección y género de punto son finalistas en la cadena de valor, por lo que tendrán poca posibilidad de ser modificados si no son vendidos. Si la producción se basa en previsiones de venta, existe el riesgo de quedarse con el producto, la cual cosa requerirá el esfuerzo adicional de buscar otros mercados en los que colocar dichos productos. 
El hecho de que estas empresas posean un elevado grado de subcontratación hace que coordinar dicha contrataciones con terceras empresas se convierta en una actividad primordial en estas industrias.

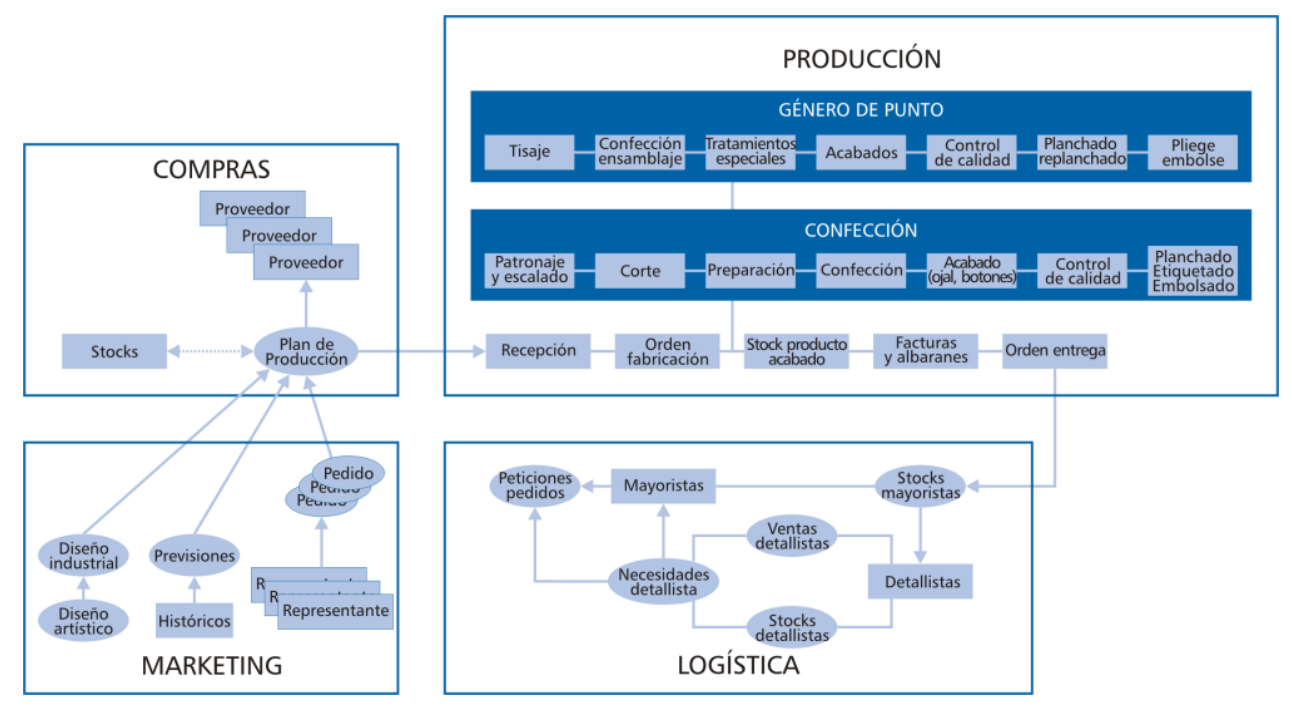

Figura 4.4: Flujos de información en género de punto y confección.

\section{Estructuras productivas}

En la actualidad ya no existen empresas que integren al completo el proceso de producción de un articulo textil, por ello existen diferentes maneras de afrontar las fases del proceso productivo, veamos algunas estrategias como muestra de la diversidad de las estructuras productivas de las empresas del sector.

Las empresas integrales controlan el ciclo completo del producto, desde la producción de base hasta la comercialización final. Existen determinadas empresas que no son necesariamente empresas integradas, pero sí se caracterizan por ejercer un control directo sobre las diversas fases del proceso productivo (por ejemplo, recurriendo a las subcontratas bajo estrecha supervisión), con objeto de controlar costes, calidades y plazos de entrega. Esta estrategia que en el pasado se limitaba a unas pocas empresas (Corte Inglés, Cortefiel) ha sido desarrollada de forma novedosa por diversos grupos que cubren distintos segmentos de mercado o que incorporan divisiones especializadas (Zara, Adolfo Domínguez, Mango, etc.). Algunos de estos grupos han desarrollado incluso una relevante estrategia internacional expandiendo sus cadenas comerciales a diversos países, en los que han mostrado una importante capacidad de penetración. 
Una segunda estrategia, de carácter más minoritario, se encuentra en aquellas empresas que optan, especialmente en la producción de las fases iniciales del ciclo productivo (hilatura y tejido), por desarrollar una elevada especialización en un tipo concreto de productos para conseguir no sólo economías de escala, sino también recursos para adaptar su experiencia productiva a las necesidades particulares de sus clientes. En este tipo de respuesta destaca el ejemplo de Tavex, grupo especializado en la producción de tela denim para tejanos que ha pasado a convertirse en un productor con capacidad internacional; aunque la misma experiencia se puede también encontrar en empresas de menor tamaño, que han encontrado en la política de especialización y de aumento de la capacidad tecnológica su mayor fuente de supervivencia.

Un tercer grupo lo constituye el de los fabricantes de productos especializados y textiles de uso técnico, en algunos casos tecnológicamente sofisticados, orientados hacia la producción de bienes industriales; destaca especialmente, en este punto, la industria textil para el automóvil, que se beneficia de la existencia de una importante industria automotriz con la que mantiene una permanente actividad de colaboración.

La cuarta estrategia se basa en la internacionalización de la producción hacia países de mano de obra más barata. Ésta la siguen empresas como varias de las citadas anteriormente, aunque no siempre se ha mostrado exitosa puesto que en algunos casos, la producción en terceros países no es completamente eficaz por problemas de control de calidad del producto.

Una quinta estrategia ha consistido en la desmembración de antiguas empresas y su conversión en empresas red, cuyo cometido fundamental es la coordinación de un gran número de pequeñas unidades a las que se contrata en función de las variaciones de la demanda. Se trata de una estrategia más habitual en aquellos subsectores o fases productivas, en las que la variabilidad del producto es menor y donde las economías de escala son despreciables, tales como la tejeduría, la confección especializada y el género de punto.

\section{Puntos débiles y problemas a resolver}

Por todo lo expuesto hasta ahora es evidente que se genera un elevado volumen de información, que fluye entre los diversos subsectores que componen la cadena de valor.

Es decir, el hecho de subcontratar parte del proceso productivo a otras empresas hace que exista un flujo de comunicación importante entre empresa subcontratista y contratada, información como por ejemplo: especificaciones técnicas del producto, requisitos específicos para el proceso, contrato de compra y venta y otros aspectos necesarios para la buena gestión y procesamiento del producto. 
Los problemas más relevantes derivan del ya comentado elevado flujo de comunicaciones existente, puesto que la falta de automatización del mismo induce a una elevada cantidad de errores y reclamaciones no debidos a la calidad del producto sino a la falta de una adecuada comunicación entre clientes y proveedores, y subcontratistas y subcontratados.

Por ello cabe concluir que los flujos de comunicación establecidos entre las empresas textiles y sus respectivos proveedores básicamente se caracterizan por dos hechos:

- Existencia de un elevado volumen de información a lo largo de la cadena.

- Intervención de multiplicidad de agentes a lo largo de la cadena de valor, lo cual supone que a menudo la transmisión de la información no sea la óptima.

Estos dos hechos, la descentralización de la cadena de valor y la problemática de transmisión de la información a lo largo de la misma, hace que las tecnologías de la información y la comunicación se conviertan en fundamentales para agilizar y optimizar los flujos de información. Las conexiones electrónicas se convierten en esenciales entre clientes y proveedores, subcontratistas y subcontratados para un eficaz intercambio de información.

El grado máximo informatización de toda la cadena nos llevaría a conocer puntualmente en que lugar del proceso productivo se encuentra un artículo determinado, o incluso el ritmo de ventas del mismo y si hace falta su reposición o no en los establecimientos minoristas.

Además, si tenemos en cuenta que los costes del reaprovisionamiento representan el $20 \%$ del precio medio de venta al público, queda justificada la integración logística y la implantación de las nuevas tecnologías con el fin de reducir los coste de la cadena logística y maximizar el valor añadido ofrecido al consumidor final.

La solución a los problemas a resolver plantea un reto a tres niveles: cambio en los procesos, cambio en la organización, y cambio en la tecnología.

- Cambio en los Procesos. La tendencia a la hora de minimizar el coste en el conjunto de la cadena de producción y suministro pasa de las técnicas aplicadas tradicionalmente como PUSH a garantizar un suministro continuo aplicando la técnica denominada PULL.

- Cambio en la Organización. Las empresas tienen que reorientar su enfoque hacia el cliente (pasar de la cultura PUSH al PULL) y romper todas aquellas barreras que sólo conllevan a una falta de colaboración y dificultad en la comunicación. La empresa debe pasar de un enfoque departamental por tareas donde cada área o departamento se gestiona de manera independiente y secuencial para satisfacer la demanda del cliente, 
al enfoque por procesos donde el trabajo colaborativo prima el resultado final hacia el cliente (una estructura responsable de todo el proceso relacionado con un cliente).

Del enfoque por tareas.

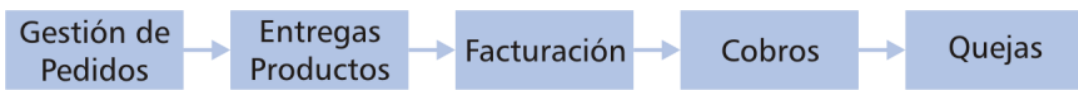
Al enfoque por procesos

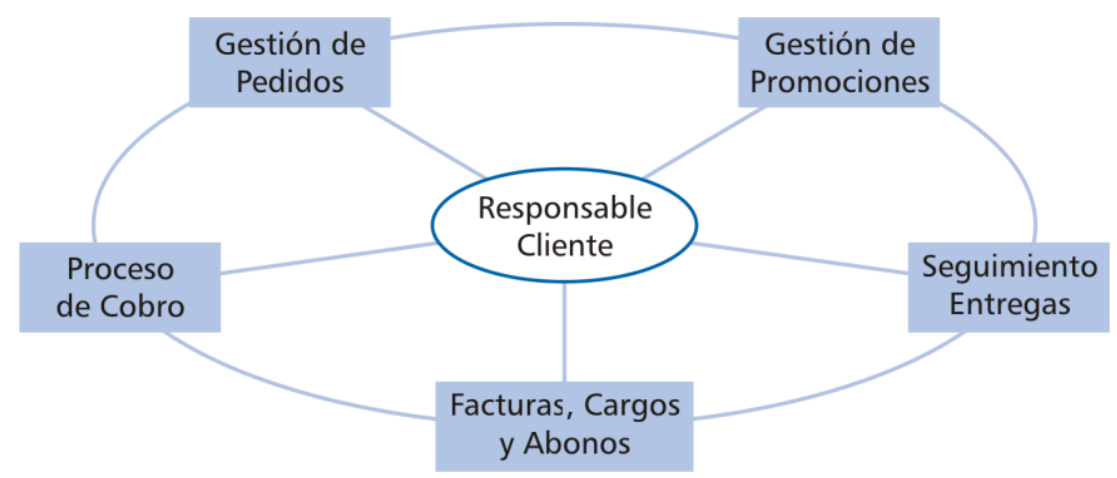

Figura 4.5: Cambios en la organización de la empresa. Enfoque por tareas vs. Enfoque por procesos. Elaboración propia.

- Cambio en la Tecnología. En la nueva relación comercial se persigue reducir los costes en el conjunto de la cadena de suministro, y la implantación del intercambio electrónico de datos facilita la reducción de dichos costes. Hay que tener en cuenta que este concepto de intercambio electrónico de datos no sólo incluye la compra y venta electrónica de bienes, información o servicios, sino sobre todo el uso de las tecnologías de la información para todas las relaciones con clientes y proveedores, anteriores o posteriores a la venta, como son:

la publicidad

la búsqueda de información sobre productos, proveedores, etc.

la negociación entre comprador y vendedor sobre precio, condiciones de entrega, etc.

la atención al cliente antes y después de la venta

la cumplimentación de trámites administrativos relacionados con la actividad comercial 
la colaboración entre empresas con negocios comunes (a largo plazo o sólo de forma coyuntural)

la integración de los sistema de logística con los de la propia empresa

Por lo tanto, la incorporación de las tecnologías de la información en las empresas soluciona de forma genérica los problemas de integración e información. Pero el hecho es que el grado de implantación de las tecnologías de la información en el sector no es suficiente, lo cual induce a promover y facilitar el uso de las mismas, de manera que se configuren como un elemento dinamizador imprescindible para flexibilizar los flujos de información, reforzar la competitividad de las empresas, asegurar su viabilidad a medio y largo plazo y mejorar las cotas de productividad.

\subsection{Las TIC's en el sector Textil}

\subsubsection{Situación actual}

Con el objetivo de analizar la preparación y disponibilidad de las empresas ante la adopción de las TICs, se ha realizado una encuesta (ANEXO 1) entre una muestra de 50 empresas textiles de la Comunidad Valenciana (estudio de aplicación de las nuevas tecnologías de la información en el sector textil, editado por ATEVAL) siguiendo cuatro vertientes claramente diferenciadas:

- Hardware Informático-Telemático y Sistemas Operativos. Con este grupo de preguntas se pretende averiguar el tipo de equipamiento informático del que disponen las empresas, a fin de estimar el grado de obsolescencia del mismo $y$, en consecuencia, la importancia dada tanto a los ordenadores como a los sistemas operativos empleados.

- Aplicaciones Informáticas. El siguiente bloque cuestionado, abarca las posibles aplicaciones de dichas tecnologías a los procesos de gestión, diseño, fabricación, CAD/CAM, simulación fotorealista, visión artificial, control de stocks, gestión de producción, etc.

- Comunicaciones. En esta parte del cuestionario se pregunta por las necesidades de comunicación de datos externos de las empresas, por el tipo de comunicaciones que llevan a cabo, como son Internet, EDI, Intranet/Extranet, videoconferencia y telefonía a través de Internet, así como de los dispositivos o tecnologías utilizados para dichas comunicaciones.

- Formación. Finalmente se busca saber el nivel de conocimientos de dichas tecnologías que posee el personal de la empresa: dirección, expertos informáticos y demás personal, al mismo tiempo que la frecuencia con la que se forma a los empleados en ámbitos relacionados con las TIC. 
A continuación se detallan los resultados obtenidos por el estudio dirigido por Javier Muñoz Giner para ATEVAL y actualizado para esta Tesis, en cada uno de los bloques de analizados.

Es necesario aclarar que los porcentajes detallados, se han calculado siempre con base al total de empresas entrevistadas, tanto en las cuestiones referidas a una pregunta anterior, como en las de respuesta múltiple, en las que las empresas han respondido a más de una posibilidad.

\subsubsection{Hardware Informático-Telemático.}

Dentro de este apartado, se pretende averiguar el perfil de las empresas en cuanto al equipamiento informático del que disponen, así como el grado de actualización de este equipamiento.

Para ello, se cuestiona el tipo de hardware con el que trabajan, a fin de conocer si se opera en red y a través de qué tipo de ordenadores se realiza. Por otro lado, es también interesante contemplar los sistemas operativos empleados, tanto en los servidores como en los PCs, aspecto que aporta información sobre el grado de obsolescencia del equipamiento. Al mismo tiempo, con este análisis se quiere saber la importancia otorgada a los sistemas de seguridad de datos, así como los criterios que llevan a las empresas a adquirir un determinado hardware o software.

\section{Sistema Informático y de Comunicaciones}

La gran mayoría de las empresas (el $84 \%$ ) dispone de red local con uno o varios servidores, seguida de lejos por un $22 \%$ de empresas que se decantan por un ordenador central con terminales.

En ocasiones se presenta el caso de organizaciones que compaginan los dos sistemas, pero normalmente este hecho se debe a que la empresa en cuestión está en proceso de adaptación a los sistemas en red.

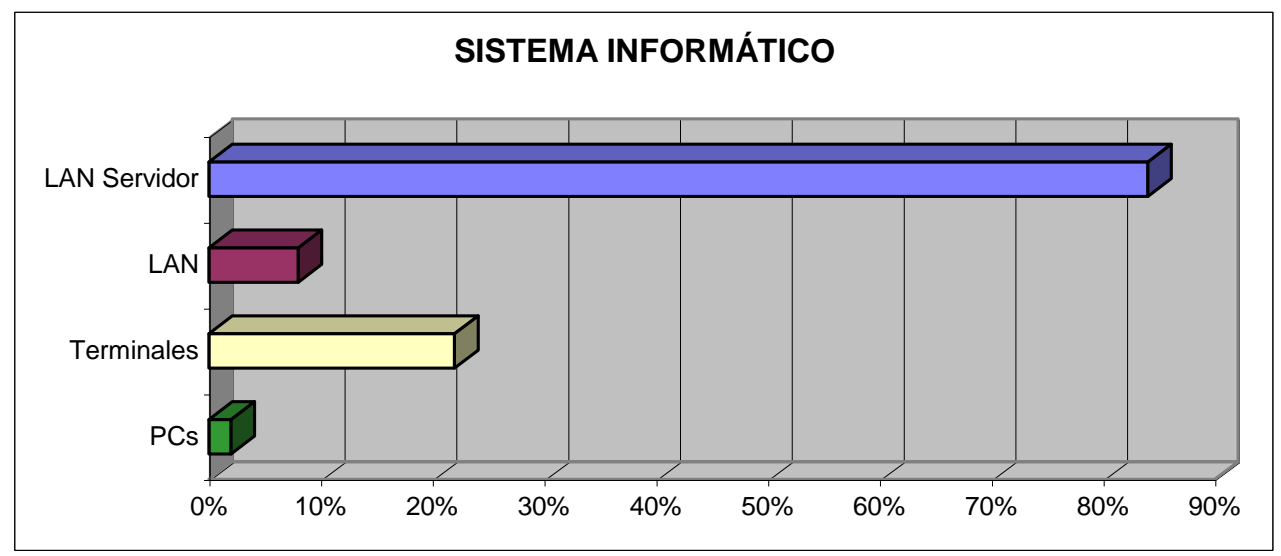




\section{Tipo y arquitectura de red}

Del total de empresas que operan en red, el $72 \%$ utiliza un sistema de cableado estructurado para la conexión, frente a un $24 \%$ que prefiere las instalaciones a medida de cada momento.

Por otra parte, más de las tres cuartas partes trabajan con los protocolos Ethernet (10 Mbps), siendo esto debido a la excelente relación calidad/precio de dicha tecnología. Referente a Fast Ethernet (100 Mbps), se observa un crecimiento en cuanto a las instalaciones o migraciones a este tipo de red, aunque no deja de ser de momento una tendencia.

En cuanto a tipos más avanzados de redes locales como podría ser por ejemplo ATM, no se encuentra ninguna instalación de esta categoría.

\section{Tipo de Hardware}

En este apartado se ha querido reflejar toda la gama de ordenadores utilizados por las empresas actualmente, teniendo en cuenta desde los PCs convencionales hasta las ordenadores que controlan máquinas industriales.

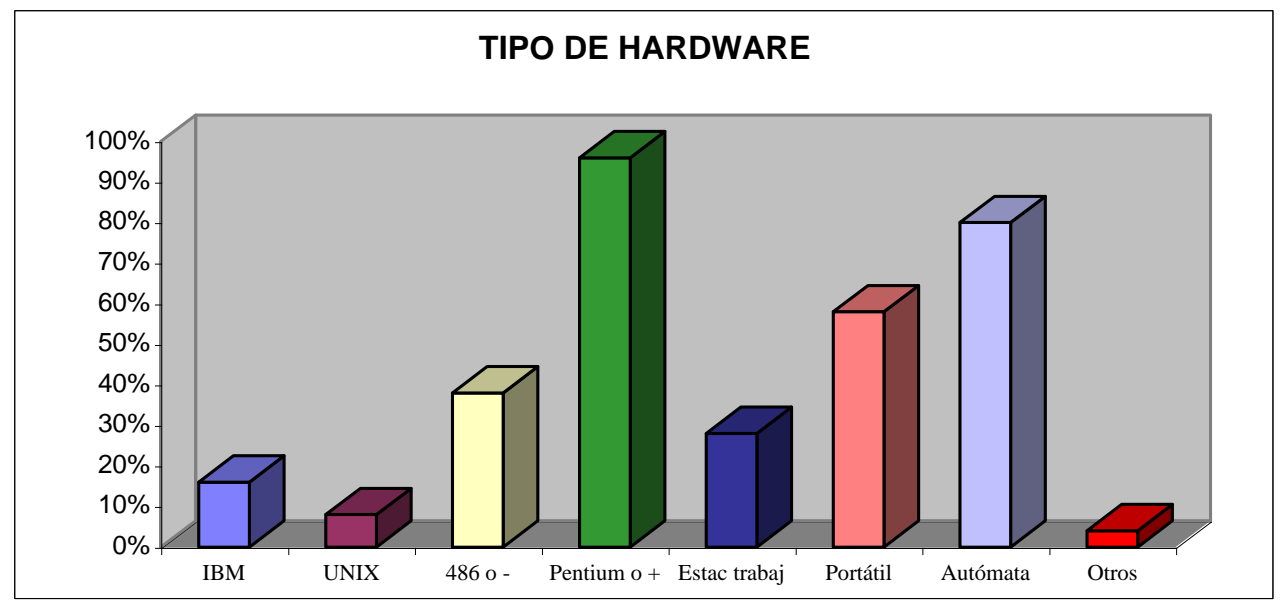

Dentro del hardware, cabe comentar que en un $28 \%$ de las empresas disponen de estaciones de trabajo aplicadas al Diseño Asistido por Ordenador CAD/CAM.

Así mismo, más de la mitad de las organizaciones tiene por lo menos un ordenador portátil, normalmente destinado a los departamentos de ventas o a la Dirección. 
Del estudio se recoge un dato importante desde el punto de vista de la automatización del proceso productivo, y es el hecho de que el $80 \%$ trabaja con máquinas controladas por ordenador o en su defecto autómatas. Si bien, esta automatización no siempre se hace extensiva a todo el proceso de fabricación, sino a una sección. Además, es raro encontrar empresas en las que dichos ordenadores estén conectados a la red local para poder centralizar la información que suministran.

Dentro de esta cuestión cabe añadir finalmente, que el $40 \%$ de las empresas disponen de más de 30 ordenadores en total, incluyendo desde los PCs hasta los autómatas. Con el $32 \%$ le siguen las empresas que trabajan con un número comprendido entre 6 y 15 ordenadores.

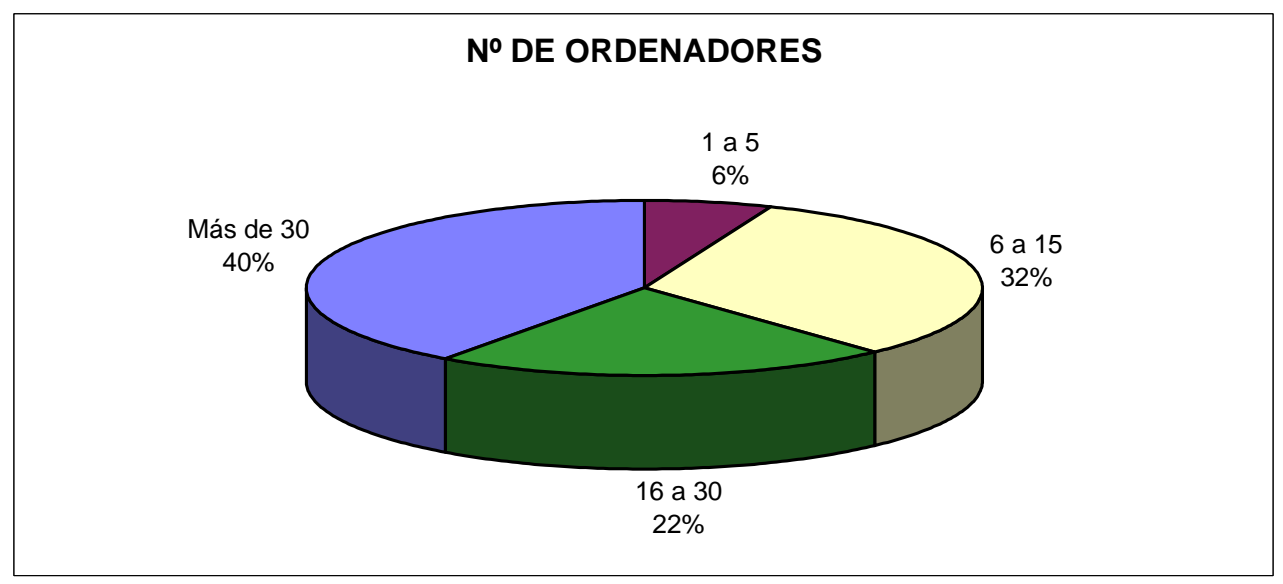

\subsubsection{Sofware y su aplicación.}

Se persigue estudiar el grado de incorporación de las Aplicaciones Software, sobre todo en el ámbito productivo, con la finalidad no sólo de conocer su aceptación, sino también de observar la capacidad de las empresas de hacer extensivas estas herramientas a otras áreas diferentes de los departamentos de administración, gestión o informática.

Por otra parte, se ha hecho hincapié en las aplicaciones de diseño asistido por ordenador CAD/CAM, así como la simulación de productos, con el objetivo de analizar la repercusión que estos sistemas tienen en el sector. 


\section{Uso de las TIC en la empresa}

El departamento más informatizado de las empresas y que cuenta con mayor apoyo de comunicaciones, es el de Administración y Contabilidad. Es en estos departamentos donde suelen estar los PCs conectados en red, PCs que normalmente acceden a Internet y en los que se trabaja bajo entorno Windows, juntamente con el software de gestión y contabilidad hecho a medida.

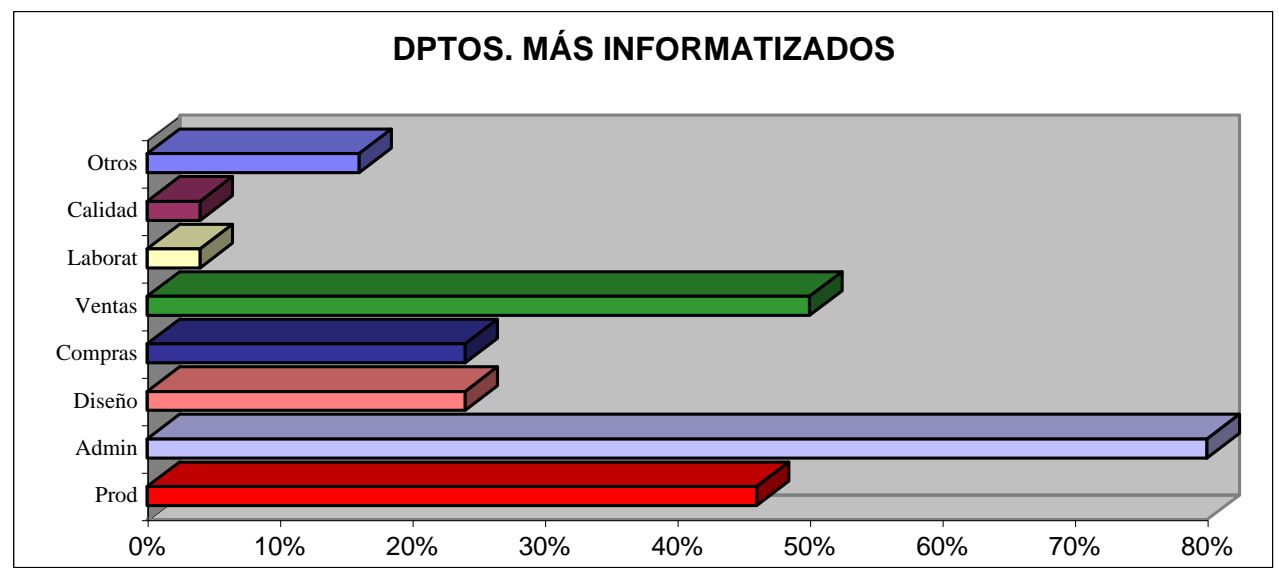

En segundo término, están el Departamento Comercial y el de Producción se apoyan también bastante en estas tecnologías. Así, la situación de las Ventas es similar a la de Administración en cuanto al sistema informático empleado.

En Producción, la tendencia es apostar cada vez más por la automatización de todo el proceso. De momento, las empresas que no tienen informatizada todas las fases de su fabricación, suelen controlar alguna sección y en muchos casos tienen previsto hacer extensivo este control asistido por ordenador. De hecho, como se ha expuesto anteriormente, el área que más está siendo actualizada es la de Producción.

Finalmente se ha preguntado por los motivos que fomentan los cambios en estas Tecnologías de la Información y las Comunicaciones en las empresas, a fin de averiguar si son debido a iniciativa propia, a imposiciones por parte de los proveedores, clientes u otras entidades, o a una presión del mercado y de la competencia.

En esta ocasión, el $80 \%$ promueve los cambios en las TIC de su empresa, por iniciativa propia y atendiendo a las crecientes necesidades en estos ámbitos. Un $34 \%$ se ve obligado a cambiar sus equipamientos o software debido al cambiante y creciente sector informático y a la necesidad de ser competitivos. 


\section{Filosofía para la renovación}

El $82 \%$ de las industrias afirma que su sistema informático responde, en general, a las necesidades de la empresa.

A su vez, un 94\% está interesado en poner en marcha nuevos sistemas informáticos, en otros departamentos o secciones, o en actualizar los ya existentes. Referente a esta política de empresa, cabe decir que, la mayor parte de ellas, opina que nunca hay que dejar de adquirir este tipo de tecnologías, puesto que siempre se puede mejorar en algún aspecto, dada la rapidez con la que se quedan obsoletos los equipos.

El área a la que se le dedica mayor atención a la hora de mejorar los equipos, es la de Producción, seguida de Administración y Ventas.

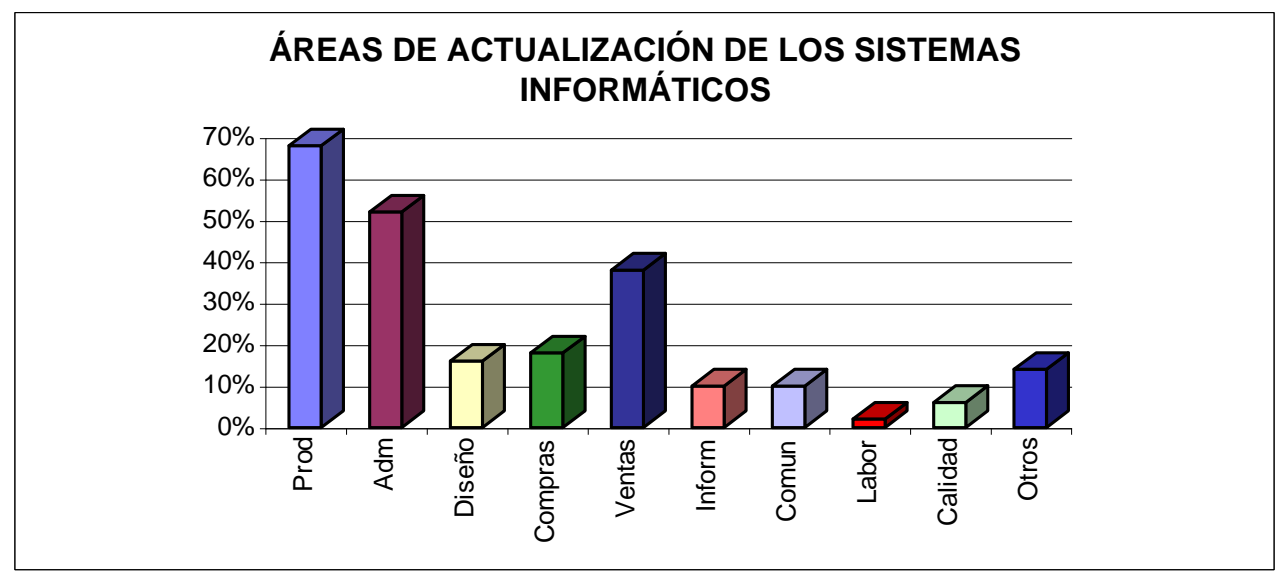

\subsubsection{Comunicaciones}

Este apartado pretende determinar las necesidades y los hábitos de comunicación de las empresas, tanto internas como externas con proveedores, clientes, bancos o la administración pública.

Así pues, se contemplan Tecnologías como Internet, Intranet/Extranet, EDI, telefonía a través de Internet o videoconferencia, pretendiendo averiguar tanto los dispositivos físicos empleados para la comunicación, como los motivos que han llevado a su utilización y las ventajas y aplicaciones que dan.

Al mismo tiempo, se efectúan preguntas de opinión que reflejan la filosofía de la empresa ante la adquisición de estas Tecnologías y por tanto, la propia cultura de la organización ante la necesidad de ser competitivos también desde un punto de vista tecnológico. 


\section{Comunicación de Datos Externos}

Es interesante conocer las necesidades de comunicación telemática externa más frecuentes de la empresa. Las empresas se comunican mayoritariamente con sus clientes $(86 \%)$, los bancos $(74 \%)$ y los proveedores más habituales $(60 \%)$.

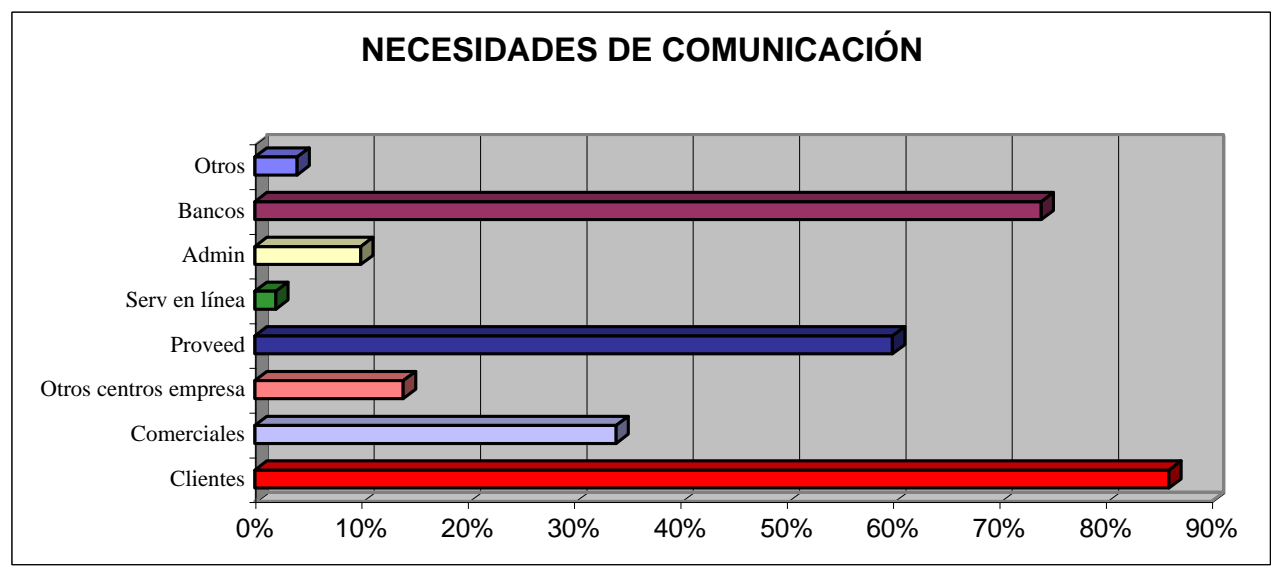

Otro dato de interés es que sólo algunas organizaciones (22\%) recurren a los servicios de información en línea, tales como la Bolsa o asistencia técnica.

Respecto a los dispositivos empleados para llevar a cabo estas comunicaciones, el más cotidiano es el módem, mencionado en un $76 \%$ de las ocasiones. Normalmente se emplean los módems para la comunicación con los bancos y para la conexión a Internet, como ya se verá más adelante.

La utilización de otras líneas tales como las X25, Frame Relay, ADSL o las conexiones permanentes dedicadas, ocupa un plano muy secundario, que en total no supera el $12 \%$.

Se ha preguntado también por la frecuencia de uso de comunicación de datos con algún proveedor, cliente o comercial, resultados que quedan reflejados en la siguiente gráfica. 


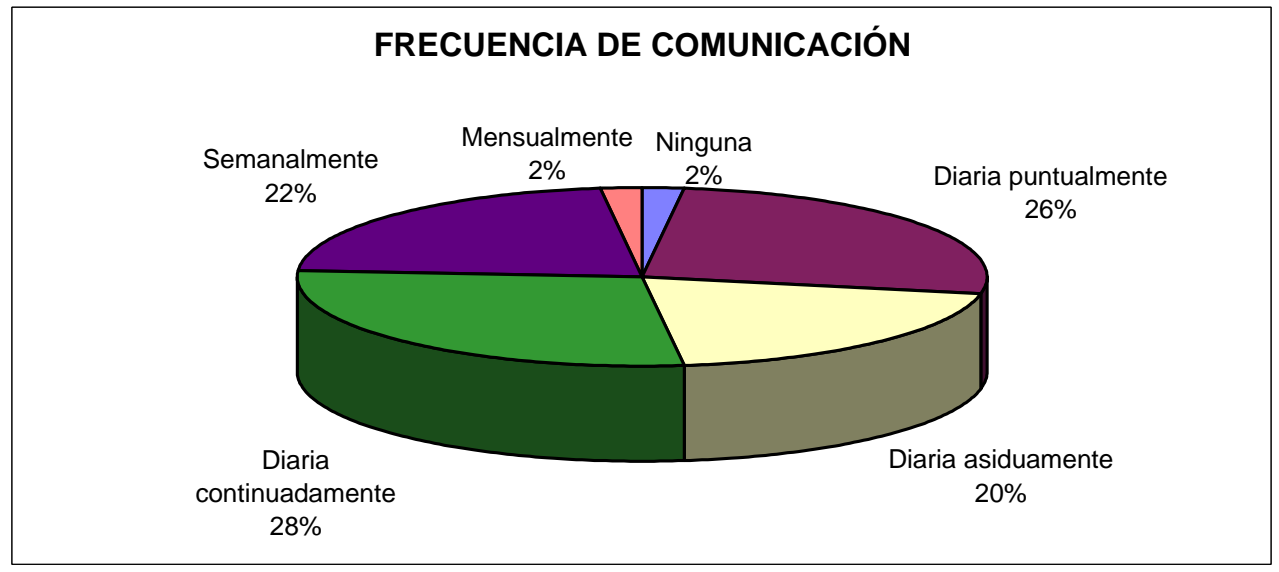

Cabe mencionar que muchos de los encuestados han mostrado una respuesta dubitativa a la hora de definir la frecuencia de sus comunicaciones, puesto que ésta depende, o bien de la estación del año, en aquellas empresas que trabajan por temporada, o bien del tipo de cliente o proveedor que sea.

\section{Internet}

Se puede afirmar que prácticamente todas las empresas entrevistadas disponen de conexión a Internet. Conexión la cual suele ser en primer lugar mediante módem a través de RTB y en segundo, mediante tarjeta a través de ADSL y RDSI.

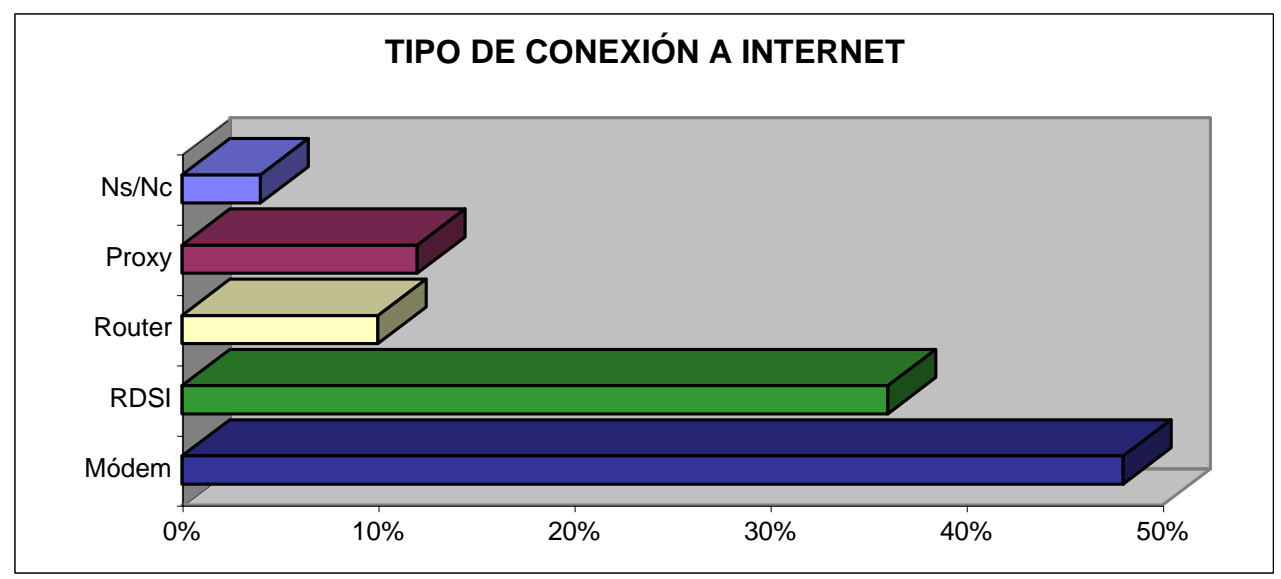

Otro interrogante es el número de buzones de correo electrónico con el que se comunican, siendo éste bastante variable. Si bien, parecen dominar las empresas 
que disponen de 2 , en un $30 \%$, pasando ya a las que cuentan con más de 6 buzones (20\%).

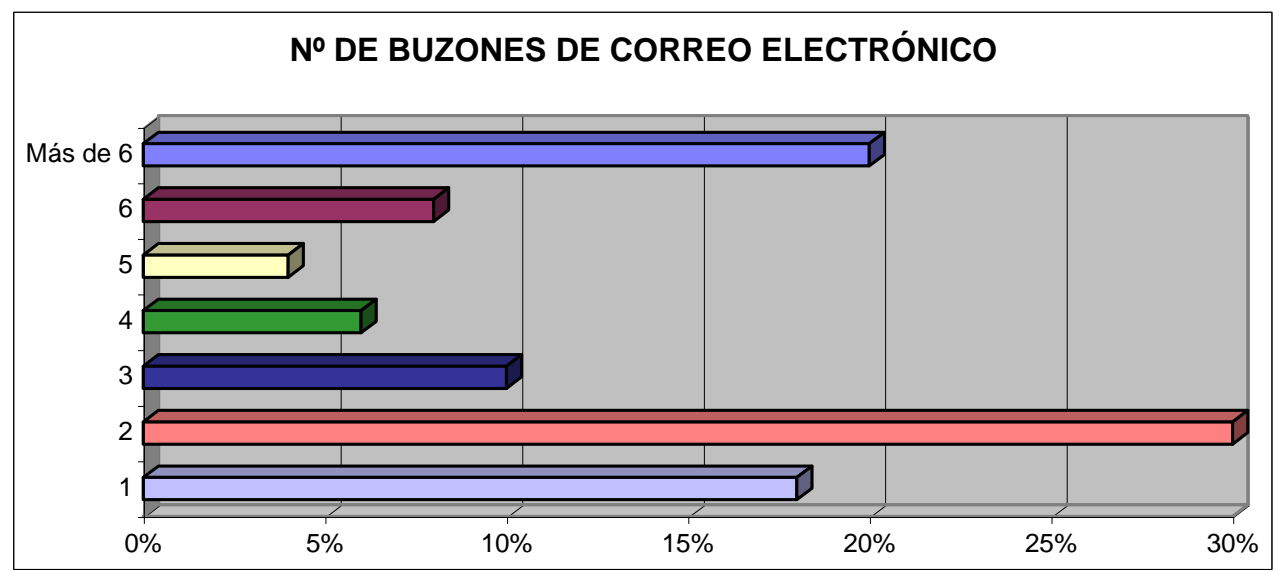

Referente a las aplicaciones para las cuales se emplea el correo electrónico, la más mencionada es la comunicación con clientes y proveedores (72\%). Bastante atrás quedan la comunicación interna de la empresa o la recepción de pedidos a través de los comerciales.

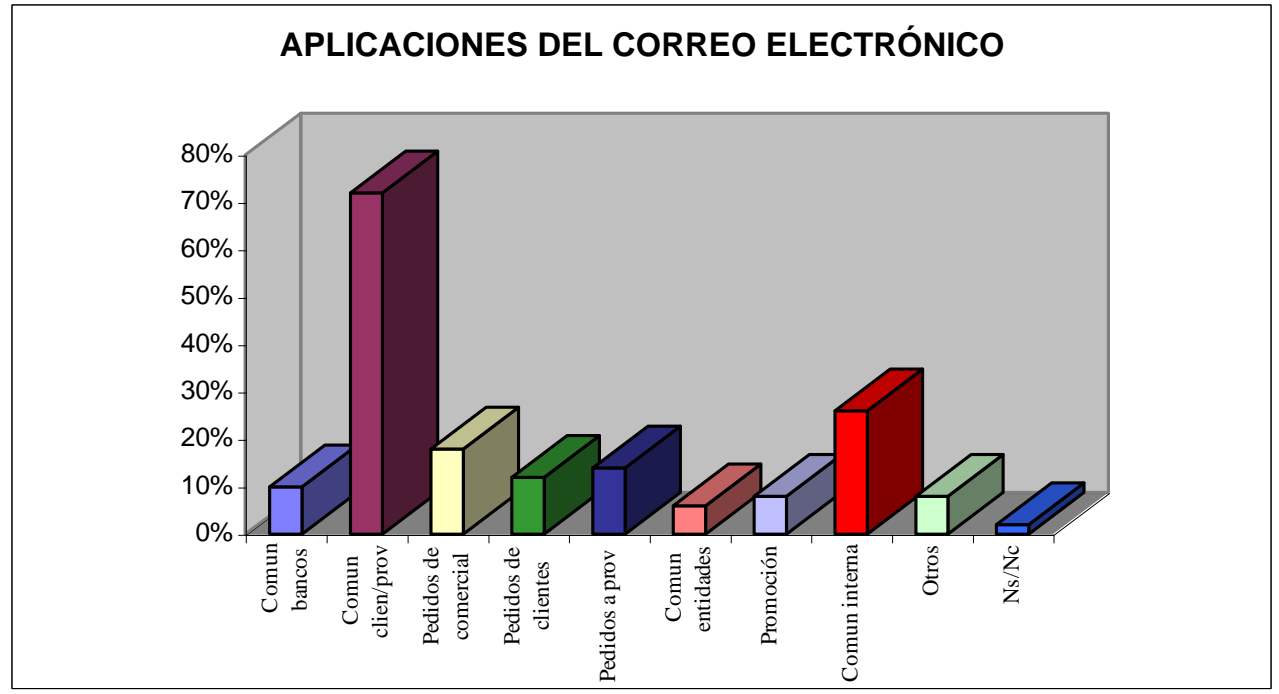

Dentro de este apartado reservado a la tecnología Internet, se ha dedicado una sección para averiguar lo familiarizados que están con las páginas web. 
Así pues, se ha obtenido que el $82 \%$ accede a dicho servicio. La finalidad perseguida es la de efectuar consultas sobre información económico-financiera e información general, como consultas técnicas o informáticas, en un $50 \%$ de las veces.

También se navega por Internet para realizar búsquedas de información sectorial textil sobre empresas competidoras, ferias, datos o indicadores del mercado de cada subsector textil, etc. (el $36 \%$ de las empresas). Además, se llevan a cabo búsquedas de clientes o proveedores de materias primas y servicios (un 26\%).

El siguiente aspecto abordado trata del enfoque dado a las páginas Web propias de las empresas entrevistadas, es decir, de la utilidad que ven en ellas y su fin.

Lo que las empresas persiguen teniendo una página Web, es en la mayoría de los casos, promocionar su imagen (64\% de las veces). Otras, sólo pretenden promocionar sus productos, como es el caso de un $24 \%$ de las industrias.

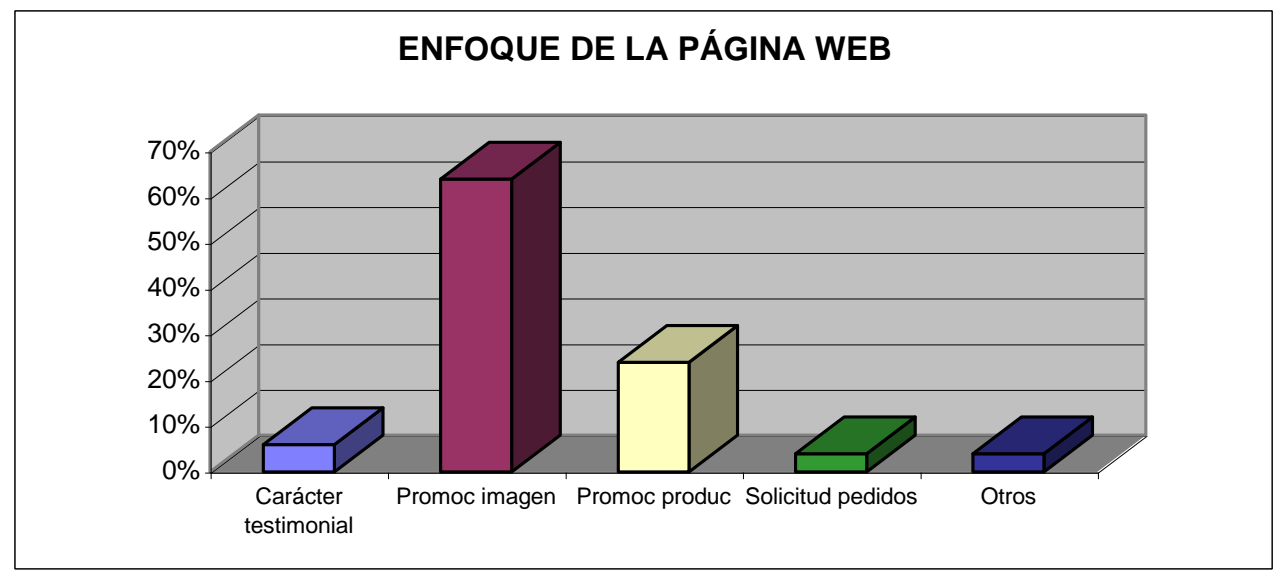

Finalmente, dentro de este apartado se ha formulado una pregunta de opinión, a cerca del tiempo que consideran que la tecnología Internet necesitará para convertirse en un medio de comunicación imprescindible entre empresas como lo es hoy el fax.

Al respecto, el $64 \%$ de los entrevistados cree que en menos de dos años, las empresas necesitarán estar conectadas a Internet si quieren poder comunicarse con otras empresas o entidades. Dentro de este grupo, hay bastantes encuestados que consideran que hoy en día, Internet ya es imprescindible para poder cubrir las necesidades de comunicación entre industrias, aunque es evidente que esa realidad no es compartida todavía por todo el Sector Textil. 


\section{Intranet/Extranet}

A continuación se plantea el conocimiento de la tecnología Intranet/Extranet por parte de las empresas textiles, de las cuales, el $58 \%$ dicen ser conocedoras. Si bien, sólo un $10 \%$ dispone de Intranet o Extranet para comunicarse, normalmente, dentro de la empresa o con comerciales de la misma.

Al mismo tiempo, un $24 \%$ está interesado en implantar esta tecnología, frente a otro $24 \%$ que no lo considera viable.

\section{EDI - intercambio electrónico de datos}

En el siguiente grupo de preguntas, se va a valorar tanto el conocimiento de los encuestados sobre el EDI, como el interés que suscita su utilización y las ventajas que aporta.

Sólo el $14 \%$ de las empresas utiliza EDI, de las cuales, en el $12 \%$ de los casos ha sido debido a la imposición de fuertes clientes, tales como las grandes cadenas de supermercados o grandes superficies que trabajan con EDI, obligando a sus suministradores a su implantación.

EI EDI más utilizado es el EDI tradicional, utilizando redes especiales (líneas especiales), con un 10\% (del 14\% que apuesta por EDI ), frente al $4 \%$ restante que se decanta por el EDIWeb.

El grado de satisfacción mostrado por el empleo de esta tecnología es más bien medio, encontrando como ventaja más significativa de su aplicación, la posibilidad de contar con un tiempo de respuesta más corto.

El $46 \%$ de empresas que no utiliza el EDI es debido a que no está implantado entre sus proveedores o clientes (el $36 \%$ ), o porque no se considera necesario debido a las características de la empresa.

Se ha pedido a los entrevistados que pronostiquen en cuánto tiempo consideran que el EDI puede convertirse en un medio muy importante para establecer transacciones comerciales, ante lo cual un $30 \%$ ha apostado por un plazo medio comprendido entre 2 y 5 años. En contrapartida, un $14 \%$ considera que con menos de 2 años será suficiente. Finalmente, el 16\% restante cree que harán falta más de 5 años. 


\section{Telefonía a través de Internet}

En general esta posibilidad es conocida en las empresas del Sector Textil, aunque todavía hay empresas que no están familiarizadas con el término. Si bien un $66 \%$ considera interesante la utilización de la telefonía a través de Internet, empleándola un $6 \%$.

En cualquier caso los encuestados coinciden en que la ventaja que aporta esta vía de comunicación es el ahorro de costes, puesto que todas las llamadas son cobradas según tarifa metropolitana.

\section{Videoconferencia}

La tecnología de la videoconferencia está más difundida, puesto que es conocida por todos los entrevistados, de los cuales, la mitad considera que podría ser interesante para su empresa, empleándolo sólo el 10\% para la comunicación con otros centros de la propia empresa.

La mitad restante que no lo considera aplicable, es debido a que su empresa está constituida por una única fábrica y no opina que actualmente les compense, dada la poca difusión entre sus clientes y proveedores.

\subsubsection{Formación en el entorno de las TICs}

Dentro del bloque de formación se van a valorar los conocimientos que el personal de la empresa posee respecto a las TICs.

Este apartado está orientado a captar la política de formación de la empresa, la importancia dada a la especialización en los aspectos informáticos y los requerimientos de una cierta titulación a la hora de contratar al personal técnico.

De esta manera se contempla el grado de formación de todo el personal, diferenciando a la dirección, de los expertos informáticos y de los empleados de los restantes departamentos.

Así mismo, se cuestiona el plan de formación llevado a cabo por las empresas, a nivel de frecuencia y áreas impartidas.

Finalmente, se hace hincapié en las inversiones en este tipo de tecnologías durante los últimos años, a fin de cuantificar la preocupación por estas herramientas. 


\section{Formación de la Dirección}

Conocer el nivel de conocimientos en las Tecnologías de la Información y las Comunicaciones que posee la Dirección de la empresa, es interesante puesto que es un indicador del mayor o menor peso específico que tienen estas tecnologías en la empresa.

Es por esto por lo que se ha pedido a los técnicos informáticos de las empresas, contando con su objetividad, que valoren el grado de conocimientos de la Gerencia, resultando que la mitad posee unos conocimientos medios, seguidos de los que tienen un nivel bajo (38\%).

\section{Formación de los Expertos Informáticos}

Bajo el término de expertos informáticos se engloban a todas aquellas personas contratadas por la empresa y que realizan actividades relativas al mantenimiento del hardware y software, o incluso análisis y/o programación, independientemente de que sean éstas o no sus únicas obligaciones en la empresa.

El $66 \%$ de las empresas cuenta con expertos informáticos, los cuales tienen en el momento de su incorporación laboral, una formación o titulación diversa. El $26 \%$ de las empresas ha contratado personal diplomado o licenciado en Informática, seguido por un $24 \%$ que contrata a autodidactas, o por un $20 \%$ que incorpora a personal formado con cursos específicos.

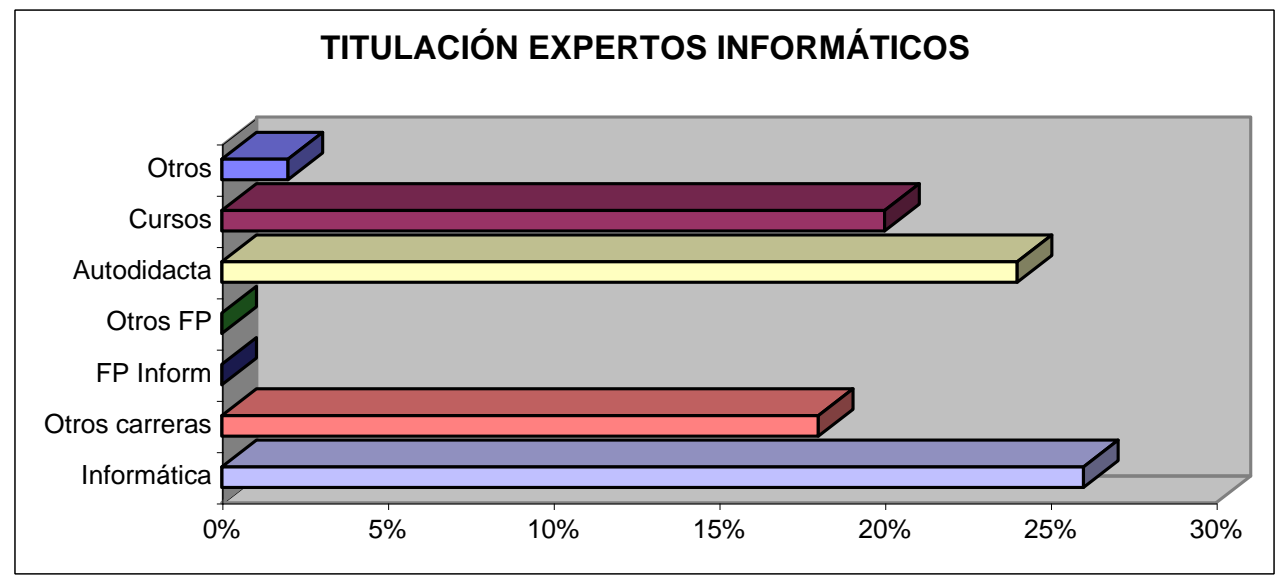

Al respecto, se hace necesario comentar que la titulación de Informática no existía hace unos años, con lo que todo el personal informático contratado es joven y de reciente incorporación.

Dentro del grupo de autodidactas, se engloban aquellas personas que aunque posiblemente han empezado realizando otras funciones en la empresa, finalmente 
se han autoformado a fin de poder desempeñar las tareas propias de un experto informático.

Por otra parte, se ha cuestionado también a las empresas que no tienen expertos informáticos, si se disponen de suficientes conocimientos de aplicaciones de comunicaciones e Internet en la empresa, ante lo cual el $40 \%$ considera que no se disponen de suficientes conocimientos, más en un mercado tan cambiante.

Se hace necesario comentar que del $34 \%$ de empresas que no cuentan con expertos informáticos, prácticamente todas subcontratan los servicios informáticos de consultores externos, tanto para funciones de programación como de mantenimiento y asistencia técnica.

\section{Formación del resto de personal}

En prácticamente todas las empresas, el personal posee conocimientos de ofimática, normalmente a un nivel medio - bajo. Sin embargo, estos trabajadores suelen ser sólo los que están trabajando a diario con los PCs, tales como el personal de Administración o Ventas.

Referente al manejo de las aplicaciones informáticas propias o a medida, se observa que los usuarios de ellas, no han recibido en la mayoría de los casos, cursos de formación como tal, sino que se les ha explicado como hacer determinada tarea de forma "no oficial".

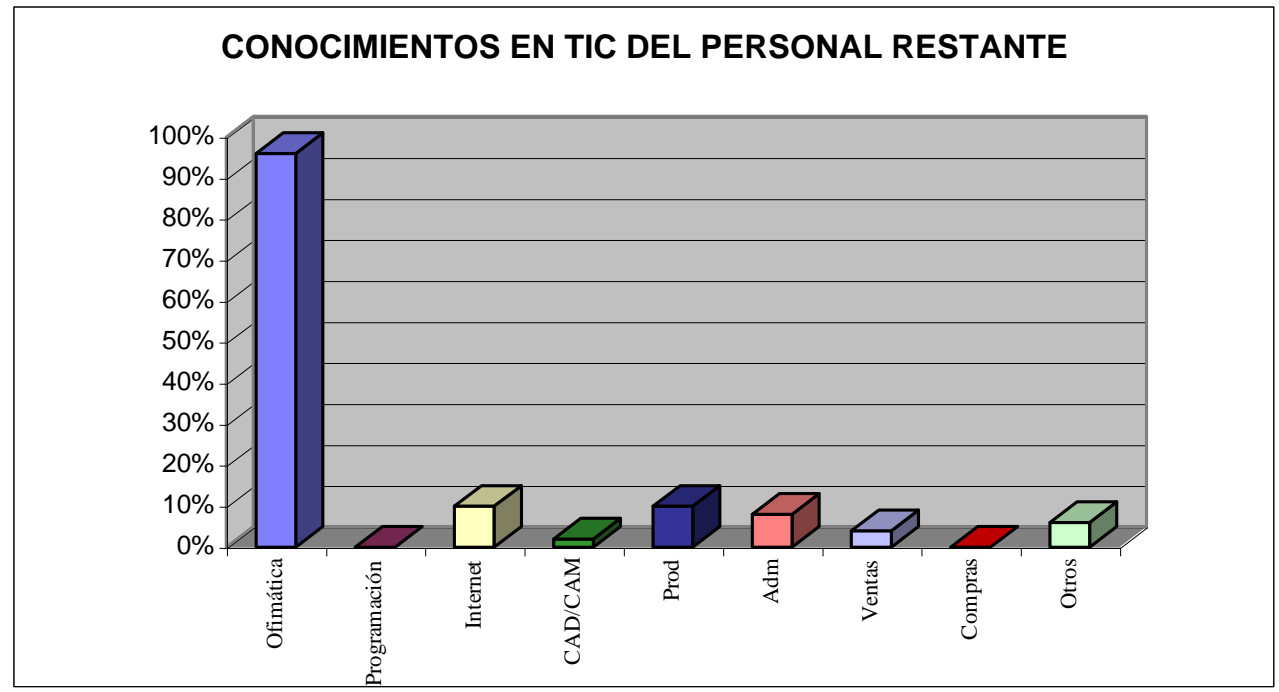

El hecho de que una empresa apueste por la formación en este campo es bastante significativo de la importancia que se le da y del grado de concienciación en estos temas que tiene la dirección. 
Cabe apuntar que el $38 \%$ de las empresas encuestadas realiza cursos, con una frecuencia anual.

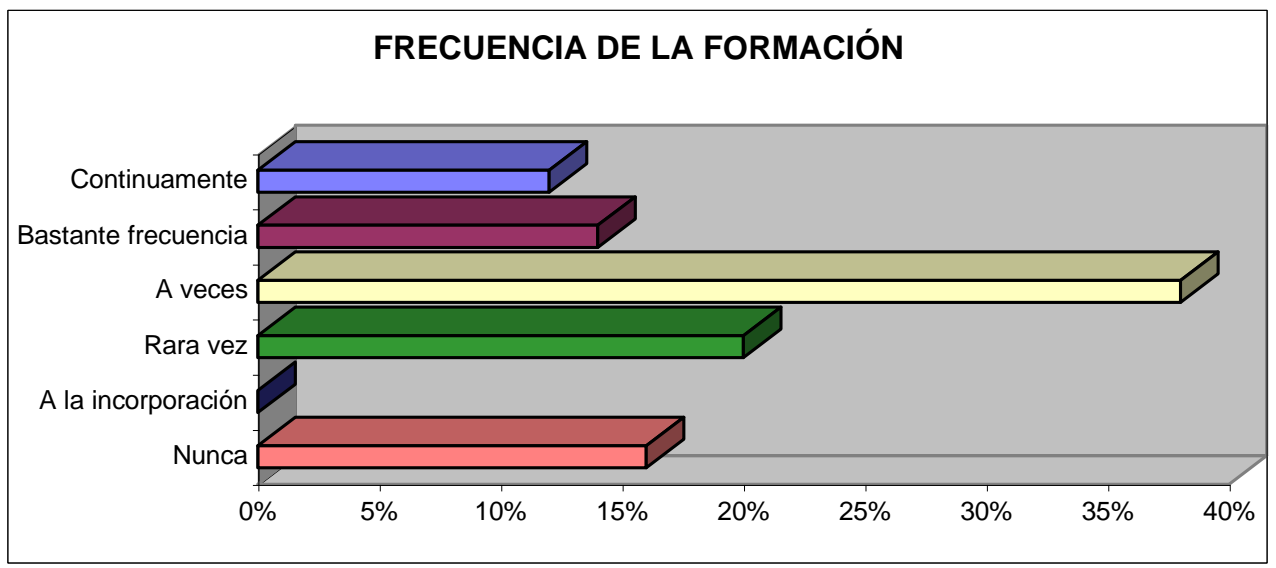

Esta formación se lleva a cabo básicamente en Ofimática, es decir, manejo del Microsoft Office a nivel de usuario. En segundo lugar se apuesta por la formación en Internet, como puede apreciarse en el gráfico adjunto.

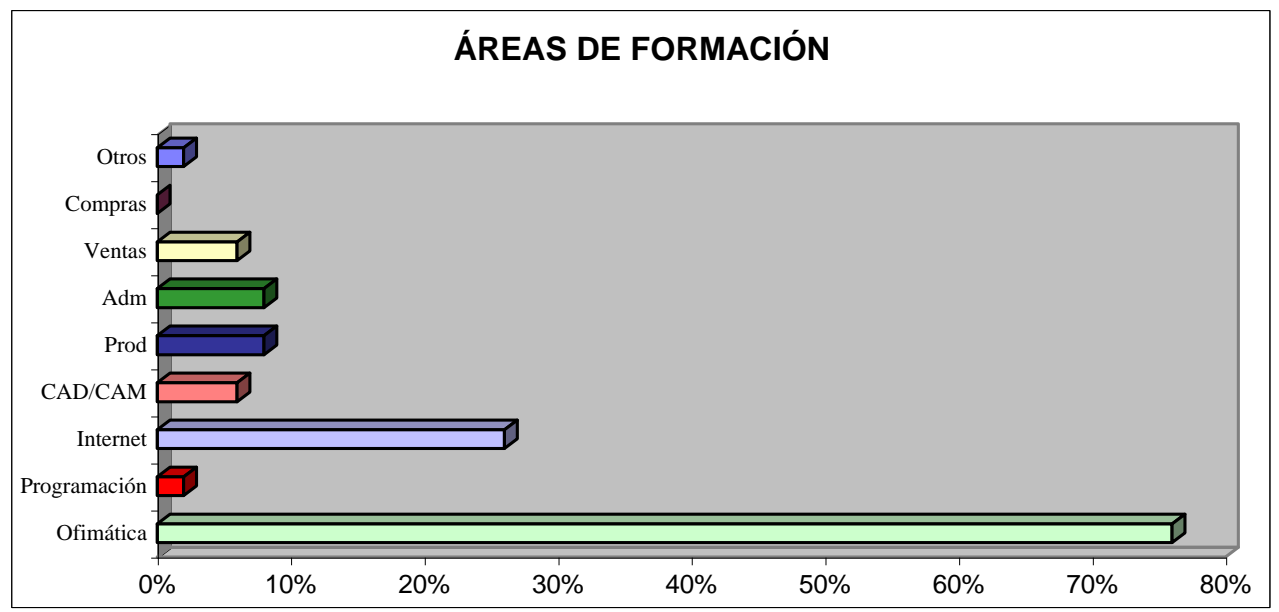

Finalmente, del estudio se obtiene que el $64 \%$ de las empresas considera que no van a necesitar a más personal especializado en comunicaciones en un periodo de tiempo corto o medio. Esto es debido a que son demasiado pequeñas para pensar en un departamento de comunicaciones, o bien siendo suficientemente grandes, no lo consideran necesario por las expectativas de su empresa, aunque en menor medida, están cubiertas sus necesidades. 


\subsection{Perspectivas de las TICs en el Sector Textil.}

El proceso de innovación tecnológica es fundamental para mantener la competitividad del Sector Textil. Las TIC constituyen el elemento clave en dicho proceso de innovación, siendo sus aplicaciones muy numerosas y clara la rentabilidad de su uso.

La evolución de los mercados, el cambio en los hábitos del consumidor y las modificaciones introducidas en el propio estilo de vida del ciudadano por la mayor oferta de ocio y transparencia en la información global, provocan la necesidad de la evolución de la industria de la moda en general, hacia los Sistemas de Respuesta Eficiente al Cliente. Se trata pues, de producir lo que el cliente nos va a demandar. Para ello es imprescindible el trabajo en grupo de los distintos eslabones de la cadena textil, trabajo que debe necesariamente soportarse en servicios avanzados de información y comunicaciones.

Siguiendo a Canals (2003) el sector debe proseguir en su esfuerzo inversor y en el aumento de la cualificación de su activo crucial, las personas que lo constituyen. La dificultad para encontrar personal capacitado es uno de los handicaps del momento actual, que propicia el completar las actividades productivas del país con la deslocalización estratégica de algunas fases del proceso.

Una prioridad básica para el sector es seguir mejorando la competitividad de la industria en el ámbito europeo. En la Cumbre de Lisboa, los Jefes de Estado y de Gobierno se fijaron como objetivo para 2010, convertir a la economía europea en la más dinámica y competitiva del mundo. La industria del textil-confección está bien situada para que contribuya a este objetivo general, siempre y cuando se aprovechen las oportunidades y se preparen las estructuras que pongan de relieve sus ventajas comparativas.

En la Segunda Jornada Sectorial del Sector Textil (Altimia, 2003) organizada por la consultora Altimia y Economía 3, bajo el título "Retos y desafíos del sector textil valenciano", se reunieron expertos y empresarios del sector para tratar de enfocar la situación en la que se encuentra el sector textil valenciano dentro del ámbito estatal y definir cuáles son los problemas a los que se tienen que enfrentar las empresas del sector y tratar de buscar soluciones a dichos problemas. Como conclusiones a esta Jornada Sectorial se extrajeron una serie de carencias y líneas de actuación para las empresas del sector textil, que se recogen aquí en forma de dos tablas situadas a continuación, en las mismas se puede comprobar: 


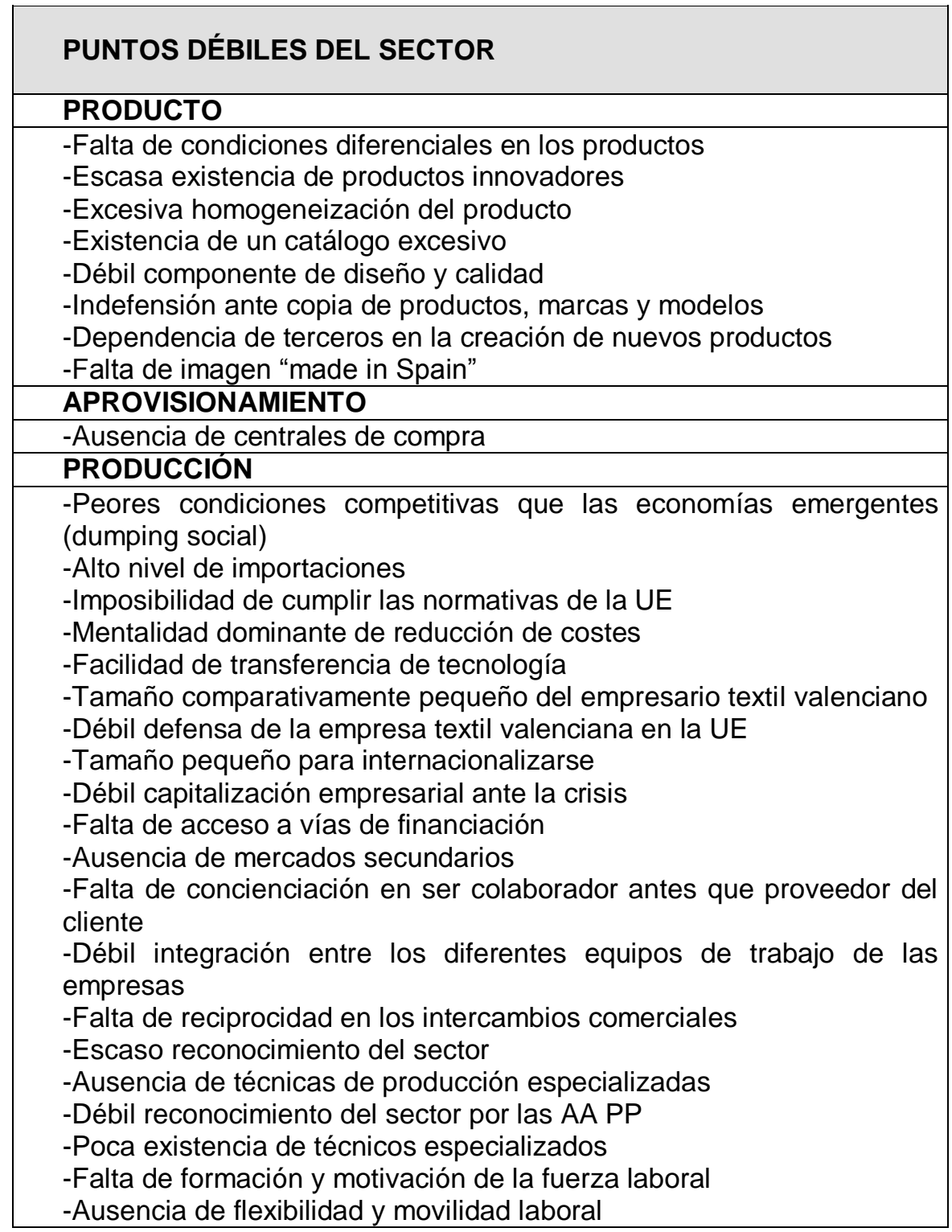




\begin{tabular}{|l|}
\hline DISTRIBUCIÓN \\
\hline -Excesiva cantidad de eslabones en la cadena de distribución \\
\hline -Alto coste de distribución para empresas de pequeño volumen \\
\hline -Débil posición en la cadena de distribución internacional \\
\hline -Redes de distribución débil para llegar al cliente final \\
\hline -Concentración de los compradores (monopolio) \\
\hline -Abaratamiento de costes de distribución en importaciones \\
\hline -Falta de canales propios \\
\hline -Escasa vocación internacional \\
\hline -Falta de mentalidad de servicio \\
\hline
\end{tabular}

Tabla 4.2: Debilidades del sector Textil. Fuente: Altimia (2003).

\begin{tabular}{|l|}
\hline DIEZ LÍNEAS DE ACTUACIÓN PRIORITARIAS \\
\hline -Invertir en I+D+I \\
\hline -Modificar la normativa laboral para favorecer la flexibilidad \\
\hline -Invertir en aplicaciones tecnológicas para el producto textil \\
\hline -Crear marca paraguas y apoyarla en mercados estratégicos \\
\hline -Acortar la cadena de distribución y crear canal minorista \\
\hline -Aplicar metodologías de diseño (acortar plazo y asegurar el exito) \\
\hline -Modificar normativa fiscal \\
\hline -Colaboración empresarial en compras y producción \\
\hline -Conseguir iguales condiciones de entorno \\
\hline -Establecer barreras técnicas contra el dumping social e invertir en la \\
reducción del ciclo de servicio al cliente \\
\hline
\end{tabular}

Tabla 4.3: Líneas de actuación prioritarias. Fuente: Altimia (2003).

Se puede observar como una línea prioritaria, que indicó este grupo de expertos, es la inversión en Tecnologías de la Información y las Comunicaciones. 


\section{PROCESO METODOLÓGICO}

\section{$5.1 \quad$ Introducción}

Este capítulo pretende desarrollar el enfoque metodológico seguido en esta Tesis Doctoral, dando respuesta a las siguientes cuestiones: ¿Qué se hará para desarrollar el estudio? ¿Cómo se recogerán los datos? ¿Qué herramientas se utilizarán?

Una vez identificado el problema objeto de estudio de la investigación, delimitados los objetivos y las hipótesis. Es preciso continuar el diseño de la investigación fijando la estrategia del proceso metodológico de la tesis. (Montoro, 2002).

Seguidamente, se presenta la metodología que se utilizará, así como, los métodos de recogida y análisis de datos; se comentan también las ventajas y de igual modo, las limitaciones que estos métodos presentan.

La metodología que se va a utilizar es de naturaleza cualitativa, ésta facilita un conjunto de herramientas que permiten profundizar en el conocimiento de las motivaciones del comportamiento de las personas y las organizaciones. las técnicas de investigación cualitativas tienen su origen en la Psicología y la Sociología y su aplicación en el mundo empresarial es cada vez mayor, extendiéndose a los ámbitos de la dirección y organización de empresas (Fernández Nogales, 1999).

\subsection{Concepto y características de la investigación cualitativa.}

Se puede entender la investigación cualitativa (Pérez Serrano, 1994) como aquella metodología de investigación que consiste en descripciones detalladas de situaciones, eventos, personas, interacciones y comportamientos que son observables. Además, esta metodología incorpora lo que los participantes dicen: sus experiencias, actitudes, creencias, pensamientos y reflexiones, tal y como son expresadas por ellos mismos. La investigación cualitativa se considera como un proceso activo, sistemático y riguroso de indagación dirigida.

También resulta posible entender la investigación cualitativa desde la perspectiva de sus características más significativas. Entre ellas podemos destacar (Taylor y Bogdam, 1986) las siguientes:

- La investigación cualitativa es inductiva, ya que en este tipo de metodología, los investigadores siguen un diseño de investigación flexible.

- En la metodología cualitativa, el investigador, ve el problema de estudio desde una perspectiva holística, es decir, las personas, los escenarios y otros elementos del problema, no se reducen a variables, sino que son considerados como un todo y en su contexto. 


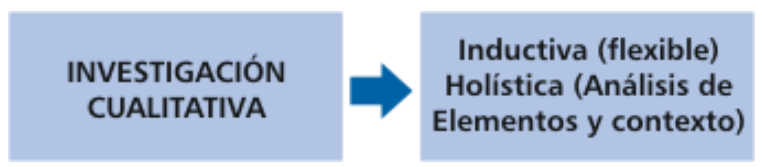

Figura 5.1 Características más significativas de la investigación cualitativa

Además, los investigadores cualitativos son sensibles a los efectos que ellos mismos causan sobre las personas que son objeto de su estudio. En este sentido, se ha dicho que son naturalistas, pues interactúan con los informantes de modo natural y no intrusivo.

Puede también decirse que los investigadores cualitativos tratan de apartar sus propias creencias, perspectivas y predisposiciones sobre el problema objeto de estudio y buscan una comprensión detallada de las perspectivas de todos los informantes, personas y fuentes de información implicadas en la investigación.

Además, las técnicas cualitativas y cuantitativas no son metodologías excluyentes (Cook y Reichdart, 1986), sino más bien complementarias, siendo posible su utilización de forma conjunta para resolver un mismo problema empresarial.

\subsection{Características metodológicas}

El proceso de aplicación de las técnicas cualitativas se estructura en las siguientes etapas: planteamiento general, elección de la técnica, muestreo y trabajo de campo y análisis de los resultados e informe final. A continuación pasaremos a revisar cada una de estas etapas.

\subsubsection{Planteamiento general de los estudios cualitativos}

Se trata de una etapa previa a la propia formulación de los objetivos específicos de la investigación a realizar (Fernández Nogales, 1999). En esta etapa se profundiza en el problema planteado y en las características de la situación de partida. Los principales aspectos a considerar son:

- Los antecedentes del problema. Por ejemplo, profundizar en el conocimiento del sector que se va a analizar, la cadena de valor, los procesos de aprendizaje u otros.

- Los colectivos implicados, por ejemplo, sus características, accesibilidad.

- Los recursos disponibles para la investigación (humanos, materiales, etc.).

El análisis de estas consideraciones previas es la base para la concreción de los objetivos específicos de la investigación, tras lo cual se realizará la planificación del proceso metodológico. 


\subsubsection{Principales técnicas cualitativas}

Las técnicas cualitativas que se suelen utilizar en el ámbito de estudio de los problemas empresariales se pueden clasificar en tres grupos (Fernández Nogales, 1999): técnicas directas, técnicas indirectas y técnicas de observación. El detalle desagregado de la tipología de las principales técnicas cualitativas aparece en la tabla 5.1:

\begin{tabular}{|l|l|l|}
\hline Directas & $\begin{array}{l}\text { Entrevista en } \\
\text { profundidad }\end{array}$ & \\
\cline { 2 - 3 } & Reunión en grupo & $\begin{array}{l}\text { Grupo de enfoque. } \\
\text { Tormenta de ideas }\end{array}$ \\
\hline Indirectas & $\begin{array}{l}\text { Técnicas } \\
\text { proyectivas }\end{array}$ & $\begin{array}{l}\text { Técnicas de asociación. } \\
\text { Técnicas de complementación. } \\
\text { Técnicas de construcción. } \\
\text { Técnicas de expresión }\end{array}$ \\
\hline $\begin{array}{l}\text { Técnicas de } \\
\text { observación }\end{array}$ & $\begin{array}{l}\text { Observación cuantitativa. } \\
\text { Observación cualitativa. } \\
\text { Observación participantes }\end{array}$ \\
\hline
\end{tabular}

Tabla 5.1: Clasificación de las técnicas cualitativas. (Fernández Nogales, 1999).

Las técnicas cualitativas directas se caracterizan por no ocultar el objetivo del estudio a los entrevistados o informantes, mientras que las técnicas indirectas no ofrecen esta información a los entrevistados. No obstante, cabe destacar la aparición de nuevas tendencias de técnicas cualitativas que combinan diversas metodologías ${ }^{1}$.

\subsubsection{Muestreo y Trabajo de campo}

Para el caso de la investigación cualitativa, dado que se trata de hacer análisis en profundidad y no en extensión de un colectivo, no es necesario utilizar muestras muy amplias, ni aplicar muestreo estadístico para determinar el tamaño de la muestra. En estos casos, se produce un efecto multiplicador del valor de la unidad o unidades utilizadas como muestra, ya que el aprendizaje y la experiencia de casos anteriores sirve para potenciar los resultados (Fernández Nogales, 1999).

No obstante, la composición de la muestra sí es un elemento decisivo para obtener un nivel de representatividad adecuado en la información cualitativa resultante del estudio. Para ello, se recomienda el método de muestreo

\footnotetext{
${ }^{1}$ Se puede hacer referencia a las técnicas cualitativas ómnibus, donde el contenido de la entrevista o de la reunión incluye distintos problemas de diferentes empresas que afectan a un mismo grupo o colectivo. Cabe distinguir también, las técnicas cualitativas asistidas por ordenador, que registran la información recogida durante la investigación en soportes informáticos que luego son tratados en programas informáticos.
} 
estratificado o por cuotas, porque permite mantener una estructura de la muestra similar a la población objeto de estudio.

\subsubsection{Análisis de los Resultados e Informe final}

Como luego veremos, cuando analicemos el estudio de casos, este es uno de los aspectos fundamentales en la validación de la metodología de investigación cualitativa. El investigador analiza los resultados aplicando técnicas que permiten valorar de forma cualitativa las motivaciones, opiniones, actitudes y emociones y la conducta de los entrevistados. Para ello, los instrumentos de registro, grabaciones de las entrevistas y de las reuniones, cuestionarios proyectivos y procedimientos electrónicos de observación cumplen una función objetivadora de la información y permiten revisarla detalladamente, facilitando el estudio y seguimiento de todo el proceso de la investigación.

Cabe destacar también, que las conclusiones de un estudio cualitativo no se extrapolan de igual forma que los resultados de un estudio cuantitativo. Es aconsejable contrastar las conclusiones de un estudio cuantitativo con las partes implicadas antes de elaborar el informe final.

\subsection{El estudio de casos}

El método del estudio de casos comienza a utilizarse con más frecuencia en las ciencias humanas y sociales como procedimiento de análisis de la realidad. Sin embargo, conviene indicar que el predominio de los métodos de carácter cuantitativo, en nuestro contexto social, no ha propiciado el desarrollo de otras metodologías de carácter cualitativo que aparecen con gran empuje en la actualidad (Pérez Serrano, 1994).

Según Yin (1989):

"Ios casos son una investigación empírica que estudian fenómenos contemporáneos dentro de su contexto real, cuando las fronteras entre el fenómeno estudiado y su contexto no son evidentes, $y$ en la que se utilizan múltiples fuentes de evidencia, es decir, un caso estudia la situación cuando se produce y sin aislarla de su entorno".

Siguiendo a Kaplan (1986), resulta difícil imaginar que se puedan verificar teorías en el campo de la dirección de empresas, si la prueba no se realiza dentro del contexto organizativo. Estas pruebas han de servir no sólo para describir la existencia o no de procedimientos, sino también para deducir y contrastar cómo y por qué ciertas prácticas tienen que ser implantadas.

Para Prieto (1998), el "estudio de casos" se ha revelado como un instrumento necesario en el proceso de experimentación de cualquier investigación en materia de dirección y gestión de empresas requiere. 
Cada vez son más los autores que recomiendan la utilización de técnicas cualitativas para estudiar los distintos fenómenos que atañen a la empresa (Kaplan, 1986; Rialp, 1998; Pérez, 1998; Prieto, 1998), porque si el objetivo perseguido es entender por qué, cómo y cuándo se producen determinadas situaciones, resulta bastante difícil llegar a comprender los motivos si la investigación se basa sólo en datos y relaciones entre ellos; de esta manera se constata la ocurrencia de un suceso pero difícilmente se comprenderán las causas o las consecuencias del mismo. Aunque su potencial ha quedado tradicionalmente infravalorado en favor de las técnicas cuantitativas (Rialp, 1998), cada vez son más numerosas las investigaciones llevadas a cabo con metodología de tipo cualitativo.

Siguiendo a Yin (1989), será el tipo de problema el que nos indique cuándo utilizar una u otra aproximación, siendo el estudio de casos la metodología de investigación más adecuada cuando nos enfrentamos a cuestiones que comienzan por ¿por qué? o por ¿cómo?.

\subsubsection{Concepto y tipología del estudio de casos}

Se trata de un análisis intensivo de algunos ejemplos seleccionados de forma que se consiga una lúcida comprensión del fenómeno estudiado y sirva para plantear teorías y modelos que guíen futuras investigaciones (Pérez , 1999).

La investigación en el estudio de casos puede caracterizarse según diversos criterios. Así podemos establecer la siguiente tipología (Bonache, 1998):

- Por su propósito:

\begin{tabular}{|l|l|}
\hline Descriptivos & $\begin{array}{l}\text { El objetivo de este análisis de casos es proporcionar una } \\
\text { descripción de la práctica que se desea observar (Prieto (1998) } \\
\text { siguiendo a Yin (1989)). }\end{array}$ \\
\hline Exploratorios & $\begin{array}{l}\text { El objetivo de este análisis de casos es descubrir hipótesis } \\
\text { susceptibles de generalización respecto a las prácticas } \\
\text { observadas (Prieto (1998) siguiendo a Yin (1989)). }\end{array}$ \\
\hline Explicativos & $\begin{array}{l}\text { El objetivo de este análisis de casos es explicar la razón de ser } \\
\text { de las prácticas observadas en el mundo real. (Prieto (1998) } \\
\text { siguiendo a Yin (1989)). } \\
\text { Se utiliza la teoría para entender y aplicar lo específico. }\end{array}$ \\
\hline Ilustrativos & $\begin{array}{l}\text { El objetivo de este análisis de casos es elucidar las prácticas } \\
\text { innovadoras (best practices) que impregnan el desarrollo } \\
\text { organizativo en las empresas más competitivas (Prieto (1998) } \\
\text { siguiendo a Yin (1989)). }\end{array}$ \\
\hline Experimentales & $\begin{array}{l}\text { El objetivo de este análisis de casos es examinar las dificultades } \\
\text { que supone la implantación de nuevas técnicas y procedimientos, } \\
\text { planteados por los investigadores, para evaluar los beneficios que } \\
\text { de ellos se derivan (Prieto, 1998). }\end{array}$ \\
\hline Históricos & $\begin{array}{l}\text { El objetivo de este análisis de casos es analizar un fenómeno } \\
\text { histórico. (Bonache, 1999). }\end{array}$ \\
\hline
\end{tabular}

Tabla 5.2: Tipologías de investigación por el método de casos (Bonache, 1998) 
- Por la aportación teórica (Snow y Thomas, 1994):

- Generar una teoría.

- Contrastar una teoría.

- Por el tipo de diseño (Yin, 1994):

\begin{tabular}{|l|l|}
\hline Tipo I & $\begin{array}{l}\text { Un único caso simple sin subunidades. Se analiza un único caso, el cual no } \\
\text { se puede descomponer en subunidades. }\end{array}$ \\
\hline Tipo II & $\begin{array}{l}\text { Un caso simple con subunidades. Se analiza un único caso, el cual se } \\
\text { descompone en distintas subunidades de análisis. }\end{array}$ \\
\hline Tipo III & $\begin{array}{l}\text { Múltiples casos sin subunidades. Varios casos en un mismo estudio, los } \\
\text { cuales no se puede descomponer en subunidades. }\end{array}$ \\
\hline Tipo IV & $\begin{array}{l}\text { Múltiples casos con subunidades. Varios casos en un mismo estudio, los } \\
\text { cuales se descomponen en distintas subunidades de análisis. }\end{array}$ \\
\hline
\end{tabular}

Tabla 5.3: Por el tipo de diseño (Yin, 1994)

\subsubsection{El estudio de casos como estrategia de investigación}

La literatura sobre la metodología de investigación del caso conduce fácilmente al lector a ciertas confusiones. Éstas se refieren a tres aspectos fundamentales: su denominación, su relación con la metodología cuantitativa y su base teórica.

En cuanto a su denominación algunos autores como Otley y Berry (1994) o Ryan et Al.(1992) afirman que el estudio de casos puede ser usado por distintas metodologías, mientras que otros autores como Hartley (1994) indican que el estudio del caso no es un método. Para aclarar esta disfunción y siguiendo a Silverman (1993), entenderemos por metodología un enfoque general para estudiar un problema de investigación, mientras que por método a cualquier técnica que sirve para recoger información.

De esta forma el estudio de casos se caracteriza por una serie de rasgos distintivos como son:

- No se separa el fenómeno de su contexto, ya que en lugar de reducir una situación a un conjunto de variables, los casos adoptan una visión holística, en la que no se olvida que el contexto y el comportamiento son interdependientes.

- Se parte de un modelo teórico. Así, frente al intento de la metodología cuantitativa de contrastar hipótesis, los casos explicativos tratan de construir teorías a partir de las observaciones, siguiendo el procedimiento inductivo.

- La elección de los casos tiene carácter teórico, no estadístico. Frente al análisis de la representatividad, los casos deben elegirse por su capacidad explicativa. Por ello, el análisis del caso no típico, es decir, la excepción a la generalidad, puede ayudarnos a hacer más precisas las teorías. 
- Tiende a utilizar más fuentes de datos (triangulación).

- Flexibilidad en el proceso de la investigación. En la metodología del estudio de casos, a medida que descubrimos nuevos hechos podemos cambiar los presupuestos teóricos iniciales y desarrollar otros nuevos.

- Inducción analítica, no estadística. En el estudio de casos se infieren hipótesis o generalizaciones teóricas a partir del análisis de campo.

La selección de un estudio de casos es preferible cuando (Yin, 1994): la pregunta de investigación es del tipo cómo o por qué, se examinan sucesos contemporáneos, o bien, el investigador no tiene control sobre los sucesos (no hay manipulación sobre comportamientos relevantes).

\subsubsection{Evaluación científica de los estudios de casos.}

Como bien sabemos, los valores dominantes en organización y dirección de empresas vienen siendo los postulados por la tradición cuantitativa. En este sentido, para que una investigación sea considerada valiosa tiene que ser rigurosa. Ello equivale a decir que debe ser fiable, válida y generalizable.

Teniendo en cuenta estos precedentes, los estudios de casos vienen sufriendo dos críticas fundamentales (Bonache, 1998). Por un lado, su falta de objetividad, ya que en los estudios de casos, el investigador especifica el fenómeno a estudiar, elige el marco teórico, pondera las distintas fuentes y analiza la conexión causal. La segunda crítica se refiera a la validez externa del estudio. Es decir, hasta qué punto el caso estudiado es realmente representativo y permite generalizar los resultados.

Según Yin (1989), para que un estudio de casos se pueda considerar relevante, debe ser riguroso, es decir, tener validez interna y externa (que sea generalizable), validez de los conceptos y fiabilidad.

Teniendo en cuenta tales valores y, tal y como indica Bonache (1999), los casos reciben dos críticas fundamentales:

- El sesgo del investigador. En estos estudios es el investigador el que especifica el fenómeno a estudiar, elige el marco teórico, pondera la relevancia de las distintas fuentes y analiza la conexión causal entre los hechos. Como consecuencia, estos estudios se tachan de no objetivos y poco fiables.

- Falta de representatividad de los casos. En un estudio de casos no se sabe hasta qué punto va a existir un paralelismo en otras circunstancias.

Por otra parte, otros autores prefieren, en lugar de criticar la metodología cuantitativa para responder a las críticas, intentar mejorar las condiciones de fiabilidad, validez y generalidad de este tipo de casos. 
Por lo que respecta a la generalización del estudio o la validez externa, Yin (1989) establece la existencia de un paralelismo entre el estudio de casos y el experimento al estudiar ambos un fenómeno bajo unas características o contexto determinados. El autor afirma que en ambas situaciones se puede generalizar pero no sobre la población, como lo haría la investigación cuantitativa, sino sobre las proposiciones teóricas. Además, el objetivo del investigador en el estudio de casos y en el experimento es "generalizar teorías y no enumerar frecuencias" (Chiva, 2000). Se trataría de generalizar sobre proposiciones teóricas y no sobre poblaciones, ya que la inducción analítica trata de ver lo general en lo particular, intentando descubrir en casos concretos las causas o condiciones generales que nos permiten explicar y predecir un fenómeno (Bonache, 1999), y este es el objetivo de esta Tesis Doctoral.

Para terminar este apartado con una aportación positiva hacia la metodología del estudio de casos, indicar que, según Prieto (1998), la investigación de casos es una técnica de contraste apropiada para validar empíricamente muchas de las hipótesis de comportamiento que se derivan de las teorías positivas, entendiendo por enfoque positivista, según indica Montoro (2002), aquel que adapta los instrumentos y las reglas de las ciencias de la naturaleza al estudio de lo social y de la conducta humana.

\subsection{Diseño e implantación del estudio de casos.}

Como se desprende de lo tratado en los epígrafes anteriores, el estudio de casos posibilita una amplia discrecionalidad en el diseño y aplicación de todos los aspectos de la investigación, tanto en la selección de los casos como en la utilización de las fuentes de evidencia y técnicas de análisis. Esta circunstancia, nos obliga a establecer, desde el primer momento, un diseño coherente que defina de forma precisa las directrices del estudio, evitando que la potestad del investigador derive en cierta arbitrariedad en sus decisiones o en una baja calidad o rigurosidad de la investigación.

Este diseño coherente, trata de facilitar la validación externa mediante la fijación de un plan a priori, de las necesidades y los criterios que justifican cada decisión importante de forma que un tercero pueda analizar si dichos criterios son adecuados al problema a resolver y si la decisión tomada se adapta a ellos. A continuación, en la figura 5.2 se muestra la estructura de la planificación de etapas de un estudio de casos (Eisenhart, 1989; Yin, 1989). 


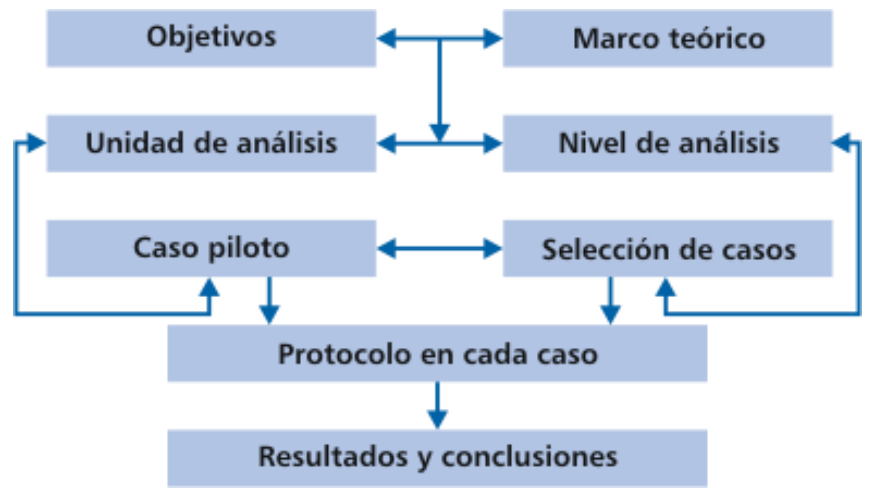

Figura 5.2: Estructura de la planificación de etapas de un estudio de casos (Eisenhart, 1989; Yin, 1989).

\subsubsection{El objetivo de la investigación.}

El estudio de casos resulta una metodología muy útil si buscamos una teoría o modelo explicativo de la realidad que se pretende analizar.

El objetivo se suele articular en torno a un determinado fenómeno, del que se desea conocer las causas de su comportamiento, actores que influyen en el cómo y por qué dichos factores actúan.

\subsubsection{El marco teórico.}

En el estudio de casos, el marco teórico de la investigación reviste una especial consideración por tres razones fundamentales (Pérez Aguilar, 1999). En primer lugar, implica la necesidad de realizar una amplia revisión bibliográfica que aclare el estado del arte, los estudios previos relacionados, aportaciones, lagunas, etc. Ello permitirá comparar los conceptos, teorías e hipótesis emergentes con la literatura existente (Eisenhardt, 1989).

En segundo lugar, se debe definir qué tipo de aportación se pretende con el estudio que se va a realizar.

Para llevar a cabo un estudio de casos es necesario partir de un marco preliminar (Yin, 1989). Para Bonache (1998), si no se dispone de un marco teórico, los datos desbordan al investigador, los casos se convierten en una sucesión de anécdotas y, teniendo en cuenta que la investigación científica tiene carácter acumulativo, las nuevas aportaciones de conocimiento se valoran en le trasfondo de lo que se conoce o se acepta.

Según Pérez, W. (1998), el marco teórico de la investigación a desarrollar merece tenerse en cuenta por tres circunstancias: 
- La investigación debe beneficiarse de las anteriores aportaciones científicas.

- La investigación debe encontrar su sitio en el marco teórico actual que significa identificar qué tipo de aportación se pretende conseguir. En la tabla 5.4 se presenta la clasificación realizada por Snow y Thomas (1994) y recogida por Pérez, W. (1998), en función del grado de desarrollo de la teoría (generación o contraste) y según el propósito (descripción, explicación o predicción).

- El punto de partida de la investigación empírica será un conjunto de variables o factores estudiados en trabajos precedentes y que se presentan como candidatos a influir en el fenómeno estudiado.

Así, si estos elementos cobran importancia a lo largo de la investigación, crecerá la base empírica de teoría emergente (Pérez, W., 1998). 


\begin{tabular}{|c|c|c|c|}
\hline & DESCRIPCIÓN & EXPLICACIÓN & PREDICCIÓN \\
\hline $\begin{array}{l}\text { GENERACIÓN DE } \\
\text { UNA TEORÍA }\end{array}$ & $\begin{array}{l}\text { La pregunta clave es } \\
\text { "qué". } \\
\text { Identifica los } \\
\text { elementos clave y } \\
\text { las variables. Los } \\
\text { estudios están } \\
\text { basados } \\
\text { habitualmente en la } \\
\text { observación y/o } \\
\text { entrevistas. }\end{array}$ & $\begin{array}{l}\text { Las preguntas claves } \\
\text { son "cómo" y "por } \\
\text { qué". } \\
\text { Establece relaciones } \\
\text { entre elementos y } \\
\text { proporciona } \\
\text { racionalidad teórica } \\
\text { para las relaciones } \\
\text { observadas. Los } \\
\text { estudios } \\
\text { normalmente usan la } \\
\text { observación y/o } \\
\text { entrevistas. }\end{array}$ & $\begin{array}{l}\text { Las preguntas claves } \\
\text { son "quién", "dónde" } \\
\text { y "cuándo". } \\
\text { Examina las } \\
\text { condiciones límite de } \\
\text { una teoría. Los } \\
\text { estudios usan } \\
\text { observación, } \\
\text { cuestionarios, } \\
\text { encuestas y } \\
\text { entrevistas. }\end{array}$ \\
\hline $\begin{array}{l}\text { CONTRASTE DE } \\
\text { UNA TEORÍA }\end{array}$ & $\begin{array}{l}\text { Se centra en } \\
\text { desarrollar y validar } \\
\text { las medidas de los } \\
\text { elementos clave. Los } \\
\text { estudios } \\
\text { normalmente utilizan } \\
\text { cuestionarios, } \\
\text { encuestas y } \\
\text { entrevistas. }\end{array}$ & $\begin{array}{l}\text { Se centra en } \\
\text { documentar las } \\
\text { relaciones entre } \\
\text { variables a través del } \\
\text { contraste de } \\
\text { hipótesis. } \\
\text { Frecuentemente se } \\
\text { usan grandes } \\
\text { muestras con } \\
\text { cuestionarios o } \\
\text { simulaciones. }\end{array}$ & $\begin{array}{l}\text { Se centra en } \\
\text { contrastar teorías } \\
\text { competidoras del } \\
\text { mismo fenómeno, a } \\
\text { través de } \\
\text { experimentos } \\
\text { cruciales. }\end{array}$ \\
\hline
\end{tabular}

Tabla 5.4: Métodos de investigación y desarrollo de teorías en economía y dirección de empresas Fuente: En Pérez, W. (1998). Adaptado de Snow y Thomas (1994)

En tercer lugar, si el objetivo planteado es la búsqueda de factores que influyen en un fenómeno, el punto de partida será el conjunto de variables estudiadas en los trabajos precedentes. De esta manera, estos factores cobran importancia y configurarán la base empírica de la teoría emergente.

Una vez fijado el objetivo de la investigación y el marco teórico previo, se debe disponer de elementos de juicio suficientes para concretar el tipo de investigación y, por consiguiente, el diseño que resulta más adecuado (Pérez, 1998). Según este autor, para cubrir el objetivo citado, se debe responder a las siguientes preguntas:

- De acuerdo con el marco teórico y con el grado de desarrollo de la teoría, ¿se pretende el contraste o la generación de una teoría?

- ¿Cuál es el propósito de la investigación, descriptivo, explicativo o predictivo?

- ¿Cuántos casos se deben estudiar?

- ¿Puede plantearse la existencia de subunidades de análisis? 
En el apartado anterior se justificó la decisión de generar una nueva teoría a través de la realización de una investigación basada en un estudio de casos de tipo explicativo. Según Montoro (2002), este tipo de estudio resulta interesante por el efecto de cada uno de los factores del tipo predictivo (variables independientes), sobre el fenómeno resultante (variable dependiente, en nuestro caso, la competitividad del sector).

Para Bonache (1998) el objetivo de los casos explicativos es construir o depurar teorías. Según este autor, tienen una larga tradición e influencia en la literatura de organización, resultan muy interesantes para aquellas áreas de conocimiento que todavía tienen carácter descriptivo facilitando la comprensión del por qué, el cómo y el cuándo, y son los que mejor complementan y enriquecen la metodología cuantitativa.

Siguiendo a Bonache (1998) las características distintivas de los casos explicativos serían:

- No separar el fenómeno del contexto. El contexto y el comportamiento son interdependientes.

- Parten de un modelo menos teórico que los estudios cuantitativos. Tratan de construir teorías a partir de las observaciones siguiendo un procedimiento inductivo.

- La elección de los casos tiene carácter teórico y no estadístico. Los casos deben elegirse por su capacidad explicativa.

- Tiende a utilizar más métodos o fuentes de datos. Las entrevistas, la observación, las grabaciones o las transcripciones son técnicas utilizadas.

- Flexibilidad en el proceso de realización de la investigación. En los casos, a medida que se descubren nuevos hechos, se pueden cambiar los supuestos teóricos iniciales y desarrollar otros nuevos.

- Inducción analítica, no estadística. Los casos explicativos se basan en la inducción analítica, que infiere hipótesis o generalizaciones teóricas a partir del análisis de campo.

Por lo tanto, este será el tipo de estudio a realizar ya que, se ajusta perfectamente a los objetivos que se pretenden alcanzar con la realización de esta tesis doctoral.

\subsubsection{La unidad y el nivel de análisis.}

La correcta definición de la unidad de análisis es una cuestión de vital importancia que puede llegar a desvirtuar los resultados de cualquier investigación. Se trata de cumplir con el objetivo de determinar una nítida demarcación del fenómeno a investigar.

Yin (1989) afirma que debe primar el sentido común. En este sentido, la correcta unidad de análisis debe ser sensible a las particularidades del objetivo de la 
investigación y del marco teórico, facilitando en todo momento las comparaciones con estudios similares.

Por otro lado, si durante el análisis se detectan en el interior de un caso la existencia de entidades con capacidad explicativa propia, se debe diferenciar entre dos posibles situaciones. $O$ bien, la unidad de análisis ha sido definida de forma incorrecta, pues hay unidades de orden inferior que pueden aportar mayor grado de significación, o bien, el caso contrario. En el primer supuesto, se reformulará todo el diseño de la investigación, mientras que en el segundo caso, se tendrá en consideración que estamos ante un diseño de uno o varios casos con subunidades.

\subsubsection{La selección de los casos. Caso piloto.}

Una vez realizada la especificación de la unidad de análisis, se debe proceder a seleccionar el caso o casos que vamos a estudiar. Esta tarea exige determinar cuántos casos se necesitan para la investigación y cuáles son los criterios de elección o requisitos que vamos a aplicar.

Con respecto al número de casos que deben constituir este tipo de estudios:

- Rialp (1998), afirma que la selección de los casos se debe realizar de forma que los seleccionados ofrezcan una mayor oportunidad de aprendizaje. Citando a Eisenhardt (1989), recomienda el manejo de un número de casos ni inferior a cuatro ni superior a diez.

- Pérez, W. (1998) indica que cualquiera que sea el criterio elegido, el número de casos siempre resultará ser inferior al número de variables utilizadas. Citando a Yin (1981), indica que el número de casos puede variar de uno a ocho.

- Bonache (1999), afirma que la certeza en este tipo de estudios se puede obtener después de un pequeño número de casos, pero no se indica cuántos ya que, según el autor, esto es una cuestión de discrecionalidad.

Se debe tratar de aislar las condiciones suficientes y necesarias para explicar y predecir un fenómeno, para poder dar así por concluida la investigación.

Los casos pueden ser elegidos de forma aleatoria, pero esto no es estrictamente necesario ni deseable. En este sentido, el número de casos debe adecuarse lo más posible al objetivo de la investigación y al marco teórico . Los casos deben ser elegidos para replicar casos previos o extender la teoría emergente o bien para recoger categorías teóricas y proporcionar ejemplos extremos. A este respecto, nos encontramos con que no hay criterios definidos para determinar el número de casos necesarios. Así, existen opiniones para todos los gustos. Mintzberg (1979) afirma que no importa lo pequeña que sea la muestra, o bien Yin (1989) comenta que el número ideal de casos puede variar de uno a ocho. 
Dado que algunos de los elementos de la investigación pueden necesitar información que no esté disponible en etapas anteriores, se suele determinar un caso piloto sobre el que se desarrolla un estudio previo. Este estudio proporcionará información sobre los aspectos más relevantes, ayudará a refinar los procedimientos a seguir, clarificará cuestiones no planteadas previamente, estructurando en todo momento el análisis del resto de los casos y conformando un prototipo de estudio que se formalizará en el protocolo.

La selección del caso piloto se realizará aplicando criterios de relevancia y de posibilidad de mantener una relación más estrecha y prolongada durante la investigación.

\subsubsection{El protocolo de cada caso.}

Establecer un protocolo del caso consiste en especificar todos los pasos que se han seguido en la elaboración del mismo. Rialp (1998) define el "protocolo formal" como aquel instrumento que aumentará la fiabilidad del estudio al hacer explícitas tanto las cuestiones relevantes como los procedimientos a utilizar y las reglas a seguir en la recogida de datos, sobre todo cuando el diseño de la investigación se realiza mediante casos múltiples.

Pérez (1998) establece una serie de pasos para realizar el protocolo de actuación en un estudio de casos, que se detallan a continuación. Para este autor, el protocolo debe contener las reglas generales y las especificaciones particulares que se deben seguir, siendo un documento esencial cuando el estudio incorpora varios casos. El autor manifiestas que es preciso contar con dos características:

- Fuentes de evidencia y procedimientos de recolección de datos. Según Pérez (1998), conviene determinar con anticipación cuáles van a ser las fuentes de evidencia así como los procedimientos de recolección de datos.

- Análisis de la evidencia del caso. Esta etapa consiste, según este autor en "examinar, categorizar, tabular o recombinar la evidencia de modo que tienda hacia el cumplimiento de los objetivos de la investigación", siendo esta etapa la más importante del estudio (Eisenhardt, 1989).

\subsubsection{El informe general y la generalización de los resultados.}

El informe general es el documento en el que se recogen los resultados y conclusiones del estudio de casos. Suele consistir en una larga narración que no presenta una estructura predecible. En todo caso, se debe ajustar a la estrategia seguida en la investigación (Pérez, 1998).

Según se indica en diversos manuales sobre estudios de casos consultados (Rialp, 1998; Pérez, 1998), no existen reglas explícitas que guíen la presentación del informe relativo al estudio. Cuando el estudio recoge varios casos caben diversas maneras de presentar cada caso individual, de forma completa o resumida utilizando tablas y cuadros conceptuales. 
A fin de conseguir una mejor estructuración del informe se propone que este parta de las proposiciones teóricas que conducen el estudio. En tal caso, se dispondrá de secciones para cada una de las cuestiones discutidas, donde se señalaran los aspectos más relevantes del marco teórico, los análisis realizados, los resultados obtenidos y las conclusiones alcanzadas (Yin, 1994; Tellis, 1997a).

Quizás, de entre las diversas tácticas de investigación, la más utilizada sea el examen de los patrones de comportamiento. En este caso:

- Se aportan referencias suministradas por marco teórico.

- Modificaciones hechas a partir del caso piloto.

- Medidas elegidas, valores hallados, necesidad de buscar nuevas evidencias, verificación o refutación y reformulación del patrón.

Por último comentar que, el estudio de casos es una estrategia de investigación inductiva, en la que se pretende establecer conclusiones generales a partir de hechos y circunstancias particulares (Hamel et al., 1993).

En este sentido, conviene recordar que los casos estudiados, igual que los experimentos, no representan elementos de una muestra, sino el estudio de un fenómeno bajo diferentes circunstancias escogidas.

No obstante, la generalización se puede realizar mediante la especificación de reglas de inferencia, que tendrán su justificación tanto en el marco teórico como en la teoría emergente, en la selección de los casos y en el número de replicaciones realizadas. De esta manera, si los casos seleccionados son muy homogéneos, los límites de la generalidad serán menores que si hubiéramos elegido casos más extremos.

\subsection{Diseño específico de la investigación.}

Se ha optado por una estrategia metodológica de análisis de casos que permitan testar el modelo de implantación y las hipótesis de trabajo esbozadas en el capítulo 3.

El "trabajo de campo" se ha desarrollado sobre el estudio de los procesos de selección e implantación de Sistemas Avanzados de Gestión en 30 empresas del sector textil-hogar y las 18 consultoras asociadas a éstas, implantadoras de los sistemas. Las empresas textiles han sido seleccionadas para que cubran los distintos subsectores del mismo, como son: hilatura, tejeduría, acabados y confección, debido principalmente, a que las necesidades de gestión empresarial de las empresas de cada uno de los subsectores son muy diferentes. 
Tanto las empresas textiles como las consultoras han jugado un papel fundamental en la investigación:

- Las primeras han aportado la experiencia que puedan haber tenido en el campo de los sistemas de gestión, facilitando la toma de datos para determinar cuales son las necesidades que les han llevado a elegir un ERP como sistema avanzado de gestión.

- Por su parte, las consultoras han aportado su experiencia en el campo de la implantación de sistemas de ERP. Este apartado es muy importante, porque estas aplicaciones no están lo suficientemente desarrolladas y la información referente a las mismas es escasa, por lo que las experiencias y conocimientos en otros sectores ha sido muy importante para la correcta implantación de sistemas ERP en las empresas del sector textil/confección.

Para poder llevar a cabo esta investigación, se han mantenido una serie de contactos y reuniones, tanto con empresas textiles, como con consultoras de software implantadoras de soluciones ERP, con la finalidad de generar una base de datos y conocimiento:

Con las primeras se ha realizado un mínimo de tres reuniones (entre 3 y 5), de las que se han extraído conclusiones a cerca de varios puntos, como:

- las experiencias anteriores que hayan tenido en implantaciones de ERP's.

- los procesos seguidos para la selección del ERP.

- las funcionalidades recomendadas o que consideran más importantes para cada empresa.

- información referente al estudio y seguimiento de la implantación de los distintos sistemas ERP's en las empresas adheridas al proyecto.

Con las consultoras, el grupo de investigación también ha mantenido un mínimo de tres reuniones, extrayendo información como:

- funcionalidades y características de los productos que comercializan.

- metodologías de implantación utilizadas.

- experiencias en implantaciones en empresas textiles.

- otros factores de importancia de estos sistemas avanzados de gestión.

En las entrevistas se han utilizado varios cuestionarios de estructura semicerrada (ver ANEXO 2), unos específicos para las reuniones con empresas textiles (cuestionario primera visita, cuestionario diagnóstico empresa, cuestionario buenas prácticas), y otros diferentes para las reuniones con consultoras de software (cuestionario primera visita, cuestionario de metodología de implantación, cuestionario buenas prácticas). El número de entrevistas para cada empresa ha sido variable (entre 3 y 5 ), dependiendo de su situación: fase de introducción del sistema, tamaño, complejidad de los procesos, etc. Además, se ha configurado 
una base de datos para registrar la información conseguida y que ha permitido elaborar una tipificación de dichas soluciones.

Adicionalmente, se han desarrollado cuatro casos, habiéndose perfilado el primero de ellos como caso piloto.

Por lo que respecta al análisis de la evidencia del caso, en esta Tesis Doctoral:

- Se ha seguido el "examen de patrones o pattern matching", que determinará la validez interna de la investigación realizada (Yin, 1998). Este procedimiento se basa en la comparación de un patrón empírico con otro preestablecido (Rialp, 1998).

- Se han utilizado instrumentos existentes que miden los fenómenos estudiados.

- Se ha construido una base de datos con toda la información recopilada así como con las transcripciones de las entrevistas realizadas.

La metodología de selección e implantación de Sistemas Avanzados de Gestión validada y mejorada en base al trabajo de campo anterior ha sido utilizada en tres empresas del sector y se ha depurado y personalizado para cada una de ellas obteniendo como resultado final la aportación más valiosa de esta investigación.

En esta Tesis se presentará cada caso de forma resumida utilizando tablas y cuadros conceptuales y, dado que la utilización de la técnica de validación interna exige que los patrones de comportamiento saquen a la luz los aspectos clave diferenciadores, se estructurará el informe en torno a las diferentes variables analizadas, tal y como propone Pérez (1998).

Las fuentes de evidencia utilizadas y los procedimientos de recolección de datos han sido:

- Los informes anuales de la empresa, información disponible en la base de datos $\mathrm{SABI}$, que recoge el balance de situación, la cuenta de pérdidas y ganancias, entre otros datos contables y de explotación.

- Información sobre situación del sector, datos importación/exportación.

- Datos sobre comercio exterior facilitados por el IVEX, Instituto Valenciano de Comercio Exterior.

- Diversos estudios sobre el sector textil publicados por AITEX, Instituto Tecnológico del Textil.

- Catálogos de productos editados por la propia empresa.

- Entrevistas estructuradas de respuestas abiertas. 
En la tabla 5.5, se indica la persona entrevistada en función de los conceptos y variables a estudiar así como el método y la herramienta utilizada para estructurar la entrevista.

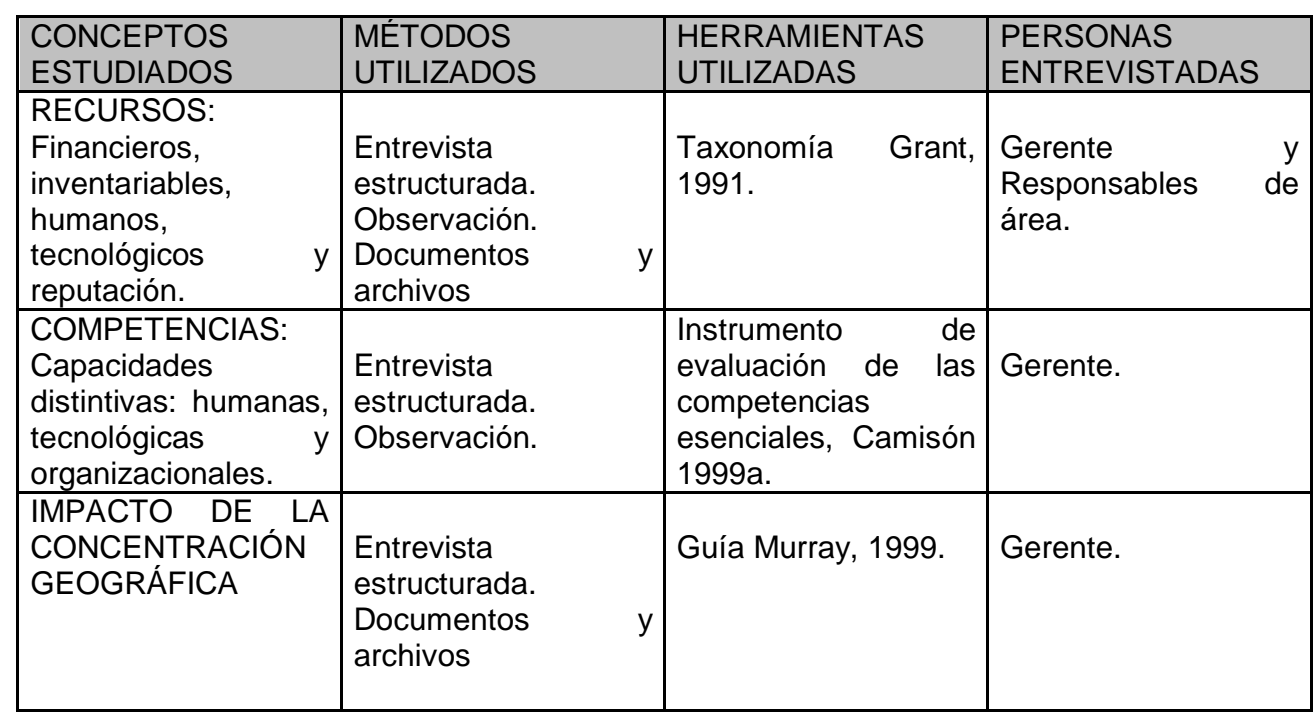

Tabla 5.5: Conceptos, métodos, instrumentos y personas entrevistadas en cada empresa. 


\section{ANALISIS DE RESULTADOS}

\subsection{Introducción.}

En primer lugar, en este capítulo de análisis de resultados se va a contrastar el modelo planteado en el capítulo tres, acerca de la metodología de implantación, posteriormente se focaliza en las primeras etapas que abarcan hasta la selección de la solución ERP (punto 6.3), al haberse constatado durante la investigación que son vitales para el éxito del proyecto en su conjunto, para acabar comprobando la consistencia de los factores críticos que se dan en la implantación de sistemas ERP mediante su evaluación en cuatro casos prácticos.

Las fuentes del análisis han sido, tal y como se cita en el capítulo que aborda la metodología, y queda reflejado en la figura siguiente; las entrevistas realizadas a 30 empresas textiles y 18 consultoras de implantación más el estudio de casos realizado en cuatro empresas textiles, incluyendo un planteamiento interactivo de testeo de la metodología de implantación en tres empresas prototipo.

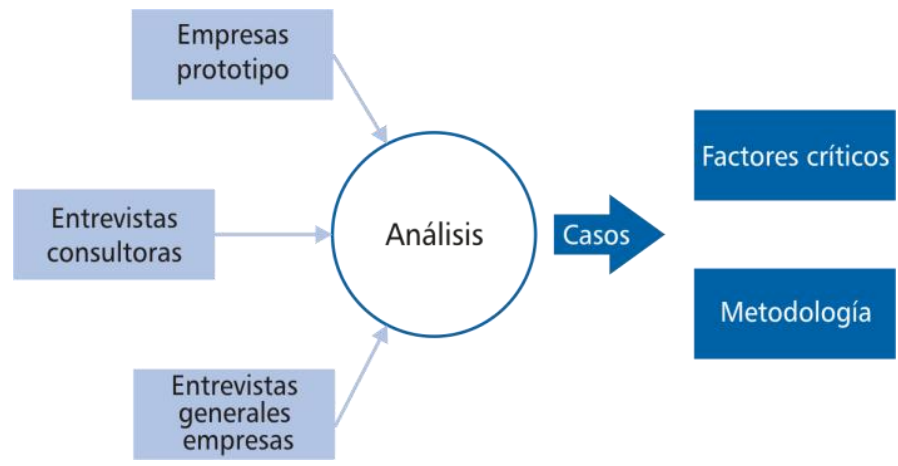

Figura 6.1: Fuentes de análisis.

\subsection{Test del modelo.}

Tal y como es habitual en la metodología cualitativa, los métodos y procedimientos empleados han permitido corroborar el modelo planteado, al mismo tiempo que han permitido elaborar nuevos constructos teóricos tanto al considerar los factores críticos de éxito que se dan en el proceso de implantación, como al analizar las primeras fases de selección de la solución.

El modelo propio elaborado para la adecuada implantación de un ERP permite distinguir las siguientes etapas: la definición de la estrategia, la implantación del ERP y la fase de post-implantación (Gable, Scott J.E, y Davenport, 1998;Mabert, Soni y Venkataramanan, 2002;Ross y Vitale, 1998). 


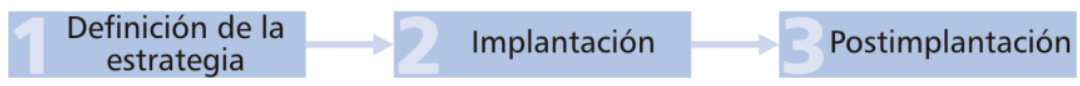

Figura 6.2.- Fases de un proyecto ERP.

Las diferentes entrevistas realizadas (ver ANEXO 2) tanto a las 30 empresas textiles como a las 18 empresas consultoras han permitido validar el modelo en sus distintos componentes. Estableciéndose además las siguientes hipótesis de trabajo y necesidades, que han dado lugar a diversos resultados:

- La necesidad de tipificar las diferentes soluciones existentes en el mercado, estableciendo un elenco demostrativo de las diferentes funcionalidades en todos los ámbitos de la organización. (ANEXO 3, Tipificación de 16 soluciones y 18 empresas consultoras).

- La fase inicial "definición de la estrategia" incluye el proceso que debe seguir una empresa desde que se plantea la necesidad de un sistema ERP hasta que elige un producto y contrata a un proveedor. El estudio sobre metodología de implantación se ha centrado en esta etapa al considerar que en la mayoría de las empresas analizadas resultaba decisiva para el éxito posterior del proyecto.

- La segunda etapa, denominada implantación del ERP contempla las actividades propias de su nombre así como las diferentes alternativas que existen. Por último, en la fase de postimplantación se incluyen aquellas actividades posteriores a la puesta en marcha del sistema, necesarias para completar con éxito la ejecución del proyecto. Todas estas etapas han sido contempladas en el estudio de casos y se ha percibido la influencia de los factores críticos de éxito a lo largo de todo el ciclo de vida de la gestión del proyecto. El modelo relacional de factores críticos se ha revisado, complementado y ampliado.

\subsection{Análisis de la estrategia de selección: un prototipo.}

En este apartado se analizan con detalle las fases de la primera etapa metodológica: "Definición de la Estrategia", para la implantación de una solución ERP en una empresa textil, que fue definida en el apartado 3.2. A partir de las definiciones previas esbozadas en el modelo, de las entrevistas y experiencias obtenidas durante el trabajo de campo con las diferentes empresas y consultoras, y del trabajo de campo realizado en tres empresas piloto, se ha revisado y ampliado el estudio de dicha fase elaborando herramientas prácticas que pueden ser utilizadas directamente (con la conveniente adaptación) por las empresas. Se tiene pues como objetivo fundamental, la correcta definición de la problemática del sistema de información, mediante el establecimiento de los objetivos organizativos y la operativa del trabajo en equipo. Además, se consideran otros aspectos adicionales relevantes para una adecuada selección de una consultora y solución ERP permitiendo profundizar en el análisis de los factores críticos del modelo: "Idoneidad de la solución ERP” y "Fijación de objetivos y planificación" 
La siguiente figura ilustra el esquema general de la metodología propuesta a realizar para la fase de "Definición de la Estrategia" (Apartado 3.2). Cada uno de los aspectos citados ha sido ampliado metódicamente en la empresa piloto del estudio.

Durante estas etapas, las empresas pueden precisar de un asesoramiento externo que colaborará con el personal de la propia empresa hasta el punto cuatro del itinerario: "Seleccionar el ERP". A la empresa le corresponde realizar las entrevistas con la terna de consultoras propuestas y llevar a cabo después a la elección y contratación.

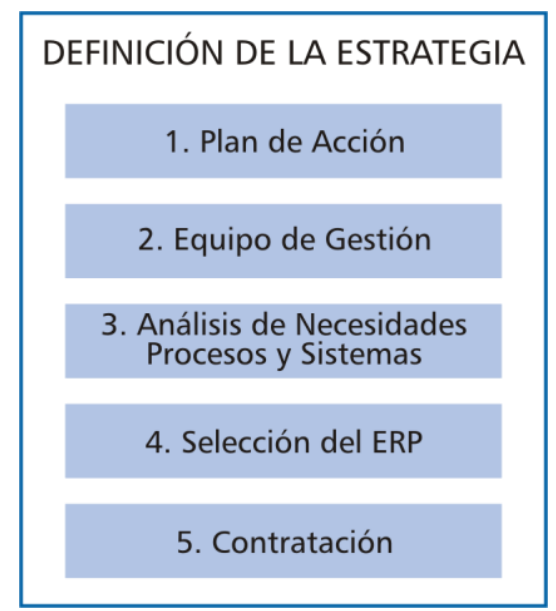

Figura 6.3.- Definición de la estrategia.

\subsubsection{Metodología de trabajo.}

Es preciso comentar, que todas las empresas piloto son de tamaño mediopequeño y se encuentran dedicadas al subsector de tejeduría. Este apartado presenta información particularizada de una de las empresas piloto ${ }^{1}$ y aquellas áreas funcionales que se han considerado representativas para esta empresa.

De acuerdo con la figura anterior y con el modelo propio, las fases a considerar son las siguientes:

1. Elaboración del Plan de Acción.

2. Selección del Equipo de Gestión.

${ }^{1}$ El estudio ha sido desarrollado en tres empresas piloto, en el resto del capítulo se hace mención genéricamente a la empresa piloto o prototipo. 
3. Análisis de Necesidades: referente a los procesos y resultado del análisis de los sistemas de información.

4. y 5. Selección de la solución ERP y contratación.

\subsubsection{Descripción de las Fases}

\subsubsection{Plan de acción}

Ha sido definido con base en las entrevistas y la observación directa llevada a cabo durante las visitas a la empresa. Se han realizado un promedio ocho visitas en las que se ha podido conocer de primera mano los procesos de negocio y realizar entrevistas con el director gerente, el director de producción, la directora de administración y comercial, así como con la persona responsable del mantenimiento de los sistemas informáticos.

1. Alcance del Proyecto:

En primera instancia, la gerencia de la empresa, de acuerdo con todos los responsables y mandos intermedios pretende la sustitución del actual Sistema de Información por una solución que integre todas las áreas funcionales de la empresa y que proporcione información en tiempo real, de forma que cualquier modificación quede reflejada de manera inmediata. Existe también una preocupación por la obsolescencia del actual sistema y su difícil adaptación a futuras innovaciones tecnológicas.

2. Objetivos del Nuevo Sistema.

Los objetivos que se pretende conseguir por medio de la implantación del nuevo sistema se ha considerado que debían quedar claros y compartidos por un gran número de personas dentro de la organización. De todas formas, no se puede obviar la influencia que tiene el director gerente a la hora de fijarlos. Se ha tenido en cuenta las consideraciones realizadas en el modelo propio respecto al factor crítico: "Fijación de objetivos y planificación". Los objetivos considerados son los siguientes:

- Sistematización y mejora de los procesos del departamento de Producción.

- Mejora en la toma de decisiones de programación en la ejecución de los lotes.

- Gestión de la capacidad productiva propia y subcontratada.

- Incremento en la fiabilidad de la información que resulta de las operaciones.

- Gestión eficaz de los almacenes de materias primas, producto en curso y producto terminado.

- Integración de todas las áreas funcionales de la empresa. Mejora del flujo de información y de la comunicación entre ellas.

- Eliminación de papeleos innecesarios, duplicidad de tareas y mejora de la organización en general. 
- "Seguridad" en el retorno de la inversión.

3. Principales necesidades de integración en los procesos y departamentos y sistemas. Procesos críticos:

a. Integración de los procesos de Fabricación:

Planificación

- Programación de Fabricación con base en la Gestión Comercial y el programa de ventas.

- Gestión de Compras y el programa de Compras.

- Planificación y control de fabricación.

- Seguimiento de plazos de entrega y envíos.

Fabricación

- Órdenes de Fabricación, cargas operarios, carga de máquinas, cargas de sección (planificación de la planta), costes estándares, costes reales, control de horarios de producción, gestión de materiales, gestión de subcontración, control de calidad de: materias primas, telares, repasado, producto terminado.

- Posibilidad de conocer permanentemente la situación exacta de cualquier pedido. Trazabilidad automatizada, en Almacén la medida de lo posible por código de barras.

- Gestión de inventarios, control de lotes, logística y expediciones. Se debe basar en reservas para atención de pedidos, el lote económico y en el control y seguimiento de materia prima recibida, la recepción y devolución de materiales (aprovisionamiento de materias primas).

- Conocimiento exacto de la situación de los diferentes almacenes y de su evolución.

b. Estos subprocesos integrados con Gestión Administrativa y Contable en dos puntos:

- Facturas de clientes: Gestión administrativa de ventas(proveedores).

- Facturas de proveedores: Gestión administrativa de Compras.

4. Posición actual de la situación informática:

\section{Hardware:}

16 PC, 1 portátil.

2 Redes.

Windows y Novell.

Impresoras 8. Laser. 


\section{Software:}

Office, EDI(Ediwin),

Desarrollos a Medida: (7 años). Documentación : NO. Fuentes: SI. 300 archivos.

Pedidos Clientes, Facturación, Control

Almacenes(materias primas, productos en curso y producto acabado) . Contabilidad, Registros

( Proveedores, Clientes, Transportes)

Conexión a EDI: Albaranes y Facturas.

Gestión de Producción. Confección. Necesidades de Producción.

Informatizado los procesos de Pedidos a empresas de servicios ( fechas de entrega, etc) entrada de datos no.

Lenguaje: Basic Compilado. Rutina de tratamiento de archivos secuenciales indexados Btrieve.

5. Nuevas oportunidades tecnológicas:

Compra prevista de máquinas Jackard electrónicas de mayor capacidad, pero dotadas de una tecnología similar.

6. Infraestructura prevista:

5 ordenadores personales (uno de ellos realiza las funciones de servidor)

Red Ethernet.

Solución ERP.

7. Implicaciones para el personal.

Formación Básica de Informática.

Formación en el uso de la solución.

8. Esquema del plan de documentos a entregar:

Identificación de procesos críticos.

Inventario del equipo informático actual.

Inventario de aplicaciones informáticas.

Valoración de Necesidades de Procesos y Sistemas.

Lista de Criterios para evaluar una solución ERP.

9. Costes previstos y/ o previsión presupuestaria.

Este punto se basa en la información que tenemos de las propuestas de las consultoras a empresas de una dimensión y problemática similar y creemos que el presupuesto oscilaría en los siguientes rangos:

Hardware: [6.000-8.000] euros

Solución: [24.000-50.000] euros

Consultoría: [24.000-40.000] euros 
10. Riesgos:

Resistencia al cambio.

Fracaso en la implantación.

Las actividades realizadas en la empresa piloto han sido:

Reunión preliminar para la determinación de los objetivos del proyecto y la identificación de interlocutores son la correspondiente asignación de roles.

Reuniones de trabajo por área.

Estudio y redacción del informe.

Presentación y entrega del informe preliminar de Consultoría de Alcance del Proyecto.

Véase el ANEXO 4.1: Formato de definición del Plan de Acción.

\subsubsection{Equipo de gestión del proyecto}

Una vez determinados los objetivos del Proyecto, es fundamental determinar las personas que son responsables de los procesos críticos para la empresa y que por su capacidad, disponibilidad y nivel de información pueden formar parte del Equipo de Gestión del Proyecto.

Sobre estas personas se deben realizar acciones formativas que permitan dar a conocer la naturaleza de los sistemas integrados de gestión, sus beneficios e inconvenientes.

En la empresa piloto este equipo ha estado formado por las personas que ocupan los siguientes cargos:

Empresa:

- Gerente.

- Director de Calidad y Producción.

- Administración Financiera.

- Responsable de informática.

Consultoría Externa:

- Consultor de procesos de negocio.

- Consultor técnico informático.

Se ha desarrollado como herramienta susceptible de poder ser utilizada en cualquier empresa el ANEXO 4.2: Formato para la definición del equipo de gestión. 


\subsubsection{Análisis de necesidades de la empresa}

Una vez determinado el Alcance y el Equipo de Gestión del Proyecto, se tiene como objetivo fundamental el conocimiento en detalle de los requerimientos y necesidades de la empresa piloto. Para lo cual, se realiza un exhaustivo análisis de Procesos y Sistemas de Información.

\section{Estudio de Procesos:}

El análisis de procesos Principales y Críticos: tiene por objetivo determinar los procesos principales, críticos, los responsables de cada proceso y las actividades de cada proceso a un nivel general de detalle.

Se identifican en la empresa dos áreas significativas: Administración y Producción. (ver figura 6.4). Los procesos y subprocesos se mencionan a continuación. La descripción y diagrama de flujo correspondiente se encuentra detallado en el ANEXO 5: Descripción de los procesos de negocio.

Administración: Funciones más relevantes:

- Gestión Administrativa de ventas (clientes).

- Gestión Administrativa de compras (proveedores).

- Gestión de Atención al cliente.

- Contabilidad.

Producción: Procesos a considerar:

- Aprovisionamiento de Materias de Primas.

- Fabricación.

- Control de subcontratas y recepción de producto acabado.

- Servicio "color".

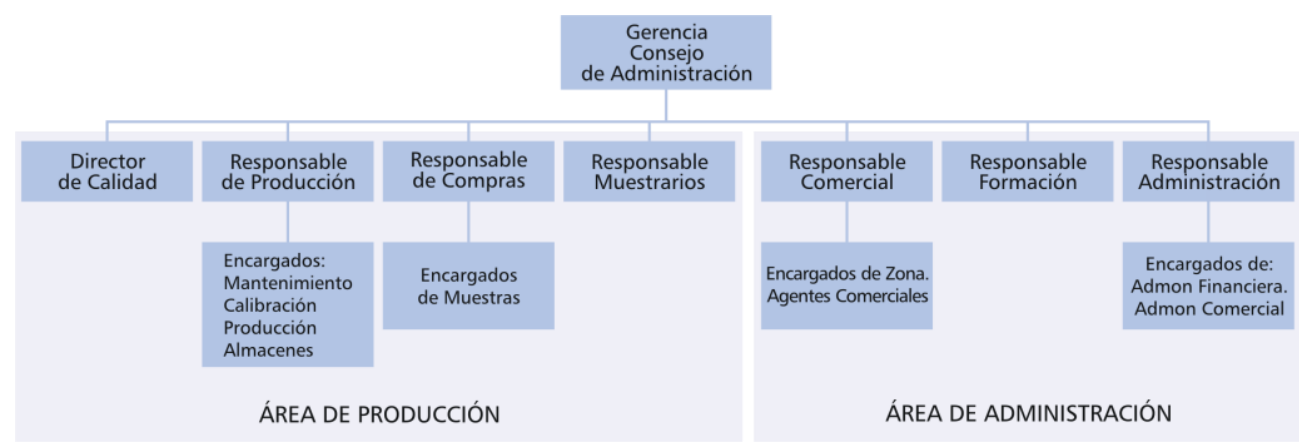

Figura 6.4.- Organigrama funcional de la empresa. 
Estudio de los Sistemas de Información:

En el sistema de información de la empresa se han considerado los siguientes aspectos:

- Aplicaciones existentes.

- Inventario del equipo informático.

- Procesos sistematizados.

- Flujos de información básicos de la empresa.

En auditoria de los sistemas de información e informáticos existentes en la empresa: características, prestaciones, componentes, etc. se analizan los siguientes elementos:

- Recursos humanos.

- Sistemas informáticos/hardware.

- Parámetros de configuración: lenguajes de desarrollo, ficheros maestros, ejecutables, etc.

- Funcionalidades que proporciona el sistema informático actual en el área administrativa y de producción/operaciones.

- Módulos.

- Procedimientos.

- Requerimientos del sistema de información futuro.

- Conclusiones

Véase el ANEXO 6.1: Análisis de Sistemas de Información.

Estudio de Flujos de Información y Comunicación Interdepartamental.

La empresa se encuentra dentro de un grupo industrial formado por las empresas A y $B$ que tienen repartidas la distribución comercial, de acuerdo con el siguiente gráfico.

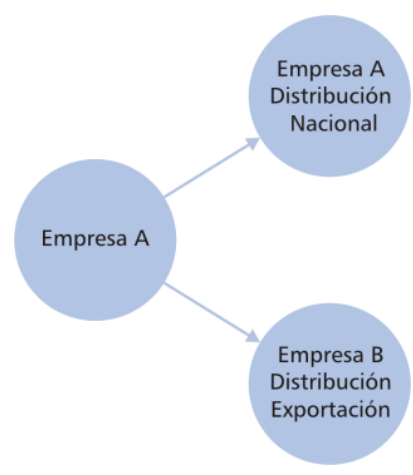

Figura 6.5.- Flujos de información en la empresa. 
A continuación se presenta el desarrollo del flujo de información existen en el proceso de Gestión de pedidos. Recepción:

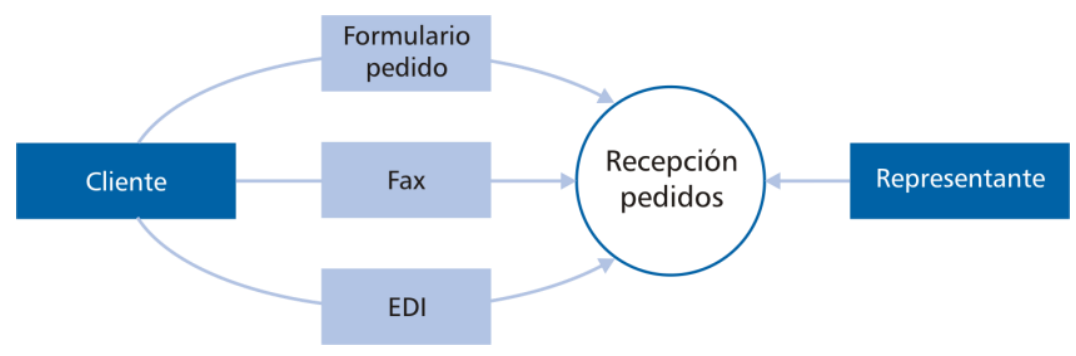

Figura 6.6.- Flujos de información en la gestión de pedidos.

La recepción telefónica de pedidos exige cumplimentar un formato manual (formulario de pedido). Los pedidos se procesan en batch agrupados diariamente. Algunos de los datos que se registran son: persona de contacto que ha realizado el pedido, número de pedido, referencia, color, número de metros, etc.

Por teléfono el cliente puede realizar también consultas sobre el plazo de servicio y proceder a anular elementos del pedido.

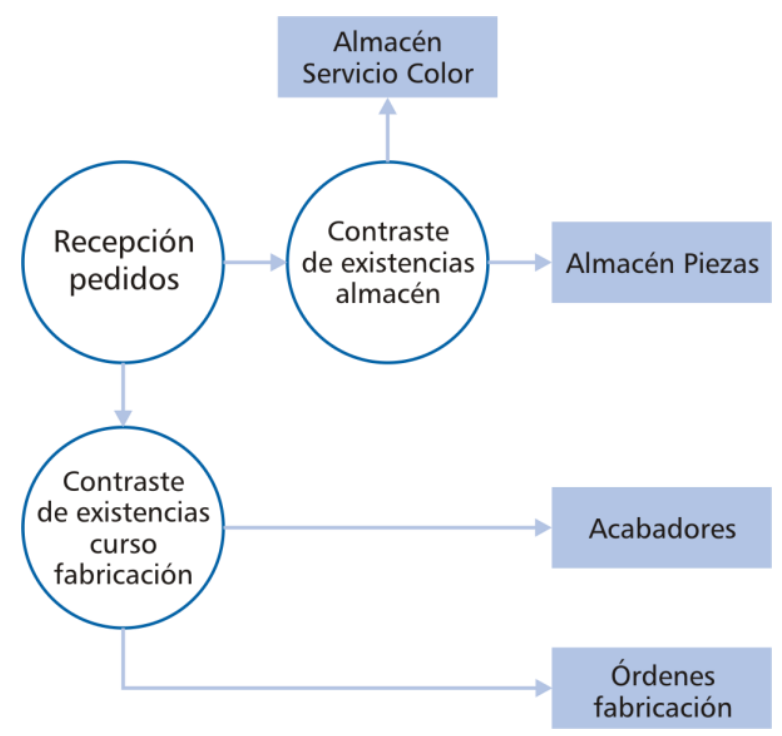

Figura 6.7.- Atención telefónica al cliente. 
A continuación consideramos que la empresa piloto presenta en resumen los siguientes flujos de información entre las áreas administrativas y de producción.

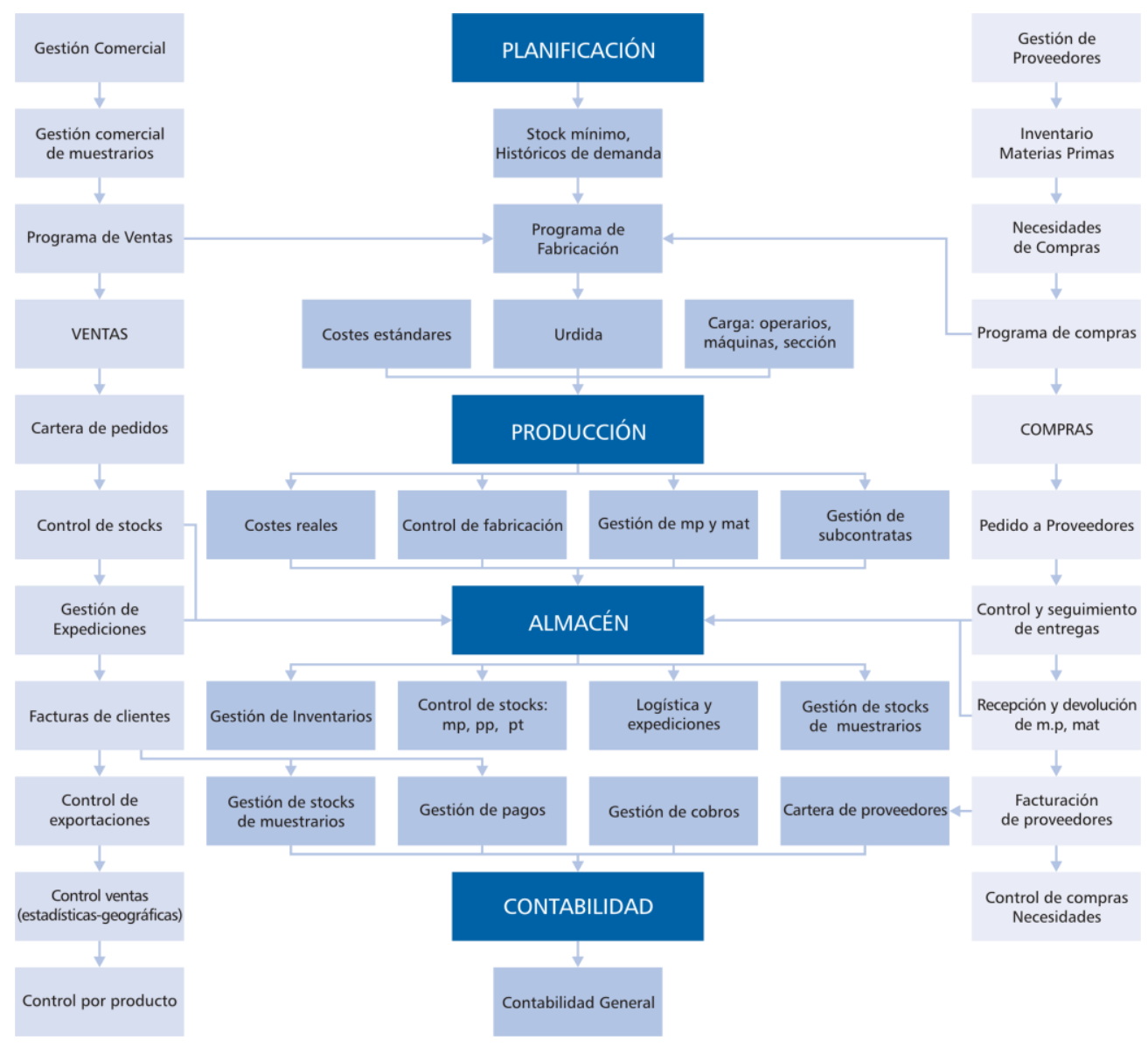

Figura 6.8.- Flujos de información interdepartamental

Por último se tienen que plasmar los requerimientos y necesidades de la empresa piloto en documento, véase el ANEXO 6.2: Lista de requerimientos solicitados a los proveedores de soluciones ERP.

El futuro sistema de información debe contemplar:

- Un sistema con interfaces gráficas mejoradas (ergonomía), abierto, que pueda ser soportado por otras empresas.

- Se requiere una actualización del lenguaje de desarrollo.

- Se necesita una integración del sistema de fabricación con el de gestión.

- Sistema de Información único para todas las líneas de negocio, que permita la consolidación a nivel de Empresa 
Las funcionalidades de la solución ERP necesarias en los diferentes departamentos son:

Área administrativa:

La nueva solución ERP debe proporcionar prestaciones similares a las ya existentes. Se corre el riesgo que la satisfacción de los usuarios con la solución informática en esta área se convierta en un elemento de inercia que incremente la resistencia al cambio dentro de la organización, actuando los sistemas informáticos como un elemento de anclaje.

Se precisa que la toma de datos se realice directamente en fábrica y no se traslade en modo batch al área administrativa.

Área de Producción/Operaciones:

Mejora de la calidad proveniente del control de procesos.

Flexibilidad. Posibilidad de cambiar la configuración de todo el Sistema de Información si es necesario porque la situación del entorno así lo requiere.

Capacidad para calcular los costes y tiempos de producción permitiendo tomar decisiones basadas en datos reales.

Disminución de espacio de almacenamiento.

Optimización de recursos productivos (mano de obra, telares, subcontratación, etc)

Reducción del número de defectos.

Gestión de costes y plazos de entrega de los talleres externos (ennoblecimiento)

Disminución de inventario. Permitiendo la reorganización de los almacenes.

Se requiere que el sistema informático proporcione información que ayude a la programación de la producción a partir de los pedidos realizados y los stocks disponibles. Incluso que puede realizar el lanzamiento de las órdenes de fabricación.

No se lleva un control en tiempo real de lo producido. Es preciso realizar una toma de datos en planta. Esta situación es problemática dada la necesidad de trabajar con lotes de fabricación cortos.

Es necesario llevar un seguimiento de la "trazabilidad" entre la materia prima y el producto terminado. Este se lleva a cabo de forma manual.

Sería útil llevar un control de sobrantes.

Mejora de la satisfacción del cliente.

Gestión de proveedores, realizando una "lista de proveedores aprobados".

Informatización del Control de Calidad.

Actualización del escandallo de productos.

Cambio de unidades, estableciendo la posibilidad de trabajar simultáneamente con piezas y metros. 


\subsubsection{Selección de la Solución ERP y contratación.}

La selección de la solución ERP es uno de los apartados de más trascendencia para el éxito de un proyecto ERP, por ello el contraste del modelo con la empresa piloto se ha demostrado que los aspectos que a continuación se detallan son los que aportan mayor garantía de éxito:

- Tipificación de la empresa

- Criterios de evaluación

- Mercado de Consultoras

- Funcionalidades especificas para el sector texil

- Soluciones ERP

- Evaluación. Demostraciones, visitas y Contraste de referencias

Es preciso preparar al equipo del proyecto, en lo relativo al proceso de selección de la solución ERP. El proceso de selección puede convertirse en una oportunidad para el planteamiento de la evolución de los procesos de la organización, pero sin que ello implique perder el enfoque estratégico de la implantación de la solución ERP.

A continuación se presenta de forma detallada la tipificación de la empresa, la elaboración de una lista de criterios ponderados que sirvan para puntuar entre las diferentes alternativas, el análisis de empresas de consultoría y el análisis de las soluciones ERP existentes, para así poder determinar la consultora que cumple en mayor medida con las exigencias de la empresa.

Estos elementos se pueden representar en la siguiente figura 6.9:

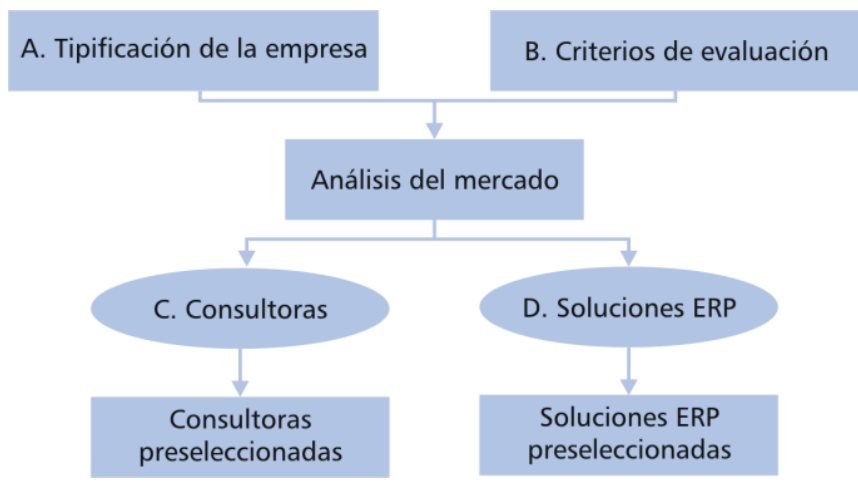

Figura 6.9.- elementos de selección de una solución ERP 
Tipificación de la empresa.

El primer aspecto a considerar es la clasificación de la empresa piloto en base a los resultados y conclusiones obtenidos en el "análisis de procesos y de sistemas de información". Para ello, se establecen criterios organizativos, tecnológicos y económicos que, de forma orientativa, permitan incluir la empresa dentro de una categoría de empresas con características similares, que van a condicionar el tipo de solución ERP a seleccionar.

Para la clasificación de la empresa se ha desarrollado una tabla de autoclasificación (ver tabla 6.1). La empresa piloto se puede autoclasificar como empresa de tipo A: Tiene 6 criterios de tipo A, y 4 criterios tipo B.

\begin{tabular}{|c|c|c|c|}
\hline $\begin{array}{l}\text { CATEGORÍA } \\
\text { CRITERIOS }\end{array}$ & TIPO A & TIPO B & $\begin{array}{l}\text { EMPRESA } \\
\text { PROTOTIPO }\end{array}$ \\
\hline ORGANIZATIVAS & \multirow[b]{2}{*}{$(1-25)$} & \multirow[b]{2}{*}{$(>25)$} & \multirow{2}{*}{28} \\
\hline Número de trabajadores & & & \\
\hline Volumen de información & Baja & Alta & Alta \\
\hline Número de procesos a controlar & $(10-50)$ & $(51-100)$ & 10 \\
\hline Número de unidades funcionales & $(3-15)$ & $(16-30)$ & 10 \\
\hline TECNOLÓGICOS & \multirow{2}{*}{$(1-15)$} & \multirow{2}{*}{$(>15)$} & \multirow{2}{*}{17} \\
\hline Equipos informáticos. & & & \\
\hline $\begin{array}{l}\text { Utilización de Base de datos. Integración de la } \\
\text { Información }\end{array}$ & Baja & Media & Baja \\
\hline Infraestructura de comunicaciones. & Escasa & Suficiente & Escasa \\
\hline ECONÓMICOS & \multirow[b]{2}{*}{$(<3)$} & \multirow[b]{2}{*}{$(>=3)$} & \multirow{2}{*}{$<3$} \\
\hline Facturación Anual (millones de euros) & & & \\
\hline $\begin{array}{l}\text { Inversión en Tecnologías Información (\%facturación } \\
\text { anual) }\end{array}$ & $(<1.5 \%)$ & $(>=1.5 \%)$ & $<1.5$ \\
\hline $\begin{array}{l}\text { Capacidad de Innovación. (\%Facturación de nuevos } \\
\text { productos sobre total facturado) }\end{array}$ & $(<10 \%)$ & $(>=10 \%)$ & $>10 \%$ \\
\hline
\end{tabular}

Tabla 6.1.- Formato para la tipificación de la empresa. Aplicación a la empresa piloto

Los criterios de evaluación.

Son los aspectos tecnológicos y funcionales que se van a tener en cuenta para cubrir las necesidades analizadas y se ponderan de acuerdo a factores determinantes para la empresa piloto. 
Indican las características más importantes a tener en cuenta a la hora de optar por una $u$ otra solución ERP. La empresa piloto, tomando como base sus necesidades, prioriza los aspectos asignándole un valor tabla 6.2.

Los criterios de evaluación atienden distintas temáticas:

1. Los criterios de cobertura funcional deben abarcar aquello descrito en la lista de requerimientos que se solicitan a la consultora, en lo concerniente a las funcionalidades que ofrece la solución ERP. Se valora aspectos relacionados con las características funcionales de los módulos y las funcionalidades específicas del subsector.

2. Los criterios de carácter tecnológico incluyen la infraestructura necesaria (hardware), seguridad de acceso y protección de datos, conectividad e integración con otros sistemas de mercado y con sistemas existentes en la propia organización.

3. Los criterios de conocimiento y referencias del sector deben valorar la experiencia del proveedor tanto en implantaciones similares, como en referencias generales, habiendo de demostrar, como mínimo su capacidad de "adaptación" al sector textil.

4. Los criterios referentes a costes permiten valorar las diferentes ofertas equilibrando la estrategia y capacidad de inversión en sistemas de información que tiene la empresa y el presupuesto de coste final presentado por las consultoras. Teniendo en cuenta los costes de software, hardware, consultoría, mantenimiento y formación.

5. Los criterios referentes a los niveles de servicio abarcan los servicios de atención al cliente, como formación, soporte y mantenimiento local, la posibilidad de disponer de un equipo de control de calidad y certificación de las implantaciones y, por último, la solvencia económica y financiera de la consultora.

6. Los criterios de estrategia de futuro teniendo en cuenta, no sólo las necesidades actuales de la empresa, sino también una previsión de las necesidades futuras atendiendo a la estrategia empresarial y la evolución del mercado. 


\begin{tabular}{|l|c|}
\hline \multirow{2}{*}{ CRITERIOS } & NECESIDAD DE LA EMPRESA \\
\cline { 2 - 3 } & ORGANIZACIÓN E INTEGRACIÓN \\
\hline 1. COBERTURA FUNCIONAL & 40 \\
\hline 2. TECNOLÓGICO & 10 \\
\hline 3. CONOCIMIENTO DEL SECTOR & 20 \\
\hline 4. COSTES & 15 \\
\hline 5. NIVELES DE SERVICIO & 10 \\
\hline 6. ESTRATEGIA DE FUTURO & 5 \\
\hline TOTAL & $\mathbf{1 0 0}$ \\
\hline
\end{tabular}

Tabla 6.2.- Formato criterios de evaluación. Aplicación a la empresa piloto

Con esta ponderación se deben evaluar las soluciones de forma objetiva y según los requerimientos de la empresa piloto, Ver ANEXO 7: Lista detallada de los criterios de evaluación de la solución ERP

\section{Evaluación}

Tomando como base la tipificación de la empresa y los criterios de evaluación, se puede optar por un grupo de consultoras y soluciones ERP, que presentan algunas características, (funcionales, tecnológicas, servicio, etc.) que las hacen más favorables para el tipo de empresas $A$, o el tipo de empresas $B$, en este caso la empresa piloto es del tipo A.

En el ANEXO 3 se presenta una tipificación de soluciones ERP, la clasificación de consultoras con implantación en el sector textil de la Comunidad Valenciana y las funcionalidades específicas recomendadas para el sector textil.

Con toda esta información se realiza un preselección de las consultoras y los productos ERP sobre los que se tiene que realizar el análisis en profundidad. Para el caso que nos ocupa de la empresa piloto la clase de consultoras que se ha considerado más adecuada pertenecen a los grupos 1 y 2 , con sus respectivos productos:

- ITEM con su producto GIT

- INASE con sus productos PYMEGEST y PROD

- CCS con su producto EKON 
Con la terna de consultoras y productos ERP sugeridos deben realizarse un conjunto de entrevistas y contrastes que permitan definir la solución idónea para la empresa prototipo al aplicar la lista criterios ponderada. Estas acciones son:

- Hacer llegar la lista de requerimientos a las consultoras preseleccionadas.

- Programar las reuniones para las demostraciones de los productos que implantan y presentación de sus empresas (consultoras).

- Contrastar telefónicamente o mediante visitas los clientes que las consultoras hayan dado como referencia de su servicio.

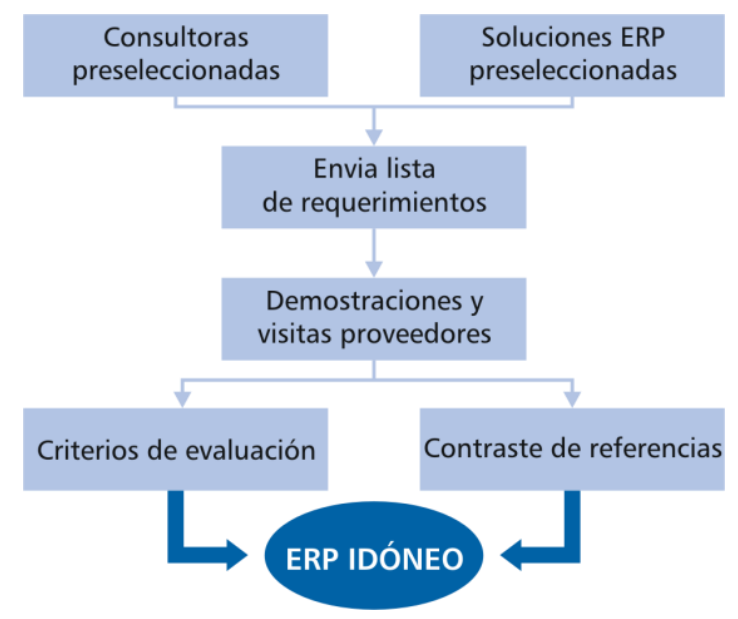

Figura 6.10.- Evaluación de la terna final

Con base en la información obtenida de los anteriores puntos, el equipo de gestión del proyecto elige la mejor opción evaluada, tanto cuantitativa como cualitativamente, y da inicio al proceso de contratación.

\section{Contratación.}

Una vez se ha decidido por la solución proporcionada por una de las consultoras que formaban parte del proceso de selección, la empresa debe conocer más en profundidad la oferta elegida.

Para ello se realizarán varias sesiones con la consultora en cuestión, en las que se tratarán más detalladamente todos los aspectos analizados anteriormente, con el objetivo de asegurarse que la opción elegida es la correcta. Así como, un presupuesto riguroso, que incluya tanto los costes directos como los indirectos atribuibles al proyecto. Debe comprender todos los costes directos de personal y equipamiento, así como la gestión general precisa. Se deben considerar las implicaciones de gastos a largo plazo, no simplemente el coste inicial. 
Elementos importantes que se deben incluir en el contrato de un proyecto ERP:

1. Definir los resultados y productos a entregar.

2. Definir los criterios de aceptación.

3. Definir la aprobación del producto.

4. El programa de entregas ha de quedar claro.

5. Definir el precio y la base de los pagos.

6. Rescisión.

7. Acceso y otros derechos.

8. Derechos de propiedad intelectual.

9. Normas.

10. Garantías.

11. Indemnizaciones y responsabilidades.

12. Confidencialidad.

13. Intensificación de conflictos.

14. No solicitación: el contrato debe prohibir al proveedor que reclute personal del cliente durante el proyecto y durante un período de tiempo razonable después de su terminación.

15. Duración y revisión.

Además, la consultora debe de presentar un Plan de Implantación que debe de contener el detalle de los siguientes apartados:

- Desglose del trabajo: tareas a realizar.

- Estimación del tiempo de duración de cada tarea.

- Dependencias entre las actividades.

- Recursos: personal y equipos necesarios.

- Coste: desglose de inversión en el proyecto.

\subsubsection{Modelo mejorado para la estrategia de selección.}

Gracias a la investigación desarrollada sobre la empresa piloto se puede concluir en el modelo mejorado para la selección de un Sistema Avanzado de Gestión ERP tal como representa la figura 6.11 . 


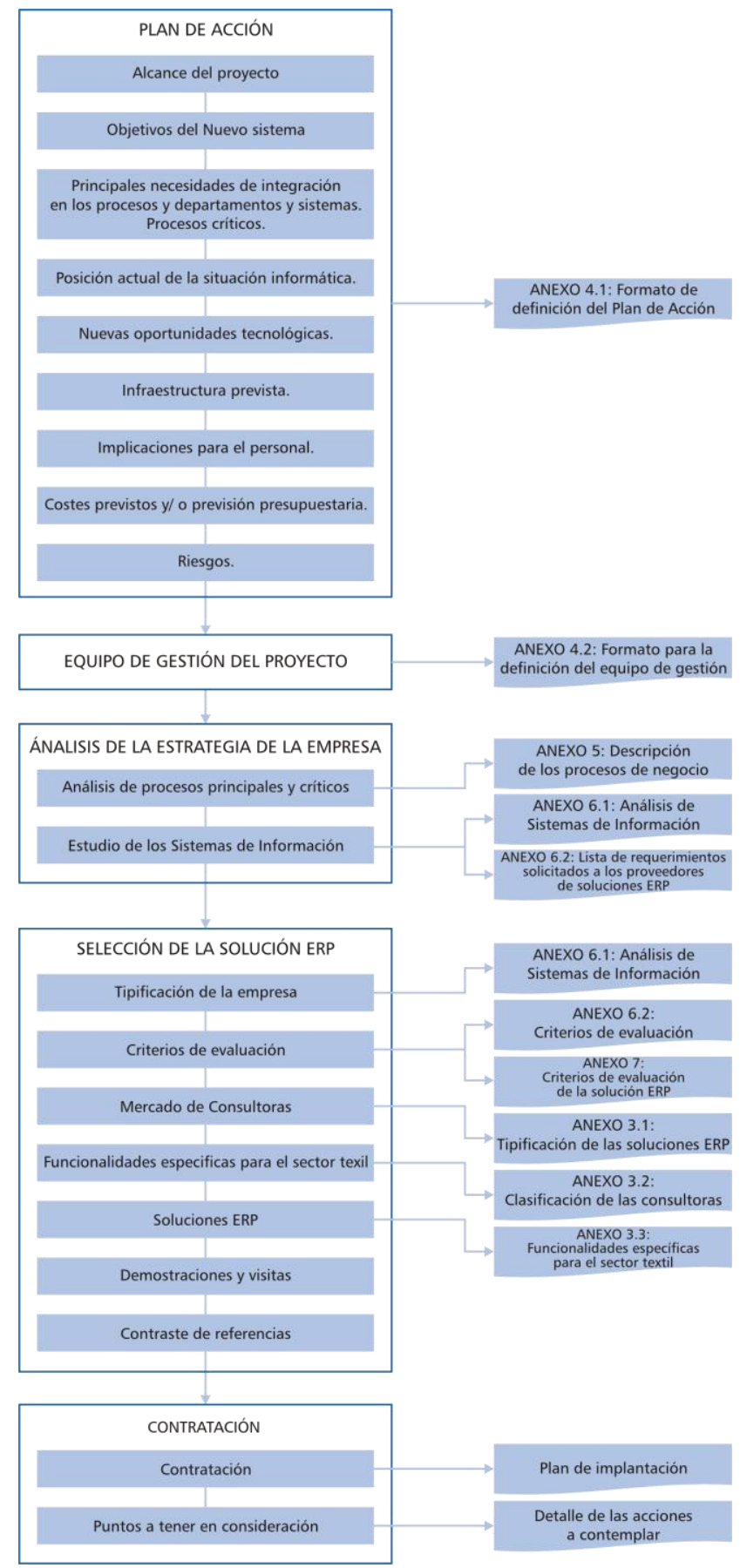

Figura 6.11.- Modelo de selección mejorado 


\subsection{Análisis de casos prácticos y contraste de los Factores Criticos de Éxito según el modelo de la investigación.}

\subsubsection{CASO A: Textiles albaida S.A.}

Textiles Albaida inicia su actividad en el año 1966 dedicándose a la producción de tejido para la tapicería dentro del mercado nacional. Posteriormente, en los años 1990 sufre un cambio en su estructura accionarial y con un nuevo rumbo se dedica a la penetración en nuevos mercados, empezando con Portugal y siguiendo por el resto de países de la Unión Europea, América del Norte, Países Árabes, etc.

Localizada en Albaida, la empresa opera en una única instalación con 38 trabajadores y una facturación comprendida alrededor de $4,5 \mathrm{M}$ de euros ${ }^{2}$. La empresa se dedica principalmente, a la fabricación de tejidos para la decoración de interiores y tapicerías para la industria del mueble: tapicerías para muebles y paredes; cortinillas y visillos, utilizando siempre fibras naturales. Otra línea de producto es la de telas ignífugas para el mercado de la hostelería. Textiles Albaida posee una marca registrada y distribuye telas por sistema de "metraje". Sus productos se utilizan en la decoración de gama alta, estando elaborados con fibras naturales, utilizándose también mezclas de poliéster y viscosa. Tiene como proyecto completar las colecciones de tejidos con complementos confeccionados a juego (cojines, faldas de mesa, etc.)

\section{"Necesitamos ser lo suficientemente flexibles como para transformar el negocio con rapidez, en respuesta a nuevos cambios estratégicos y a desafíos del mercado"}

En la actualidad se ha apostado por la introducción de una nueva marca en el mercado, con el objetivo de librarse de la imagen de tejido de tapicería profesional que tiene la marca propia de la empresa, y de este modo vender una gama de tejidos de alta calidad para la media-alta decoración siendo comercializada por sus clientes con esta marca propia y no con la del vendedor. En palabras de su gerente:

"Nos consideramos una pequeña empresa con un nicho de clientes fijos, caracterizada por una excelente relación calidad-precio. De hecho estamos dejando de "servir a la industria", nuestros clientes son tiendas de decoración que naturalmente no quieren tener stocks".

Realiza únicamente el proceso industrial de tejeduría, con una capacidad de fabricación aproximada de un millón de metros /año. Fabrica tejidos con "anchos" de 140 y $160 \mathrm{~cm}$, inferiores a la mayoría de sus competidores. Cada colección

${ }^{2}$ Dato referidos al año 2002 
tiene hasta 6 dibujos con diversas gamas de colores. Destina su producción tanto al mercado internacional (50\%) como al nacional y considera que una adecuada estrategia de negocio consistiría en desarrollar negocios distintos a los realizados actualmente. La empresa subcontrata alrededor de un $10 \%$ de sus procesos industriales.

"En fechas próximas se reducirán los aranceles y nos invadirán con productos a bajo coste. Es hora de diferenciarse en calidad cuidando los costes. Queremos conseguir más clientes adaptándonos a sus necesidades. En ese aspecto, la informática nos puede ayudar mucho."

La empresa tiene dos titulados superiores en el departamento de administración. Su sistema de gestión de calidad no está todavía certificado, realizando control de calidad en recepción y /o de producto terminado. La empresa se encuentra en proceso de conseguir la certificación ISO 9001; y, dado los procesos industriales que realiza, no presenta problemas de contaminación medioambiental.

Durante el último año ha sufrido un cambio en su dirección y esto ha motivado, entre otros cambios, un incremento en el porcentaje de ventas de nuevos productos sobre el total de ventas, que ha pasado del 10 al $65 \%$.

\subsubsection{El pasado: causas y antecedentes del sistema ERP.}

La empresa tiene subcontratada la función de proceso de datos: no tiene, en la actualidad, ninguna persona contratada dedicada a realizar dicha función. Ha cambiado varias veces de proveedor informático, habiendo instalado un programa de gestión de producción (probado en varias empresas del sector), que ha sido adaptado para adecuarse a las características productivas específicas de la empresa. Con anterioridad, en el área de producción únicamente se realizaba el control de stocks.

"En una empresa tan pequeña como ésta es caro tener una persona dedicada sólo a la informática, pero a veces pienso que nos traería cuenta."

Dadas las características de los productos fabricados: telas artesanales, con una amplia variedad de productos y gamas, elaborando hasta 70 urdidos, teniendo en cuenta el sistema de "metraje" utilizado, y el tamaño de los lotes; se tienen unos costes de lanzamiento altos, que obligan a unos ajustes continuos de la programación de la producción para reducirlos. Se han incorporado también, en el último año, telares automatizados que proporcionan información completa sobre el rendimiento de la máquina: número de roturas, tiempos muertos, nivel de aprovechamiento de la fibra, etc. Se pretende incorporar esta información al nuevo sistema de información de gestión de producción.

En la empresa se dispone de dos equipos de sobremesa en producción, dos en comercial y cuatro en administración. Las TI se están utilizando para tareas de 
naturaleza administrativa, existiendo una amplia capacidad de mejora en su utilización.

En nuestro caso, gerencia estaba completamente decidida por el cambio, el sistema informático, suministrado por una empresa local, estaba completamente obsoleto, era muy rígido. Apenas suministraba información contable, y no contaba con la posibilidad de generar informes que nos permitieran tomar decisiones: ventas por secciones, por departamentos, devoluciones por cliente y período, impagados, control de inventarios, pedidos pendientes de servir, etc. Se pidió a la empresa suministradora la incorporación de una serie de mejoras que nos permitieran continuar con el sistema anterior satisfaciendo las nuevas necesidades, pero la respuesta no fue la adecuada. Se argumentó que la "plataforma tecnológica" no les permitía..., más tarde que lo tenían en proyecto, que lo estaban estudiando. Pero realmente, no podíamos esperar, era un cambio imprescindible.

\section{"Al ser poco conocedores de las cuestiones técnicas de la informática, tienes que fiarte del proveedor... Algunas veces me gustaría tener un intermediario de confianza que nos ayude en temas que no entendemos del todo"}

La empresa participa en el proyecto textil.org y tiene dos direcciones de páginas web.

\subsubsection{El presente: proceso de implantación del ERP.}

Teniendo en cuenta los recursos de la empresa se analizaron dos opciones. La decisión estuvo influenciada por las experiencias de empresas del sector que consideraban el servicio post-venta de una de las alternativas como deficiente. La solución adoptada se juzgó que presentaba una solución robusta, suficientemente modulable, con mayor capacidad de adaptación, robusta y con suficiente respaldo. A la hora de negociar con la consultora, en los primeros momentos, se buscó el asesoramiento de un "experto informático" familiar de uno de los empleados de la empresa, que sirvió como elemento de enlace transmitiendo los requerimientos de Textiles Albaida a la empresa informática. Su papel se consideró positivo y se hubiera deseado que hubiera realizado su labor durante más tiempo. Transmitía confianza y hacía disminuir la incertidumbre de la negociación, porque se sentía "de nuestro lado".

Siendo importante realizar contratos claros, es difícil tenerlo todo documentado porqué siempre surgen cosas nuevas. En definitiva los consultores tampoco te aclaran las cosas desde el principio, esperan que surjan esas novedades, es normal, en definitiva "ellos viven de eso". Quizás si hubieran previsto algunas de los cambios posteriores no se hubieran producido tantas modificaciones al sistema. 


\begin{abstract}
"Una vez realizada la implantación, en la negociación de posteriores ampliaciones del sistema, te sientes impotente y "cautivo". No se puede tensar mucho la cuerda porque estás negociando con un proveedor especial, con el que tienes una fuerte dependencia. El sabe que tú no puedes estar cambiando continuamente"
\end{abstract}

Durante el proceso de implantación no ha habido disminución de productividad, pero sí aumentó el "papeleo" en administración y durante un par de meses estuvimos trabajando con los dos sistemas para comprobar posibles discrepancias. Hubo sí, algunos desfases que necesitaron de continuos ajustes, facturas que tenían que salir en otros idiomas y salían en español, problemas con la utilización del código de barras, etc.

No tuvimos problemas con el traspaso de datos del sistema antiguo, aunque ciertamente contamos con la colaboración de la empresa informática anterior que migró los datos a ASCII.

Las áreas que más se han visto beneficiadas con la implantación han sido administración y facturación, en la que hemos conseguido "funcionar con el código de barras" y poder abordar el aumento de pedidos como consecuencia de las características de nuestra actividad y del tipo de producto que elaboramos, control de stocks (piezas, metraje e incluso de muestrarios) y una mayor versatilidad a la hora de obtener informes de gestión en todas las funciones; éste era uno de los objetivos buscados del que nos encontramos más satisfechos. El control de inventarios es especialmente importante en nuestra empresa, nos hemos convertido en el almacén de nuestros clientes, y necesitar llevar un control de existencias por medio de un sistema de máximos y mínimos (la menor cantidad para servir bien).

También se ha incorporado un sistema de gestión documental que nos permitirá ahorrar muchos papeles, al procesarse pedidos directamente sin necesidad de recibirlos por fax y luego introducirlos en el ordenador, aunque no ha comenzado a funcionar todavía, porque tenemos algunos problemas con la operadora de comunicaciones.

\title{
6.4.1.3 El futuro: la evolución de los sistemas de información.
}

Recientemente se ha producido un cambio estratégico en la utilización de las $\mathrm{TI}$, estando consideradas como: “... Un elemento facilitador que debe ser utilizado convenientemente". Estamos empezando a trabajar con el área de urdidos y tisaje. Sería muy interesante poder captar datos directamente de los telares electrónicos, una mejora en la gestión de los escandallos y en el rendimiento de los telares. Creemos incluso, que este desarrollo va a servir para otras empresas del sector. El área comercial es la menos perfilada y nos gustaría utilizar la conectividad que ofrece internet $y$ que nuestros comerciales pudieran consultar el nivel de existencias disponible. Pero éste es un proyecto que llevara todavía algo de tiempo. 
Todos estos nuevos desarrollos afectarán al precio final del ERP que de momento es difícil predecir con exactitud.

\subsubsection{Lecciones aprendidas.}

Si tuviera que resumir lo que consideramos más importante para el éxito de un proyecto de este tipo podría decir que gerencia debe estar plenamente convencida y apoyar el proyecto, de la necesidad del cambio, muchas veces sugerido y solicitado por los propios trabajadores. Otros aspectos a considerar serían:

- Es muy importante acertar con la empresa proveedora del software.

- Interesa convencer a quien tiene que utilizar el software mediante diálogo, comunicación: aclarando requerimientos y objetivos. Las cosas no son tan bonitas como los comerciales te hacen creer; la realidad no responde a las promesas y luego viene la frustración.

- Con los informáticos es conveniente tener paciencia porque no conocen el negocio, además de dedicar recursos y tiempo para aclarar los requerimientos y objetivos, porque si te equivocas es tu responsabilidad.

- Es imprescindible gestionar bien los contratos, "dejarlo todo muy claro, por escrito", el presupuesto y los servicios a conseguir, sino se "desmadra".

" Estamos satisfechos con las prestaciones del sistema. La productividad ha aumentado. El coste ha merecido la pena; pero... algunas cosas se podían haber hecho mejor. "

\subsubsection{Correlación con los factores críticos del modelo de investigación}

1: Apoyo de la dirección.

La gerencia de la empresa es consciente de la necesidad de cambio en el sistema informático ya que no proporciona la información suficiente y necesaria para el análisis y la toma de decisiones crítica para el avance y el progreso de la compañía. Además, la gerencia se percató de que un sistema de información adecuado podría aumentar su competitividad en el sector y sería una inversión imprescindible. La idea de cambio surge de la alta dirección y por tanto está sensibilizada en el éxito del proyecto, lo que permite el apoyo continuo en el mismo.

2: Fijación de objetivos y planificación. 
El objetivo de la gerencia es claro: un sistema de información oportuno ayudará a conseguir más clientes y a fidelizarlos adaptandose a sus necesidades de manera que en todo momento se obtenga una gestión y control adecuados de todos los procesos de la empresa.

Para alcanzar el objetivo, la empresa es consciente que necesita establecer una planificación que le permita conseguirlo. En primer lugar encargan a la empresa suministradora que le de una solución en función de "lo que hay" y al ver que no es capaz de ofrecer nada recurren a una empresa consultora que les oriente en el camino.

Por tanto podemos concluir que el objetivo y la planificación estratégica adecuada es un factor claro de éxito en este caso en particular.

\section{3: Idoneidad de la solución ERP.}

La solución ERP llega a ser una solución lo suficientemente robusta como para no tener quejas de las funcionalidades que tiene. La empresa considera crítico el acertar con la empresa proveedora, aunque muchas veces te llevan a su terreno. La empresa tiene quejas de que al final se genera una dependencia muy seria con la empresa proveedora, por lo que si no se escoge la solución acertada el proyecto fracasará. A pesar de la modularización del sistema los avances del mismo dependen de la empresa proveedora.

Los consultores no se adaptan al $100 \%$ a las necesidades de la empresa sino que esperan que surjan novedades y van provocando las modificaciones que toquen.

\section{4: Administración del proceso de implantación}

La administración en el proceso de implantación es fundamental para que el "cambio" no resulte caótico. Este factor crítico tiene una relación directa con el anterior ya que la empresa proveedora de la solución debe colaborar estrechamente en el paso a la nueva situación sin perjudicar ni paralizar los procesos de la empresa.

\section{5: Comunicación y participación.}

La empresa considerada ve fundamental este factor ya que considera que debe existir comunicación y diálogo con las personas que van a "usar" el sistema de forma que no solamente sea una acción meramente informativa sino también participativa, de esta forma el trabajador que a la postre se convierte en el usuario se involucra en el proyecto considerandose un elemento crítico en el desarrollo del mismo. 


\subsubsection{CASO B: Textiles Valencia S.A.}

Textiles Valencia S.A. es un fabricante tradicional de mantas. Inició su actividad en una zona con importante industria textil en Valencia, pero desde muy pronto empezó una constante internacionalización, no sólo exportando productos sino abriendo plantas en otros países.

La empresa realiza los procesos de hilatura de carda y semipeinado, el tisaje de mantas, así como el tisaje de telas de tapicería y decoración; además se realizan los procesos auxiliares de perchado, acabado, confección y vaporizado. El tinte de hilos, fibras y los procesos de ennoblecimiento son subcontratados.

Hasta la década de los 90 su actividad principal era la ropa de cama. Actualmente, las dos líneas más importantes de productos son la ropa de cama: mantas y colchas tejidas y de punto, edredones y sábanas; y los tejidos para tapicería y decoración: muebles y paredes, terciopelos, acolchados, cortinillas y visillos a la plana.

Ha llegado a alcanzar un alto volumen de ventas, pero en los últimos años ha visto como sus ventas caían un $20 \%$, debido fundamentalmente a la importación desde terceros países con menores costes de fabricación y el cambio de los hábitos de consumo. Frente a estos cambios en las preferencias de los consumidores, según palabras de su propia dirección general, es preciso adaptarse, revitalizándose técnicamente sin descuidar el lado humano de la firma.

La empresa ha diseñado un plan estratégico a cuatro años que se basa en tres líneas de actuación: el ajuste de costes (la empresa ha llevado a cabo una reducción del personal pasando de unos 185 trabajadores a 150), la expansión internacional, intentando que las exportaciones representen un $70 \%$ de la facturación (actualmente suponen un 30\%) y la diversificación de productos. Se pretende iniciar la fabricación de fundas nórdicas y la ampliación de todas las gamas actuales, para abarcar el conjunto del textil hogar, para adecuarse a las nuevas tendencias del consumo, aprovechando la rotación de productos.

Dentro de este plan estratégico, que precisa de una gestión profesionalizada, los sistemas de información juegan un papel crítico. La empresa cuenta con una persona en el departamento de informática; al menos un $20 \%$ de los empleados tienen conocimientos de informática, contando en su plantilla con un $8 \%$ de titulados universitarios y un 10\% con una titulación de Formación Profesional.

Aún siendo una empresa que se moderniza, podría decirse que tiene una filosofía algo conservadora: las nuevas ideas de mejora se obtienen básicamente del interior de la empresa que de fuentes externas; considera que su fortaleza es la producción frente a la comercialización o la administración; de sus inversiones 
espera siempre un retorno reflejado en la cuenta de resultados, y para aumentar sus ventas busca aumentar sus clientes en lugar de aumentar las ventas a los que ya tiene.

\subsubsection{El pasado: causas y antecedentes del sistema ERP}

Originariamente los sistemas de información dependían del jefe de administración, pero en la actualidad, en el diagrama organizativo de la empresa se encuentran ubicados como staff de la dirección general, al mismo nivel que la función de marketing o la dirección de calidad. Se la ha situado a este nivel para resolver problemas que afecten al conjunto de la empresa de una forma equilibrada y eficiente.

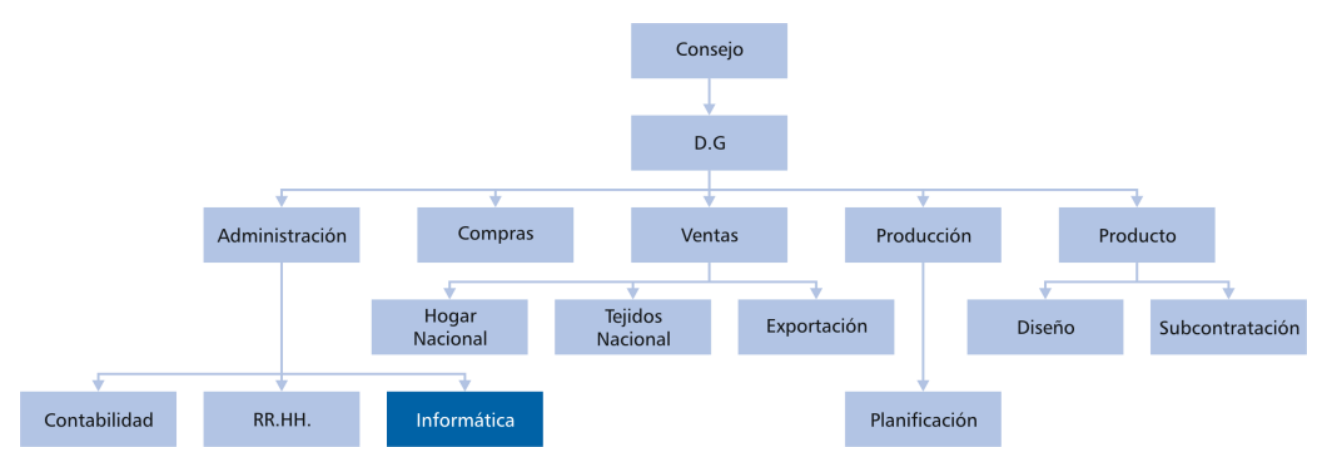

Figura 6.12: Ubicación original del departamento de informática

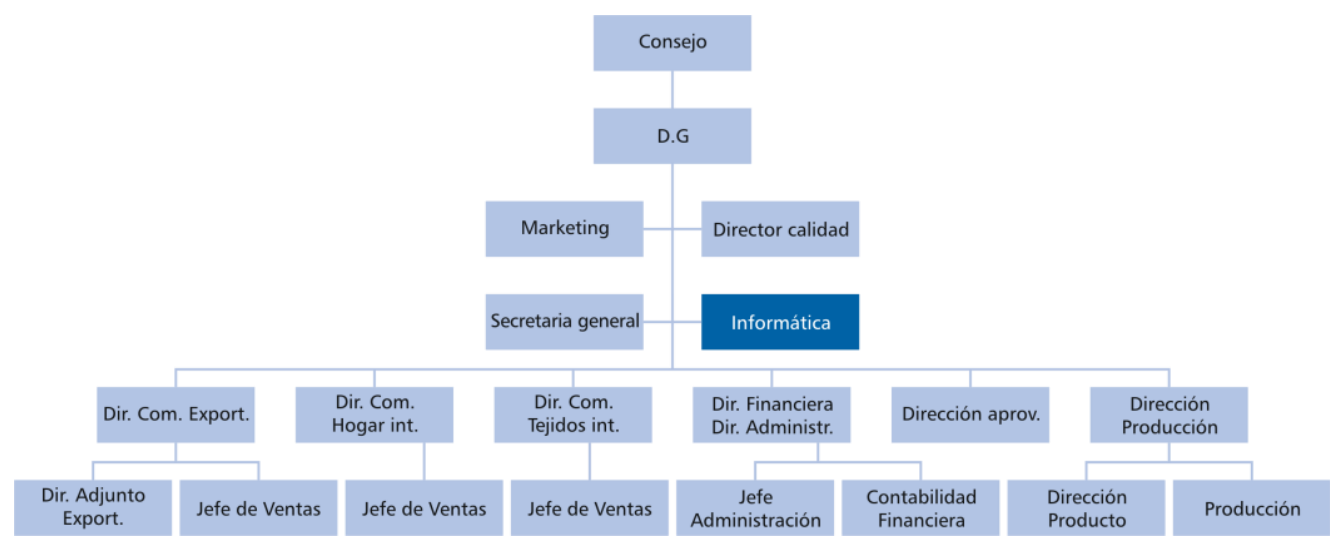

Figura 6.13 Actual ubicación del departamento de informática

Tradicionalmente vinculada a sistemas propietarios de IBM, en el año 1997, la empresa disponía de dos arquitecturas basadas en Unix y AS400. La primera, más reciente y desarrollada a medida por una empresa local, se dedicaba al control de 
la fabricación de tejidos, mientras que la segunda daba soporte al resto de áreas de la empresa.

"Un ERP es un sistema de gestión integrada. Todo es estándar. Estable. Menor introducción de datos y mayor salida."

Pero se consideraba que ninguno de los dos sistemas era un ERP. "No podemos hablar ni de estándar ni de dato único". Se sentía la necesidad de integrar todas las actividades logísticas, de producción, comerciales y financieras dentro de un único software que asegurara la fiabilidad de la gestión.

Se buscaba una menor dependencia del departamento de informática. Esta situación de dependencia se entiende originada por utilizar una aplicación programada a medida.

"En muchas empresas los informáticos sienten que tienen el poder porque programan y desarrollan el sistema y son los únicos que lo conocen, y por eso puede que no quieran cambiar a un sistema más estándar. No es el caso de la gente de nuestra empresa."

Las repercusiones que el efecto año 2000 y el cambio al euro pudieran tener sobre su sistema informático les impulsó finalmente a buscar un nuevo y moderno sistema de información, en lugar de llenar de parches el que usaban.

Estas necesidades de cambio fueron detectadas por el departamento de informática, pero gerencia fue quien decidió e impulsó ese cambio. Gerencia no pretendía alcanzar ningún objetivo económico directo del nuevo sistema, pero sí conseguir mayor control, calidad de interacción en menor tiempo y mejorar la gestión en general, lo que de forma indirecta siempre desemboca, a la larga, en una mejora de los resultados económicos.

\subsubsection{El Presente: selección e implantación del ERP}

La elección del ERP que satisficiera las necesidades de la empresa fue encomendada a Diego, responsable del departamento de Informática. Es un hombre con experiencia, al contrario de la gente que es habitual encontrar en departamentos de informática. De personalidad sencilla, es gran conocedor y entusiasta de su trabajo y de todo el funcionamiento de la empresa. Ya desde el año 94 estaba pensando en la problemática del año 2000.

"Los programas hechos a medida necesitan mucho análisis, y luego hay que hacer muchos cambios en el corazón del sistema para ir adaptándolos a nuevas necesidades y a cambios de la legislación. Eso además te causa fuerte dependencia de la empresa que realiza las adaptaciones" 
Durante dos años consideró diversas soluciones. Tenía claras las características que debía tener el sistema que buscaba: debía ser un único sistema integral (dato único); con un entorno operativo actual y una interfaz gráfica; capaz de interactuar con las tecnologías de comunicaciones y correo electrónico; había de ser flexible y standard de forma que se pudieran implantar nuevas versiones sin afectar a la estructura existente; había de ser seguro, y estar respaldado por una marca acreditada. Un criterio importante en la elección fue la capacidad para la gestión de la producción que tuviera el sistema.

Se desecharon opciones por diversas razones: estar demasiado dirigidas a algún subsector; tener alguna área como la de fabricación sin desarrollar (con lo que se necesitaría algún módulo específico de otro proveedor); otro sistema fue descartado por no ser lo suficiente estándar, lo que causaría dependencia de la empresa desarrolladora; por la misma razón se descartaron sistemas programados a medida. Se desecharon opciones con referencias negativas, o por considerar a los consultores de escasa experiencia aunque el producto fuera atractivo. En el estudio para la selección se analizaron incluso noticias aparecidas en prensa sobre las consultoras. Al final se seleccionó 2 opciones.

La opción A es un sistema de gestión empresarial reconocido mundialmente. Se trata de una solución completa e integrada que abarca todos los procesos de la empresa siendo adaptable a cualquier sector. Esta solución informática no resultaba desconocida para la "propiedad" de la empresa, al tratarse del sistema implantado en otra empresa del mismo grupo aunque de otro sector. Por esta razón, en un principio, les resultó una opción muy interesante. Se pensó incluso en formar un departamento de informática, a modo de empresa independiente externalizada, que diera servicio a ambas empresas con el mismo sistema. Sin embargo, la experiencia obtenida en la implantación de este sistema en la otra empresa no había sido satisfactoria. Además, la gran magnitud de este sistema y su exhaustividad prácticamente exige un análisis funcional profundo y extenso para adaptarlo a una empresa textil, y puede que no se llegue nunca a explotar del todo. La implantación de este sistema iba a requerir mucho tiempo, dedicación y recursos. Por todo esto, esta solución fue descartada finalmente.

Finalmente se decantaron por la opción B. Este sistema también es un software uniforme y una solución integrada que abarca todos los procesos de la empresa. De menor dimensión que la opción A y, por lo tanto, con un proceso de implantación menos complicado y con más probabilidad de alcanzar objetivos de funcionalidad y cumplimiento de plazos de forma satisfactoria.

Además, la opción B funciona con la misma plataforma AS400 que ya tienen y conocen. Esto les facilitaría el trabajo en paralelo con los dos sistemas durante la implantación, así como aprovechar una amplia experiencia con ventajas adicionales al poder aprovechar los sistemas físicos ya existentes. 
En alguna ocasión podemos haber oído decir que lo importante de un ERP es su correcta implantación y utilización más que el producto en sí. Sin embargo, la selección tan minuciosa que se llevó a cabo en Textiles Valencia S.A. demuestra que, para esta empresa, es importante elegir un buen producto, adecuado a las necesidades de la misma.

Para asegurar los resultados y una buena implantación se optó por la incorporación de un director de proyecto externo, cuya misión fundamental era servir "de puente" entre la empresa y la consultora de implantación. Este director de proyecto no es un experto en la implantación de la opción B como sí se pretende que sean los consultores de la empresa implantadora, pero tiene una experiencia de 25 años y un currículum difícil de superar en el mundo de la informática.

A la consultora se le exigía que proporcionaran para el proyecto unos consultores con cierta garantía profesional (currículum de implantadores con perfiles y experiencia aceptables), además de exigirle garantías contractuales (penalizaciones en caso de incumplimiento de fechas o de objetivos).

Por parte de la empresa también participaba un jefe de proyecto, así como informáticos y usuarios avanzados de cada departamento, que dedicaban gran parte de la jornada laboral al proyecto de implantación del ERP.

"Es importante el currículum de los consultores, y sobre todo que conozcan bien el paquete informático que implantan. Ya que la gente de la empresa conoce bien los procesos de la empresa, los consultores deben conocer bien el producto que venden"

Los usuarios finales se mantuvieron al margen en las primeras etapas, involucrándose en el proyecto a partir de la fase de formación que consistió en clases magistrales, ejercicios, elaboración de manuales de usuario... Como es normal, se encontraron personas algo reacias al cambio, sobre todo entre el personal menos cualificado. Este problema se abordó con reuniones por parte de dirección y de los directores de cada área.

La consultora llevó a cabo un análisis detallado previo; se encargó también de la parametrización del sistema y de los desarrollos específicos iniciales. Textiles Valencia considera que "es importantísimo que el consultor conozca bien el producto que vende y que sepa parametrizarlo correctamente para ajustarlo a la empresa. Un error en la parametrización se sufriría siempre". Según el nuevo jefe del departamento de informática: "si nos equivocamos en la clasificación de cierto artículo, lo tendremos siempre mal clasificado para todas las funciones que se realicen sobre él en cualquier parte del programa"

Aunque en la empresa se llevó a cabo una reingeniería previa para acomodarse en gran parte al nuevo sistema, no pudo evitarse tener que realizar algunos 
desarrollos específicos en el ERP. La ficha técnica en producción se desarrolló a medida por la consultora; también los tratamientos relativos a la logística y transportes, y las mermas. La generación de informes fue llevada a cabo por el departamento de informática de Textiles Valencia S.A. de acuerdo con las especificaciones de los usuarios. La experiencia ha demostrado que el sistema de la opción B no es tan fuerte en producción como su propaganda hace ver, por lo que se tuvieron que hacer modificaciones. Pero hay que reconocer que la producción en el sector textil y concretamente en Textiles Valencia S.A. es bastante específica. Como conclusión, pudo extraerse que por muchas posibilidades de parametrización que tenga un ERP, para ajustarse, al final siempre hay que desarrollar líneas de código.

A posteriori, no se puede decir, que se hayan ganado muchas funciones con el nuevo sistema, pues la empresa ya tenía un grado alto de informatización. Pero lo que no cabe duda, es que se ha ganado en integración de los datos y funciones y en evitar redundancia de los mismos.

\subsubsection{El futuro: la evolución de los sistemas de información.}

En futuras ampliaciones o mejoras del ERP se pretende incorporar escaners lectores de códigos de barras (expendedores, inventarios...) y poder insertar pedidos en el ERP a través de internet.

Se sigue trabajando en la búsqueda de un módulo informático que satisfaga los procesos operativos de la empresa y todavía no se ha encontrado, lo cual ratifica que no existen ERP's que se ajusten a la perfección a las necesidades de una empresa y nunca podemos escapar de programar.

\subsubsection{Lecciones aprendidas.}

El caso vivido por Textiles Valencia S.A permite considerar las siguientes observaciones:

- En la otra empresa del grupo se notó la falta de experiencia de la consultora que era el primer proyecto de implantación de la opción $A$ que realizaba. En Textiles Valencia dieron importancia al reconocimiento del producto que eligieron (opción B) pero volvieron a errar contratando a una consultora "novata" en implantaciones de este sistema. Además, para finalizar la parte de producción se tuvo que cambiar de consultora.

- Casi siempre se pretende arrancar el nuevo sistema con inicios de años reales o años fiscales y así dejar los datos de años cerrados en el sistema que se abandona. Esto puede hacer que se alargue la implantación de un nuevo sistema para hacer coincidir el arranque con años nuevos. 
- Es necesario el apoyo de la alta gerencia, que generalmente sólo ve la parte de arriba. La tarea de gerencia no acaba con la adquisición del ERP sino que debe ser continuada abasteciendo la implantación del mismo con los recursos necesarios.

- Un punto crítico en el arranque del sistema es la carga de datos. La migración de los datos históricos suele hacerse antes de la fase de pruebas. Se puede migrar una parte de esos datos junto con algunos datos "vivos" ficticios. El resto de datos históricos pueden ser migrados por la misma empresa tiempo después de la implantación o puede optar por no migrarlos y/o guardarlos en el sistema antiguo. Pero la carga de los datos vivos de la empresa se ha de hacer justo el día antes del arranque para que estén totalmente actualizados y debe ponerse un especial cuidado en su fiabilidad.

- "En las pruebas, antes de arrancar el sistema, se deben probar ciclos completos reales. Generalmente la gente prueba algunos casos de unos pocos procesos". Es imprescindible intensificar esfuerzos en las pruebas pues permite detectar si el sistema está correctamente parametrizado (antes de que sea demasiado tarde) y si la carga de datos es precisa.

- El trabajo en paralelo con los dos sistemas debería ser lo más corto posible para no sobrecargar de trabajo a los usuarios; para ello es preciso una buena sincronización y el cumplimiento de los tiempos programados.

- Una buena opción es cargar todos los datos en una compañía ficticia de prueba. Esto no es un paralelo realmente puesto que el paralelo es sobrellevado por el usuario. La carga en una compañía de prueba es algo que hace el consultor, permitiendo dar marcha atrás si algo no funciona correctamente.

- Las empresas suelen querer heredar y mantener lo que ya tienen, y eso no siempre es lo mejor. Las empresas deberían no aferrarse a su manera de operar "de siempre" y abrirse a sugerencias de los consultores o a las nuevas modalidades de trabajo del ERP. Por ejemplo, respecto a los códigos de los clientes, Textiles Valencia solía hacer que empezaran con un número u otro según fueran de exportación, nacional... Con su nuevo sistema ERP ese tipo de numeración no hace falta para controlar a los clientes y resulta mucho más cómodo asignarles códigos consecutivos. También tenían sistemas distintos para el tratamiento comercial de mantas y tejidos pero se dieron cuenta que no valía la pena mantenerlo separado. Hablando de códigos resulta interesante que el ERP permita relacionar códigos nuevos con códigos antiguos. Esto es algo a valorar en la elección de un ERP pues resulta interesante para ver datos históricos sin necesidad de migrarlos.

- El nuevo jefe del departamento de informática insiste en que no hay que obviar "las pequeñas cosas". En la puesta en marcha hay que comprobar antes que cada PC esté totalmente preparado, comprobar 
impresoras, configuraciones, etc. Podría darse el caso que, por descuido, algún PC continuara configurado para la compañía de prueba y que el usuario se diera cuenta cuando lleva ya unos días introduciendo datos reales. Cualquiera reconoce la importancia de la fiabilidad en el conjunto de datos históricos y de operaciones; pero no es suficiente reconocer la importancia que tiene, hay que concienciarse y ser meticuloso sobre todo en la carga de los datos vivos de la compañía.

- No desestimar recursos en la formación del personal. Una formación piramidal acarrea el peligro de que se vaya de la empresa "alguien de los que saben" y ya no se pueda formar al resto. Por eso la formación debe estar bien documentada y se debe proporcionar a todos, no sólo a usuarios clave. La falta de formación es una de las causas que puede producir una reducción de la productividad, sobretodo en la fase de arranque.

“En nuestra empresa primero arrancó finanzas. Como no se midieron bien los tiempos, el resto arrancó mucho más tarde. Tuvimos que mantener un paralelo en finanzas mucho tiempo. Lo mejor es arrancarlo todo al mismo tiempo. Hay que ir preparándolo todo por fases pero esperarse a que esté todo preparado para arrancar”

\subsubsection{Correlación con los factores críticos del modelo de investigación}

\section{1: Apoyo de la dirección.}

En la empresa objeto de estudio existe un departamento de informática que ya venía observando y detectando la necesidad de un cambio en el sistema informático. Es con la llegada del euro cuando esta sensibilidad se hace más latente y el departamento propone el cambio a un sistema de información mucho más moderno y la alta dirección termina por apoyar e impulsar ese cambio. Gerencia tenía claro que necesitaba mayor control de los procesos y buscaba una mejora en la gestión en general que le permitiese ganar en calidad y mejorar a la larga los resultados económicos.

\section{2: Fijación de objetivos y planificación.}

- Lo que se pretendía era integrar todos los procesos en un único sistema para aumentar la eficiencia y productividad de la empresa. Este sistema debía tener unas características diferenciadoras claras: ser único e integral (debía heredar datos de dos aplicaciones), ser flexible y standard de forma que permitiese la incorporación de nuevas aplicaciones, ser seguro y estar respaldado por buenos profesionales.

El proyecto era una realidad con una planificación clara y detallada. Este punto es también considerado como un factor crítico relevante en el proceso. 
3: Idoneidad de la solución ERP.

La empresa del caso valora las alternativas que puede tener y observa la experiencia que otra empresa conocida ha tenido en el asunto y esto es un elemento de juicio importante. Dentro de la planificación inicial tenían claro que la elección de una solución idónea era clave para el éxito del proyecto pero esta solución debe venir dada por el correcto diseño de las necesidades ya que el producto debe cubrir estas necesidades y debe facilitar el uso del mismo. Otro elemento clave es la experiencia y profesionalidad de la empresa que facilite la aplicación ya que sabrá detectar la verdadera necesidad de la organización

\section{4: Administración del proceso de implantación}

En el caso que nos ocupa y en línea con el comentario anterior la empresa pese a haber elegido una solución adecuada considera clave la intervención de un director de proyecto externo que pueda servir de "puente" entre la empresa y la consultora de implantación. Esta persona tendrá una misión crítica ya que no permitiría que la consultora marcase su pauta y dirigiría la implantación de acuerdo a las necesidades marcadas a priori. Un punto crítico en el proceso es la migración de datos de los viejos sistemas a la nueva aplicación: el trabajo en paralelo de ambos sistemas debería ser lo más corto posible para no interferir en la productividad.

Un punto crítico importante que se apunta en este caso estudiado es la formación: no hay que desestimar los recursos en la formación del personal porque al final para que la aplicación tenga éxito debe ser usada eficientemente por los trabajadores, son ellos los que tienen la llave final del éxito.

\section{5: Comunicación y participación}

La empresa es consciente que el proyecto no depende sólo de la gerencia, de hecho la idea parte del departamento de informática que detecta la necesidad. Los usuarios finales se mantuvieron al margen de las primeras etapas, involucrándose en el proyecto a partir de la fase de formación. Esto implicó que algunas personas, sobre todo las menos cualificadas se mostraran reacias al cambio.

Quizá deberían haber tenido más presente la comunicación desde el principio para evitar estas situaciones no deseadas de rechazo por parte de algunos trabajadores. 


\subsubsection{CASO C: Textiles Alcoi S.A.}

Textiles Alcoi, S.A. es un punto de referencia en el competitivo sector de la moda infantil. Como muchas empresas del sector, forma parte de un grupo empresarial compuesto por 3 empresas con un alto ingrediente de colaboración, no sólo a nivel estratégico sino incluso operativo.

Se trata de una empresa familiar que ha sabido modernizar su gestión, adaptándola a las cambiantes necesidades de un público y unos canales de comercialización cada vez más exigentes. La problemática de su segmento competitivo viene dada por la elaboración de un número elevado de colecciones cada año y un poder negociador cada vez mayor de la demanda. Es por tanto crítico realizar una adecuada gestión de producto que facilite un vertiginoso proceso de diseño y desarrollo, así como su posterior comercialización a partir de una cuidada previsión de ventas.

Con una significativa presencia en el mercado internacional, su estrategia empresarial pasa por una disminución de los costes operativos y un incremento en las ventas, sin dejar de lado la calidad del producto. Todo esto les exige un aumento de la eficiencia y de la competitividad, para lo cual consideran imprescindible un uso intensivo de las tecnologías de la información.

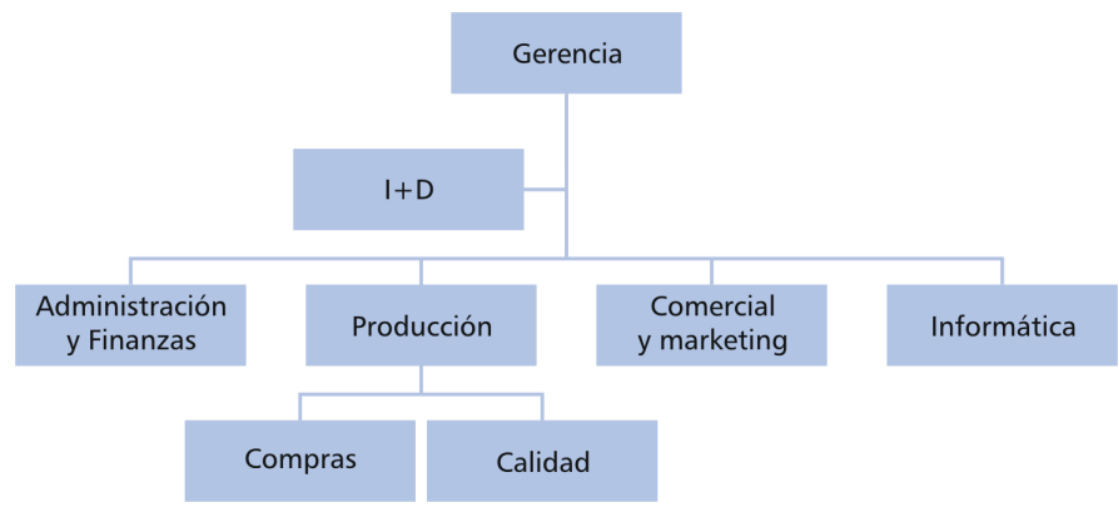

Figura 6.14: Estructura organizativa

La empresa posee un sistema de calidad basado en ISO9000, teniendo documentados de forma exhaustiva sus procesos operativos. El hecho de que no estén certificados según la ISO9000 viene dado, porque no creen que aporte ningún valor de cara al cliente, sin embargo la empresa tiene la etiqueta OEKOTEX en una línea de producto. 
Como el conjunto de empresas de su subsector, consigue una gran flexibilidad operativa recurriendo a la subcontratación de operaciones al utilizar talleres externos, aunque ello les exige llevar un estricto y difícil control de los tiempos y destinos de las entregas y recogidas de los talleres subcontratados

El conjunto de las operaciones realizadas, en instalaciones propias y de proveedores externos, son las siguientes: corte, bordados, confección, plancha, y acabado. La empresa realiza en cualquier caso la adquisición de las materias primas, la planificación y programación de la producción a partir de una cuidada previsión de ventas, la logística de distribución, la función comercial y la función de I+D. Para ésta última cuenta con un avanzado equipo de diseño de moda aunque no descarta la utilización de diseñadores externos independientes.

Una preocupación de la dirección de la empresa, que se ve reflejada en su minuciosa descripción de procesos, es que el conocimiento útil para la toma de decisiones operativas, quede reflejado, en la medida de lo posible, en un conjunto de documentos, manuales y naturalmente en el propio sistema de información, de forma que las personas cuenten con un adecuado soporte en su quehacer diario. Asimismo, se han elaborado parámetros de calidad y servicio que miden los resultados de la empresa comparándolos con años pasados y, en la medida de lo posible, con otras empresas de su segmento competitivo.

\subsubsection{El pasado: causas y antecedentes del sistema ERP}

La empresa tiene una dilatada experiencia en el uso de las tecnologías de la información, que se manifiesta en el alto número de máquinas instaladas y en su profunda penetración en la mayoría de los procesos de la empresa (cuarenta empleados, de un total de cincuenta, utilizan las TI en el desarrollo de sus tareas). De este desarrollo tecnológico tiene buena parte de culpa el interés y curiosidad personal de su dirección general, persona dinámica y entusiasta de su trabajo, que le gusta conocer y participar en todas las actividades de la empresa.

\section{"En la empresa hay mucha filosofía informática. Si algo se puede hacer con el ordenador se hace con el ordenador, no se hace a mano."}

El proceso de informatización se remonta a la década de los 80 . Durante ésta, se procedió a utilizar aplicaciones para las funcciones contable y comercial desarrolladas por una empresa ya desaparecida. Éstas se fueron enriqueciendo con un número cada vez mayor de aplicaciones desarrolladas a medida por empresas externas y con una colaboración creciente del personal interno. Para la mayoría de sus competidores en los 80 la informatización acababa ahí mismo: en la contabilidad y en la gestión comercial, o simplemente, en la facturación. Sin embargo, en Textiles Alcoi, a mediados de los 80 ya se utilizaban los ordenadores para calcular consumos en producción. 
Hace aproximadamente unos 7 años y detectado por las propias áreas funcionales de la empresa, se contempló la necesidad de un "cambio". La necesidad de una mayor integración de la información empresarial, y de procurar una trazabilidad en los procesos operativos se mezclaban con una imperiosa necesidad de colaborar en el desarrollo y comercialización de nuevos productos. Aumentaba así la variedad de productos, pero muchos de ellos con estructuras similares y con pequeñas diferencias respecto a los productos de campañas anteriores. Se buscaba entonces, una funcionalidad que permitiera la creación de escandallos de producto a partir de prendas ya elaboradas por la empresa.

\section{“Nuestro cuello de botella es la creación del producto porque es muy variada"}

Se percibía la necesidad de disponer de un sistema integrado de gestión que permitiera disponer de las prestaciones anteriores y que en definitiva colaborara en la búsqueda de nuevas oportunidades.

El proceso de selección de la solución adecuada no fue nada fácil y discurrió por complicados vericuetos de encuentros y desencuentros con empresas informáticas implantadas en la zona, y también con líderes nacionales con los que no se llegó nunca a desarrollar un sistema que diera satisfacción a los requerimientos planteados.

Las empresas del sector de la confección llevan a cabo un gran número de procesos; no obstante, el problema no era que Textiles Alcoi tuviera unos procesos específicos a los que ningún ERP se pudiera ajustar. De hecho, algunos de los ERP's estudiados en la selección tenían unas prestaciones funcionales similares a las del sistema de información que ya se poseía. La dificultad en encontrar un software a gusto de Textiles Alcoi residía más bien en que la empresa ya disponía de un sistema de información que, aunque comenzaba a manifestar en algunos aspectos su obsolescencia, permitía resolver muchos de los problemas que la empresa tenía. Teniendo este sistema como referencia, lo que se pretendía era ganar niveles de profundidad en el tratamiento de la información. Los ERP's vistos eran perfectamente útiles e interesantes para empresas que no habían tenido nunca ningún sistema de información, pero tenían poco valor añadido para una empresa con una trayectoria de informatización como la de Textiles Alcoi.

\section{“Descartamos sistemas porque no tenían suficiente potencia, o sea, no se ajustaban a una empresa que ya cuenta con un sistema avanzado"}

En cualquier caso, el proceso de desarrollo dio lugar en la mayoría de los casos a la aparición de un auténtico "rosario" de jefes de proyecto que aparecían y desaparecían por la empresa, sin que el nuevo sistema de información tuviera visos de llegar a buen puerto. 
Las circunstancias anteriores plantearon la posibilidad de continuar con el desarrollo del sistema antiguo, adaptándolo a una arquitectura abierta cliente/servidor; que sustituyera su sistema tradicional de gestión de ficheros y utilizara en su lugar, un gestor de bases de datos relacional basado en estándares SQL; que permitiera realizar una programación orientada a objetos y que por supuesto incorporara las prestaciones funcionales que la empresa demandaba ahora y previsiblemente aparecerían con la incorporación a la Unión Europea y el efecto 2000.

\subsubsection{El presente: desarrollo e implantación del ERP.}

Se decidió que los nuevos desarrollos de software fueran realizados por los propios informáticos de Textiles Alcoi, en lugar de contratarlo a una empresa programadora. De esta forma, se ganaba en varios aspectos: por una parte, parecía una solución más barata, el desarrollo por una empresa externa sería más caro, y más aún si esta no ve suficiente mercado para rentabilizar su producto. Además, la empresa disponía en nómina de personal informático cualificado para realizar este cometido. Adicionalmente, se conseguía un software desarrollado, no sólo para el cliente, sino también desde el punto de vista del cliente y desde casa del cliente, lo cual le permite alinearse estrechamente con la estrategia de negocio de Textiles Alcoi, proporcionando al ERP un planteamiento innovador y competitivo. En todo momento, este enfoque de desarrollo propio permite a la alta dirección conocer y seguir de primera mano la evolución de su nuevo sistema de información.

"Es más fácil tener un programador con un sueldo justo, aquí en la empresa, que tener que pagar a una empresa programadora externa que programe para ti"

El desarrollo de un sistema de información de las características anteriores implicó una fuerte reestructuración del departamento de informática, que empezó a operar casi como una empresa independiente. Liderado por el jefe de departamento, se le dispuso de un equipo de 7 personas para el análisis y desarrollo. La posición de esta área en la estructura funcional cambiaba, pasando a situarse a nivel de staff, y dependiendo directamente de gerencia. 


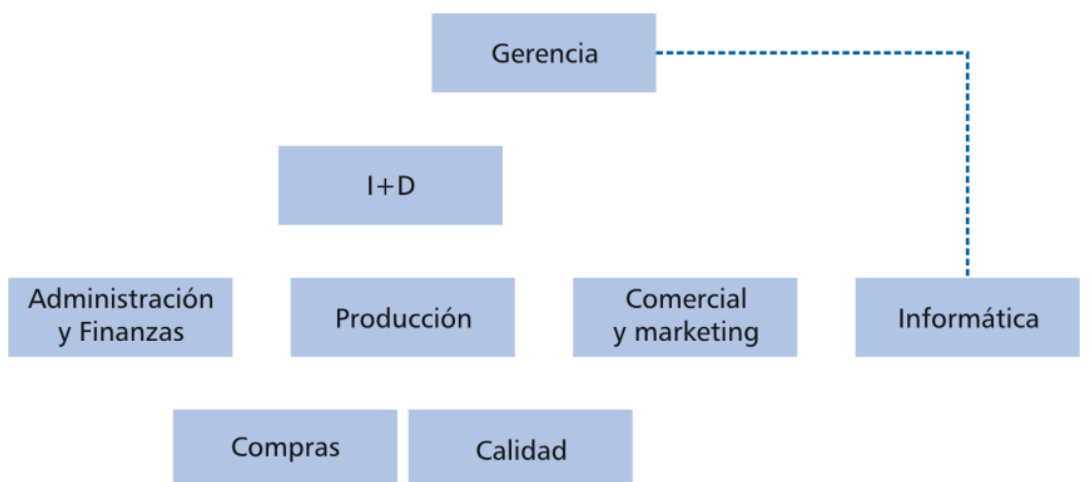

Figura 6.15: Nueva estructura organizativa

Para el desarrollo de nuevas funcionalidades relativas a la programación de la producción y el control de procesos se contó con la colaboración de profesores universitarios. Se buscaba así, no caer en el error de programar "algo demasiado encorsetado" a las particularidades y a la coyuntura de Textiles Alcoi. Sino, de alguna manera, anticiparse a los requerimientos venideros del sistema, tratando de conseguir un producto bastante estándar, suficientemente parametrizable y con visión de futuro.

Se comenzó a realizar, en primer lugar, un análisis y descripción de procesos y en algunos casos un rediseño. Este proceso se llevó a cabo durante 6 meses y permitió plantear los requerimientos de los procesos al contemplar las rutas, operaciones y el tiempo empleado. Asimismo, se contemplaron funcionalidades como la programación de la producción "scheduling", que se pensó podían ser abordadas posteriormente.

El resultado de este trabajo ha sido un potente ERP en muchos aspectos superior a los existentes en el mercado. Por poner un ejemplo, una de las consultoras con las que se contactó para desarrollar el ERP estaba trabajando con empresas que apenas aportaban cuatro folios de requerimientos. El sistema desarrollado surge a partir de cientos de folios de requerimientos de Textiles Alcoi. Es por eso que, tiene muchos más niveles de profundidad en el tratamiento de la información que otros sistemas, pero también puede funcionar correctamente con estructuras más planas.

"Una aplicación horizontal difícilmente llega a funcionar en confección. El usuario tiene que dar muchos pasos para hacer algo. La parametrización resulta una tarea muy difícil.

El Sistema ERP.

Algunas características funcionales del producto que dan fe del planteamiento innovador del mismo son las siguientes: 
- Análisis de precisión de demanda con empleo de modelos no lineales. En confección, los plazos son muy reducidos ya que cada vez se tiende a cambiar más rápidamente de colección. Para poder cumplir plazos hay que empezar antes la producción y eso puede hacerse sin apenas riesgo gracias la gestión del ERP. Puede empezarse con las primeras fases de fabricación basándose en las previsiones; el ERP compara las previsiones con los datos reales y de esa forma indica las cantidades que deben pasar a las siguientes etapas de fabricación o a talleres subcontratados. Con esta gestión no es necesario esperarse a tener el $80 \%$ de los pedidos para empezar a fabricar.

- La aplicación calcula consumos estimados de recursos y luego los compara con consumos reales en varios momentos del proceso de fabricación. De esta forma, se van calculando las desviaciones que sirven de realimentación para afinar en los consumos estimados.

- Asignación de piezas a tejidos y marcadas. No sólo para control de stocks sino para mejorar la trazabilidad de las operaciones, (ligado a una orden de producción)

- Control de la conversión de las unidades de medida, pues el tejido se compra en kilos, pero se consume en metros.

- Control de ubicaciones y organización del almacén.

- "Una de las fortalezas de un sistema es que la información reside en el sistema y no en las personas que lo utilizan". Con este ERP el sistema propone y el usuario confirma teniendo siempre la última palabra (ej., el sistema hace un escandallo y el empleado lo confirma o modifica).

- Importación de estructuras: se le puede pedir al sistema que busque estructuras de producto, ya desarrolladas, similares a una dada.

Resulta obvio pensar que la implantación del sistema ERP en Textiles Alcoi fue modular. Al coincidir en tiempo y lugar los desarrollos y la implantación, lo más sensato fue ir arrancando los módulos conforme se iban acabando y probando. Esto provocó que coexistieran el sistema antiguo y el viejo durante mucho tiempo, pero sin que esto significase trabajo en paralelo. El usuario no introduce en ningún momento los datos de forma duplicada; cuando empieza a utilizarse un módulo deja de utilizarse el equivalente del sistema antiguo. Lo que sí era de vital importancia era que los usuarios utilizaran el nuevo sistema y que comunicaran cualquier problema al departamento de informática. En este aspecto cabría destacar el papel de uno de los empleados de la empresa.

"Es de esas personas que no llegas a ver nunca porque es tan pequeño y tan
nervioso..." "Le gusta experimentar y probar cosas nuevas". "Una persona así
en la empresa ayuda a romper la resistencia al cambio"

Esta persona entró en la empresa como mozo de almacén, pero su entusiasmo y afán de mejora lo han convertido en un líder natural entre los empleados. Su formación viene complementada por una innata curiosidad. Conocedor de los antiguos sistemas de información. Desde hace mucho tiempo, viene programando 
pequeños controles en todas las áreas de la empresa. Especialista en compras, ha revisado las estructuras de productos y su encadenamiento con la planificación de compras, de producción y diseño. También asume todos los módulos que le vas entregando, los utiliza, los prueba y hace cálculos paralelos para comprobar que el sistema va bien. Encuentra desviaciones y el porqué de esas desviaciones. Esta persona ha sido clave para el desarrollo e implantación con éxito del nuevo software, al hacer disminuir con su participación y "ejemplo" la resistencia al cambio, natural en todas las organizaciones. De todas formas, en la organización han aparecido roles que han dificultado el desarrollo del sistema, normalmente asumidos por empleados expertos, conocedores de su función pero que no han asumido como propio el sistema, no se han implicado, han obstaculizado la depuración de errores, no informaban a los equipos de desarrollo y han puesto toda clase de inconvenientes al ver amenazado su statu quo. Estos usuarios, aferrados a un esquema que puede ser descrito por la frase: "Yo estoy aquí para hacer este trabajo y de aquí no me saques. En definitiva, a mi no me pagan para pensar." deben ser identificados y motivados, en la medida de lo posible, para estimular su colaboración o al menos mitigar sus obstrucciones.

Gracias a una implantación modular y "paso a paso" no hubo ninguna disminución de la productividad, al menos que se pudiera relacionar directamente con el mismo proceso de implantación. Sí que disminuyó ligeramente la productividad en la facturación pero fue debido a fallos en la programación del software que ralentizaban algunos procesos, y que posteriormente se resolvieron sin dificultad.

“Los operarios ven que tienen que cumplir con su jefe o con la empresa, entonces si encuentran un pequeño obstáculo con el ERP pero ven que pueden seguir haciendo su tarea como la hacían antes pues no se detienen en aprender y siguen haciéndola como antes."

Mirando la tabla 6.3 se puede ver como Textiles Alcoi disponía de muchas funciones informatizadas antes de implantar el sistema ERP. Algunas de ellas, las más innovadoras se han incorporado, pero lo más notable es la mejora obtenida en todas ellas. 


\begin{tabular}{|l|c|c|}
\hline \multicolumn{1}{|c|}{ FUNCIONES } & ANTES DEL ERP & DESPUES DEL ERP \\
\hline 1-Aprovisionamiento & Sí & Sí, mejorado \\
\hline 2-Plan./Prog de Proyectos & No & Sí, mejorado \\
\hline 3- Gestión de stock & Sí & Sí, mejorado \\
\hline 4- Logística y distribución & Sí & Sí, mejorado \\
\hline 5- Marketing y publicidad & Sí & Sí, mejorado \\
\hline 6- Gestión comercial & Sí & Sí, mejorado \\
\hline 7- Aten. Cliente y postventa & Sí & Sí, mejorado \\
\hline 8- Contabilidad & Sí & Sí, mejorado \\
\hline 9- Gestión tesorería & Sí & Sí, mejorado \\
\hline $10-$ Gestión de activos fijos & Sí & Si \\
\hline $11-$ Nóminas & No & No (Externa) \\
\hline $12-$ Gestión RRHH & No & No \\
\hline $13-$ SIAD & No & Sí \\
\hline $14-$ Correo electrónico & No & Sí \\
\hline $15-$ Flujo de trabajo. Workflow & No & Sí \\
\hline $16-$ Paginas en Internet & No & Sí \\
\hline $17-$ Comercio electronico & No & Sí \\
\hline $18-$ Intranet & No & No \\
\hline $19-$ Extranet & & \\
\hline 20- Otros & & \\
\hline
\end{tabular}

Tabla 6.3: Funcionalidades antes y después.

Calcular el coste del ERP no resulta nada fácil siendo un caso tan particular. ¿Qué parte de los sueldos del departamento de informática debería adjudicarse a la programación del ERP?

\subsubsection{El futuro: la evolución de los sistemas de información.}

La empresa tiene como proyecto ir ampliando las prestaciones del sistema. Aspectos tales como la gestión de tesorería, actualmente desarrollada en Access y que se quiere migrar a SQL; la gestión documental, que permita gestionar el flujo de documentos administrativos y en general de todo los procesos de negocio, la programación scheduling, permitiendo la coordinación entre las distintas fases, adecuando la capacidad productiva interna con la externa subcontratada; gestión de recursos humanos, etc.

\section{“Este ERP no se va acabar nunca... Cada seis meses se sacarán versiones nuevas."}

En definitiva, Textiles Alcoi se encuentra en la encrucijada de disponer de los desarrolladores del ERP indoor, con las ventajas e inconvenientes que esto supone. Esto define un futuro de retos excitantes y motivadores para la empresa. 


\subsubsection{Lecciones aprendidas.}

La consideración de este caso empresarial nos permite extraer algunas otras consideraciones:

- El ERP tiene que "venderse" dentro de la empresa y convencer, para ello se necesita un esfuerzo de todo el personal de la empresa y una implicación potente y continuada de gerencia.

- En el caso analizado, dadas sus propias particularidades, la implantación ha seguido una metodología de carácter modular. Aunque de esta forma han tenido que coexistir los dos sistemas, no podemos considerar que se haya trabajado en paralelo. No conviene cargar al usuario con más trabajo.

- Hay que tener cuidado con empleados "tímidos", que ante cualquier problema con el ERP se callan e intentan salir del paso, realizando las operaciones como pueden con tal de cumplir con su trabajo. Es preferible que comuniquen cualquier problema y que al final todos acaben utilizando el ERP. Del mismo modo, hay que prestar atención a empleados "no tan tímidos" que se niegan a utilizar el ERP por pereza en aprender o porque sienten que el ERP se entromete en su parcela de poder.

- Se debe dar una buena formación al usuario, asegurándose que realmente ha aprendido, al menos en lo referente a la aplicación práctica del sistema a sus tareas cotidianas.

- $\quad$ Cada módulo que se implanta debe ser probado y testeado rigurosamente.

“La aplicación es tan grande que no la conoce nadie. El usuario se centra en su trabajo y no se dedica a buscar información por el resto del sistema ".

\subsubsection{Correlación con los factores críticos del modelo de investigación}

\section{1: Apoyo de la dirección}

La empresa muestra desde la década de los 80 una importante sensibilidad hacia el área de la informática, de hecho dispone de un departamento propio de informática que depende directamente de gerencia (el $80 \%$ de los trabajadores usa habitualmente el ordenador como herramienta de trabajo). La propia dirección detecta cuellos de botella en la creación del producto, ya que este es muy variado por lo que son conscientes de la necesidad de cambio hacia un sistema que integre de una forma más completa los diferentes procesos. La gerencia desde el primer momento apoya y lidera de una forma total el proyecto de modernización del sistema de información. 


\section{2: Fijación de objetivos y planificación}

El objetivo del "cambio" lo tienen muy claro: tener un sistema integrado de gestión que permita disponer de las prestaciones anteriores y que muestre un mayor nivel de profundidad en el tratamiento de la información crítica.

La empresa establece una detallada planificación estratégica del proyecto teniendo claro la herencia de los datos disponibles en un nuevo sistema de bases de datos relacionales que incorporase las funcionalidades actuales y las futuras.

\section{3: Idoneidad de la solución ERP}

Un punto crítico de la planificación es la evaluación de las diferentes alternativas que ofrece el mercado. La empresa genera un equipo de trabajo que se encarga de ese asunto pero al final deciden que ninguna solución del mercado se adapta al $100 \%$ a las necesidades y requerimientos de la empresa, ya que, recordemos, esta tiene una importante filosofía informática. Al final deciden crear ellos mismos sus propios desarrollos informáticos.

\section{4:Administración del proceso de implantación}

Al haber decidido que la nueva solución la crearían ellos mismos, desde su departamento de informática, necesitan tener completamente controlado el proceso de implantación, por lo que precisan de una gestión y administración del proyecto total. Esto obliga incluso a que el departamento de informática, encargado del desarrollo e implantación de la solución, sufra una importante reestructuración que hace que opere como una empresa independiente ya que la parametrización del nuevo sistema requiere una dedicación muy exigente.

Conscientes de la importancia de la implantación la empresa la realiza de forma modular y "paso a paso" para que la disminición de la productividad sea mínima.

Al ser un desarrollo propio la implantación no finaliza nunca porque siempre hay nuevos módulos o nuevas funcionalidades que se pueden incorporar.

\section{5: Comunicación y participación}

El éxito de la aplicación depende de que el usuario final haga buen uso del sistema. La empresa parte con la ventaja de que los operarios tienen la "costumbre" de trabajar con el ordenador lo que lleva a que la tecnología no les resulte incómoda. Ahora bien, a pesar de ello la empresa no descuida el tema del diálogo y la comunicación y lo considera crítico ya que hay que habituar a la gente al nuevo sistema. Al hilo de esto son consciente que el usuario debe tener una buena formación continua de manera que se adapte al nuevo sistema. Tienen un lema que genera una importante reflexión: "el ERP tiene que venderse dentro de la empresa". 


\subsubsection{CASO D: Textiles Ontinyent, S.A.}

La empresa Textiles Ontinyent, S.A. pertenece en la actualidad a un grupo de empresas. De procedencia "tradicional" familiar, con la evolución de los años se ha ido modernizando hasta convertirse en una empresa dinámica y competitiva, pese a conservar elementos típicos de las empresas familiares tales como el paso de la gerencia de padres a hijos.

Está estructurada, por razones fundamentalmente operativas y fiscales, como un conjunto de cinco razones sociales diferentes que realizan distintos procesos productivos.

Fabrica tejidos para la industria de la tapicería de muebles y los comercializa en todo el mundo, con características que benefician tanto al fabricante como al consumidor. Considera que sus factores diferenciales competitivos son el precio, calidad, servicio (cumplimiento de los plazos de entrega) e innovación (sobre todo en diseño). Se han realizado cambios a partir de productos existentes en el mercado americano permitiendo la realización de "lotes económicos".

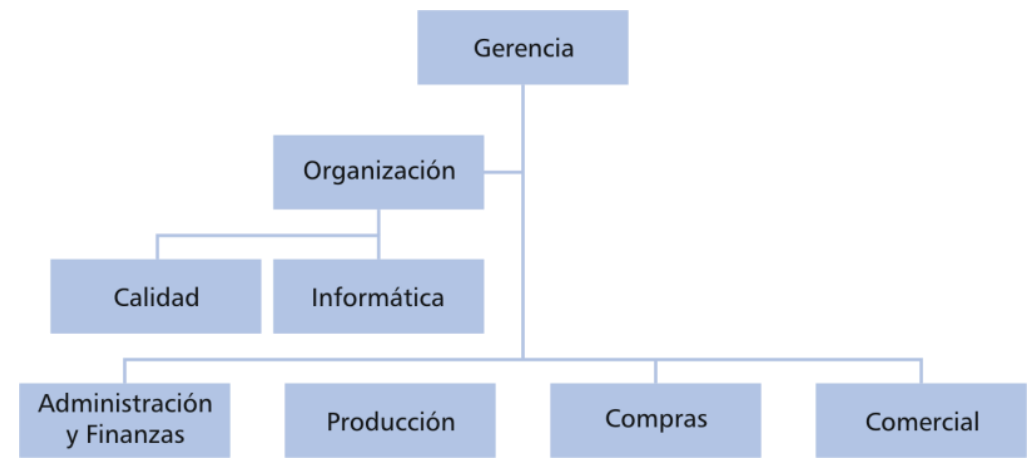

Figura 6.16: Estructura organizativa

Sus productos son conocidos por su gran durabilidad y fácil mantenimiento ofreciendo diseños y colores constantemente actualizados. La empresa ha superado el test de sustancias nocivas OEKO-Standard 100. El área de innovación y desarrollo de productos y también de máquinas y utillaje propios, una de las fortalezas de la empresa, da soporte a la función de Producción, que realiza fundamentalmente la preparación y ensamblado de tres materias primas que compran a sus proveedores: la tela, el adhesivo y el flock, cuyo tratamiento es la tarea más crítica. Posteriormente, se realizan los procesos de acabados, revisados y expedición.

Hace 3 años se incorporó el ISO 9002 del 94 . Además siguen una serie de normas propias de calidad tanto en producción como en administración de informes, estadísticas, seguimientos, etc. La empresa fomenta la formación de grupos de 
mejora en las áreas de producción, calidad y diseño que buscan la mejora continua; se dispone también de un buzón para la recogida de sugerencias de mejora.

Para Textiles Ontinyent, la formación, tanto obligatoria como facilitando la realización de cursillos voluntarios, es muy importante para facilitar la colaboración de los usuarios con los cambios, y que éstos conozcan la misión empresarial y se impliquen con ella. Alineadas con este planteamiento están las políticas de retribución de la empresa que pretenden basarse en el rendimiento, desarrollo e implantación de nuevas ideas y participación en proyectos de mejora; a pesar de la estructura de empresa familiar que se posee, se está buscando una mayor profesionalización.

La empresa dispone de un departamento de marketing que comercializa sus productos en más de 60 países. El objetivo es aumentar la cartera de clientes, éstos, son fabricantes y mayoristas que utilizan su tejido principalmente en tapicería; pero su objetivo es convencer al consumidor final incentivando directamente a las tiendas, que son quienes realmente convencen al consumidor final. Se mide la satisfacción de los clientes desarrollando métodos de medición de reclamaciones, devolución de pedidos, encuestas de satisfacción ${ }^{3}$, etc.

El departamento de informática depende de la función de organización, ésta última como un staff de gerencia, como un intento de asegurar una coordinación de objetivos y requerimientos de los sistemas de información entre los distintos departamentos, coordinador para definir las mejoras organizacionales que afecten a todos los departamentos por igual, ya que de otra forma las reformas solo mejoran el trabajo de los departamentos que las promueven sin importarles los demás.

\subsubsection{El pasado: causas y antecedentes del sistema ERP.}

Hace 7 años, cuando se contrató a un responsable para el nuevo departamento de informática, con amplia experiencia en consultoría, no había nada informatizado, tan solo la parte administrativa, en la que contaban con un IBM (Sistema 36) con las limitaciones propias de los equipos de esos años. Desde esa fecha hasta la actualidad, la empresa ha vivido un proceso de expansión: se ha pasado de 80 a 300 personas.

\section{"El objetivo de los sistemas de información, es solventar las deficiencias de comunicación entre las diferentes partes de la empresa."}

\footnotetext{
${ }^{3}$ Se tiene un grado de satisfacción del cliente en cuanto al cumplimiento del plazo de entrega de pedidos del $80 \%$. Este cumplimiento es básico para la empresa, cuando se recibe un pedido si no puede cumplirse con el plazo de entrega, una vez negociado, se prefiere rechazarlo a proceder a su subcontratación.
} 
La necesidad del cambio fue detectada por el director financiero, que en aquellos tiempos tenía bajo su responsabilidad la función informática de la empresa. En principio se buscaba un paquete de software que informatizara los diferentes departamentos y que pudiera implantarse con suficiente rapidez. Pero el responsable de informática no deseaba implantar una solución informática sin más, sino que entendía, que realmente lo que se buscaba era un nuevo modelo de negocio, por eso pasó un año entero, a petición propia, familiarizándose con los procesos de la empresa. Llegando a la conclusión de la imposibilidad o inutilidad de informatizar simplemente los ineficientes sistemas de la empresa, y convenció a gerencia para "empezar desde cero", rediseñando los procesos de la empresa, para lo cual se contó con la colaboración de consultores externos durante un periodo de un año. Este proceso de reingeniería abordó en primer lugar el tema de la administración y función comercial, y tras un "parón" se abordó la planificación y programación de la producción. El proceso de reingeniería gozó del apoyo del director financiero y del propio gerente de la empresa. En él se detectó que la calidad del trabajo realizado podía mejorar si se abordaba el problema de la falta de comunicación de objetivos y de coordinación entre todas las áreas de la empresa.

Se confiaba que la aplicación del nuevo sistema trajera consigo una mejora de las relaciones tanto con clientes como con proveedores, y de rebote un incremento de las ventas: "los representantes inevitablemente nos comparan con los competidores, con lo que cualquier ventaja que puedas sacarles es decisiva" comenta el director comercial.

Después de realizar un profundo análisis de las necesidades de información que se necesitan en los procesos de la empresa, llegaron a la conclusión de que lo que necesitaban era un ERP.

Se dividieron los sistemas integrados de gestión en varios tipos: los básicos que incorporan las áreas económico-financiera, compras y gestión comercial; los sectoriales que incorporan todos los conceptos y funciones del sector y los específicos que atienden a las funcionalidades específicas de la empresa, que no pueden encontrarse en un sistema estándar.

Se formó un equipo de trabajo inicial en el que participaban el director financiero y el responsable de informática; éste se amplió posteriormente con otros directores de área, para seleccionar entre las distintas alternativas. Siguiéndose los pasos que aparecen a continuación:

1. Análisis de todas las soluciones del mercado.

2. Comprobar con detalle las soluciones que, en principio, parecen más convenientes

3. Demostración de cada una de las áreas funcionales, de los diferentes ERP's que parecen mas apropiados, a priori, con la directiva.

4. Demostración departamental con los usuarios finales. Los directores y mandos intermedios no conocen "la verdad de la producción", hay que ver 
la opinión de los operarios finales, que son los que aportan la información más importante para el éxito final.

"Para nosotros, al margen de terminologías, un ERP debe englobar todas las funciones de la empresa. Con un núcleo básico robusto que "conecte" bien con módulos específicos especializados, incluso de varios fabricantes, para todas las áreas de la empresa, especialmente en producción y expedición."

Se realizaron estudios de viabilidad de índole técnica y económica, que incorporaban los sistemas informáticos previos, los distintos elementos de coste y las características funcionales de las distintas soluciones.

Los requerimientos técnicos especificados en la búsqueda del software son:

- Facilidad en la instalación.

- Entorno abierto que permita elegir entre diferentes sistemas operativos y hardware.

- Modularizable.

- Formación técnica y de usuarios.

- Fácil configuración.

- Filosofía cliente-servidor.

- Lenguaje de programación abierto y de amplia difusión.

- Base de datos abierta y posibilidad de seleccionar cualquier otra.

- Servicio técnico.

- Fácil adaptación del sistema a la empresa.

- Coste de licencias.

Se diseñó también una batería de requerimientos funcionales, de las distintas áreas de la empresa, que permitieron valorar los distintos sistemas, en base a una plantilla de valoración que consideraba si se incorporaba la función y el grado de mejoras que debían realizarse. Las áreas y módulos considerados fueron los representados en la tabla 6.4.

\begin{tabular}{|l|l|}
\hline Área & Módulo \\
\hline Económico- financiera & Tesorería de cobros. \\
\hline & Tesorería de pagos. \\
\hline & Previsión de tesorería. \\
\hline & Contabilidad. \\
\hline Compras & Declaraciones fiscales. \\
\hline Comercial & General \\
\hline Almacenes & Nacional/extranjero. \\
\hline General & $\begin{array}{l}\text { Elaboración de estadísticas, E-commerce, soporte al sistema de } \\
\text { calidad, multiempresa, multilenguaje, seguridad y } \\
\text { confidencialidad. }\end{array}$ \\
\hline
\end{tabular}

Tabla 6.4: Requerimientos por área 
Se tenía un condicionante de hardware muy fuerte: el IBM S400 que habían adquirido recientemente y que dada la cuantía de la inversión en este aparato, condicionó las posibilidades del resto de opciones al tener que ser abandonado. Por lo que únicamente se tuvieron en cuenta las opciones del mercado que pudieran implementarse en este equipo. Se analizaron varias opciones en base a aspectos técnicos, funcionales y económicos. Se consideraron como críticas las características de trazabilidad, seguridad, generación de informes y confidencialidad. Son secundarias las características de conectividad, simulación, interfaz gráfico y adaptabilidad. En aquel tiempo, se prefiere la fiabilidad al entorno visual.

El responsable de informática tenía claro que no se trataba simplemente de elegir el ERP que mejor se adaptase a la empresa e implantarlo, sino que había que replantearse cada una de las acciones que se llevaban a cabo en la empresa en busca de una optimización profunda de todos los recursos de la empresa y después plantearse las necesidades en cuanto a sistemas de información, ya que la complejidad de los sistemas que necesita una empresa se puede relacionar directamente con el número de licencias utilizadas, con lo que empresas pequeñas no necesitan un verdadero ERP con todo el proceso de reingeniería que éste implica, sino tan solo una simple informatización.

\subsubsection{El presente: proceso de implantación del ERP.}

En primer lugar se abordó el tema de administración ya que era prácticamente el único que contaba con alguna experiencia en informática y por lo tanto, el departamento en el que sería más fácil la adaptación.

Los módulos que se implantaron en primer lugar, tuvieron la siguiente secuencia de instalación ${ }^{4}$ :

- La gestión contable y la gestión de tesorería: pagos y cobros de proveedores y clientes; así como el registro de facturas.

- Previsiones de tesorería: éste fue considerado un módulo crítico, por lo que aunque se intentó no trabajar en paralelo, esto obligó a la realización de muchas pruebas con datos reales mediante un interfaz entre el sistema antiguo y el nuevo.

- Gestión de facturas, pagos, con un interfaz hasta contabilidad

- Planificación de pagos: nacional y exportación.

- Planificación de cobros: nacional y exportación.

- Módulo de activos fijos: gestión, previsión de amortizaciones.

- Gestión de ventas, con otro interfaz.

- Gestión de compras

\footnotetext{
${ }^{4}$ En todos los casos hubo que realizar modificaciones analizando bien el sistema y las peticiones de los usuarios.
} 
Las fases que se han seguido en el proceso de implantación han sido las siguientes:

\begin{tabular}{|c|c|}
\hline \multirow[t]{3}{*}{ ANÁLISIS FUNCIONAL (50\%) } & Estudio previo \\
\hline & Estudio detallado con los departamentos \\
\hline & Análisis de mejoras \\
\hline ANÁLISIS ORGÁNICO (15\%) & Análisis orgánico \\
\hline \multirow{6}{*}{$\begin{array}{l}\text { DESARROLLO (35\%) } \\
\text { INSTALACIÓN }\end{array}$} & $\begin{array}{l}\text { Desarrollo-pruebas: } \\
\text { Proaramador }\end{array}$ \\
\hline & $\begin{array}{l}\text { Pruebas dpto. informática. Interno. Migración de } \\
\text { datos maestros }\end{array}$ \\
\hline & Pruebas con dpto. / formación \\
\hline & Instalación \\
\hline & Implantación \\
\hline & Transvase de datos de movimientos \\
\hline
\end{tabular}

Tabla 6.5. Fases del proceso de implantación.

Como puede verse se ha dedicado un $50 \%$ de recursos y tiempo al análisis funcional en el que se planifican las actuaciones a realizar.

El cambio, reflejado en la aplicación de tecnología, ha sido drástico. De un pasado en el que se disponía de un ordenador central (mainframe), 8 terminales tontas (pantallas Telnet) y un PC se ha pasado a disponer de 4 servidores y más de 100 ordenadores personales configurados en red Tokenring con cableado de fibra óptica entre las distintas empresas del grupo. Si se analiza el cambio desde la perspectiva de software, el cuadro siguiente refleja el cambio: 


\begin{tabular}{|l|c|c|}
\hline \multicolumn{1}{|c|}{ FUNCIONES } & $\begin{array}{c}\text { ANTES DEL } \\
\text { ERP }\end{array}$ & DESPUES DEL ERP \\
\hline 1-Aprovisionamiento & $\mathrm{Si}$ & $\mathrm{Si}$ \\
\hline 2-Plan./Prog de Proyectos & & $\mathrm{Si}$ \\
\hline 3- Gestión de stock & & $\mathrm{Si}$ \\
\hline 4- Logística y distribución & & $\mathrm{Si}$ \\
\hline 5- Marketing y publicidad & Básica & $\mathrm{Si}$ \\
\hline 6- Gestión comercial & & $\mathrm{Si}$ \\
\hline 7- Aten. Cliente y postventa & $\mathrm{Si}$ & $\mathrm{Si}$ \\
\hline 8- Contabilidad & & $\mathrm{Si}$ \\
\hline 9- Gestión tesorería & & Externa \\
\hline 10- Gestión de activos fijos & & Actualmente buscan un \\
\hline 11- Nóminas & & paquete \\
\hline 12- Gestión RRHH & & En desarrollo o a nivel \\
& departamental \\
\hline 13- SIAD & & $\mathrm{Si}$ \\
\hline 14- Correo electrónico & & $\mathrm{Si}$ \\
\hline 15- Flujo de trabajo. Workflow & & $\mathrm{Si}$ \\
\hline 16- Paginas en Internet & & Si \\
\hline 17- Comercio electronico & & Si \\
\hline 18- Intranet & & Portal \\
\hline 19- Extranet & & Planificación de tesorería \\
\hline 20- Otros
\end{tabular}

Tabla 6.6: Funcionalidades antes y después de la implantación

El departamento de Informática, disponía, además de su responsable, de dos programadores, uno centrado en el desarrollo de sistemas y el otro en la administración y configuración de equipos; y dada la estructura organizativa de la empresa, ésta dispone de un encargado del tema de calidad.

La empresa realiza pequeños desarrollos propios utilizando Visual Basic y Visual FoxPro accediendo a las bases de datos de la empresa mediante API; no obstante, los desarrollos con requerimientos más complejos son subcontratados. Las aplicaciones informáticas comienzan con un análisis del flujo de información disponible que se complementa con un análisis del flujo de información necesaria. Estos procesos de análisis permiten definir en un primer nivel los sistemas de información. En cualquier caso, se tiene en cuenta a los distintos departamentos, lo que permite paliar la falta de comunicación en la definición de necesidades y planteamiento de objetivos. Este establecimiento de objetivos, en el marco de una adecuada planificación, tanto si se trata de desarrollos propios como

\footnotetext{
${ }^{5}$ Distinta de la gestión de tesorería, ya que ésta se basa en la gestión de cobros y pagos, mientras que la planificación sirve para presupuestar esta gestión y hacer previsiones a medio y largo plazo de acciones y consecuencias
} 
subcontratados, es seguida por los tradicionales análisis funcional y orgánico, así como la consiguiente fase de pruebas.

El director de organización ha sido el enlace entre la empresa y la consultora de implantación. Hubo una estrecha colaboración con la consultora, no se la dejó sola, dado que en la empresa se contaba con personal cualificado y además buscaban una auténtica reingeniería de procesos, eliminar vicios, buscar las tareas imprescindibles y necesarias para la producción y si es posible adaptarse a la forma en que éstas son abordadas por la aplicación. Esto hay que tenerlo claro desde un principio y no ponerse en manos de los consultores directamente, ya que estos tienen como objetivo la "perpetuidad" en las empresas, prueba de ello es que su primera inquietud suele ser la facturación de la empresa, cuando en la práctica, éste dato no tiene ninguna relación con la complejidad de los procesos de la empresa.

Por parte de la consultora había un responsable del proyecto, un analista funcional, un analista de proyecto y programadores. Los directores de cada área se reunían solo para decidir las fechas de las reuniones, que estarían dirigidas a los usuarios a su cargo, que eran también los encargados de las pruebas, en las que colaboraban además de los usuarios finales, un programador y un informático interno de la empresa. En relación a la dedicación se estima a un 60 - 70\% por parte del equipo de la consultora.

Se ha luchado contra la resistencia al cambio motivando al personal para conseguir su participación e implicación en el proyecto. Se potenció la comunicación al máximo, realizando reuniones a todo nivel en las que, entre otras cosas se informaba de las mejoras que el nuevo sistema incorporaría en la operativa de trabajo. Pese a que pasaron 6 meses recopilando información continuó habiendo resistencia al cambio por parte de los trabajadores, lo cual es inevitable, pero cuantitativamente mucho menor que de lo contrario. Se informó fundamentalmente a los trabajadores de las mejoras que se iban a incorporar, muchas de ellas habían sido solicitadas por ellos, en base a un estudio organizativo. Este hecho provocó una mayor implicación de los trabajadores disminuyendo su reticencia al cambio.

\subsubsection{El futuro: la evolución de los sistemas de información.}

En un principio, el sistema proporcionaba a través de Internet información precisa y en tiempo real del proceso de fabricación de los pedidos a cada uno de los clientes, pero después de un tiempo se decidió eliminar ese servicio, ya que suponía una carga de trabajo extra para atender a las numerosas llamadas de los clientes. De esta forma se separó la intranet, donde esta información está disponible, de la extranet, donde no lo está.

Actualmente, el objetivo del nuevo gerente es la implantación de un sistema de información único en todas las empresas del grupo industrial. Realmente, el 
proceso de implantación no acaba nunca, porque las necesidades de información aumentan cuando el sistema comienza a ser funcional siendo demandadas por los usuarios que van pidiendo mejoras siendo éstas racionalizadas en base a un estudio organizativo; así se han desarrollado los aplicativos de gestión comercial y el módulo de activos fijos. Actualmente, seguimos renovándonos en todas las áreas especialmente en producción y expedición, donde las posibilidades parece que no acaban de agotarse.

\subsubsection{Lecciones aprendidas.}

La empresa se encontraba en proceso de expansión, por lo que no se pretendía una reducción de personal; no obstante, quizás si no se hubiera implantado el sistema de gestión, la plantilla habría alcanzado un mayor tamaño. En definitiva, las metas pasan por un aumento de la eficiencia mediante una reducción de costes con un aumento de la calidad y el servicio. Otros aspectos a considerar como aspectos de aprendizaje, que pudieran aconsejarse a otras empresas del sector, son los siguientes:

- No se trata de acumular capa sobre capa de tecnología, pues ésta por sí sola, no conduce a la ventaja competitiva. Es preciso lograr una adecuada armonía entre las estrategias, las personas, los procesos y las tecnologías. Las empresas que no afrontan sus problemas de una manera global o se centran en uno de estos factores están erigiendo barreras, no asimilando la tecnología o peor aún, anquilosando los procesos antiguos de gestión, obstaculizándose cada vez más la capacidad de cambio de la organización.

"No Ilegará primero el que más tecnología compre, sino el que aplique mejor."

- Es preciso ser paciente y sistemático en el análisis de los requerimientos: el coste de un error en el análisis funcional es mucho mayor que cuando se produce en la fase de programación.

\section{"No debe importar pasarse mucho tiempo planificando el proceso: <-Medir dos veces cortar una>>"}

- Necesidad de un rediseño de los procesos.

- La implantación del sistema "no acaba nunca", continuamente surgen nuevas necesidades fruto de cambios, mejoras, nuevas solicitudes de información.

- El sistema debe suministrar información homogénea, de calidad y que permita su proceso mediante herramientas ofimáticas. 
Siendo importante el disponer de información en tiempo real, hay que equilibrar este aspecto con su coste, en definitiva, no siempre se necesita "información al momento".

"Dependiendo de la motivación e implicación de las personas, los proyectos más complicados pueden simplificarse notablemente"

- La motivación de los recursos humanos es un aspecto crítico pues la implantación puede provocar desconfianza e incremento en la carga laboral al verse obligados a realizar un control adicional sobre las tareas realizadas, con el consiguiente malestar que esto provoca. Es preciso estar atentos a los usuarios, los fracasos en la implantación de sistemas provocan en ellos una desmotivación y desconfianza que potencia una mayor resistencia al cambio que dificultará la consecución del éxito en futuras implantaciones.

\subsubsection{Correlación con los factores críticos del modelo de investigación}

\section{1: Apoyo de la dirección}

La necesidad de cambio fue detectada por el director financiero que era responsable de la función informática de la empresa quien tras un análisis inicial de la situación decidió llevar a la gerencia la necesidad del rediseño de los procesos de la organización a través de una reingeniería de forma que se llegase a un nuevo modelo de negocio. Este proceso contó con el apoyo de la gerencia de la empresa.

\section{2: Fijación de objetivos y planificación}

El objetivo era crear un nuevo modelo de negocio donde la informática desempeñase un papel primordial de forma que las diferentes funcionalidades de la empresa quedasen integradas en un solo sistema informático de gestión: necesitaban un ERP.

Desarrollan una metodología que les lleva a tener una planificación detallada de las diferentes fases del proyecto bajo unos requerimientos claramente establecidos.

\section{3: Idoneidad de la solución ERP}

Se analizaron varias opciones en base a aspectos técnicos, funcionales y económicos, y se comienza por abordar el área de administración que era el que más experiencia informática tenía y por tanto donde la adaptación y el cambio sería menos traumático. En la solución implantada interviene también la propia empresa, aparte de la consultora seleccionada, realizando desarrollos propios 


\section{4: Administración del proceso de implantación}

El director de organización es el enlace entre la empresa y la consultora de la implantación generándose una estrecha colaboración de forma que la gestión y administración del proceso es correcta. Por otra parte tienen claro que la implantación del sistema no finaliza nunca ya que continuamente surgen necesidades.

\section{5: Comunicación y participación}

Quizá el elemento más crítico para el éxito del proyecto sea este: la dirección tiene claro que la motivación de los RRHH de la empresa es fundamental y más cuando se lleva a cabo un proyecto de reingeniería completo donde hay que rediseñar todos los procesos. La dirección realiza desde el principio una labor continua de comunicación y formación a los usuarios finales del sistema generando la confianza necesaria para el éxito del mismo.

\subsubsection{Comparativa de los casos analizados}

A continuación se realiza un resumen de los Factores Críticos de éxito considerados en los casos analizados atendiendo al modelo propuesto en el capítulo 3. En la tabla que se presenta podemos observar la importancia de los factores críticos que aparecen en los diferentes casos (valoración cualitativa entre 1 y 3$)$ :

\begin{tabular}{|l|l|l|l|l|}
\hline & $\begin{array}{l}\text { A: Textiles } \\
\text { Albaida }\end{array}$ & $\begin{array}{l}\text { B: Textiles } \\
\text { Valencia }\end{array}$ & $\begin{array}{l}\text { C: Textiles } \\
\text { Alcoi }\end{array}$ & $\begin{array}{l}\text { D: Textiles } \\
\text { Ontinyent }\end{array}$ \\
\hline $\begin{array}{l}\text { Apoyo de la } \\
\text { dirección }\end{array}$ & $\star \star \star$ & $\star \star \star$ & $\star \star \star$ \\
\hline $\begin{array}{l}\text { Fijación de } \\
\text { objetivos y } \\
\text { planificación }\end{array}$ & $\star \star \star$ & $\star \star \star$ & $\star \star \star$ & $\star \star$ \\
\hline $\begin{array}{l}\text { Idoneidad de la } \\
\text { solución ERP }\end{array}$ & $\star \star$ & $\star \star \star$ & $\star \star$ & $\star \star$ \\
\hline $\begin{array}{l}\text { Administración del } \\
\text { proceso de } \\
\text { implantación }\end{array}$ & $\star \star$ & $\star \star \star$ & $\star \star \star$ & $\star \star \star$ \\
\hline $\begin{array}{l}\text { Comunicación y } \\
\text { participación }\end{array}$ & $\star \star$ & $\star$ & $\star \star \star$ & $\star \star \star$ \\
\hline Formación & $\star$ & $\star \star \star$ & $\star \star$ & \\
\hline $\begin{array}{l}\text { Director de } \\
\text { proyecto externo } \\
\text { puente empresa / } \\
\text { consultora) }\end{array}$ & & & & \\
\hline
\end{tabular}

Tabla 6.7: Comparativa de la importancia de los factores críticos en los casos analizados. 
Se observa que en los 4 casos estudiados en la investigación se corroboran los factores críticos planteados en el modelo inicial. Todos los factores de éxito resultan importantes en el proyecto de integración del ERP en las labores cotidianas de la organización, pero sobre todo existe una coincidencia que es necesario resaltar y que es la base del éxito general y también es la que alimenta el resto de factores: me refiero al apoyo de la alta dirección. Las cuatro empresas estudiadas dan prioridad a la implicación del equipo directivo y el empuje continuo del mismo para garantizar el éxito del "nuevo sistema".

\subsection{Modelo mejorado de los Factores Críticos de Éxito}

A partir del estudio realizado, se propone un nuevo modelo que parte del propuesto e integra los diferentes Factores Críticos de Éxito que deben ser tenidos en cuenta durante la puesta en marcha del nuevo sistema de información.

En este "modelo mejorado" se han identificado cuatro FCE principales que sintetizamos en la siguiente figura:

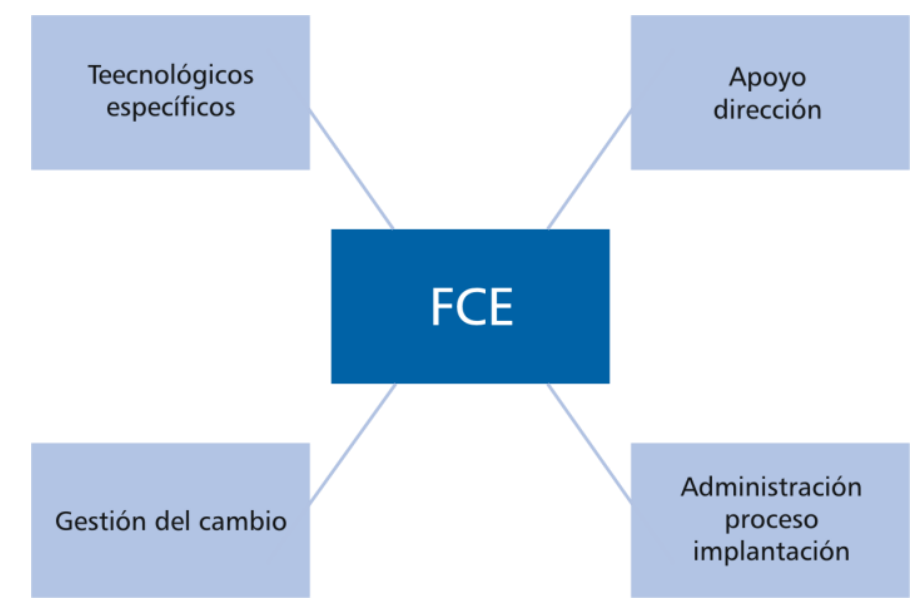

Figura 6.17: Modelo mejorado de los Factores Críticos de Éxito. 
Los cuatro elementos que observamos en la anterior figura 6.17 permiten explicar completamente el éxito del proyecto.

\section{A: Gestión del Cambio}

Todo Proyecto que afecte al área de las Tecnologías y Sistemas de Información de la Empresa implica un Cambio importante en la Organización, tal y como justificamos en el marco teórico de la presente investigación. En este sentido es necesario unos condicionantes que permitan la gestión adecuada del mismo. Inicialmente debe existir un clima que permita afrontar dicho cambio de la mejor manera, para ello el capital humano de la organización debe mostrarse en todo momento proactivo y con un compromiso total con el proyecto, este compromiso implica una motivación y participación continua en el mismo: es fundamental que toda la gente "tire del carro" y entienda el proyecto como una vía de mejora continua de los procesos de la empresa en general y del suyo en particular. Dentro de esta gestión deben existir unos facilitadotes que permitan que la gestión sea lo más idónea posible, entre estos debemos destacar la comunicación, pieza clave para lograr que todo el personal se "apunte al cambio" y la formación continua ya que es evidente que el cambio lleva implícito que los procesos se llevarán a cabo de una forma diferente a como se venía haciendo y por tanto, será necesaria una fase crítica de aprendizaje: la formación debe ser planificada convenientemente para lograr el éxito del nuevo sistema. La organización implicada en la gestión del cambio creará una espiral de conocimiento continua (Nonaka, 1995) que permitirá que exista una transferencia del mismo por toda la organización aumentando la base de conocimientos de la empresa. También es oportuno volver a comentar que hay que estar continuamente atentos a la resistencia que puede existir ante esta nueva filosofía y el peligro que tenemos en el anclaje de los sistemas antiguos: el inicio del cambio viene precisamente por estar de acuerdo en que debemos evolucionar e innovar en nuestro quehacer diario.

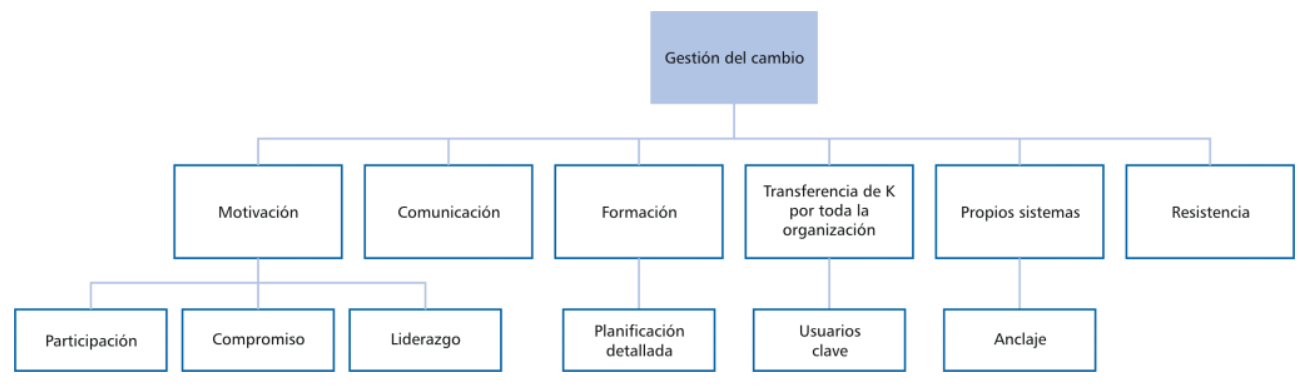




\section{B: Apoyo de la Dirección}

Desde la dirección se deben establecer los mecanismos más oportunos para que el proyecto se convierta en una realidad y es el apoyo permanente de los directivos el que permitirá y logrará que el cambio se produzca de la forma menos traumática.

La Dirección debe ser el motor del cambio en la organización, los miembros de la Dirección deben generar continuamente una actitud favorable e impulsora de acuerdo a unas ideas que faciliten la evolución de los sistemas. Son ellos los que deben tener la visión de futuro que les permita establecer una perspectiva estratégica adecuada que facilite el cambio en la organización. Además, debe tenerse presente que se trata de una solución que irá mejorándose con el tiempo, al incorporar los nuevos requerimientos y especificaciones de negocio.

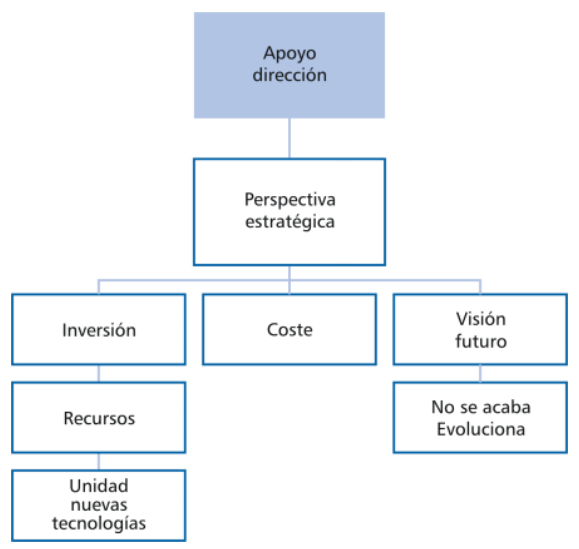




\section{C: Tecnológicos Específicos}

Una vez que la organización está mentalizada y comprometida en la evolución y el cambio que permite la mejora continua de los procesos y que la Dirección apoya el proyecto resulta crítico el análisis y la evaluación de las diferentes soluciones para ver cual es la mejor se adapta a nuestras necesidades. En este aspecto es imprescindible tener todos nuestros procesos bien definidos: es decir debemos saber inicialmente qué es lo que hacemos y como lo hacemos para de esta forma facilitar al nuevo sistema la herencia adecuada. La gestión del proyecto debe soportarse en un equipo que obtenga el máximo rendimiento. De acuerdo con la presente investigación debe existir un equipo mixto donde haya componentes de la propia empresa y de la empresa consultora que facilite la solución. Se ha detectado la conveniencia de que el director del proyecto sea externo y haga de puente entre la empresa y la consultora Las decisiones a tomar incluyen la conveniencia 0 no de realizar reingeniería de procesos o el nivel de "customización" (ajuste a las características específicas de la organización") que debe tener la solución. Es conveniente cerciorarse que se realiza una adecuada transferencia de conocimiento entre el equipo de consultoría y el resto de la organización.

Por otra parte, es fundamental para el éxito del proyecto la idoneidad de la solución elegida y para ello, se tienen que valorar de manera especial los requerimientos sectoriales de las empresas textiles. De las experiencias estudiadas se saca la conclusión de que las implantaciones realizadas por consultoras especializadas en el sector y con productos sectoriales ofrecen mayores garantías de éxito.

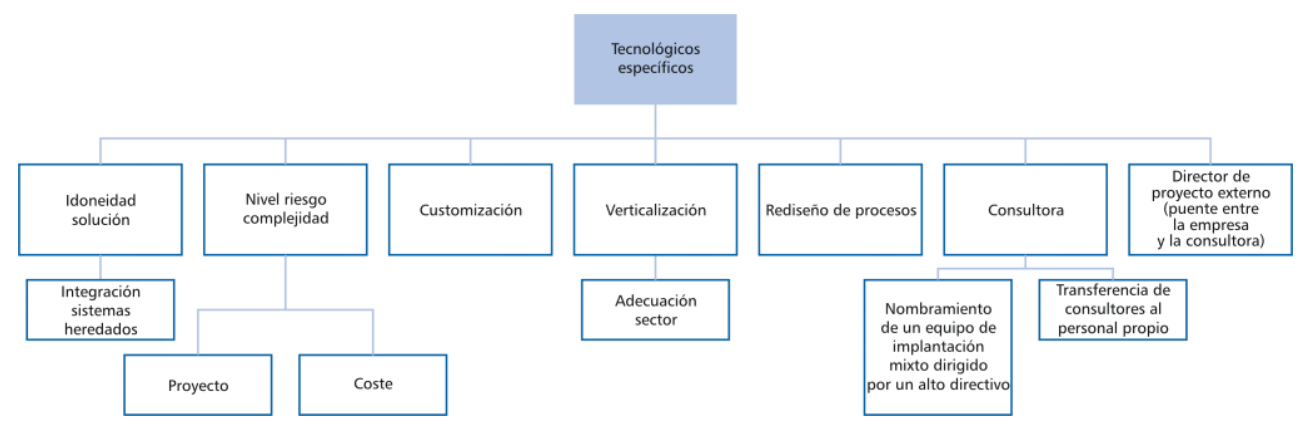




\section{D: Administración del Proceso de Implantación}

Una vez que hemos determinado la solución que mejor se adapta a nuestra organización es necesario administrar y gestionar todo el proceso de implantación y es por ello que creemos que este es el Factor Crítico de éxito que completa el modelo redefinido de la investigación.

En este elemento es imprescindible tener una metodología de acción que nos permita alcanzar el éxito deseado. Esta metodología debe contar con una fijación de objetivos inicial y una planificación detallada y clara de todos los pasos a realizar. En la misma debe existir una visión sistémica que nos permita resolver los problemas atendiendo al conjunto de la organización y también debe haber una mentalización en el trabajo de equipo. Es importante considerar la experimentación de forma que la propia experiencia nos permita aprender de forma continua. Se ha constatado también la necesidad de no eliminar pasos en la metodología sino seguir una cierta "disciplina" y constancia sin menoscabo de la necesaria flexibilidad para dar respuesta a los problemas que surjan. El trabajo en equipo nos permitirá fortalecer la creatividad de la organización y generar nuevas ideas que ayudarán a resolver los problemas.

El equipo de implantación debe abordar una labor de contraste con otras prácticas y experiencias del sector y también una continua labor de observación tecnológica para de esta forma estar siempre a la vanguardia del desarrollo tecnológico que permite la mejora continua de los procesos.

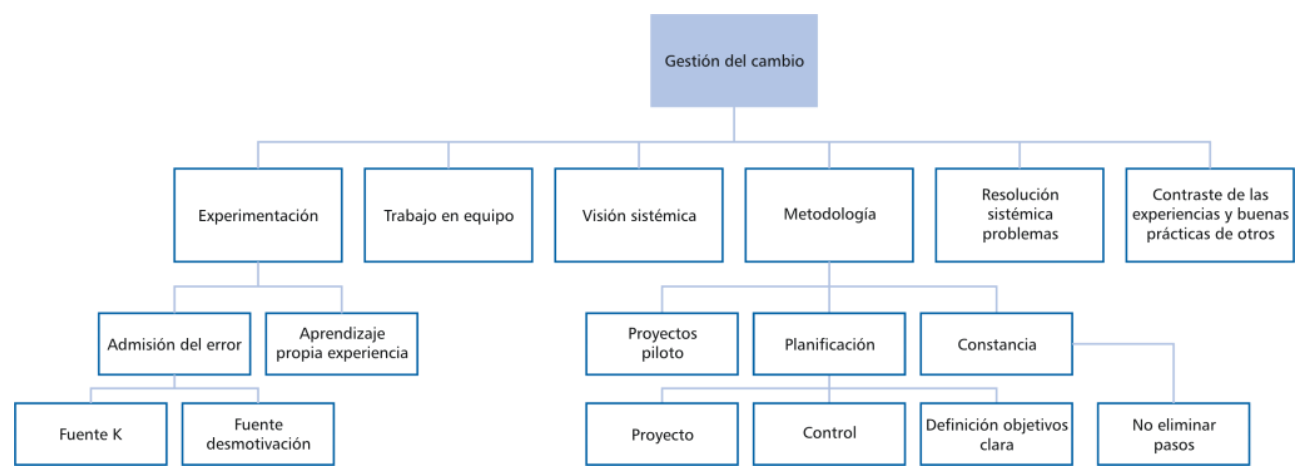




\section{CONCLUSIONES}

\subsection{Introducción}

La situación inicial de esta investigación era la de encontrar soluciones tecnológicas que permitiesen contribuir a incrementar la productividad en el sector textil de la Comunidad Valenciana que actualmente se encuentra en una situación crítica y delicada.

En este sentido apoyándonos en la literatura, según el estudio reflejado en el capítulo 2 de esta tesis, encontramos que el Capital Tecnológico es un elemento clave dentro del conocido Capital Intelectual de las Organizaciones y es estudiado con profundidad en la última década debido a la importancia estratégica del conocimiento y los activos intangibles en el actual entorno socioeconómico. En este capítulo se refleja la necesidad de incorporar innovaciones continuas en las organizaciones y queda patente como las Tecnologías de la Información y las Comunicaciones constituyen un elemento esencial par el desarrollo competitivo presente y futuro.

Al hilo de lo tratado en el capítulo 2, en el siguiente capítulo de la investigación se recoge el modelo propuesto donde se establecen unos elementos críticos en la implantación de los sistemas ERP en las organizaciones.

De esta forma, el modelo propuesto en el capitulo 3 se aplica al sector textil de la Comunidad Valenciana, después de haber estudiado en el capitulo 4 la situación actual del sector respecto a las TIC, mediante una metodología cualitativa documentada y justificada en el capítulo 5 de la presente memoria de investigación, y con ello, llegamos al Objetivo General planteado al inicio de la investigación:

- Contribuir al desarrollo de un modelo para el fortalecimiento de la competitividad en el sector textil de la Comunidad Valenciana por medio la correcta utilización de sistemas y tecnologías de la información.

Por otro lado los Objetivos Específicos también se han conseguido en esa Tesis (Ver Capítulo 6) ya que:

- Se han analizado elementos de la situación tecnológica en lo referente a sistemas de información del sector textil de la Comunidad Valenciana.

- Se han determinado los riesgos que las empresas de este sector soportan al gestionar sistemas y tecnologías de la información. 
- Se ha elaborado una metodología en base al trabajo de campo realizado que permite entre otras cosas:

- Seleccionar los sistemas de información de apoyo a los procesos de negocio adecuados atendiendo a diversos factores, entre los que cabe citar: sistemas heredados, recursos de toda índole y la propia naturaleza y estrategia empresarial.

- Definir los elementos de la implantación de dichos sistemas y su correcta secuencia contemplando tanto factores técnicos como organizativos.

- La investigación también propone un modelo específico de gestión para las empresas objeto de estudio que permite la elaboración de una estrategia tecnológica en sistemas de información coherente con la estrategia general de la empresa y que posibilita una implantación eficiente tal que se valoran y atienden los Factores Críticos de Éxito.

- También, se ha conseguido aportar una metodología que permita a las empresas disminuir los riesgos existentes, tanto los que se derivan de la complejidad como de la ambigüedad.

Hemos visto que la economía actual al basarse en el conocimiento y la innovación, cada vez más global y digital, esta fuertemente influenciada por el impacto que sobre ella vienen ejerciendo las TIC. Estas características la conducen a su transformación en una economía donde la implantación de Sistemas Avanzados de Gestión es clave en la competitividad.

Esta competitividad de las organizaciones viene dada por las ideas de los individuos, el conocimiento y la tecnología, y de cómo éstas organizaciones sean capaces de capacitarse con la tecnología adecuada, adquiriendo y asimilando el conocimiento tecnológico, de modo que aprendan más y más rápido que sus competidores.

El éxito o el fracaso de una organización depende cada vez más de su capacidad de innovación tecnológica en las TIC.

Dado que la mayoría de las PYMEs tecnológicas no son capaces de desarrollar la tecnología que necesitan y que las PYMEs componen el grueso de empresas no sólo a nivel nacional sino también de la UE (suponen más del $99 \%$ de las empresas españolas), deben elegir vías alternativas a asumir actividades de I+D propias si quieren ser competitivas, a través de "socios tecnológicos". 
Las mayores dificultades a la implantación y desarrollo del Capital Tecnológico en las organizaciones son culturales y de resistencia al "cambio". Cada vez se hace más patente la frase: "pensar en global y actuar en local".

\subsection{Aportaciones}

\subsubsection{Aportación a la Comunidad Científica}

Las aportaciones de carácter más científico de esta investigación se han basado en:

- Introducción de un modelo que permite la identificación de los Factores Críticos de Éxito en la incorporación de un Sistema Avanzado de Gestión (ERP) en empresas del sector Textil de la Comunidad Valenciana.

- Desarrollo de una metodología cualitativa que ha permitido corroborar el modelo planteado, al mismo tiempo que han permitido elaborar nuevos constructos teóricos tanto al considerar los factores críticos de éxito que se dan en el proceso de implantación de un ERP, como al analizar las primeras fases de selección de la solución. Este contraste se ha realizado en cuatro casos reales desarrollados y estudiados en profundidad.

- Determinación de la influencia que tiene un Sistema de Información adecuado (en nuestro caso un ERP) en el desarrollo del Capital Tecnológico de la Organización y en definitiva del Capital Intangible de la misma.

- Se han contrastado las hipótesis planteadas en el capítulo 3 ya que hemos podido concluir que:

1. El ajuste de la organización al ERP está directamente relacionado con el suceso en la implantación del ERP.

2. Existe una relación entre la resistencia de la organización frente a la implantación, la perspectiva de un ajuste organizativo necesario y el éxito en la implantación del ERP.

\subsubsection{Aportación a la Comunidad Empresarial, Social y Política}

Como aportaciones tenemos las siguientes:

- La investigación se realiza en el sector del textil y concretamente en las empresas de la Comunidad Valenciana.

- Se analizan elementos del Capital Tecnológico, que permite conocer en el sector, la forma en que estos elementos tecnológicos contribuyen al desarrollo competitivo del mismo. 
- Se aporta una nueva metodología que permite gestionar con garantías de éxito un proyecto de selección e implantación de un Sistema Avanzado de Gestión en las empresas del sector textil, abarcando todas sus fases desde que aparece la idea de cambio hasta la postimlantación y determinar los Factores Críticos del Éxito en los que hay que tener especial atención.

- Cada empresa puede situarse en relación a los factores estudiados y ejecutar un benchmarking.

- Los resultados encontrados en la presente investigación, señalan unas fortalezas y debilidades que pueden facilitar a los diversos gobiernos tomar medidas políticas para potenciarlos o corregirlos. Así por ejemplo, serían políticas convenientes: la concienciación del potencial de la aplicación de las TIC en los sistemas organizativos de las PYMEs, la necesidad de aplicación de estilos culturales participativos y de la concienciación de las amenazas competitivas que sufren las empresas por la carencia en la aplicación estas tecnologías.

\subsection{Limitaciones y Evolución}

Algunas consideraciones que pueden ser de interés para futuras investigaciones son las siguientes:

- Para mejorar la representatividad y alcance del modelo convendría ampliar la recogida de datos, con el fin de generalizar el planteamiento inicial.

- La investigación ha considerado un modelo orientado hacia un elemento concreto de los Sistemas de Información que es el caso de los ERP con objeto de identificar otras áreas y aspectos tecnológicos para profundizar en posteriores investigaciones.

- La presente investigación tiene una primera ampliación mediante un trabajo de investigación que trata de identificar las oportunidades que pueden tener los sistemas CRM (Gestión de Relaciones con los Clientes) y SCM (Gestión de la cadena de suministro) en el desarrollo tecnológico de la empresa.

- Otra evolución de la presente investigación es la que se plantea en el campo de los Sistemas de Apoyo a la Toma de Decisiones (Sistemas EIS) donde el objetivo principal sería el poder conseguir un soporte para la toma de decisiones para los directivos y responsables de los diferentes departamentos de la empresa, así como la integración con el Sistema Avanzado de Gestión ERP (Enterprise Resource Planning).

- La siguiente evolución de esta Tesis viene de la mano del novedoso concepto del e-Business o negocio electrónico, en el que el objetivo principal consistiría en el de desarrollar una serie de metodologías que permitan explotar con éxito los sistemas de comunicaciones interempresariales. 
- El área de las Tecnologías de la Información y las Comunicaciones y los Sistemas de Información genera unas posibilidades de investigación continuas ya que su evolución y desarrollo es permanente, y de su forma de aplicación depende de forma crítica el avance competitivo de las organizaciones. 


\section{BIBLIOGRAFÍA}


ACTE (2003): Las actividades del sector textil y de la confección en España. Capítulo extraído del libro El sector Textil, una aproximación Territorial, elaborado por la Asociación de Colectividades Textiles Europeas (ACTE).

Alió, Laura. (2001) "El camino de IBM hacia la Organización Inteligente", Escuela de Verano: La Gestión del Conocimiento y las Organizaciones Inteligentes. San Sebastián, Julio.

ALTIMIA (2003):" La Industria Textil define su estrategia competitiva", Economía 3. Febrero.

Al-Mashari, M. "Constructs of Process Change Management in ERP Context: A Focus on SAP R/3", Americas Conference on Information Systems (AMCIS).

Amit, R. y Schoemaker, P (1993). "Strategic Assets and Organizational Rent", Strategic Management Journal, vol. 14, núm 1, pp. 33-46.

Andreu, R.; Ricart, J. E. y Valor, J. (2000): Estrategia y sistemas de información, 2ª ed., Mac Graw-Hill, Madrid.

Andreu, R.; Ricart, J.E. y Valor, J. (1995): $\quad$ La Organización en la Era de la Información: Aprendizaje, Innovación y Cambio, Estudios y Ediciones IESE.

Argote, Ignacio. En el número de Enero-febrero de la Revista Confección Española año 2000.

Barney, J.B. (1991) "Firm Resources and Sustainig Competitive Advantage". Journal of Management, vol 17, núm 1.

Benavent, P.C. Desarrollo de Sistema de Control de la trazabilidad de materiales y comprobación Poka-Yoke en automoción. Integración con el ERP corporativo. Proyectos Informáticos, 2001, Anexo I

Bennis, W. G. y Nanus, B. (2001): Líderes. Estrategias para un desarrollo eficaz, Paidós Ibérica, Barcelona.

Bingi, P.; Sharma, M. y Godla, J. (1999): "Critical Issues Affecting an ERP Implementation", Information Systems Management, vol. 16, n. 3, pp. 7-14

Blanco, A. (6-11-2002): El liderazgo sistémico de la organización. Lider integrador de los sistemas de la empresa. Personal Communication

Bonache Pérez, Jaime (1998): "El estudio de casos como estrategia de investigación: críticas y defensas", IV Taller de Metodología ACEDE, La Rioja. 
Bontis, N. (1996): "Intellectual Capital: An Exploratory Study that Develops Measures and Models", pp 96-11, Richard Ivey School of Business, Canada.

Brooking, A. (1997): El Capital Intelectual, Ed. Paidos Empresa, Barcelona.

Brynjolfsson, E. y Hitt, L. (1996): "Paradox lost? Firm-level evidence on the returns to information systems spending", Management Science, vol. 42, n.․ 4, pp. 541558

Bueno, E. (1998): "El Capital Intangible como Clave Estratégica en la Competencia Actual”, Boletín de Estudios Económicos, vol. LIII no 164, pp 207-229.

Bueno, E. (1999a): "Gestión del Conocimiento, Aprendizaje y Capital Intelectual", Boletín del Club Intelec, № 1, enero.

Bueno, E. (1999b), “¿Por qué Gestión del Conocimiento?”, Documento de Trabajo del curso de verano Capital Intelectual y Gestión del Conocimiento, San Lorenzo del Escorial (Madrid).

Bueno Campos, E. y Salmador, M.P. (2000): Perspectivas sobre dirección del conocimiento y capital intelectual. Instituto Universitario Euroforum Escorial, Madrid.

Bueno Campos, E. y Salmador, M.P. (2001): "Influencia de las dimensiones del conocimiento y de la complejidad en el proceso estratégico", XI Congreso Nacional de ACEDE. Zaragoza, 15, 16 y 17 Septiembre de 2001.

Bueno, E. (2001), "El Capital Intangible frente al Capital Intelectual de la empresa desde la perspectiva de las capacidades dinámicas", XI Congreso Nacional de ACEDE, Zaragoza, Septiembre.

Camisón, C; Palacios, D; Devece, C: (2000): "Un nuevo modelo para la medición del Capital Intelectual: El modelo NOVA", X Congreso Nacional de ACEDE, Septiembre.

Camisón, C. (1999a): "Sobre cómo medir las competencias distintivas: Un examen empírico de la fiabilidad y validez de los modelos multi-item para la medición de los activos intangibles". First International Conference Management Related Theory and research: An iberoamerican perspective, Universidad Carlos III de Madrid.

Canals, J. (2003): "El sector textil-confección español: situación actual y perspectivas". Boletín Económico ICE N 2768

CEV (2001): Propuestas para la mejora del Sistema de Transferencia de Tecnología al Tejido empresarial Valenciano. Confederación Empresarial Valenciana. 
Chiva, R. (2000): Aprendizaje organizativo y sistemas complejos con capacidad de adaptación: implicaciones en la gestión del diseño del producto en el negocio español de fabricación de pavimentos y revestimientos cerámicos. Tesis Doctoral, Universidad Jaume I de Castellón.

CIC (2002): "Guías y Directrices de Utilización del Modelo Intellectus". Documento Intellectus, Centro de Investigación sobre la Sociedad del Conocimiento, abril.

Coll Tortosa, Libert (2004): Innovaciones en los materiales y los productos y su incidencia en los procesos textiles. Ponencia congreso APLIMATEC 2004

Cook, T. D. y Reichdart, Ch. S. (1986): Métodos cualitativos y cuantitativos en investigación educativa, Morata, Madrid.

Cubeiro J.C. (2001): "Liderazgo y Gestión por Competencias", Curso de Verano de la Universidad de Deusto. San Sebastián.

Cubeiro J. C. (2002): "Sobre certezas, esperanza y libertad". Canal Eurotalent, noviembre.

Davenport, T. (1998): "Putting the Enterprise into the Enterprise System: a Case Study", Harvard Business Review, vol. Jul-Aug, pp. 121-131

David, J., Dunn, C., \& McCarthy, W. "Enterprise Resource Planning Systems Research: the Necessity to Explicating and Examining Patterns in Symbolic Form", 10 International Workshop on Enterprise Management Resource and Planning Systems EMRPS, Venice, Italy, pp. 347-357.

De Miguel Fernández, E. Introducción a la Gestión, (Management) I, Servicio de Publicaciones de la Universidad Politécnica de Valencia, 1993, pp. 90-111.

Díez, E.J. (2002): "Orígenes del concepto de cultura organizativa", www3.unileon.es/dp/ado/ENRIQUE/Doctorad/cultura.htm

Dianne Galloway (1998): Mejora Continua de Procesos, Ediciones Gestion 2000, S.A ed.,

Domínguez Machuca, J. A.; Álvarez Gil, M. J.; Domínguez Machuca, M. A.; García González, S. y Ruíz Jiménez, A. (1998): Dirección de operaciones. Aspectos estratégicos en la producción y los servicios, McGraw-Hill, Madrid.

Drogonetti, N. y Roos, G. (1998): la evaluación de AusIndustry y el business network programe: una perspectiva desde el capital intelectual", Boletín de Estudios Económicos, № 164, Agosto. 
Drucker P. F. (2002):"The discipline of innovation", Harvard Business Review, agosto, pp 95-103.

Edvinsson L. y Malone M. S. (1997): El Capital Intelectual: Como identificar y calcular el valor de los recursos intangibles de su empresa, Ed. Gestión 2000.

Eisenhardt, K. M. (1989): "Building Theories from Case Study Research", Academy of Management Review, vol. 14, pp. 532-550

Elías J. y Mascaray J. (1998): Más allá de la Comunicación Interna: La Intracomunicación. Diez estrategias para la implantación de valores y la conquista del comportamiento espontáneo de los empleados, Ed. Gestión 2000.

Escorsa, P. y Valls, J. (1997): Manual de Gestión e Innovación Tecnológica en la empresa. Santiago de Chile: CINDA-AECI.

Esteves J., Pastor J., \& Casanovas J. (2002): A Framework Proposal for Monitoring and Evaluating Training in ERP Implementation Projects, Technical Research Report.

Esteves, J y Pastor, J (2001): Enterprise Resource Planning Systems Research: an Annotated Bibliography, [en línea]. Dirección URL: <http://www.imm.ecel.uwa.edu.au/unit450421/ERP\%20bibliog/article.htm> [Consulta: 2-8-2001]

Esteves Sousa, J. y Pastor Collado, J. "Hacia la Unificación de los Factores Críticos para el éxito de implantaciones ERP", 2000, pp 1-10.

Euroforum Escorial (1998): Medición del Capital Intelectual. Modelo Intelect, Ed. I.U. Euroforum Escorial, Madrid.

Fabregat Muñoz, V. (2003): "La internacionalización del sector textil-confección". Boletín Económico ICE № 2768

Felis, J. J. Estudio del paquete BaaN Servicio del software BaaN IVc como soporte para la gestión de los distintos tipos de mantenimiento industrial. Desarrollo de un modelo de referencia.. Gestión de proyectos informáticos, 2001

Fernández Nogales, Ángel (1999): La investigación cualitativa, en Sarabia Sánchez, F.J. (coord.) (1999): Metodología para la investigación en marketing y dirección de empresas, Pirámide, Madrid, pp. 201-224.

García Muiña, F.E.; Martín de Castro, G. y Navas López, J. E. (2001): "El Papel de la Complejidad, Complementariedad y Escasez en la Creación, Mantenimiento y Apropiación de la Ventaja Competitiva", Documento de trabajo presentado en el Curso de Doctorado La Dirección de la Tecnología en la Empresa, del 
Departamento de Organización de Empresas de la Universidad Complutense de Madrid

Gable, G., Scott J.E, \& Davenport, T. "Cooperative ERP Lifecycle Knowledge Management", Proceedings of the 9 Australasian Conference on Information Systems (ACIS), Sydney, Australia.

Garvin D. A. (1993): "Crear una organización que aprende", Gestión del Conocimiento, Ed. Deusto. pp 51-90

Gil, H; Torralba, J.Ma y Rodenes, M (2003): "El Aprendizaje Interorganizativo en la Economía de la Información y el Conocimiento". VII Congreso Internacional de Ingeniería de Proyectos. Pamplona.

Gil, H. (2003): Relaciones del Capital Intelectual y el Aprendizaje Organizativo en el entorno de un Centro de Investigación Tecnológica. Aplicación al sector Textil de la Comunidad Valenciana. Tesis Doctoral. Universidad Politécnica de Valencia.

González Ladrón de Guevara, F (2001): Caracterización de los procesos de Aprendizaje Organizativo y su relación con las Tecnologías de la Información. Aplicación al sector Textil Hogar de la Comunidad Valenciana. Tesis Doctoral. Universidad Politécnica de Valencia.

González Ladrón de Guevara, F. \& Torres Rodríguez, A. R. (2002): "Factores de éxito en la implantación de ERP en las organizaciones", II Conferencia de Ingeniería de Organización, Vigo, pp. 831-848.

Gonzalo P. (2002): "La utilidad de la comunicación interna para los directivos", Harvard Deusto Business Review, marzo/abril, pp 36-44

Grant, R. M. (1991): "The resource-based theory of competitive advantage: implications for strategy formulation". California Management Review, spring 33, pp. 114-135.

Grant, R.M. (1996): "Toward a knowledge-based theory of the firm", Strategic Management Journal, Vol. 17, Winter Special Issue, pp. 109-122.

Grupo Scala Latina, "Metodología de Implantación", Gestión de proyectos, 66, 2001, pp.55

Guarch, J. J. Cuenca, LI. " Las aplicaciones informáticas y las empresas, Soluciones

ERP", Gestión de proyectos informáticos, 2002, pp. 25-27,

Guía Sectorial para la innovación en Tecnologías de la información y las comunicaciones. Sector Textil. Institut Cerdà 1998. 
Hamel, G. y Prahalad, C.K (1995): Compitiendo por el futuro. Estrategia crucial para crear los mercados del mañana. Editorial Ariel. Barcelona.

Hamel, J.; Dufour, S. y Fortin, D. (1993) : Case Study Methods, Sage Publications, Newburry Park.

Hartley, T. S. (1994): "Case Studies in Organizational Research" en Cassel y Symon (eds): Qualitative Methods in Organizational Research: A Practical Guide, Sage Publications.

Holland, C. P. y Light, B. (1999): "A Critical Success Factors Model for ERP Implementation", IEEE Software, vol. 16, n.ำ 3, pp. 30-36

Hong, K. K. y Kim, Y. G. (2002): "The critical success factors for ERP implementation: an organizational fit perspective", Information and Management,

Huber G. (1991): Organizational Lerning: the Contribuiting Process and the literatures, Ed. Organization Science.

IMPIVA (2003): Plan estratégico Regional de Innovación de la Comunidad Valenciana. IMPIVA: Generalitat Valenciana.

John Pallatto (1-2-2002): Get the Most Out of ERP. Internet World Magazine Article

Kaplan, R. S. (1986): The role for empirical research in management accounting. Accounting, Organizations and Society.

Kaplan, R.S. y Norton, D.P. (1992): "The Balance Scorecard: Measures that Drive Performance", Harvard Business Review, enero-febrero, pp 71-79.

Kaplan, R. Norton, D. (2000): Cuadro de Mando Integral, Ed Gestión 2000.

Laudon, K. C. y Laudon, J. P. (1996): Administración de los Sistemas de Información. Organización y Tecnología., 3ª̣ ed., Pearson Educación, México.

Lee Pender (15-5-2001): Faster, Cheaper ERP. CIO Magazine Internet, CXO Media Inc. Magazine Article

Levit B. y March J. G. (1988): Organizational Learning, Ed. American Review of Sociology, vol. 14.

López Cabarcos, M.A; Vázquez Rodríguez, P. (2002): "La importancia de gestionar el valor que no se ve”, Harvard Business Review, mayo/junio, pp. 32-44. 
López Sánchez, J. I. (2004): "¿Pueden las tecnologías de la información mejorar la productividad?", Universia Business Review - Actualidad Económica, n.ำ Primer trimestre 2004, pp. 82-95

López Sintas, J. (1996) "Los Recursos Intangibles en la Competitividad de las Empresas. Un Análisis desde la Teoría de los Recursos”, Economía Industrial, núm. 307, pp. 25-32.

Mabert, V. A.; Soni, A. y Venkataramanan, M. A. (2002): "Sistemas ERP: mitos comunes versus realidad evolutiva", Harvard Deusto Business Review, vol. 106,

Marimón, Isidre (2004): Innovación en la gestión de empresas. Ponencia congreso APLIMATEC 2004

Marlene F. y Lyles A. (1985): "Organizational Learning", Academy of Management review, octubre.

Medrano, I. y Suárez, L. (2001): "Ensayo sobre estrategias para documentar el conocimiento en una organización", Artículo publicado en la revista PH, del Instituto Andaluz del Patrimonio Histórico

Mintzberg, H. (1979): "An Emerging Strategy of Direct Research", Administrative Science Quarterly, 24, pp. 580-589.

Miñana, J.L. (2001): Desarrollo de un modelo que permita el diagnóstico en la Aportación de valor de la Infraestructura de Tecnologías de la Información (TI). Tesis Doctoral. Universidad Politécnica de Valencia.

Moncaleano Rodríguez, G.I. (2002): La Tecnología de la Información en Organizaciones Cooperativas: Influencia sobre el Aprendizaje, la Creación de Valor y la Cultura. Tesis Doctoral. Universidad Politécnica de Valencia.

Montoro, J. (2002): Metodología Social. Documentación del curso Los métodos de investigación en las Ciencias Sociales, impartido en la Universidad Politécnica de Valencia, Junio 2002.

Muñoz Giner, Javier y otros. Estudio de la aplicación de las nuevas tecnologías de la información y las comunicaciones en el sector textil. 1999. Edita: ATEVAL Asociación de empresarios textiles de la Comunidad Valenciana.

Murray, E. (1999): "Cluster-based development strategies: lessons from the plastics industry in North Central Massachusetts". Economic Development Quarterly, vol. 13, n. 3, pp. 266-280.

Nonaka I., Takeuchi H. (1995): The Knowledge-Creating Company. Oxford University Press, New York. 
Nonaka, I (2000): "La empresa creadora de conocimiento". En Gestión del Conocimiento Harvard Business Review.

Ordoñez de Pablos, P. (2000): "Herramientas estratégicas para medir el capital intelectual organizativo", Revista de Estudios Empresariales, $n^{\circ} 102$, Junio. Universidad de Deusto.

Otley, D. T. y Berry, A. J. (1994): "Case Study Research in Management Accounting and Control", Management Accounting Research, v. 5, pp. 45-65.

Pallatto, J. (1-2-2002): Get the Most Out of ERP. Internet World Magazine Article

Parr, A. y Shanks, G. (2000): "A Model of ERP Project Implementation", Journal of Information Technology, vol. 15, n. -4 , pp. 289-304

Pender, Lee (15-5-2001): Faster, Cheaper ERP. CIO Magazine Internet, CXO Media Inc. Magazine Article

Pérez Serrano, Gloria (1994): Investigación cualitativa. Retos e interrogantes. Métodos, La Muralla, Madrid.

Pérez, W. (1998): "El estudio de casos por patrones de comportamiento". Ponencia presentada en el IV Taller de Metodología, ACEDE, Arnedillo, La Rioja.

Porter M. (1982): Estrategia competitiva, Ed. Compañía Editorial Continental.

Porter M. (1990): The competitive edge of Nations, Ed. Macmillan.

Prahalad, C.K. y Hamel, G. (2001): "La estrategia como objeto de estudio: ¿por qué buscar un nuevo paradigma?", Harvard Deusto Business Review, especial 100.

Prieto, M.B. (1998): "Verificación empírica y método del caso: experiencias en contabilidad de gestión". Ponencia presentada en el IV Taller de Metodología, ACEDE, Arnedillo, La Rioja.

Rialp, A. (1998): "El método del caso como técnica de investigación y su aplicación al estudio de la función directiva". Ponencia presentada en el IV Taller de Metodología, ACEDE, Arnedillo, La Rioja.

Rodenes, Manuel (2002): Análisis de Factores Críticos para la Gestión. Aplicación en el sector Textil-Hogar de la Comunidad Valenciana. Trabajo de Investigación para el concurso de acceso a la categoría de Catedrático de Universidad en el área de conocimiento de "Organización de Empresas". Universidad Politécnica de Valencia. 
Ronca, C. "Beyond the ERP Experience Change Management as a Key Factor a Winning Enterprise", 1ำ International Workshop on Enterprise Management Resource and Planning Systems EMRPS, Venice, Italy, p. 373.

Roos, G. y Roos, J. (1997): "Measuring your Company's Intellectual Performance " Long Range Planning, junio.

Roos G. y Lövingsson F. (1999): "El proceso $\mathrm{Cl}$ en el nuevo mundo de las Telecomunicaciones". Homo Faber, Homo sapiens, Ed. Bronce, pp 141-168.

Ross, J. \& Vitale, M. (1998): The ERP Revolution: Surviving versus thriving, Center for Information Systems research, Sloan School of Management M.I.T.

Ryan, B.; Scapens, R. W. y Theobal, D. M. (1992): Research Method and Methodology in Finance and Accounting, Academic Press.

Senge P. M. (1990): La Quinta Disciplina, Ed. Granica.

Silverman, J. (1993): Interpreting Qualitative Data, Sage Publications.

Slevin, D. P. y Pinto, J. K. (1987): "Balancing Strategy and Tactics in Project Implementation", Sloan Management Review, vol. 29, n.o 1, pp. 33-41

Somers, T. M. \& Nelson, K. "The Impact of Critical Succes Factors across the Stages of Enterprise Resource Planning Implementations", Procedings of the 34th International Conference on System Sciences, Hawaii, pp. 1-10.

Snow, C. C. y Thomas, J. B. (1994): "Field Research Methods in Strategic Management. Contributions to Theory Building and Testing", Journal of Management Studies, vol. 31, n.ำ 4, pp. 457-480

Stata R. (1989): "Organizational Learning - the key to Management Innovation", Sloan Managment Review, primavera.

Steward, T.A. (1997): Intellectual Capital. The New Wealth of Organizations, Nicolas Brealey Publishing, London, 1를 ed.; Versión española La Nueva Riqueza de las Organizaciones: El Capital Intelectual, Ed. Granica, Buenos Aires

Sumner, M. "Critical success Factors in Enterprise Wide Information Management Systems", Proceedings of the Americas Conference on Information Systems, Milwaukee, WI, 1999, pp. 232-234.

Sveiby, K.E. (1997), The New Organizational Wealth Managing and Measuring Knowledge. Berrett-Koehler Publishers Inc., 1a ed. Traducido al español por 
Mazars (2000), bajo el título: La nueva riqueza de las empresas. Cómo medir y gestionar los activos intangibles para crear valor.

Taberner, M. (2003): El sector textil: análisis de situación. Revista de ATEVAL.

Taxen, L. "A Strategy for Organisational Knowledge Evolution", 1ำ International Workshop on Enterprise Management Resource and Planning Systems (EMPRS), Venice, Italy, pp. 17-34.

Taylor, S. J. y Bogdan, R. (1986): Introducción a los métodos cualitativos de investigación, Paidós, Buenos Aires.

Tellis, W. (1997a): "Application of a Case Study Methodoloy", The Qualitative Report, v.3, n. 3, september, http://www.nova.edu/ssss/QR/QR3-3/tellis2.html (2012-1999), pp. 4-

17.

Tellis, W. (1997b): "Introduction to Case Study", The Qualitative Report, v. 3, n. 2, july, http://www.nova.edu/ssss/QR/QR3-2/tellis1.html (20-12-1999), pp. 1-12.

Tremosa i Balcells, R. y Trigo Portela, J. (2003): "La empresa textil española en el contexto europeo".

Ventura Victoria, J. (1996) "Análisis Dinámico de la Estrategia Empresarial: Un Ensayo Interdisciplinar". Universidad de Oviedo, Oviedo.

Yin, R. (1989): Case Study Research: Design and Methods, Sage Publications, Newburry Park.

Yin, R. (1994): Case Study Research: Design and methods (snd edition), Beverly Hills, Sage Publishing, California. 


\section{ANEXOS}


ANEXOS 


\section{ANEXO 1}

\section{ENCUESTA SOBRE TECNOLOGÍAS DE LA INFORMACIÓN Y COMUNICACIONES (TIC)}

PO- NÚMERO DE ENCUESTA:

\section{REFERENCIAS:}

\begin{tabular}{|c|c|c|}
\hline Nombre de la empresa: & & \\
\hline Dirección: & & \\
\hline Localidad: & & \\
\hline Tel: & Fax: & \\
\hline Persona de contacto: & & Cargo: \\
\hline
\end{tabular}

P1- SECTOR:

$\theta$ PRIMERAS MATERIAS E HILOS

$\theta$ TEJIDOS PARA LA DECORACIÓN

$\theta$ OTROS ARTÍCULOS DE

MOBLAJE

$\theta$ ALFOMBRAS Y MOQUETAS

OTROS PRODUCTOS

TEXTILES

$\theta$ CONFECCIÓN HOGAR

$\theta$ TEJIDOS Y PRENDAS DE VESTIR

$\theta$ TINTE ESTAMPACIÓN Y ACABADO

$\theta$ ROPA DE CAMA, MESA, BAÑO, COCINA

$\theta$ OTROS SERVICIOS A LA IND. TEXTIL

P2- FACTURACIÓN (EN MILLONES DE PTAS.):
$\theta$ DE 0 A 50
$\theta$ DE 501 A 1.000
$\theta$ DE 51 A 100
$\theta$ DE 1.001 A 2.500
$\theta$ DE 101 A 250
$\theta$ MÁS DE 2.500

$\theta$ DE 251 A 500

P3- NÚMERO DE EMPLEADOS:
$\theta$ DE 0 A 10
$\theta$ DE 11 A 25
$\theta$ DE 101 A 250
$\theta$ DE 26 A 50
$\theta$ DE 251 A 500
$\theta$ DE 501 A 1.000
$\theta$ DE 51 A 100
$\theta$ MÁS DE 1.000

P4- ANTIGÜEDAD DE LA EMPRESA (EN AÑOS):
$\theta$ MENOS DE 5
$\theta$ DE 11 A 25
$\theta$ DE 5 A 10
Ө MÁS DE 25

P5- DISPONIBILIDAD DE UN DEPARTAMENTO INFORMÁTICO EN LA EMPRESA:
$\theta$ Sí
$\theta \mathrm{NO}$

\section{CUESTIONARIO}

A. HARDWARE Y SOFTWARE.

P6- ¿DE QUÉ SISTEMA INFORMÁTICO DISPONE LA EMPRESA? 
(1) $\theta$ ORDENADOR PERSONAL ÚNICO O VARIOS INDEPENDIENTES

(2) $\theta$ ORDENADOR CENTRAL CON TERMINALES

(3) $\theta$ RED LOCAL DE ORDENADORES

(4) $\theta$ RED LOCAL CON UNO O VARIOS SERVIDORES

(3, 4) P6A- ARQUITECTURA DE RED:

$\theta$ CABLEADO ESTRUCTURADO

$\theta$ INSTALACIONES A MEDIDA DE CADA MOMENTO

$\theta$ NS / NC

(3, 4) P6B- TIPO DE RED:
$\theta$ ETHERNET
$\theta$ FAST ETHERNET
$\theta$ TOKEN RING

(2, 4) P6C - TIPO DE SERVIDORES:
$\theta$ NOVELL
$\theta$ NOVELL NETWARE
$\theta$ WINDOWS NT
$\theta$ UNIX

P7 - TIPO DE PCs:

$\theta$ MS-DOS

$\theta$ MS-DOS + WINDOWS 3.11

$\theta$ WINDOWS 95 / 98

$\theta$ ATM
$\theta$ OTROS:
$\theta$ NS/NC

$\theta$ IBM

$\theta$ OTROS:

$\theta$ NS / NC

$\theta$ MAC OS

OOTROS:

$\theta$ NS / NC

P8- TIPO DE HARDW ARE:

$\theta$ SISTEMAS IBM Y OTROS

$\theta$ SISTEMAS UNÍS

$\theta$ PC 486 O INFERIOR

$\theta$ PC PENTIUM O SUPERIOR

$\theta$ ESTACIONES DE TRABAJO APLICADAS A DETERMINADAS FUNCIONES INDEPENDIENTES.

$\theta$ PORTÁTILES

$\theta$ AUTÓMATAS Y MÁQUINAS CONTROLADAS POR ORDENADOR

$\theta$ OTROS:

P9- EN TOTAL, ¿DE CUÁNTOS ORDENADORES DISPONE SU EMPRESA?
$\theta$ NINGUNO
$\theta$ DE 1 A 5
$\theta$ DE 16 A 30
$\theta$ DE 6 A 15
$\theta$ MÁS DE 30

P10- ¿PREFIERE UTILIZAR SOFTWARE ESTÁNDAR SIEMPRE QUE SEA POSIBLE (O ELIGE EL SOFTWARE A MEDIDA)?.

$\theta$ Sí

P11- EN LÍNEAS GENERALES, ¿CUÁLES SON LOS CRITERIOS PARA LA ADQUISICIÓN DE LAS TECNOLOGÍAS DE INFORMACIÓN Y COMUNICACIÓN EN SU EMPRESA?:

$\theta$ PRECIO

$\theta$ SE BUSCAN LOS SISTEMAS DE ÚLTIMA GENERACIÓN

$\theta$ QUE SE ADAPTE A LAS CARACTERÍSTICAS PARTICULARES DE LA EMPRESA

$\theta$ SE ATIENDE A LAS RECOMENDACIONES DEL PROVEEDOR INFORMÁTICO

$\theta$ OTROS :

$\theta \mathrm{NS} / \mathrm{NC}$

P12- ¿DISPONE DE SISTEMAS DE SEGURIDAD PARA EL ACCESO A DATOS?
$\theta$ Sí
$\theta$ NO

P13- ¿REALIZA LAS COPIAS DE SEGURIDAD DE FORMA PLANIFICADA?

$\theta$ Sí

$\theta$ NO

\section{B. APLICACIONES INFORMÁTICAS}

P14- EN GENERAL, ¿SU SISTEMA INFORMÁTICO RESPONDE A LAS NECESIDADES DE LA EMPRESA? 
$\theta$ sí

$\theta$ NO 
P15- ¿ESTÁ SU EMPRESA INTERESADA EN PONER EN MARCHA SUS SISTEMAS INFORMÁTICOS O ACTUALIZARLOS?

$\theta$ Sí *

*P15A- ¿EN QUÉ ÁREAS?
$\theta$ PRODUCCIÓN
$\theta$ ADMINISTRACIÓN
$\theta$ DISEÑO
$\theta$ COMPRAS
$\theta$ MARKETING Y VENTAS

$\theta$ NO

$\theta$ INFORMÁTICA

$\theta$ COMUNICACIONES

$\theta$ LABORATORIO

$\theta$ CALIDAD

$\theta$ OTROS:

P16- ¿CUÁL ES LA SITUACIÓN DE LAS SIGUIENTES APLICACIONES EN SU EMPRESA?

\begin{tabular}{|c|c|c|c|c|}
\hline & $\underline{\text { Tiene }}$ & interesa & $\stackrel{\text { No }}{\text { interesa }}$ & $\underline{\mathrm{NS} / \mathrm{NC}}$ \\
\hline $\begin{array}{l}\theta \text { GESTIÓN INFORMATIZADA DE LAS } \\
\text { CARACTERÍSTICAS DE TODOS LOS } \\
\text { PRODUCTOS DE LA EMPRESA }\end{array}$ & $\theta$ & $\theta$ & $\theta$ & $\theta$ \\
\hline $\begin{array}{l}\theta \text { CONTROL EN TIEMPO REAL DE STOCKS } \\
\text { DE MATERIAS PRIMAS Y/O PRODUCTO } \\
\text { ACABADO }\end{array}$ & $\theta$ & $\theta$ & $\theta$ & $\theta$ \\
\hline $\begin{array}{l}\theta \text { GESTIÓN DE LA PLANIFICACIÓN DE LA } \\
\text { PRODUCCIÓN }\end{array}$ & $\theta$ & $\theta$ & $\theta$ & $\theta$ \\
\hline $\begin{array}{l}\theta \text { GESTIÓN DE EXPEDICIÓN DE PEDIDOS DE } \\
\text { LOS CLIENTES (Reserva, plazos de } \\
\text { entrega, tarifas, seguimientos, distribución, } \\
\text { etc.) }\end{array}$ & $\theta$ & $\theta$ & $\theta$ & $\theta$ \\
\hline $\begin{array}{l}\theta \text { CONTROL INFORMÁTICO DE LA } \\
\text { FABRICACIÓN (Incidencias, cálculos } \\
\text { productivos, fallos...) }\end{array}$ & $\theta$ & $\theta$ & $\theta$ & $\theta$ \\
\hline
\end{tabular}

P17- ¿CONSIDERA QUE LOS SISTEMAS DE DISEÑO ASISTIDOS POR ORDENADOR (CAD) TIENEN APLICACIÓN EN SU EMPRESA?

$\theta$ SÍ * $\quad \theta$ NO

*P17A- ¿CUENTA CON ALGÚN SISTEMA?
$\theta \mathrm{SI}^{* *}$
$\theta \mathrm{NO}$

**P17B- ¿PARA QUÉ UTILIZA ESTOS SISTEMAS?
$\theta$ NS/NC
$\theta$ ESTAMPACIÓN
$\theta$ TEJEDURÍA DE PUNTO
$\theta$ DISEÑO O BOCETOS
$\theta$ PATRONAJE
OOTROS:

$\theta$ JACQUARD

P18- ¿CONSIDERA QUE LOS SISTEMAS DE FABRICACIÓN ASISTIDOS POR ORDENADOR (CAM) TIENEN APLICACIÓN EN SU EMPRESA?
$\theta$ Sí *
$\theta$ NO

*P18A- ¿CUENTA CON ALGÚN SISTEMA?

$\theta S^{* *}$

**P18B- ¿PARA QUÉ UTILIZA ESTOS SISTEMAS CAM?

$\theta$ NO
$\theta$ SISTEMAS DE CORTE GUIADO
$\theta$ GRABACIÓN DE CILINDROS ESTAMPACIÓN
$\theta$ TEJEDURÍA
$\theta$ OTROS:
$\theta \mathrm{NS} / \mathrm{NC}$

P19- EN SU OPINIÓN, ¿LOS SISTEMAS DE SIMULACIÓN DE PRODUCTOS EN 3D ASISTIDOS POR ORDENADOR, O DE SIMULACIÓN DE PRESENTACIÓN DE PRODUCTOS, TIENEN APLICACIÓN EN SU EMPRESA?
$\theta$ Sí *
$\theta \mathrm{NO}$

*P19A- ¿DISPONE DE ALGÚN SISTEMA? 
$\theta$ sí

$\theta$ NO 
*P19B-¿ QUÉ UTILIDAD CONSIDERA QUE PERMITEN ESTOS SISTEMAS?

$\theta$ DECIDIR INTERNAMENTE SOBRE PROPUESTAS DE NUEVOS PRODUCTOS

$\theta$ DECIDIR CON CLIENTES Y COMERCIALES SOBRE PROPUESTAS DE PRODUCTOS

$\theta$ PARA LA REALIZACIÓN DE CATÁLOGOS Y MUESTRARIOS CON AHORRO DE COSTES

$\theta$ PARA LA REALIZACIÓN DE VENTA ELECTRÓNICA

$\theta$ NS/NC

P20- ¿CONSIDERA QUE LOS SISTEMAS DE VISIÓN ARTIFICIAL PUEDEN TENER APLICACIÓN EN SU EMPRESA?
$\theta$ Sí *
$\theta$ NO

$\theta$ NS / NC

*P20A- ¿QUÉ UTILIDAD CREE QUE PERMITIRÍAN ESTOS SISTEMAS?

$\theta$ RECONOCIMIENTO Y DETECCIÓN DE DEFECTOS

$\theta$ SISTEMAS DE CORTE GUIADO

$\theta$ OTRAS APLICACIONES:

C. COMUNICACIONES

P21- ¿CUÁLES SON LAS NECESIDADES DE COMUNICACIÓN MÁS FRECUENTES DE SU EMPRESA?

$\theta$ NO TIENEN NECESIDADES

$\theta$ CON CLIENTES IMPORTANTES

$\theta$ CON REPRESENTANTES O COMERCIALES DE LA EMPRESA

$\theta$ CON FACTORÍAS O CENTROS DE DISTRIBUCIÓN DE LA EMPRESA

$\theta$ CON PROVEEDORES HABITUALES

$\theta$ SERVICIOS DE INFORMACIÓN EN LÍNEA (Bolsa, asistencia técnica...)

$\theta$ ADMINISTRACIÓN PÚBLICA

$\theta$ BANCOS

$\theta$ OTROS:

P22 - ¿UTILIZA COMUNICACIONES DE DATOS EXTERNOS? $\theta$ SÍ *

*P22A- TIPO DE COMUNICACIONES DE DATOS EXTERNOS:

$\theta$ NINGUNO

$\theta$ MÓDEM (Línea Telefónica RTB)

$\theta$ DISPOSITIVOS RDSI ( Tarjeta o Router)

$\theta$ LÍNEAS DEDICADAS (Punto a punto)

$\theta$ LÍNEAS X25 O FRAME RELAY

$\theta$ OTROS:

*P22B- ¿A QUÉ SERVICIOS DE COMUNICACIONES DE DATOS EXTERNOS ACCEDE LA EMPRESA?

$\theta$ BANCOS

$\theta$ INTERNET

$\theta$ SERVICIOS DE INFORMACIÓN EN LÍNEA (Bolsa, asistencia técnica...)

$\theta$ COMUNICACIÓN CERRADA CON EMPRESAS (Clientes, proveedores...)

$\theta$ ADMINISTRACIÓN PÚBLICA

$\theta$ OTROS:

P23- FRECUENCIA DE USO DE COMUNICACIÓN CON ALGÚN PROVEEDOR, CLIENTE O COMERCIAL:

$\theta$ NINGUNA

$\theta$ DIARIA PUNTUALMENTE

$\theta$ DIARIA ASIDUAMENTE

$\theta$ DIARIA CONTINUADAMENTE

$\theta$ NO (Pase a la P23)

P24- ¿DISPONE SU EMPRESA DE CONEXIÓN A INTERNET?

$\theta$ sí

$\theta$ SEMANALMENTE

$\theta$ MENSUALMENTE

$\theta$ NS / NC

$\theta$ NO (Pase a la P31) 
P25- TIPO DE CONEXIÓN A INTERNET:

$\theta$ MEDIANTE MÓDEM A TRAVÉS DE RTB

$\theta$ MEDIANTE TARJETA A TRAVÉS DE RDSI

$\theta$ MEDIANTE ROUTER

$\theta$ MEDIANTE SERVIDOR PROXY

P26- ¿TIENE DOMINIO DE EMPRESA EN INTERNET?

$\theta$ SÍ

$\theta$ NO

P27- NÚMERO DE BUZONES DE CORREO ELECTRÓNICO: .......

P28- ¿EN QUÉ APLICACIONES EMPLEA EL CORREO ELECTRÓNICO EN SU EMPRESA?

$\theta$ COMUNICACIÓN CON BANCOS O ASESORÍAS

$\theta$ COMUNICACIÓN CON CLIENTES Y PROVEEDORES

$\theta$ RECEPCIÓN DE PEDIDOS A TRAVÉS DE LOS COMERCIALES DE LA EMPRESA

$\theta$ RECEPCIÓN DE PEDIDOS DIRECTAMENTE DE LOS CLIENTES

$\theta$ SOLICITUD DE PEDIDOS A LOS PROVEEDORES

$\theta$ COMUNICACIÓN CON OTRAS ENTIDADES

$\theta$ PROMOCIÓN COMERCIAL, PUBLICIDAD

$\theta$ COMUNICACIÓN INTERNA DE LA EMPRESA

$\theta$ OTROS:

P29- ¿ACCEDE A LAS PÁGINAS WEB DE INTERNET?

$\theta$ Sí *

$\theta$ NO

*P29A- ¿CON QUÉ FINALIDAD ACCEDE A ESTAS PÁGINAS WEB?

$\theta$ CONSULTAS DE UNA INFORMACIÓN ECONÓMICA Y GENERAL

$\theta$ BÚSQUEDAS DE INFORMACIÓN SECTORIAL TEXTIL

$\theta$ BÚSQUEDAS DE INFORMACIÓN DIVERSA (Buscadores)

$\theta$ BÚSQUEDAS DE PROVEEDORES O CLIENTES DE LA EMPRESA

$\theta$ INSCRIPCIONES, SOLICITUDES, PEDIDOS, COMPRA ELECTRÓNICA, ETC

$\theta$ OTROS:

P30- ¿DISPONE SU EMPRESA DE PÁGINA WEB?
$\theta \mathrm{SI}^{\star}$
$\theta \mathrm{NO}$

*P30A- ¿CUÁL ES EL ENFOQUE DE LA PÁGINA WEB DE SU EMPRESA?

$\theta$ DE CARÁCTER TESTIMONIAL.

$\theta$ PROMOCIÓN DE LA IMAGEN CORPORATIVA DE LA EMPRESA

$\theta$ PROMOCIÓN DE LOS PRODUCTOS QUE EN ELLA SE EXPONEN

$\theta$ INSTRUMENTO DE SOLICITUD DE PEDIDOS (FORMULARIOS) O DE INFORMACIÓN.

$\theta$ OTROS:

P31- ¿EN CUÁNTO TIEMPO CONSIDERA QUE LA TECNOLOGÍA INTERNET SE CONVERTIRÁ EN UN MEDIO DE COMUNICACIÓN IMPRESCINDIBLE ENTRE EMPRESAS (COMO EL FAX)?

$\theta$ LARGO (+5 AÑOS) $\theta$ MEDIO (2-5 AÑOS) $\theta$ CORTO (<2 AÑOS)

P32- ¿CUENTA CON SERVIDOR DE FAXES?

$\theta$ SÍ $\theta$ NO

P33- ¿CONOCE LOS SISTEMAS INTRANET/EXTRANET?

$\theta$ Sí *

$\theta$ NO

*P33A- ¿ESTÁN INTERESADOS EN IMPLANTAR ESTE TIPO DE TECNOLOGÍA?

$\theta$ YA DISPONE

$\theta$ ESTÁN INTERESADOS

$\theta$ NO ESTÁN INTERESADOS

P34- ¿CONOCE EL EDI (INTERCAMBIO ELECTRÓNICO DE DATOS)?
$\theta$ Sí
$\theta$ NO (Pase a la P37)

P35- ¿UTILIZA EL EDI?

$\theta$ SÍ *
*P35A- ¿QUÉ TIPO DE EDI UTILIZA?

$\theta \mathrm{NO}$ **

$\theta$ EDI TRADICIONAL (Líneas especiales)

$\theta$ EDIWeb

$\theta$ NS / NC

*P35B- ¿QUÉ GRADO DE SATISFACCIÓN MUESTRA CON LA UTILIZACIÓN DEL SISTEMA EDI? 
ANEXO 1

$\theta$ ALTO

$\theta$ MEDIO

$\theta$ BAJO 
*P35C- ¿POR QUÉ MOTIVO EMPEZÓ A UTILIZAR EL EDI?

$\theta$ INICIATIVA PROPIA

$\theta$ IMPOSICIÓN POR PARTE DE PROVEEDORES, CLIENTES U OTRAS ENTIDADES

*P35D- ¿CUÁLES SON LAS VENTAJAS MÁS IMPORTANTES DE LA APLICACIÓN DEL EDI EN SU EMPRESA?

$\theta$ MINIMIZACIÓN DEL STOCK

$\theta$ TIEMPO DE RESPUESTA MÁS CORTO

$\theta$ DISMINUCIÓN DE ERRORES

$\theta$ MEJOR CONTROL DEL PRODUCTO Y PEDIDOS

$\theta$ COMODIDAD DE GESTIÓN

$\theta$ OTROS:

**P35E- ¿DEBIDO A QUÉ MOTIVOS NO SE UTILIZA EL SISTEMA EDI EN SU EMPRESA?

$\theta$ NO ESTÁ IMPLANTADO ENTRE LOS PROVEEDORES O CLIENTES

$\theta$ EL FLUJO DE ENVÍO/RECEPCIÓN DE DATOS CON LOS PROVEEDORES Y CLIENTES NO ES ELEVADO

$\theta$ TÉCNICAMENTE SUPONE CIERTA COMPLEJIDAD

$\theta$ SUPONE UN GASTO IMPORTANTE EN COMUNICACIONES

$\theta$ OTROS:

P36- ¿EN CUÁNTO TIEMPO CONSIDERA QUE EL EDI PUEDE CONVERTIRSE EN UN MEDIO MUY IMPORTANTE PARA ESTABLECER LAS TRANSACCIONES COMERCIALES?
$\theta$ LARGO (+5 AÑOS)
$\theta$ MEDIO (2-5 AÑOS)
$\theta$ CORTO (<2 AÑOS)

P37- ¿CONSIDERA INTERESANTE PARA SU EMPRESA LA APLICACIÓN DE TELEFONÍA A TRAVÉS DE INTERNET?

$\theta$ SÍ* $^{*}$

*P37A- ¿EMPLEA HABITUALMENTE ALGÚN SISTEMA?

$\theta$ Sí

$\theta$ NO

$\theta$ NO

P38- ¿CONSIDERA INTERESANTE PARA SU EMPRESA VIDEOCONFERENCIA?

$\theta$ Sí * $\theta$ NO

*P38A- ¿UTILIZA HABITUALMENTE ALGÚN SISTEMA?
$\theta$ Sí
$\theta$ NO

P39- ¿QUÉ ÁREAS O DEPARTAMENTOS SE APOYAN INFORMACIÓN Y COMUNICACIÓN DE LA EMPRESA?
$\theta$ PRODUCCIÓN
$\theta$ ADMINISTRACIÓN
$\theta$ DISEÑO
$\theta$ COMPRAS

P40- ¿QUÉ FOMENTA LOS CAMBIOS EN SUS TIC?

EN LAS TECNOLOGías DE LA $\theta$ MARKETING Y VENTAS

$\theta$ LABORATORIO

$\theta$ CALIDAD

$\theta$ OTROS:
$\theta$ INICIATIVA PROPIA
$\theta$ IMPOSICIÓN POR PARTE DE PROVEEDORES, CLIENTES U OTRAS ENTIDADES
$\theta$ IMPOSICIÓN DEL MERCADO Y DE LA COMPETENCIA
$\theta$ NS / NC

\section{FORMACIÓN}

P41- ¿QUÉ NIVEL DE CONOCIMIENTOS DE LAS TIC POSEE LA DIRECCIÓN?
$\theta$ ALTO
$\theta$ MEDIO
$\theta$ BAJO

P42- ¿CUENTA SU EMPRESA CON EXPERTOS INFORMÁTICOS?
$\theta$ Sí *
$\theta$ NO **

*P42A- ¿QUÉ FORMACIÓN O TITULACIÓN TIENEN ESTOS EXPERTOS EN EL MOMENTO DE SU INCORPORACIÓN LABORAL?

$\theta$ INFORMÁTICA

$\theta$ OTRAS TITULACIONES UNIVERSITARIAS

$\theta$ FP INFORMÁTICA

$\theta$ AUTODIDACTAS

$\theta$ FP DE OTRAS ESPECIALIDADES

$\theta$ CURSOS ESPECÍFICOS

$\theta$ OTROS: 
*P42B- ¿QUÉ FUNCIONES REALIZAN LOS EXPERTOS EN LAS TIC EN LA EMPRESA?

$\theta$ MANTENIMIENTO DE HARDWARE, SOFTWARE Y RED LOCAL.

$\theta$ PROGRAMACIÓN A MEDIDA DEL SOFTWARE DE LA EMPRESA

$\theta$ DESEMPEÑA ADEMÁS OTRAS FUNCIONES (DIRECTIVAS, TÉCNICAS,

ADMINISTRATIVAS, ETC.)

$\theta$ ANÁLISIS Y PLANIFICACIÓN DE NECESIDADES INFORMÁTICAS DE LA EMPRESA

${ }^{*}$ P42C- ¿SE DISPONE DE SUFICIENTES CONOCIMIENTOS DE APLICACIONES DE COMUNICACIONES E INTERNET EN LA EMPRESA? $\theta$ sí

**P42D- ¿CÓMO SE GESTIONAN LAS TECNOLOGÍAS DE LA INFORMACIÓN Y DE LA COMUNICACIÓN EN SU EMPRESA?

$\theta$ CONSULTORES EXTERNOS

$\theta$ PERSONAL EXPERTO, NO INFORMÁTICOS

P43- ¿QUÉ CONOCIMIENTOS DE LAS TIC POSEE EL PERSONAL RESTANTE?
$\theta$ OFIMÁTICA
$\theta$ PROGRAMACIÓN
$\theta$ INTERNET Y COMUNICACIONES
$\theta$ CAD / CAM
$\theta$ PRODUCCIÓN

$\theta$ ADMINISTRACIÓN

OMARKETING, VENTAS, DISTRIBUCIÓN

OCOMPRAS, GESTIÓN PROVEEDORES

$\theta$ OTROS:

P44- ¿RECIBEN LOS TRABAJADORES DE SU EMPRESA FORMACIÓN EN INFORMÁTICA Y/O COMUNICACIONES?
$\theta \mathrm{NO}$
$\theta$ SÓLO A LA INCORPORACIÓN
$\theta$ A VECES*
$\theta$ MUY RARA VEZ*
$\theta$ CON BASTANTE FRECUENCIA*
$\theta$ CONTINUAMENTE*

*P44A ¿EN QUÉ ÁREAS SE LLEVA A CABO ESTA FORMACIÓN EN TIC?
$\theta$ OFIMÁTICA
$\theta$ PROGRAMACIÓN
$\theta$ INTERNET Y COMUNICACIONES
$\theta$ CAD / CAM
$\theta$ PRODUCCIÓN

$\theta$ ADMINISTRACIÓN

OMARKETING,VENTAS, DISTRIBUCIÓN

$\theta$ COMPRAS, GESTIÓN PROVEEDORES

$\theta$ OTROS:

P45- ¿OPINA QUE SU EMPRESA NECESITARÁ EN UN PERIODO DE TIEMPO CORTO O MEDIO, A MÁS PERSONAL ESPECIALIZADO EN COMUNICACIONES?

$$
\theta \text { Sí }
$$

P46- INVERSIONES REALIZADAS EN TECNOLOGÍAS DE LA INFORMACIÓN Y LAS COMUNICACIONES:

1.996 (MM. PTAS.):

$$
\begin{aligned}
& \theta \text { NADA } \\
& \theta \text { HASTA } 1 \\
& \theta \text { DE } 1 \text { A } 4
\end{aligned}
$$

1.997 (MM. PTAS.):

$\theta$ NADA

$\theta$ HASTA 1

$\theta$ DE 1 A 4

1.998 (MM. PTAS.):

$\theta$ NADA

$\theta$ HASTA 1

$\theta$ DE 1 A 4
$\theta$ DE 4 A 10
$\theta$ MÁS DE 10
$\theta \mathrm{NS} / \mathrm{NC}$
$\theta$ DE 4 A 10
$\theta$ MÁS DE 10
$\theta \mathrm{NS} / \mathrm{NC}$
$\theta$ DE 4 A 10
$\theta$ MÁS DE 10
$\theta \mathrm{NS} / \mathrm{NC}$ 


\section{ANEXO 2}

\section{CUESTIONARIO PARA EMPRESAS TEXTILES}

\begin{tabular}{|c|c|c|c|c|c|}
\hline Fecha & Hora & Lugar & & Entrevistador & Clave \\
\hline Empresa & & & Entrevistado & & Cargo \\
\hline
\end{tabular}

\section{Sección A.}

CAUSAS Y ANTECEDENTES DEL PROYECTO DE IMPLANTACIÓN DE UN "ERP"

1. CAUSAS, Identificación de eventos generales de necesidad de cambio

1.1 ¿En su opinión, cuáles son los motivos principales por los que han decidido cambiar su sistema de información?

Euro

Efecto 2000

La información financiera no está integrada

Necesidad de estandarización de los procesos de producción.

Adquisición o fusión con otra empresa.

Crecimiento de la empresa.

Incrementar visiblemente las operaciones.

Mejorar la accesibilidad, calidad y tiempo en la generación de información.

Otras...

1.2 ¿Quién ha detectado la necesidad del cambio? área?

Dueños, Gerente, Jefe de Informática, Jefes de departamentos, operarios, de que

Otros.....

1.3 ¿Quién ha impulsado el cambio? Decisión de intervenir área?

Dueños, Gerente, Jefe de Informática, Jefes de departamentos, operarios, de que

Otros.....

1.4 ¿Qué es un ERP, que satisfaga las necesidades de su empresa?

1.5 ¿Por qué se han decidido por una solución ERP?

Consejo de empresa compañera

Consejo de cliente o proveedor (para facilitar relaciones)

Benchmarking: copia de empresa competidora que va bien.

Por publicidad: Internet, Visitas de consultoras, Publicidad en general, por sus administradores de Sistemas?

Otros...

Identificación de aspectos generales para decidir entre las distintas soluciones ERP del mercado

1.6 ¿Han tenido un proceso de selección de ERP? No (pase pregunta 1.5.1); Si (pase pregunta 1.5.2)

1.6.1 ¿Con base en qué, o quiénes lo seleccionaron? 
Ofrecimiento de Consultora, cómo? Publicidad, visita, etc

Recomendación externa, quién? Socios, clientes, proveedores, amigos, competencia.

Recomendación interna, qué área? Informática, producción, contabilidad, comercial.

¿Qué conocimientos o preparación previa tiene quienes participaron en la selección del ERP, acerca de los procesos de la empresa y de la aplicación ERP?

\subsubsection{Proceso de selección.}

1.6.2.1 ¿Quiénes eran los encargados del proceso de selección del ERP?

Dueños, gerentes.

TI, Personal de informática.

Personal de algún otro departamento:

Un equipo interdepartamental:

Ninguno Otros

1.6.2.2 ¿En qué consiste el proceso de selección?, solicitaron ofertas a consultoras, observaron otras empresas, cuestionario...

1.6.2.3 ¿Qué criterios han tenido en cuenta para la selección del ERP?

Costo, funcionalidad, servicio posventa, tiempo de implantación, tecnología, facilidad de uso, solución a sus problemas críticos de: procesos, información, cumplimiento a pedidos, etc

1.6.2.4 ¿Cuál ha sido el criterio decisivo?

1.6.2.5 ¿Qué conocimientos o preparación tienen quienes participaron en la selección del ERP, acerca de los procesos de la empresa y la aplicación ERP?

1.7 ¿Qué objetivos tienen con la implantación del ERP?

Objetivos Organizacionales

Mejoras en productividad y gestión de órdenes de compra

Mejoras en la entrega a tiempo de la mercancía.

Simplemente reducción de tiempos de tarea y mejora calidad de trabajo

Salto al e-comerce

Objetivos Financieros

Reducción inventarios

Reducción personal

Reducción costo $\mathrm{TI}$

Reducción costos por compras, transporte, logística, mantenimiento... Otros

1.8 ¿ Cree que habrá un cambio en la forma de trabajar de la empresa, en la organización y en las relaciones externas e internas de la empresa? ¿Cómo se nota?

1.9 ¿Qué limitaciones usted cree que traerá la implantación del ERP?

2. ANTECEDENTES, Identificación de la situación de la empresa antes de decidir un cambio. Sistemas Heredados.

\subsection{Tecnología}

\begin{tabular}{|l|l|l|}
\hline FUNCIONES & ANTES DEL ERP & DESPUES DEL ERP \\
\hline 1-Aprovisionamiento & & \\
\hline 2-Plan./Prog de Proyectos & & \\
\hline 3- Gestión de stock & & \\
\hline 4- Logística y distribución & & \\
\hline 5- Marketing y publicidad & & \\
\hline 6- Gestión comercial & & \\
\hline
\end{tabular}




\begin{tabular}{|l|l|l|}
\hline 7- Aten. Cliente y postventa & & \\
\hline 8- Contabilidad & & \\
\hline 9- Gestión tesorería & & \\
\hline 10- Gestión de activos fijos & & \\
\hline 11- Nóminas & & \\
\hline 12- Gestión RRHH & & \\
\hline 13- SIAD & & \\
\hline 14- Correo electrónico & & \\
\hline 15- Flujo de trabajo & & \\
\hline 16- Páginas de internet & & \\
\hline 17- Comercio electrónico & & \\
\hline 18-Intranet & & \\
\hline 19- Extranet & & \\
\hline
\end{tabular}

\subsection{Procesos}

2.2.1 Descripción de las peculiaridades de los procesos de la empresa: Diagramas de flujo, posibilidad de recorrer su planta. Organigramas.

2.2.2 ¿Cuáles son los procesos críticos que se presentan en su empresa? contrastar con la pregunta...

2.2.3 ¿Cuáles son las características propias de su forma de trabajo y cuáles son las propias del subsector? contrastar con la pregunta...

2.3 Cultura Organizacional,. Identificación del clima laboral, motivación, formación del personal, liderazgo, disposición al cambio, comunicación, relaciones interpersonales.

\subsubsection{Características generales:}

1. Las nuevas ideas y conocimiento, que surgen en los procesos de cambio provienen de:

a. Del exterior. Buscamos inspiración en las ideas desarrolladas en el exterior.- También recogemos información de clientes, proveedores y competidores, institutos tecnológicos, ATEVAL, universidades, asistimos a ferias y buscamos ideas en Internet.

b. Del interior de la propia empresa. Aprovechamos nuestra información (rentabilidad, devoluciones, niveles mínimos de calidad, sugerencias del personal, etc) para intentar mejorar. Se han producido innovaciones o correcciones ideadas por la propia empresa.

2. Las fortalezas de mi organización están en la parte de:

a. Comercial y distribución

b. I+D, aprovisionamiento

c. Administración

d. Producción

3. En su empresa se paga al personal en atención a:

a. Posición dentro de la estructura de la empresa. Antigüedad y/o fidelidad.

b. Remuneración basada en rendimiento, desarrollo e implantación de nuevas ideas y participación en proyectos de mejora.

4. Las modificaciones en la actividad empresarial se introducen fruto de:

a. La corrección de deficiencias, buscando mejorar los procesos, sin cambios drásticos ni replanteamientos de la forma de hacer las cosas habitual en la empresa.

b. De la búsqueda de las causas subyacentes a los problemas, criticando, si es necesario, lo que se hace y como se hace. Se provocan cambios radicales.

5. El conocimiento útil para la toma de decisiones está almacenado en: 
a. Personas expertas. Experiencias, listas de contactos, anécdotas, opiniones.

b. Manuales de procedimientos. Bancos de datos y sistemas de archivos.

6. La inversión en Tecnologías de la Información obedece a:

a. La filosofía y política de innovación de la empresa.

b. Una situación puntual con el objetivo de mejorar los sistemas de información actuales.

7. Los beneficios de inversiones esperamos se vean reflejados en :

a. El estado de resultados ( $P$ y $G$ ) de la empresa.

b. La capitalización de la empresa.

8. Las inversiones realizadas tienen como objetivo:

a. Obtener mayores / nuevos ingresos.

b. Disminución de gastos.

9. La prioridad de inversión obedece a:

a. Aplicaciones informáticas de gestión en las diferentes áreas de la empresa.

b. Infraestructura tecnológica.

c. Externas a su negocio ( bolsa, otras industrias, etc)

10. Nos destacamos por ser:

a. Una empresa familiar, tradicional, con reconocimiento en el mercado.

b. Una empresa estable con un alto potencial de mercado y productos competitivos.

c. Una empresa sólida, vanguardista, de gran trayectoria y líderes en el mercado.

11. Las inversiones se hacen de una manera:

a. Planificada, programada periódicamente, obedeciendo a una política de inversión de la empresa.

b. Cuando se presenta una oportunidad de Negocio.

12. Que fuente de financiación utilizan para lograr sus objetivos de inversión:

a. Beneficios propios.

b. Endeudamiento.

c. Capital externo.

13. La política de ventas obedece a:

a. Aumentar el número de clientes.

b. Aumentar las ventas a los clientes actuales.

14. El uso de las nuevas tecnologías me permite:

a. Mejorar las relaciones con clientes y proveedores.

b. Mejorar los procesos de mi empresa.

15. Medimos la satisfacción de nuestros clientes basados en:

a. Desarrollo métodos de medición de reclamaciones, devolución de pedidos, encuestas de satisfacción, etc.

b. La experiencia, comunicaciones informales, comentarios de clientes, intuición.

16. Los procesos de compras, selección de proveedores y control de materia primas:

a. Están estandarizados, documentados, son claros y obedecen a una política de calidad de la empresa.

b. Son sencillos, claros y satisfacen las necesidades de la empresa.

17. Los plazos de entrega de pedidos:

a. Se cumplen satisfactoriamente y arriba de las expectativas de los clientes.

b. Presentan frecuentemente retardos y sobrecostos.

18. En la selección de proveedores lo importante es:

a. Servicio, calidad, tiempo de entrega.

b. Costo, tiempo, producto.

19. Al recibir un pedido de un cliente que sobrepasa mi capacidad de producción:

a. Se rechaza.

b. Se acepta y se subcontrata.

c. Se acepta con el riesgo de no poder cumplir con la fecha de entrega.

20. En mi empresa se hace análisis de procesos con el objeto de:

a. Automatizar tareas, estandarizar procesos, rediseñar procesos. 
b. Hacer mejoras correctivas.

21. Los procesos de mi empresa permiten:

a. Optimizar los tiempos de entrega de semielaborados gracias a los stocks existentes.

b. Reducción de inventarios y cumplimiento con las ordenes de producción.

22. Los procesos generan información:

a. De calidad, homogénea y de fácil acceso en tiempo real.

b. Necesaria para operar.

23. Los procesos de producción:

a. Permiten el cumplimiento con los pedidos de mis clientes satisfactoriamente en los plazos acordados.

b. Frecuentemente atrasan el cumplimiento de entrega de pedidos.

24. En la empresa:

a. Perfeccionamos los procesos utilizando nuevas tecnologías para reducir los costes.

b. Mejoramos el producto para darle valor añadido al cliente.

\section{Sección B. EXPERIENCIAS DURANTE EL PROYECTO DE IMPLANTACIÓN DE UN "ERP"}

\section{CARACTERÍSTICAS BÁSICAS DEL PRODUCTO}

\subsection{Aspectos generales sobre el Hardware y Software del ERP}

¿Qué ventajas de hardware y software ofrece el ERP que van a implantar con respecto a otras posibilidades? ¿Estás satisfacen sus necesidades y deseos? ¿Se sienten seguros con esos sistemas?

\subsection{Funcionalidad del producto}

¿Qué procesos de la empresa van a sistematizar, prioritariamente, con el ERP? (módulos del ERP).

De la siguiente lista de características, puntué de 1 a 5 las que considere más importantes para su negocio. Y puntué en que grado están siendo satisfechas con el ERP elegido.

\begin{tabular}{|l|l|l|}
\hline & Importancia & Satisfacción \\
\hline Segurid & & \\
\hline Trazabilidad & & \\
\hline Posibilidad de ampliar funciones, escalabilidad & & \\
\hline Conectividad(Internet, Intranet, etc) & & \\
\hline Simulación & & \\
\hline Interfaz gráfico & & \\
\hline Generación de Informes & & \\
\hline Confidencialidad & & \\
\hline Adaptabilidad & & \\
\hline Otros & & \\
\hline
\end{tabular}

\section{PROCESO DE IMPLANTACIÓN}

\subsection{ORGANIZATIVO}

CONSULTORA

¿Cuál ha sido el papel de la consultora en el proceso de implantación? 
PERSONAL DEL EQUIPO

¿Qué criterios de selección se tuvieron en cuenta para conformar el equipo?

¿Quién lo conforma?

¿Quién lo lidera?

¿Qué dedicación se ha asignado al proyecto? ( tiempo)

Implicación

(Compromiso de la alta dirección)-----DEDUCIR PERSONALMENTE

PROCEDIMIENTOS ORGANIZATIVOS

¿Qué tipo de comunicaciones se han generado en la empresa para informar sobre el proyecto? (informes, actas, cursos...)

¿Cómo se motiva al personal para lograr su participación y aceptación (pago de horas extras, premios, presentación de futuras mejoras en el trabajo...)

\subsection{FUNCIONES ABORDADAS POR EL NUEVO SISTEMA}

\begin{tabular}{|l|l|}
\hline Solución global o modular & \\
\hline Iniciación por módulos o Big-Bang & \\
\hline Grado de acomodamiento de la empresa al ERP & \\
\hline Funciones Internas / Externas & \\
\hline
\end{tabular}

5. COSTE

6. OBSERVACIONES GENERALES 


\title{
CUESTIONARIO PARA CONSULTORAS
}

\author{
I-Datos Generales de la Empresa \\ Razón
}

Social:

Dirección:

$\overline{\mathrm{Tel}}$

/Fax:

\begin{tabular}{lllll}
\hline Año & de & inicio & de & actividades:
\end{tabular}

Actividad

Principal:

Persona entrevistada:

Cargo:

\section{EMPRESA}

\begin{tabular}{|c|c|c|c|}
\hline $\begin{array}{l}\text { 1. Tipo: marque el } \\
\text { grupo que más se } \\
\text { ajuste a su tipo de } \\
\text { consultora }\end{array}$ & $\begin{array}{c}\text { Grupo } 1 \\
\text { Consultoras con } \\
\text { Solución ERP } \\
\text { Propia, y desarrollos } \\
\text { a medida }\end{array}$ & $\begin{array}{c}\text { Grupo } 2 \\
\text { Consultoras con Solución } \\
\text { ERP Propia, de } \\
\text { considerable } \\
\text { Parametrización }\end{array}$ & $\begin{array}{c}\text { Grupo 3 } \\
\text { Consultoras } \\
\text { implantadoras de } \\
\text { Solución ERP ajena, } \\
\text { altamente Parametrizable }\end{array}$ \\
\hline 2. Tamaño/año & 2001 & 2002 & 2003 \\
\hline 2.1. № trabajadores & & & \\
\hline 3. Facturación (año) & & & \\
\hline $\begin{array}{l}\text { 4. Número de clientes } \\
\text { nuevos en promedio } \\
\text { respecto al año anterior }\end{array}$ & & & \\
\hline $\begin{array}{l}\text { 4.1. № implantaciones } \\
\text { nuevas }\end{array}$ & & & \\
\hline $\begin{array}{l}\text { 5.1. Número de } \\
\text { sectores, seleccionar el } \\
\text { que corresponde }\end{array}$ & $2-4$ & $5-7$ & $>8$ \\
\hline $\begin{array}{l}5.2 \text { Sectores más } \\
\text { importantes. }\end{array}$ & $1^{\circ}$ & $2^{\circ}$ & $3^{\circ}$ \\
\hline $\begin{array}{l}5.3 \text { Subsectores del } \\
\text { Textil }\end{array}$ & $1^{\circ}$ & $2^{\circ}$ & $3^{\circ}$ \\
\hline $\begin{array}{l}\text { 6. Productos ERP que } \\
\text { implantan }\end{array}$ & $1^{\circ}$ & $2^{\circ}$ & $3^{\circ}$ \\
\hline
\end{tabular}




\section{SERVICIOS}

Por favor de la siguientes líneas de servicio, indique cuales ofrecen y si ofrecen o no las características mencionadas.

\begin{tabular}{|c|c|c|c|c|}
\hline Гipo & Líneas de servicios & Características & SI & NO \\
\hline 1 & $\begin{array}{l}\text { Análisis, diseño y desarrollo de } \\
\text { soluciones }\end{array}$ & $\begin{array}{l}\text { Conceptualización, análisis de requerimientos, diseño, } \\
\text { codificación, etc }\end{array}$ & & \\
\hline \multirow[t]{2}{*}{2} & \multirow[t]{2}{*}{ Consultoría de negocio } & Consultoría de procesos de negocio & & \\
\hline & & Consultoría de Calidad & & \\
\hline \multirow[t]{6}{*}{3} & \multirow[t]{6}{*}{ Consultoría de infraestructura } & Consultoría de comunicaciones & & \\
\hline & & Consultoría de rendimientos & & \\
\hline & & Consultoría de seguridad y antivirus & & \\
\hline & & Auditoria de Sistemas & & \\
\hline & & Ingeniería de Redes & & \\
\hline & & Planificación y verificación de copias. & & \\
\hline \multirow[t]{7}{*}{4} & \multirow[t]{7}{*}{ Servicio de Instalaciones } & Instalación y configuración de servidores y clusters & & \\
\hline & & Instalación de alta disponibilidad & & \\
\hline & & Almacenamiento de alta capacidad (storage) & & \\
\hline & & Instalación de PC & & \\
\hline & & Arranque de sistemas: Windows $2000 / N T$; base de datos, etc. & & \\
\hline & & Arranque de Servidores & & \\
\hline & & Cableado de red & & \\
\hline 5 & Implantación de Soluciones & $\begin{array}{l}\text { Organización del proyecto de implantación. } \\
\text { Diseño conceptual de la implantación. } \\
\text { Diseño Lógico y Físico de la implantación. } \\
\text { Puesta en Marcha de la solución. }\end{array}$ & & \\
\hline \multirow[t]{4}{*}{6} & \multirow[t]{4}{*}{ Consultoría e-business } & Consultoría de procesos de negocio electrónico & & \\
\hline & & Implantación de soluciones e-business & & \\
\hline & & Asesoramiento en diseño, estructura y navegación de webs & & \\
\hline & & Integración de aplicaciones externas. & & \\
\hline \multirow[t]{3}{*}{7} & \multirow[t]{3}{*}{ Mantenimiento y Soporte } & Mantenimiento de aplicaciones propias & & \\
\hline & & Mantenimiento de aplicaciones externas & & \\
\hline & & Mantenimiento de equipos & & \\
\hline \multirow[t]{5}{*}{8} & \multirow{5}{*}{$\begin{array}{l}\text { Formación: Transferencia de } \\
\text { conocimientos }\end{array}$} & Usuarios & & \\
\hline & & Administradores de sistemas & & \\
\hline & & Programadores & & \\
\hline & & Aula Presencial & & \\
\hline & & Aula virtual & & \\
\hline 9 & Servicio Postventa & Help desk & & \\
\hline 10 & Otros: & & & \\
\hline
\end{tabular}


Partners: Indique los partners con quienes trabajan como proveedores de software y hardware. Si existen otros de mayor importancia, indíquelos en las casillas dispuestas a tal efecto.

\begin{tabular}{|c||l||l||l||}
\hline Tipo & \multicolumn{1}{|c|}{ Partners } & Software & Hardware \\
\hline \hline A & Microsoft & & \\
\hline \hline B & IBM & & \\
\hline \hline C & Oracle & & \\
\hline \hline D & Compaq & & \\
\hline \hline E & Otros: & & \\
\hline \hline F & Otros: & & \\
\hline G & Otros: & & \\
\hline \hline H & Otros: & \\
\hline \hline
\end{tabular}

Clientes: Marque la cantidad promedio de clientes que tienen y el tamaño promedio de las empresas de esos clientes.

\begin{tabular}{|l|c|c||c|c||c||}
\hline a. Cantidad & $2-5$ & $6-10$ & $11-16$ & $>16$ & Otro: \\
\hline $\begin{array}{l}\text { b. Tamaño de la empresa del } \\
\text { cliente }\end{array}$ & Micro & Pequeña & Mediana & Grande & \\
\hline \hline
\end{tabular}

En el siguiente apartado, valore el conocimiento que tienen de la problemática del sector textil. E indique el número de implantaciones tanto en la Comunidad Valenciana como a nivel nacional.

\begin{tabular}{|l|l|l|l||}
\hline $\begin{array}{l}\text { Conocimiento del sector y su } \\
\text { problemática }\end{array}$ & Aceptable & Bueno & Excelente \\
\hline № implantaciones en el sector textil & Nacional & Comunidad Valenciana & Total \\
\hline \hline
\end{tabular}




\section{PRODUCTO}

Valore el grado que su producto ERP presenta de cada característica mencionada en las siguientes tablas.

a. Características generales

\begin{tabular}{|c|c|c|}
\hline \multicolumn{2}{|c|}{ Características } & Valoración \\
\hline \multicolumn{3}{|c|}{ Modularidad: cantidad } \\
\hline \multicolumn{3}{|c|}{ Integración: procesos de la empresa } \\
\hline \multicolumn{3}{|l|}{ Flexibilidad } \\
\hline \multicolumn{3}{|l|}{ Fiabilidad } \\
\hline \multicolumn{3}{|c|}{ Facilidad de uso } \\
\hline \multicolumn{3}{|c|}{ Personalización } \\
\hline \multirow{2}{*}{$\begin{array}{l}\text { Seguridad } \\
\text { (datos) }\end{array}$} & Confidencialidad & \\
\hline & Integridad & \\
\hline \multicolumn{2}{|l|}{ Simulación } & \\
\hline
\end{tabular}

b. Características técnicas.

\begin{tabular}{|l||l||}
\hline Características & Valoración \\
\hline \hline Multiplataforma & \\
\hline \hline Parametrización & \\
\hline \hline Conectividad & \\
\hline Interoperabilidad & \\
\hline \hline $\begin{array}{l}\text { Interfaz gráfico de usuario (Facilidad de } \\
\text { uso) }\end{array}$ & \\
\hline \hline Asistentes & \\
\hline \hline Consulta y generación de informes & \\
\hline \hline Otros & \\
\hline \hline
\end{tabular}


c. Plataforma Tecnológica: Marque los componentes más frecuentes con los que implantan su producto ERP.

\begin{tabular}{|c|c|c|c|c|c|c|c|c|}
\hline $\begin{array}{l}\text { Sistema } \\
\text { Operativo }\end{array}$ & NT & FreeBSD & LINUX & $\begin{array}{l}\text { Windows } \\
2000 \\
\text { Server }\end{array}$ & Solaris & $\begin{array}{l}\text { HP-UX } \\
11.0\end{array}$ & $\mathrm{AS} / 40 \mathrm{C}$ & Otro \\
\hline $\begin{array}{l}\text { Sistema de } \\
\text { Gestión de } \\
\text { Base de } \\
\text { datos }\end{array}$ & Informix & DB2 & MySQL & ORACLE & $\begin{array}{l}\text { Microsoft } \\
\text { SQLServ } \\
\text { er }\end{array}$ & Otro & Otro & Otro \\
\hline $\begin{array}{l}\text { Lenguaje } \\
\text { Programac } \\
\text { ión }\end{array}$ & $\mathrm{C} / \mathrm{C}_{++}$ & Delphi & $\begin{array}{l}\text { Visual } \\
\text { Basic }\end{array}$ & Java & ASP & PHP & $4 \mathrm{GL}$ & Otro: \\
\hline $\begin{array}{l}\text { Software } \\
\text { de red }\end{array}$ & \multicolumn{2}{|l|}{ Noven } & NT & \multicolumn{2}{|c|}{ Otro } & Otro & \multicolumn{2}{|c|}{ Otro } \\
\hline
\end{tabular}

d. Arquitectura del Sistema: Seleccione el entorno más frecuente con el que implantan su producto ERP dentro del sector textil.

\begin{tabular}{||l||l|l|}
\hline $\begin{array}{l}\text { Entorno Cliente } \\
\text { Servidor }\end{array}$ & $\begin{array}{l}\text { Aplicación en clientes: Servidor con } \\
\text { BD y múltiples clientes con } \\
\text { aplicaciones }\end{array}$ & $\begin{array}{l}\text { Aplicación en servidor de } \\
\text { ficheros: Servidor con las } \\
\text { aplicaciones, Servidor con BD } \\
\text { y múltiples clientes. }\end{array}$ \\
\hline \hline $\begin{array}{l}\text { Entorno Terminal } \\
\text { Server o Citrix }\end{array}$ & $\begin{array}{l}\text { Servidor con aplicaciones y Servidor } \\
\text { de Terminales (WNT o 2000); servidor } \\
\text { con BD y múltiples clientes con } \\
\text { terminal Server }\end{array}$ & \\
\hline \hline Entorno Internet & $\begin{array}{l}\text { Servidor Web (html) } \\
\text { Servidor BD } \\
\text { Múltiples clientes con browser de } \\
\text { Internet }\end{array}$ & $\begin{array}{l}\text { Modelo ASP } \\
\text { Servidor Web } \\
\text { Servidor de aplicaciones } \\
\text { Múltiples Clientes }\end{array}$ \\
\hline \hline
\end{tabular}

e. Describa el entorno de desarrollo software (de programación) utilizado en su producto ERP. Ejemplos: lineal, distribuida, por capas, etc). 
f. Elabore un esquema de la relación, interconexión interna y externa de los módulos que forman su ERP, Esquema Lógico.

\begin{tabular}{|l||l||l||l||l|}
\hline Módulos & Gestión Comercial & Contabilidad y Finanzas & Logística & Producción/Fabricación \\
\hline
\end{tabular}

Ejemplo:

(Esquema)

g. Marque las soluciones integrales, adicionales al producto ERP, que ofrecen a clientes del sector textil.

\begin{tabular}{||l||l||}
\hline \hline$\cdot$ CRM & \\
\hline \hline - Supply Chain Management & \\
\hline \hline - Supplier Relationship Management & \\
\hline - Business Intelligence & \\
\hline \hline - Collaborative Portal & \\
\hline - Workflow $\quad$ Westión documental & \\
\hline - $\quad$ Gol|| & \\
\hline \hline
\end{tabular}


h. Funcionalidades de los módulos para el sector textil.

Describa específicamente las 5 principales funcionalidades que ofrece cada módulo adaptándose a las características propias de los procesos del sector textil.

\begin{tabular}{||l||l||}
\hline Módulo & Funcionalidad \\
\hline PRODUCCIÓN & 1. \\
Nombre propio & 2. \\
& 3. \\
& 4. \\
\hline LOGISTICA & 5. \\
\hline Nombre propio & 1. \\
& 2. \\
& 3. \\
\hline GESTIÓN & 4. \\
COMERCIAL & 5. \\
Nombre propio & \\
& 1. \\
& 2. \\
\hline CONTABILIDAD Y & 3. \\
\hline FINANZAS & 4. \\
Nombre propio: & 5. \\
& 1. \\
\hline OTRO & 2. \\
\hline NEMURSOS & 3. \\
\hline & 4. \\
\hline & 5. \\
\hline
\end{tabular}

¿El cliente puede adquirir solo los módulos que necesita? 
¿El sistema permite la integración con otras aplicaciones existentes?

¿Se tiene disponibilidad del código fuente de la capa de presentación y de la lógica de negocio? 


\section{ANEXO 3}

\section{TIPIFICACIÓN DE SOLUCIONES ERPS}

El cuadro de descripción de ERPs muestra una breve definición del producto. La tabla comparativa muestra la tipificación de cada solución. Se verifica la fuerte orientación a los subsectores textiles de las soluciones verticales y el alto grado de especialización que los mismos poseen. Las soluciones estándares investigadas se destacan por su capacidad de parametrización a la realidad del sector textil, lo que representa también un alto nivel de desarrollo y experiencia orientadas a dichas empresas.

\section{DESCRIPCIÓN DE SOLUCIONES ERP}

\begin{tabular}{|c|c|c|}
\hline \# & ERP & DESCRIPCIÓN \\
\hline 1 & ACATEX & $\begin{array}{l}\text { Solución vertical especializada en el subsector de tinte, } \\
\text { acabado y estampación. Tiene también implantaciones en } \\
\text { lavanderías industriales, suministros industriales. } \\
\text { Es una solución diseñada para el sector de la Pyme. }\end{array}$ \\
\hline 2 & ACTIVA ERP & $\begin{array}{l}\text { Solución estándar, con desarrollos verticales para los } \\
\text { subsectores de acabado, confección textil y distribución. } \\
\text { Solución diseñada para el sector Pyme. }\end{array}$ \\
\hline 3 & AXAPTA & $\begin{array}{l}\text { Solución estándar, de alto desarrollo tecnológico. Tiene } \\
\text { desarrollos verticales para los subsectores de hilatura, } \\
\text { tejeduría y confección. } \\
\text { Es una solución desarrollada para las medianas y grandes } \\
\text { empresas. }\end{array}$ \\
\hline 4 & BAAN & $\begin{array}{l}\text { Solución estándar, de alto desarrollo tecnológico. Tiene } \\
\text { desarrollos verticales para el sector textil. } \\
\text { Es una solución para medianas y grandes empresas. }\end{array}$ \\
\hline 5 & EKON ERP & $\begin{array}{l}\text { Solución estándar, de alto desarrollo tecnológico. Tiene } \\
\text { desarrollos verticales para los subsectores de confección, } \\
\text { hilatura y tejeduria. } \\
\text { Tiene versión para Pymes. }\end{array}$ \\
\hline 6 & ERASMUS & $\begin{array}{l}\text { Solución vertical para el subsector confección. } \\
\text { Es una solución diseñada para el sector Pyme. }\end{array}$ \\
\hline 7 & EVOLOGYERP & $\begin{array}{l}\text { Solución estándar, tiene aplicaciones especificas para el } \\
\text { subsector de acabados con la solución "EvologyERP } \\
\text { ACAB" y parametrizaciones para otros subsectores como } \\
\text { tejeduría. } \\
\text { Solución diseñada para el sector Pyme. }\end{array}$ \\
\hline 8 & FENIX ERP & $\begin{array}{l}\text { Solución estándar, tiene desarrollos verticales para } \\
\text { diferentes industrias, en el caso del sector textil se } \\
\text { encuentra Fénix Textil para las empresas de confección } \\
\text { Es una solución diseñada para el sector de las Pyme. }\end{array}$ \\
\hline 9 & GIT & $\begin{array}{l}\text { Solución vertical especializada en el subsector textil-hogar } \\
\text { y con implantaciones en los subsectores confección y } \\
\text { tejeduría. } \\
\text { Es una solución diseñada para el sector Pyme. }\end{array}$ \\
\hline 10 & GLOBAL FASHION & $\begin{array}{l}\text { Solución vertical especializada en el subsector de } \\
\text { Confección. } \\
\text { Es una solución para el sector Pyme. }\end{array}$ \\
\hline 11 & KAIVALIA & $\begin{array}{l}\text { Solución estándar, con desarrollos verticales para los } \\
\text { subsectores textil-hogar y confección. Funcionalidades } \\
\text { operativas. }\end{array}$ \\
\hline
\end{tabular}




\begin{tabular}{l|l|l}
\hline 12 & MOVEX & $\begin{array}{l}\text { Solución estándar, con especialización en el subsector } \\
\text { textil-moda con la solución Movex Moda. } \\
\text { Ofrece soluciones verticales para los subsectores de textil- } \\
\text { hogar e hilaturas, confección y tejidos. }\end{array}$ \\
\hline 13 & $\begin{array}{l}\text { MySAP BUSINESS SUITE } \\
\text { SAP R/3 }\end{array}$ & $\begin{array}{l}\text { Solución estándar, de alto desarrollo tecnológico. Ofrece } \\
\text { soluciones verticales para los subsectores de moda, } \\
\text { estampado y confección. }\end{array}$ \\
\hline 14 & NAVISION & $\begin{array}{l}\text { Solución estándar con alto desarrollo tecnológico. Tiene } \\
\text { desarrollos verticales para la fabricación y distribución del } \\
\text { sector textil. } \\
\text { La versión Solutions-Navision Step está dirigida } \\
\text { específicamente a Pymes. }\end{array}$ \\
\hline 15 & PLAUT WORKS FASHION & $\begin{array}{l}\text { Solución vertical para el subsector textil-moda. Es una } \\
\text { solución preconfigurada mySAP Business Suite, } \\
\text { desarrollada para las Pymes del sector textil. }\end{array}$ \\
\hline 16 & PYMEPROD & $\begin{array}{l}\text { Solución vertical para el subsector textil-hogar. Tiene } \\
\text { desarrollos para los subsectores hilatura, tejeduría, } \\
\text { confección. } \\
\text { Es una solución diseñada para el sector Pyme. }\end{array}$ \\
\hline
\end{tabular}


Comparativo de soluciones ERP (I)

\begin{tabular}{|c|c|c|c|c|c|c|c|c|c|c|c|c|c|c|c|c|c|}
\hline 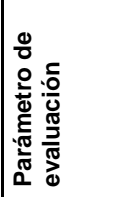 & 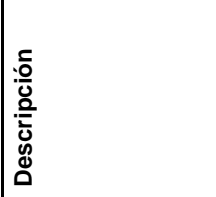 & 屁 & 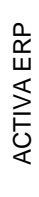 & $\underset{\frac{1}{6}}{\frac{5}{4}}$ & 发 & $\begin{array}{l}\frac{Q}{0} \\
w \\
z \\
\text { ò } \\
\frac{y}{w}\end{array}$ & 禹 & 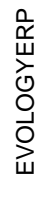 & 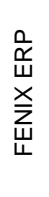 & 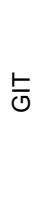 & 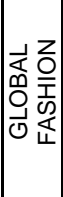 & 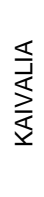 & 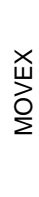 & 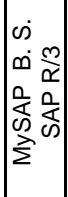 & $\frac{\frac{Z}{0}}{\frac{0}{2}}$ & 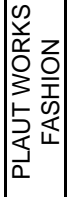 & 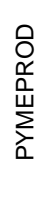 \\
\hline \multirow{2}{*}{ 을웡 흥 } & $\begin{array}{l}\text { Globalizado } \\
\text { Estándar }\end{array}$ & & $\mathrm{x}$ & $\mathrm{x}$ & $\mathrm{x}$ & $\mathrm{x}$ & & $\mathrm{x}$ & $\mathrm{x}$ & & & $\mathrm{x}$ & $\mathrm{x}$ & $\mathrm{x}$ & $\mathrm{x}$ & & \\
\hline & $\begin{array}{l}\text { Especialización } \\
\text { Vertical }\end{array}$ & $x$ & & & & & $x$ & $x$ & $\mathrm{x}$ & $x$ & $\mathrm{x}$ & & $x$ & & & $x$ & $\mathrm{x}$ \\
\hline \multirow{3}{*}{ 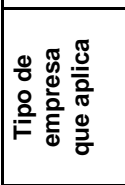 } & $\begin{array}{l}\text { Pequeña: }<=6 \\
\text { licencias }\end{array}$ & $\mathrm{x}$ & $\mathrm{x}$ & & & & $\mathrm{x}$ & $x$ & $x$ & $x$ & $x$ & $x$ & & & & $\mathrm{x}$ & $\mathrm{x}$ \\
\hline & \begin{tabular}{|l|} 
Mediana: $>6$ y $<$ \\
15 licencias \\
\end{tabular} & $x$ & $x$ & $\mathrm{x}$ & $x$ & $\mathrm{x}$ & $\mathrm{x}$ & $\mathrm{x}$ & $\mathrm{x}$ & $\mathrm{x}$ & $\mathrm{x}$ & $x$ & $\mathrm{x}$ & $\mathrm{x}$ & $\mathrm{x}$ & $x$ & $\mathrm{x}$ \\
\hline & $\begin{array}{l}\begin{array}{l}\text { Grande: > = 15 } \\
\text { licencias }\end{array} \\
\end{array}$ & & & $x$ & $x$ & $\mathrm{x}$ & & & & & & & $\mathrm{x}$ & $\mathrm{x}$ & $\mathrm{x}$ & & \\
\hline \multirow{5}{*}{ 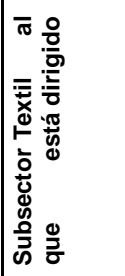 } & Hilatura & & $x$ & $x$ & $x$ & $\mathrm{x}$ & & & & $x$ & & $x$ & & & & & $\mathrm{x}$ \\
\hline & Tejeduría & & $x$ & $\mathrm{x}$ & $x$ & $x$ & & & & $x$ & & $x$ & & & & & $x$ \\
\hline & Ennoblecimiento & $x$ & $x$ & & & & & $x$ & & $x$ & & & & & & & \\
\hline & Confección & & $x$ & $\mathrm{x}$ & $x$ & $\mathrm{x}$ & $\mathrm{x}$ & & $\mathrm{x}$ & $\mathrm{x}$ & $\mathrm{x}$ & $x$ & $\mathrm{x}$ & & & $x$ & $\mathrm{x}$ \\
\hline & Otros & & & $x$ & $x$ & & & & & & & $x$ & & $x$ & $\mathrm{x}$ & & \\
\hline \multirow{4}{*}{ 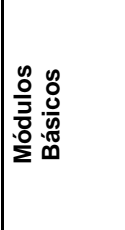 } & Producción & $\mathrm{x}$ & $x$ & $x$ & $x$ & $x$ & $\mathrm{x}$ & $x$ & $x$ & $x$ & $\mathrm{x}$ & $x$ & $\mathrm{x}$ & $x$ & $\mathrm{x}$ & $x$ & $\mathrm{x}$ \\
\hline & Logística & $x$ & $x$ & $\mathrm{x}$ & $x$ & $\mathrm{x}$ & $\mathrm{x}$ & $\mathrm{x}$ & $x$ & $\mathrm{x}$ & $\mathrm{x}$ & $x$ & $\mathrm{x}$ & $\mathrm{x}$ & & & $x$ \\
\hline & Gestión Comercial & $x$ & $x$ & $\mathrm{x}$ & $x$ & $\mathrm{x}$ & $\mathrm{x}$ & $x$ & $\mathrm{x}$ & $x$ & $\mathrm{x}$ & $x$ & $x$ & $\mathrm{x}$ & $\mathrm{x}$ & $x$ & $x$ \\
\hline & $\begin{array}{l}\text { Contabilidad y } \\
\text { Finanzas }\end{array}$ & $\mathrm{x}$ & $\mathrm{x}$ & $\mathrm{x}$ & $x$ & $\mathrm{x}$ & & $\mathrm{x}$ & $\mathrm{x}$ & $x$ & $\mathrm{x}$ & & $\mathrm{x}$ & $x$ & $x$ & $x$ & $x$ \\
\hline \multirow{9}{*}{ 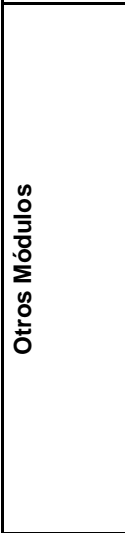 } & \begin{tabular}{|l|} 
Recursos \\
Humanos \\
\end{tabular} & & & $\mathrm{x}$ & $\mathrm{x}$ & $\mathrm{x}$ & & & $x$ & & & & $\mathrm{x}$ & $x$ & $x$ & & \\
\hline & CRM & & $x$ & $x$ & $x$ & $x$ & $x$ & $x$ & $x$ & & & & $x$ & $x$ & $x$ & & $x$ \\
\hline & SCM & & $\mathrm{x}$ & $\mathrm{x}$ & $x$ & $\mathrm{x}$ & & & $\mathrm{x}$ & $\mathrm{x}$ & & & $\mathrm{x}$ & $x$ & $\mathrm{x}$ & & $x$ \\
\hline & SRM & & & $x$ & $x$ & $x$ & & & $\mathrm{x}$ & & & & $x$ & $x$ & $x$ & & \\
\hline & BI & $x$ & & $x$ & $x$ & $x$ & & $x$ & $x$ & & & & $x$ & $x$ & $x$ & & \\
\hline & \begin{tabular}{|l|} 
Portal \\
Colaborativo \\
\end{tabular} & & $x$ & $x$ & $x$ & $x$ & & & $x$ & & & & $x$ & $x$ & $x$ & & \\
\hline & Workflow & & $x$ & $x$ & $x$ & $x$ & & & $x$ & $x$ & & & $x$ & $x$ & $x$ & & $x$ \\
\hline & \begin{tabular}{|l|} 
Gestión del \\
Conocimiento \\
\end{tabular} & & & $x$ & $x$ & $x$ & & & & & & & & & $x$ & & \\
\hline & \begin{tabular}{|l|} 
Gestión \\
Documental \\
\end{tabular} & & & $x$ & $x$ & $x$ & $x$ & & $\mathrm{x}$ & $x$ & & & & $x$ & $x$ & & \\
\hline \multirow{3}{*}{ 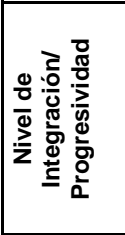 } & \begin{tabular}{|l} 
Instalación \\
independiente de \\
los Módulos \\
\end{tabular} & Sí & Sí & Sí & & Sí & Sí & Sí & Sí & Sí & & Sí & Sí & No & Sí & Sí & Sí \\
\hline & \begin{tabular}{|l|} 
Integración con las \\
aplicaciones \\
existentes
\end{tabular} & Sí & Sí & Sí & & Sí & Sí & No & Sí & Sí & & Sí & Sí & No & Sí & Sí & Sí \\
\hline & $\begin{array}{l}\text { Código fuente } \\
\text { abierto }\end{array}$ & Sí & Sí & Sí & & Sí & No & Sí & Sí & Sí & & Sí & Sí & Sí & Sí & No & No \\
\hline
\end{tabular}


Comparativo de soluciones ERP (II)

\begin{tabular}{|c|c|c|c|c|c|c|c|c|c|c|c|c|c|c|c|c|c|}
\hline 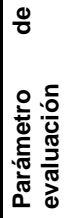 & 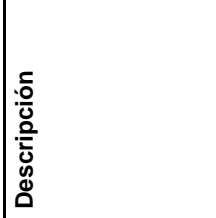 & 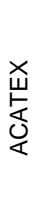 & 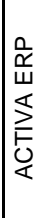 & 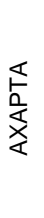 & 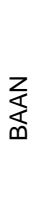 & 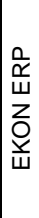 & 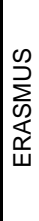 & 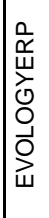 & 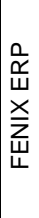 & $\frac{上}{\sigma}$ & 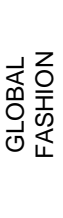 & 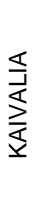 & ญ & 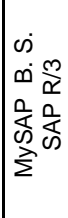 & $\frac{Z}{\frac{Z}{D}}$ & 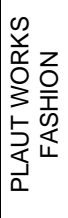 & 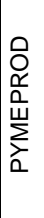 \\
\hline \multirow{8}{*}{ 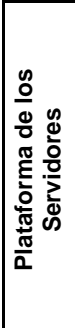 } & Linux & & $x$ & & & $x$ & & $x$ & $\mathrm{x}$ & $x$ & & & & $x$ & & $x$ & \\
\hline & NT & & & $x$ & & $x$ & & $x$ & $\mathrm{x}$ & $x$ & & $x$ & & $x$ & $x$ & $\mathrm{x}$ & $x$ \\
\hline & AS/400 & & & $x$ & & $\mathrm{x}$ & & & & & & & $x$ & $x$ & $x$ & $x$ & \\
\hline & IBM & & & & & $x$ & & & & & & & & & & & \\
\hline & Windows & $x$ & $x$ & $x$ & & $x$ & $x$ & $x$ & $x$ & $x$ & & $x$ & $x$ & $x$ & $x$ & $x$ & \\
\hline & $\mathrm{HP}$ & $x$ & & & & $x$ & & $x$ & $\mathrm{x}$ & & & & & $x$ & & $x$ & \\
\hline & Solaris & $x$ & & & & & & & & & & & $x$ & $x$ & & $x$ & \\
\hline & Otro & & $x$ & & & & & & & & & & & & & & \\
\hline \multirow{7}{*}{ 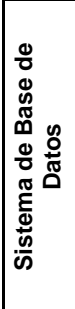 } & IBM DB2 & & & & & $x$ & & $x$ & & & & & $\mathrm{x}$ & $x$ & & $x$ & \\
\hline & $\begin{array}{|ll|}\text { Microsoft } & \text { SQL } \\
\text { er } & \\
\end{array}$ & & $x$ & $x$ & & $x$ & $\mathrm{x}$ & & $x$ & $x$ & $x$ & $x$ & $\mathrm{x}$ & $x$ & $x$ & $x$ & $x$ \\
\hline & Oracle $7 / 8 / 9$ & $x$ & & $x$ & & $x$ & & $\mathrm{x}$ & $x$ & $x$ & & & $x$ & $x$ & & $x$ & \\
\hline & My SQL Server & & $x$ & & & & & & & & & & & $x$ & & $x$ & \\
\hline & Informix & & & & & & & & $\mathrm{x}$ & & & & & $x$ & & & $x$ \\
\hline & AS400 & & & $\mathrm{x}$ & & & & & & & & & & & & & \\
\hline & Otro & & & & & $x$ & $x$ & & & $x$ & & & & $x$ & $x$ & $x$ & \\
\hline \multirow{7}{*}{ 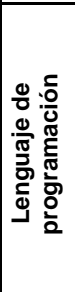 } & DELPHI & & & & & & $x$ & $x$ & & & & & & & & $\mathrm{x}$ & \\
\hline & Visual FoxPro & $x$ & & & & & & & & & & & & & & & \\
\hline & $\mathrm{C}++$ & & $x$ & $x$ & & $x$ & & $x$ & & $x$ & $x$ & & & $x$ & $x$ & $x$ & \\
\hline & \begin{tabular}{|l|} 
JAVA \\
\end{tabular} & & & $x$ & & $x$ & & $x$ & & & & $x$ & $x$ & $x$ & & $x$ & \\
\hline & $4 \mathrm{GL}$ & & $x$ & $x$ & & $x$ & & $x$ & $x$ & $x$ & & & & $x$ & $x$ & & $x$ \\
\hline & Visual Basic & $x$ & & $x$ & & & $x$ & & & $x$ & $x$ & & & $x$ & $x$ & $x$ & $x$ \\
\hline & Otro & $x$ & $x$ & & & $x$ & & $x$ & $x$ & $x$ & & & & $x$ & $x$ & $x$ & \\
\hline
\end{tabular}




\section{CLASIFICACIÓN DE CONSULTORAS}

La investigación realizada ha permitido el análisis de las características de las consultoras, las soluciones ERP que implantan y la metodologías de implantación que siguen, de una muestra de empresas proveedoras de soluciones ERP, donde se puede distinguir entre tres grupos para su clasificación en base a sus características funcionales, técnicas y su metodología de implantación.

\section{Grupo 1: Consultoras con solución ERP propia, de con desarrollos a medida.}

Se trata de empresas que normalmente se dedicaban al diseño de aplicaciones a medida para sus clientes y que, siguiendo la tendencia del mercado, han evolucionado desarrollando su propia solución estándar ERP, e incorporándose a este mercado.

Dentro de este grupo de empresas podemos distinguir dos subgrupos:

1. Las que cuentan con un producto estándar no sectorizado, capaces de adaptarlo a empresas prácticamente de cualquier sector.

2. Las empresas especializadas en un subsector concreto o con soluciones específicas diferentes para varios subsectores.

Además, ambas cuentan con productos para otros subsectores no pertenecientes al sector textil. Estos proveedores de software y su producto se caracterizan por:

\begin{tabular}{|l|l|}
\hline Trato personal y cercano: & $\begin{array}{l}\text { Se trata de empresas que normalmente actúan en un radio cercano } \\
\text { a sus oficinas y suelen ser de pequeño tamaño en cuanto a } \\
\text { empleados, proporcionan un alto nivel de atención y acercamiento } \\
\text { a sus clientes. Estas pequeñas empresas suelen tener una escasa } \\
\text { rotación del personal, garantizando la continuidad y } \\
\text { consecuentemente el mayor conocimiento de las necesidades del } \\
\text { cliente. }\end{array}$ \\
\hline $\begin{array}{l}\text { Conocimiento del sector y su } \\
\text { problemática: }\end{array}$ & $\begin{array}{l}\text { Este es uno de los puntos fuertes de estas empresas, gracias a la } \\
\text { experiencia en el desarrollo de aplicaciones a medida, conocen } \\
\text { muy bien al cliente del sector en que trabajan, en este caso el } \\
\text { Textil, y toda la problemática relacionada con sus procesos de } \\
\text { negocio. } \\
\text { Este profundo conocimiento les permite asimilar rápidamente los } \\
\text { requerimientos del cliente y proporcionarle soluciones acordes a lo } \\
\text { que éste espera de un sistema de información. Sin embargo este } \\
\text { factor puede llegar a convertirse en un lastre, ya que al adaptarse } \\
\text { tan fielmente a la forma de trabajar de la empresa, generan } \\
\text { soluciones muy cerradas, limitando las opciones de cambio del } \\
\text { empresario. }\end{array}$ \\
\hline $\begin{array}{l}\text { Facilidad de desarrollo de } \\
\text { funcionalidades específicas } \\
\text { no contempladas por su } \\
\text { estándar. }\end{array}$ & $\begin{array}{l}\text { Elogarativamente pequeño tamaño de la solución y el carácter } \\
\text { programador de estas empresas hacen que la adición o } \\
\text { modificación de nuevas funcionalidades del estándar que no } \\
\text { puedan hacerse con la escasa parametrización que permite éste, } \\
\text { no supongan ninguna dificultad para ellas. La mayoría de ellas } \\
\text { cuenta con herramientas de desarrollo que facilitan aún más la }\end{array}$ \\
\hline
\end{tabular}




\begin{tabular}{|l|l|}
\hline & $\begin{array}{l}\text { generación del código, lo que les permite construir soluciones a las } \\
\text { especificaciones de sus clientes en tiempos mínimos. } \\
\text { Algunas de ellas incluso realizan formación del personal de la } \\
\text { empresa en la utilización de estas herramientas de desarrollo para } \\
\text { que lo hagan ellos mismos o entregan el código fuente de sus } \\
\text { soluciones. }\end{array}$ \\
\hline $\begin{array}{l}\text { Escasa parametrización de } \\
\text { su solución: }\end{array}$ & $\begin{array}{l}\text { El producto estándar no es de una gran complejidad en cuanto a } \\
\text { capacidad de parametrización. En este aspecto se limitan } \\
\text { básicamente a cuestiones de forma, como el interfaz gráfico, } \\
\text { dejando el fondo para el desarrollo. }\end{array}$ \\
\hline $\begin{array}{l}\text { Rapidez del proceso de } \\
\text { implantación. }\end{array}$ & $\begin{array}{l}\text { En cuanto a velocidad de implantación, algunas de ellas aseguran } \\
\text { ser capaces de poner en marcha un sistema en cuestión de } \\
\text { semanas. }\end{array}$ \\
\hline Reducido coste & $\begin{array}{l}\text { Comparativamente con los otros grupos de soluciones, la inversión } \\
\text { necesaria en todos los aspectos para la implementación de uno de } \\
\text { estos ERPs es bastante menor. }\end{array}$ \\
\hline
\end{tabular}

\section{Grupo 2: Consultoras con solución ERP propia, de altamente parametrización}

Este es el caso menos frecuente entre las consultoras estudiadas en el proyecto, ya que es complicado que una empresa del sector de sistemas de información, logre desarrollar una solución ERP, de magnitud y potencia comparable a los productos de los grandes proveedores de sistemas ERP, pero existen consultoras que tienen productos de alta competitividad en el mercado nacional e internacional como las que a continuación se mencionan.

\section{Características:}

\begin{tabular}{|l|l|}
\hline $\begin{array}{l}\text { Productos de alto desarrollo } \\
\text { tecnológico e innovación. }\end{array}$ & $\begin{array}{l}\text { Son soluciones ERP que se han desarrollado con un alto } \\
\text { componente tecnológico y tienen una evolución paralela a } \\
\text { las últimas innovaciones informáticas. }\end{array}$ \\
\hline $\begin{array}{l}\text { Considerable parametrización de su } \\
\text { producto. }\end{array}$ & $\begin{array}{l}\text { Las herramientas de parametrización con que cuenta su } \\
\text { producto, les permite realizar gran parte de las } \\
\text { adaptaciones asociadas a las especificaciones del cliente } \\
\text { sin necesidad de realizar ningún desarrollo, con la } \\
\text { reducción de tiempo y coste que esto conlleva. }\end{array}$ \\
\hline $\begin{array}{l}\text { Facilidad de desarrollo de } \\
\text { funcionalidades específicas. }\end{array}$ & $\begin{array}{l}\text { Dado que se trata de una solución desarrollada por ellos } \\
\text { mismos, la conocen al detalle y tienen acceso a todos sus } \\
\text { componentes, lo que les facilita la incorporación de } \\
\text { cualquier funcionalidad requerida por el cliente. Este } \\
\text { profundo conocimiento les permite además conseguir una } \\
\text { alta integración de los desarrollos. }\end{array}$ \\
\hline $\begin{array}{l}\text { Análisis y revisión de los procesos de } \\
\text { la empresa. }\end{array}$ & $\begin{array}{l}\text { Cuentan con una amplia experiencia en consultoría de } \\
\text { procesos empresariales. Su método de trabajo arranca } \\
\text { de una revisión de procesos previa que proporciona a los } \\
\text { empresarios un análisis interno de su empresa de gran } \\
\text { utilidad. }\end{array}$ \\
\hline Sólida metodología de implantación. & $\begin{array}{l}\text { Poseen una metodología formal de implantación bajo la } \\
\text { cual se gestionan todos sus proyectos. La descripción } \\
\text { documental y revisión de cada uno de los pasos a seguir } \\
\text { y objetivos a cumplir, asegura un proceso de implantación } \\
\text { completo y seguro. }\end{array}$ \\
\hline
\end{tabular}


Grupo 3: Consultoras implantadoras de solución ERP ajena, altamente parametrizable

Consultoras que se dedican a la implantación de una o varias soluciones proporcionadas por un socio fabricante. Trabajan con soluciones de una gran fiabilidad, dado que se trata de productos probados e implantados desde hace años en el mundo entero. Además son soluciones ERP muy completas, la mayoría de las funcionalidades requeridas se realizan con la parametrización del sistema.

\section{Las principales características que definen a este grupo en cuanto a producto y metodología son:}

\begin{tabular}{|c|c|}
\hline $\begin{array}{l}\text { Alta capacidad de parametrización de } \\
\text { su producto. }\end{array}$ & $\begin{array}{l}\text { Poseen la mayor capacidad de parametrización de todos } \\
\text { los grupos señalados, reduciendo de este modo, tanto } \\
\text { tiempos como costos. }\end{array}$ \\
\hline $\begin{array}{l}\text { Desarrollo continuo de la solución } \\
\text { estándar. }\end{array}$ & $\begin{array}{l}\text { El respaldo de las grandes compañías fabricantes de } \\
\text { ERP's les permite contar continuamente con } \\
\text { actualizaciones de la solución, incorporando } \\
\text { funcionalidades o mejoras sugeridas por los usuarios del } \\
\text { sistema. } \\
\text { Las consultoras de este grupo muestran una innovación } \\
\text { constante de su producto sin inversión adicional. }\end{array}$ \\
\hline $\begin{array}{l}\text { Soporte adicional de las grandes } \\
\text { corporaciones fabricantes del } \\
\text { software. }\end{array}$ & $\begin{array}{l}\text { Tras la implantación de una de estas soluciones, además } \\
\text { de la propia consultora implantadora, se cuenta con la } \\
\text { garantía y soporte propios de la mpresa fabricante del } \\
\text { software que conlleva el pago de la licencia. }\end{array}$ \\
\hline Sólida metodología de implantación. & $\begin{array}{l}\text { Al igual que las del grupo anterior, estas consultoras } \\
\text { poseen una metodología formal de implantación, en } \\
\text { muchos casos proporcionada por el propio fabricante de } \\
\text { la solución, bajo la cual se gestionan todos sus proyectos. } \\
\text { Este es un elemento diferenciador frente a otras } \\
\text { consultoras que implantan el mismo producto, por lo que } \\
\text { deben esforzarse al máximo en el seguimiento y } \\
\text { optimización de esta metodología. }\end{array}$ \\
\hline $\begin{array}{l}\text { Personal altamente capacitado en } \\
\text { todas las áreas de consultoría. }\end{array}$ & $\begin{array}{l}\text { Se trata de otro elemento que diferencia varias } \\
\text { consultoras implantadoras del mismo sistema. El } \\
\text { personal cualificado es el mayor valor de estas empresas, } \\
\text { ya que finalmente son las personas las encargadas de } \\
\text { seguir la metodología, y las que hacen que ésta se lleve a } \\
\text { cabo con éxito. }\end{array}$ \\
\hline $\begin{array}{l}\text { Estándar distribuido por diferentes } \\
\text { consultoras. }\end{array}$ & $\begin{array}{l}\text { Cuando un empresario emprende el proyecto de cambio } \\
\text { de sistema de información con una de estas consultoras, } \\
\text { sabe que no tiene necesidad de estar ligado a ésta } \\
\text { mientras mantenga la solución, sino que una vez } \\
\text { adquirida la licencia del producto, puede buscar otra } \\
\text { consultora del mismo ERP para su mantenimiento o las } \\
\text { posibles modificaciones que necesite. }\end{array}$ \\
\hline Manejan diferentes soluciones & $\begin{array}{l}\text { Suelen contar con distintas soluciones ERP, de } \\
\text { características diferentes, con lo que pueden seleccionar, } \\
\text { la que mejor se adapte a los requerimientos del cliente. }\end{array}$ \\
\hline
\end{tabular}




\begin{tabular}{|l|l|}
\hline Complicados desarrollos a medida & $\begin{array}{l}\text { Éstas no han desarrollado la solución, con lo que a pesar } \\
\text { de contar con todo el material proporcionado por el } \\
\text { fabricante, difícilmente llegarán al nivel de conocimiento } \\
\text { de estructura y algoritmos que les permita un desarrollo } \\
\text { de funcionalidades específicas de su cliente de forma tan } \\
\text { ágil como sus competidores con producto propio. }\end{array}$ \\
\hline Depurado interfaz de usuario. & $\begin{array}{l}\text { Mediante la continua actualización de versiones del } \\
\text { producto, incorporan las últimas tendencias en cuanto a } \\
\text { diseño y navegabilidad del interfaz de usuario. }\end{array}$ \\
\hline
\end{tabular}

El la siguiente tabla se representa la clasificación de las consultoras en función de los grupos anteriormente definidos y la solución ERP que implantan, como se puede observar analizadas que implanta la solución de Microsoft AXAPTA.

\begin{tabular}{|c|c|c|}
\hline CONSULTORA & $\begin{array}{l}\text { GRUPO EN EL QUE SE HA } \\
\text { CLASIFICADO }\end{array}$ & PRODUCTO \\
\hline CIPIC & Grupo 1.2 & ACATEX \\
\hline ACTIVA ICON & Grupo 1.1 & ACTIVA ERP \\
\hline AITANA SBS & Grupo 3 & AXAPTA \\
\hline OPEN SOLUTIONS & Grupo 3 & AXAPTA \\
\hline WATERMARK SPAIN & Grupo 3 & AXAPTA \\
\hline STERIA & Grupo 3 & BAAN \\
\hline CCS & Grupo 2 & EKON ERP \\
\hline SOFITEC & Grupo 2 & ERASMUS \\
\hline ACTEA & Grupo 1.2 & EVOLOGYERP \\
\hline ABAST GROUP & Grupo 2 & FENIX ERP \\
\hline ITEM & Grupo 1.2 & GIT \\
\hline INVESTRONICA & Grupo 3 & GLOBAL FASHION \\
\hline KAIVALIA & Grupo 2 & KAIVALIA \\
\hline INTENTIA & Grupo 2 & MOVEX \\
\hline ALTIMIA & Grupo 3 & $\begin{array}{lll}\text { MySAP } & \text { BUSINESS } & \text { SUITE } \\
\text { SAP R/3 } & & \end{array}$ \\
\hline AUREN MICROVAL & Grupo 3 & NAVISION \\
\hline $\begin{array}{l}\text { CIT } \\
\text { DEVELOPMMMENT }\end{array}$ & Grupo 3 & PLAUT WORKS FASHION \\
\hline INASE & Grupo 1.1 & PYMEPROD \\
\hline
\end{tabular}




\section{FUNCIONALIDADES ESPECIFICAS PARA EL SECTOR TEXTIL}

\section{Funcionalidades de las Soluciones ERPs (I)}

\begin{tabular}{|c|c|c|c|}
\hline$\frac{n}{\frac{\pi}{w}}$ & $\begin{array}{l}\text { MÓDULO } \\
\text { PRODUCCIÓN }\end{array}$ & $\begin{array}{l}\text { MÓDULO } \\
\text { LOGISTICA }\end{array}$ & $\begin{array}{c}\text { MÓDULO } \\
\text { GESTIÓN COMERCIAL }\end{array}$ \\
\hline 屁 & $\begin{array}{l}\text { Seguimiento de Producción. } \\
\text { Gestión de Laboratorio. } \\
\text { Control de Calidad. } \\
\text { Tiempos y Costes de Producción. } \\
\text { Incidencias / Tiempos Muertos / Estadísticas. } \\
\text { Modulo de Automatismos. } \\
\text { Centralización de tintura. } \\
\text { Dosificación de sólidos y líquidos. } \\
\text { Pesaje automatizado. } \\
\text { Automatismos para continua. } \\
\text { Expediciones automatizadas. } \\
\text { Conexión con sistemas externos, tanto en } \\
\text { entrada como en salida. }\end{array}$ & $\begin{array}{l}\text { Control de Almacenes } \\
\text { Empresa / Partidos. } \\
\text { Gestión de entrada / } \\
\text { Devoluciones series. } \\
\text { Expediciones Automatizadas. } \\
\text { Etiquetaje Salida / Albaranaje } \\
\text { Expedición. } \\
\text { Enlace sistemas externos / } \\
\text { Almacenamiento Logística. }\end{array}$ & $\begin{array}{l}\text { Planificación de entregas. } \\
\text { Control exhaustivo estado pedidos. } \\
\text { Expedición / valoración / Facturación. } \\
\text { Diario de abordo con Información } \\
\text { estadística y dinámica. } \\
\text { Comunicación Internet con agentes y } \\
\text { clientes. }\end{array}$ \\
\hline 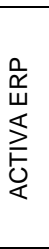 & $\begin{array}{l}\text { Control de Procesos / Seguimiento. } \\
\text { Gestión de escandallos / Consumos. } \\
\text { Gestión y Control Cocina Colores / Tinturas. } \\
\text { Gestión Partes Trabajo / Incidencias. } \\
\text { Gestión de Primas / Incentivos según } \\
\text { Producción. }\end{array}$ & $\begin{array}{l}\text { Gestión Almacenes de } \\
\text { materia prima y depósito. } \\
\text { Gestión de lotes y números } \\
\text { de serie. } \\
\text { Almacenes configurables a } \\
\text { cada situación. } \\
\text { Conexión permanente con } \\
\text { producción. } \\
\text { Codificación. de artículos por } \\
\text { modelo, serie, talla, color, etc }\end{array}$ & $\begin{array}{l}\text { Pedidos y expedición básica de } \\
\text { albaranes. } \\
\text { Gestión de tarifas de clientes. } \\
\text { Gestión de comisionistas. } \\
\text { Expedición de mercancías mediante } \\
\text { terminales lectores de código de barras }\end{array}$ \\
\hline 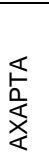 & $\begin{array}{l}\text { Gestión de Órdenes, fases y operaciones. } \\
\text { Ficha técnica: serie, modelo, talla, color. } \\
\text { Planificación. } \\
\text { Gestión de talleres externos. } \\
\text { Cálculo necesidades. }\end{array}$ & $\begin{array}{l}\text { Multicompañía logística. } \\
\text { Gestión de compras. } \\
\text { Gestión de almacenes } \\
\text { externos, interno, tránsito. } \\
\text { Trazabilidad documental. } \\
\text { Gestión de partidas. }\end{array}$ & $\begin{array}{l}\text { Facilidad entrada pedidos. } \\
\text { Punto de venta. } \\
\text { CRM. } \\
\text { Análisis de venta con OLAP. } \\
\text { Multi-idioma. }\end{array}$ \\
\hline 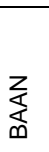 & $\begin{array}{l}\text { Fabricación bajo pedido, contra stock, bajo } \\
\text { proyecto, montaje bajo pedido, repetitiva e } \\
\text { híbrida. }\end{array}$ & $\begin{array}{l}\text { Compras, ventas, precios y } \\
\text { descuentos. } \\
\text { Estadísticas, EDI. } \\
\text { Gestión avanzada de } \\
\text { almacenes. }\end{array}$ & $\begin{array}{l}\text { Contratos de venta. } \\
\text { Control de ventas. } \\
\text { Información de ventas y marketing. } \\
\text { Ofertas de venta. }\end{array}$ \\
\hline 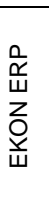 & $\begin{array}{l}\text { Ficha técnica, escandallos. } \\
\text { Cálculo de necesidades, simulaciones de } \\
\text { servicio. } \\
\text { Ordenes de corte. } \\
\text { Gestión de talleres externos. } \\
\text { Control de costes. } \\
\text { Imputación en planta. }\end{array}$ & $\begin{array}{l}\text { Gestión de temporadas, tallas } \\
\text { y colores. } \\
\text { Multialmacen. } \\
\text { Circuitos de compras y } \\
\text { ventas. } \\
\text { Pedidos por tallas y colores. } \\
\text { Expediciones, etiquetado. } \\
\text { Puntos de venta. }\end{array}$ & $\begin{array}{l}\text { Gestión de ofertas. } \\
\text { Gestión de contactos. } \\
\text { Seguimiento fuerza de ventas. } \\
\text { Gestión cartera clientes. } \\
\text { Gestión procesos (ventas, compras, } \\
\text { administrativos). }\end{array}$ \\
\hline
\end{tabular}


Funcionalidades de las Soluciones ERPs (II)

\begin{tabular}{|c|c|c|c|}
\hline 吕 & $\begin{array}{l}\text { MÓDULO } \\
\text { PRODUCCIÓN }\end{array}$ & $\begin{array}{l}\text { MÓDULO } \\
\text { LOGISTICA }\end{array}$ & $\begin{array}{c}\text { MÓDULO } \\
\text { GESTIÓN COMERCIAL }\end{array}$ \\
\hline 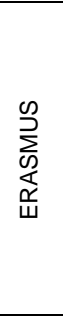 & $\begin{array}{l}\text { Reducción del coste de los excedentes } \\
\text { de materias primas. } \\
\text { Control total. } \\
\text { Control absoluto de costes. } \\
\text { Control de producción. } \\
\text { Control sobre talleres externos. } \\
\text { Modulo de Gestión de Producto } \\
\text { Alta velocidad en la creación de } \\
\text { muestrarios. } \\
\text { Reducción del coste por modelos } \\
\text { descartados. } \\
\text { Reducción de la complejidad del proceso } \\
\text { de escandallado. }\end{array}$ & $\begin{array}{l}\text { Gestión de almacenes y ubicaciones. } \\
\text { Optimización del picking de almacén. } \\
\text { Agilidad en la asignación de pedidos. }\end{array}$ & $\begin{array}{l}\text { Herramienta de fijación de precios y } \\
\text { creación de tarifas. } \\
\text { Soporte informático para la red } \\
\text { comercial. } \\
\text { Control de representante. }\end{array}$ \\
\hline 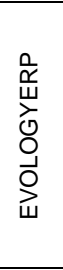 & $\begin{array}{l}\text { Definición de materiales, operaciones y } \\
\text { recursos. } \\
\text { Escandallo de materiales, operaciones, } \\
\text { recursos y aplicación de costes. } \\
\text { Escandallos por multicamino. } \\
\text { Operaciones internas y exteriores. } \\
\text { Planificación de necesidades y recursos. } \\
\text { Planning gráfico de materiales y recursos } \\
\text { (Diagrama de Gantt). } \\
\text { Órdenes de fabricación y hojas de ruta. }\end{array}$ & $\begin{array}{l}\text { Cadena de compras: propuesta, pedido, } \\
\text { recepción de mercancías y registro de } \\
\text { facturas. } \\
\text { Almacenes ilimitados: internos, externos } \\
\text { y depósitos. } \\
\text { Stock detallado por artículo y trazabilidad } \\
\text { de movimientos. Inventario a cualquier } \\
\text { fecha y valoración a diferentes precios. } \\
\text { Gestión de ubicaciones y gestión } \\
\text { individualizada de bultos. } \\
\text { Códigos de barras. }\end{array}$ & $\begin{array}{l}\text { Ventas a centrales de compra. } \\
\text { Tarifas genéricas y personalizadas, listas } \\
\text { promocionales y ventajas comerciales. } \\
\text { Gestión de mediadores y comisionistas. } \\
\text { Cadena de ventas: propuesta, pedido, } \\
\text { expedición y emisión de facturas. } \\
\text { Listas de contenido (packing list). }\end{array}$ \\
\hline 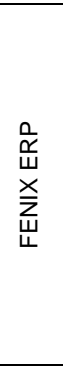 & $\begin{array}{l}\text { Escandallos (estructuras, componentes, } \\
\text { rutas, maquinas, operaciones, tiempos, } \\
\text { etc.). } \\
\text { Subcontratación. } \\
\text { Gestión órdenes de trabajo/ gestión } \\
\text { operarios / control de calidad. } \\
\text { Análisis de costes. } \\
\text { Planificador producción (MRP.). }\end{array}$ & $\begin{array}{l}\text { Tratamiento de características como } \\
\text { talla, color, temporada, etc. } \\
\text { Multialmacen. } \\
\text { Gestión de ubicaciones, lotes, no de } \\
\text { serie, etc. } \\
\text { Gestión de inventarios. } \\
\text { Trazabilidad de los movimientos de } \\
\text { almacén. }\end{array}$ & $\begin{array}{l}\text { Entrada ágil de líneas de pedidos } \\
\text { /albaranes, para artículos con diferentes } \\
\text { tallas, colores, modelos, etc. } \\
\text { Gestión de preventas, pedidos } \\
\text { (reservas), albaranes y facturas. } \\
\text { Análisis de ventas. } \\
\text { Control de riesgos clientes. } \\
\text { Servicio atención al cliente (SAC). } \\
\text { Modulo de Compras. } \\
\text { Circuito de aprovisionamiento } \\
\text { (pedido/parte de entrada/factura). } \\
\text { Evaluación de proveedores. } \\
\text { Gestión de precio de compra. } \\
\text { Análisis de compras. } \\
\text { Contabilización facturas. }\end{array}$ \\
\hline$\frac{\models}{\sigma}$ & $\begin{array}{l}\text { Programación de fabricación. } \\
\text { Control de distribuciones. } \\
\text { Integración servicios externos. } \\
\text { Operatividad en tiempo real. } \\
\text { Alta calificación de stocks. }\end{array}$ & $\begin{array}{l}\text { Planificación de servicios. } \\
\text { Automatización expediciones. } \\
\text { Gestión de necesidades. } \\
\text { Operatividad en tiempo real. } \\
\text { Integración con terceros. }\end{array}$ & $\begin{array}{l}\text { Calificación productos textil. } \\
\text { Control de muestrarios. } \\
\text { Gestión de exclusivas. } \\
\text { Integración EDI. } \\
\text { Terminología sectorial textil. }\end{array}$ \\
\hline 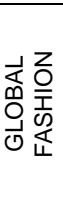 & $\begin{array}{l}\text { Registro de máquinas por operario. } \\
\text { Registro de operarios por máquina con } \\
\text { control de incidencias. } \\
\text { Registro y control de las operaciones de } \\
\text { los productos. } \\
\text { Registro de tablas de cronometraje de } \\
\text { productos, establecimiento de metas y } \\
\text { objetivos de producción diaria por célula. }\end{array}$ & $\begin{array}{l}\text { Control de materiales en los diferentes } \\
\text { almacenes. } \\
\text { Control de stocks. } \\
\text { Generación automática de albaranes de } \\
\text { artículos ya embalados. } \\
\text { Control de expediciones. }\end{array}$ & $\begin{array}{l}\text { Control de ventas de productos. } \\
\text { Recepción de pedidos vía Internet. } \\
\text { Control de fechas de entrega y límite de } \\
\text { entrega. } \\
\text { Control de pedidos aprobados, } \\
\text { rechazados y en estudio. }\end{array}$ \\
\hline 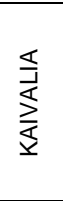 & $\begin{array}{l}\text { Planes de producción en los que se } \\
\text { consultan posibilidades y se prevén } \\
\text { consumos, tiempos y costes. } \\
\text { Preparación automática de los } \\
\text { escandallos en tiempo real. } \\
\text { Calcula y controla los costes reales } \\
\text { inherentes a cada operación de todos los } \\
\text { procesos. }\end{array}$ & $\begin{array}{l}\text { Control de todos los artículos en tiempo } \\
\text { real. } \\
\text { Seguimiento de su flujo en cada almacén } \\
\text { y centro de trabajo, interno o } \\
\text { subcontratado. } \\
\text { Control se realiza por partidas, tanto de } \\
\text { compras. } \\
\text { Multialmacén. }\end{array}$ & $\begin{array}{l}\text { Gestión de comerciales de ventas. } \\
\text { Gestión de ventas, descuentos, etc. } \\
\text { Evaluación de proveedores. } \\
\text { Gestión de pedidos. }\end{array}$ \\
\hline
\end{tabular}


Funcionalidades de las Soluciones ERPs (III)

\begin{tabular}{|c|c|c|c|}
\hline 呈 & $\begin{array}{l}\text { MÓDULO } \\
\text { PRODUCCIÓN }\end{array}$ & $\begin{array}{l}\text { MÓDULO } \\
\text { LOGISTICA }\end{array}$ & $\begin{array}{c}\text { MÓDULO } \\
\text { GESTIÓN COMERCIAL }\end{array}$ \\
\hline 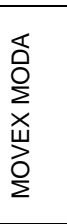 & $\begin{array}{l}\text { Gestión de operaciones en muchos } \\
\text { emplazamientos. } \\
\text { Planificación compleja de cortado, } \\
\text { cosido, subcontratado. } \\
\text { Fabricación para stock y bajo pedido en } \\
\text { la misma empresa. } \\
\text { Exigencias de etiquetado y empaquetado } \\
\text { definidas por los clientes. } \\
\text { Definición de estilo. }\end{array}$ & $\begin{array}{l}\text { Gestión de cadenas de suministro } \\
\text { complejas. } \\
\text { Gestión del transporte. } \\
\text { Trazabilidad total. } \\
\text { Gestión de contenedores. }\end{array}$ & $\begin{array}{l}\text { Gestión de márgenes pequeños. } \\
\text { Gestión de patrones de ventas volátiles. } \\
\text { Gestión de grandes volúmenes de SKU. } \\
\text { Gestión de promociones con precios y } \\
\text { descuentos flexibles. } \\
\text { Proceso de recepción de pedidos con } \\
\text { una sola llamada. } \\
\text { Gestión de precios de venta al por } \\
\text { menor. }\end{array}$ \\
\hline 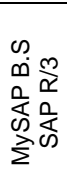 & $\begin{array}{l}\text { Ordenes de producción. } \\
\text { Lista de materiales. } \\
\text { MRP integrado. } \\
\text { Control de capacidad de las maquinas. } \\
\text { Hojas de ruta. }\end{array}$ & $\begin{array}{l}\text { Gestión de almacenes caóticos. } \\
\text { Gestión de rutas. } \\
\text { Control de stocks. } \\
\text { Gestión de transportistas. } \\
\text { Clasificación ABC de artículos. }\end{array}$ & $\begin{array}{l}\text { Gestión de todo tipo de descuentos. } \\
\text { Gestión de comisionistas. } \\
\text { Tipos de cambio. Trabajo multidivisa. } \\
\text { Pedidos abiertos y ofertas. } \\
\text { Estadísticas de venta. }\end{array}$ \\
\hline $\begin{array}{l}Z \\
\frac{O}{\text { O }} \\
\frac{Z}{Z}\end{array}$ & $\begin{array}{l}\text { Fabricación base. } \\
\text { Fabricación ágil. } \\
\text { Cadena de suministro. } \\
\text { Planificación de necesidades y } \\
\text { capacidad. } \\
\text { Carga finita. }\end{array}$ & $\begin{array}{l}\text { Gestión de almacén. } \\
\text { Gestión de ubicaciones. } \\
\text { Piking. } \\
\text { Captura de datos en planta. }\end{array}$ & $\begin{array}{l}\text { Compras y pagos. } \\
\text { Ventas y cobros. } \\
\text { Existencias. } \\
\text { Gestión de servicio. } \\
\text { Recursos y proyectos. }\end{array}$ \\
\hline 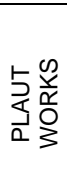 & $\begin{array}{l}\text { Lanzamiento de la producción en función } \\
\text { de un recurso crítico. } \\
\text { Control de la producción subcontratada. } \\
\text { Planificación de necesidades de compra } \\
\text { y fabricación. } \\
\text { Notificaciones de producción a través de } \\
\text { código de barras. }\end{array}$ & $\begin{array}{l}\text { Multialmacen. } \\
\text { Optimización de stocks en períodos de } \\
\text { repetición. } \\
\text { Eliminación de necesidades redundantes. }\end{array}$ & $\begin{array}{l}\text { Introducción de los diversos tipos de } \\
\text { pedido en función del momento de la } \\
\text { temporada. } \\
\text { Entrada de pedidos por correo } \\
\text { electrónico. } \\
\text { Asignación de stocks a pedidos de venta } \\
\text { con filtro de control. }\end{array}$ \\
\hline 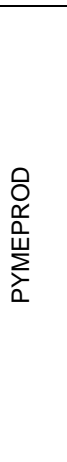 & $\begin{array}{l}\text { Control de Producción de Hilaturas. } \\
\text { Materias Primas. } \\
\text { Mezcladas. } \\
\text { Continuas. } \\
\text { Doblado/enconado/urdido. } \\
\text { Expediciones. } \\
\text { Control de Producción de Tejedurias. } \\
\text { Materias Primas. } \\
\text { Fichas técnicas y escandallos. } \\
\text { Repasado (control calidad). } \\
\text { Trazabilidad (etiquetas termo adhesivas). } \\
\text { Planificación visual. } \\
\text { Control de Producción de Talleres y } \\
\text { Confecciones. } \\
\text { Compras. } \\
\text { Fichas técnicas y escandallos. } \\
\text { Ordenes de producción. } \\
\text { Recepción de la producción. } \\
\text { Planificación visual. }\end{array}$ & $\begin{array}{l}\text { Inventarios con terminales móviles de } \\
\text { CDB. } \\
\text { Movimiento entre almacenes. } \\
\text { Expediciones. } \\
\text { Enlace con cualquier ERP. } \\
\text { Modulo Pymetienda. } \\
\text { Venta en mostrador con código barras. } \\
\text { Facturación crédito y contado. } \\
\text { Cierres de caja. } \\
\text { Conexión ON-LINE con central. } \\
\text { Control stock en línea resto de la cadena. } \\
\text { Modulo Pymemovil. } \\
\text { Pedidos en CDB, por radio frecuencia } \\
\text { (versión ON-LINE). } \\
\text { Pedidos en CDB y envió a central. } \\
\text { (versión OFF-LINE). } \\
\text { Envió información vía e-mail. } \\
\text { Integración con cualquier ERP. }\end{array}$ & $\begin{array}{l}\text { Almacén proa. Terminado. } \\
\text { Pedidos y albaranes CDB. } \\
\text { Facturas. } \\
\text { Compras. }\end{array}$ \\
\hline
\end{tabular}




\section{ANEXO 4}

\section{FORMATO PARA LA DEFINICIÓN DEL PLAN DE ACCIÓN}

\begin{tabular}{|l|l|}
\hline Fecha & Código del Documento \\
\cline { 2 - 3 } \multicolumn{1}{|c|}{ EMPRESA PILOTO } & Fase del Proyecto \\
Proyecto & PLAN DE ACCIÓN \\
\hline Equipo del Proyecto & Departamento Objeto \\
& STAF DE GERENCIA \\
\hline $\begin{array}{l}\text { Entrevistado } \\
\text { Gerente: } \\
\text { Informático: }\end{array}$ & Objetivo \\
& IDENTIFICAR OBJETIVOS DE LA EMPRESA ACERCA DE \\
& S.I. \\
\hline
\end{tabular}

OBJETIVO DEL NEGOCIO

FABRICACIÓN Y COMERCIALIZACIÓN DE TEJIDOS

PILOTO A: COMERCIALIZACIÓN NACIONAL DETALLISTAS.

PILOTO B: FABRICACIÓN. COMERCIALIZACIÓN DISTRIBUIDORES EXPORTACIÓN

ATENCIÓN 1500 CLIENTES APROX.

MISIÓN FUTURA DE LA EMPRESA:

PROCESOS: MEJORAMIENTO DE PROCESOS . 5 6 AÑOS CAMBIO EN LA UBICACIÓN DE LAS INSTALACIONES POR MAYOR CAPACIDAD Y MAS TECNOLOGÍA.

CLIENTES/ MERCADOS: 5-6 AÑOS EXPANSION

S.I.: NO. AMPLIAR CAPACIDAD DEL VOLUMEN DE PRODUCCIÓN

1. ALCANCE DEL PROYECTO:

CAMBIO DEL S.I ACTUAL POR UN S.I. QUE PERMITA SABER LO QUE ESTÁN HACIENDO EN TIEMPO REAL Y MÁS AMIGABLE PARA EL USUARIO.

\section{NECESIDADES DE INTEGRACIÓN:}

Integrar Fabricación con Administración. Es decir integrar el paquete de Gestión, eliminado tareas manuales duplicadas.

Integrar Logística con Fabricación.

Trazabilidad desde Materia Prima hasta Producto terminado.

Gestión de las dos empresas con el mismo S.I. pero de forma independiente. 


\section{SISTEMAS ACTUALES:}

Sistema Informático:

Hardware: 16 PC, 1 portátil.

2 Redes.

Windows(Vanico) y Novell (Cid).(solapadas)

Impresoras 8. Laser.

\section{Software:}

Office, EDI(Ediwin),

Desarrollos a Medida: (7 años). Documentación : NO. Fuentes: SI. 300 archivos.

Pedidos Clientes, Facturación, Control Almacenes(materias primas, productos en curso y producto acabado) . Contabilidad, Registros( Proveedores, Clientes, Transportes)

Conexión a EDI: Albaranes y Facturas.

Gestión de Producción. Confección. Necesidades de Producción.

Informatizado los procesos de Pedidos a empresas de servicios( fechas de entrega, etc) entrada de datos no.

Lenguaje: Basic Compilado. Rutina de tratamiento de archivos secuenciales indexados Btrieve. 


\begin{tabular}{|c|c|c|}
\hline \multicolumn{3}{|l|}{ Procesos } \\
\hline \multicolumn{2}{|c|}{$\begin{array}{l}\text { Fabricación: } \\
\text { Pedidos Materia Prima } \\
\text { Revisión de Calidad } \\
\text { Urdido. (Talleres externos) } \\
\text { Tejeduría (Talleres externos, drapaires) } \\
\text { Repasado } \\
\text { Control de Calidad ¿? } \\
\text { Empresas de Servicios: Estampado, Tintado, } \\
\text { Acabados. Embalaje. Expedición. }\end{array}$} & $\begin{array}{l}\text { Administración } \\
\text { Calidad } \\
\text { Compras } \\
\text { Comercial } \\
\text { Formación } \\
\text { Administración: } \\
\text { Comercial } \\
\text { Muestrario }\end{array}$ \\
\hline 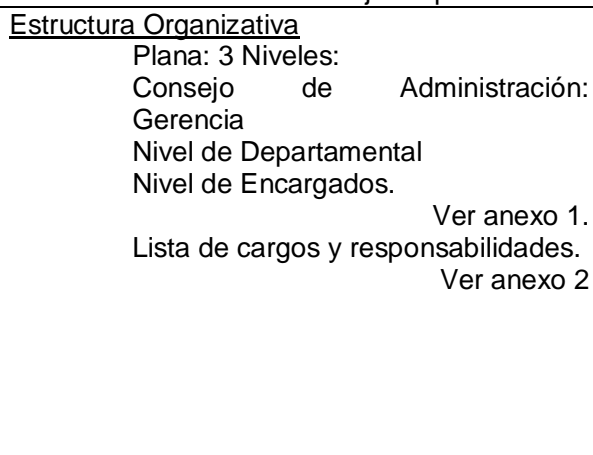 & \multicolumn{2}{|c|}{$\begin{array}{l}\text { Información Adicional } \\
\text { Manual de Calidad. Norma ISO } 9001 . \\
\text { Producción Lotes muy pequeños } \\
\text { Trazabilidad del producto es manual. } \\
\text { Volumen de Ventas Externas: } 1200 \\
\text { millones. La fabrica. No la facturación } \\
\text { propia. } \\
\text { Exportación } 40 \% \text { y Nacional } 60 \% \\
\text { No se realiza previsión. } \\
\text { Planificación Manual y Semanal. } \\
\text { Tiradas largas se subcontratan. } \\
\text { Se lanzan órdenes de fabricación para } \\
\text { atender a la rotura del stock. } \\
\text { Sistema de Ventas a Metros. }\end{array}$} \\
\hline \multicolumn{3}{|c|}{$\begin{array}{l}\text { 4. OPORTUNIDADES TECNOLÓGICAS: } \\
\text { Innovaciones tecnológicas a corto plazo. No. } \\
\text { Compra prevista de Máquinas Jackar electrónicas de mayor capacidad, diseño de máquina } \\
\text { pero de igual tecnología. }\end{array}$} \\
\hline \multicolumn{2}{|l|}{ Ninguna. } & $\begin{array}{l}\text { PRESL } \\
\text { No pre } \\
\text { benefic }\end{array}$ \\
\hline \multicolumn{3}{|c|}{$\begin{array}{l}\text { 6. IMPLICACIONES PARA EL PERSONAL: } \\
\text { Formación baja. Office } 8 \text { personas. } \\
\text { Plantilla Antigua. Rotación baja. Edad Media } 45-50 \text { años. } \\
\text { Trabajadores: } 28-30 \text { Fabrica: } 14 \text { Administración + Comercial: } 14\end{array}$} \\
\hline \multicolumn{2}{|c|}{$\begin{array}{l}\text { 7. ESQUEMA DEL PLAN DE ENTREGAS: } \\
\text { Identificación de procesos críticos. } \\
\text { Inventario del equipo informático actual. } \\
\text { Inventario de aplicaciones informáticas. } \\
\text { Valoración de Necesidades de Procesos y Sistemas. } \\
\text { Lista de Criterios para evaluar una solución ERP. }\end{array}$} & $\begin{array}{l}\text { 9. RIESGOS: } \\
\text { Temen el colapso por fal } \\
\text { Miedo Fracaso. } \\
\text { Resistencia al Cambio. }\end{array}$ \\
\hline \multicolumn{2}{|c|}{$\begin{array}{l}\text { 10. OBSERVACIONES } \\
\text { Detectar Cuellos de Botella Administrativos como de } \\
\text { fabricación. } \\
\text { Problemas de Gestión del producto acabado. } \\
\text { Han recibido ofertas de INASE, demostración del } \\
\text { producto. } \\
\text { Propuesta de visita de ITEM. }\end{array}$} & $\begin{array}{l}\text { Producto diferenciado por tipo en } \\
\text { almacenes. } \\
\text { Fabricación de } 900 \text { tipos de tejido. } \\
18 \text { tejedoras. (VAMATEX, BONES) } \\
\text { Los albaranes se expiden manualmente. } \\
\text { En Control de Calidad, existe una } \\
\text { persona que verifica los hilos en la } \\
\text { tejedoras. }\end{array}$ \\
\hline
\end{tabular}




\section{FORMATO PARA LA DEFINICIÓN DEL EQUIPO DE GESTIÓN}

\begin{tabular}{|l|l|}
\hline Fecha & Código del Documento \\
\cline { 2 - 2 } & $\begin{array}{l}\text { Fase del Proyecto } \\
\text { PLAN DE ACCIÓN }\end{array}$ \\
\hline $\begin{array}{l}\text { Proyecto } \\
\text { CONSULTORIA TEXTILES EL CID }\end{array}$ & $\begin{array}{l}\text { Departamento Objeto } \\
\text { STAF DE GERENCIA }\end{array}$ \\
\hline Equipo del Proyecto & $\begin{array}{l}\text { Objetivo } \\
\text { ESTABLECER EQUIPO DE CONTACTO }\end{array}$ \\
\hline $\begin{array}{l}\text { Entrevistado } \\
\text { Inforente: }\end{array}$ & \\
\hline
\end{tabular}

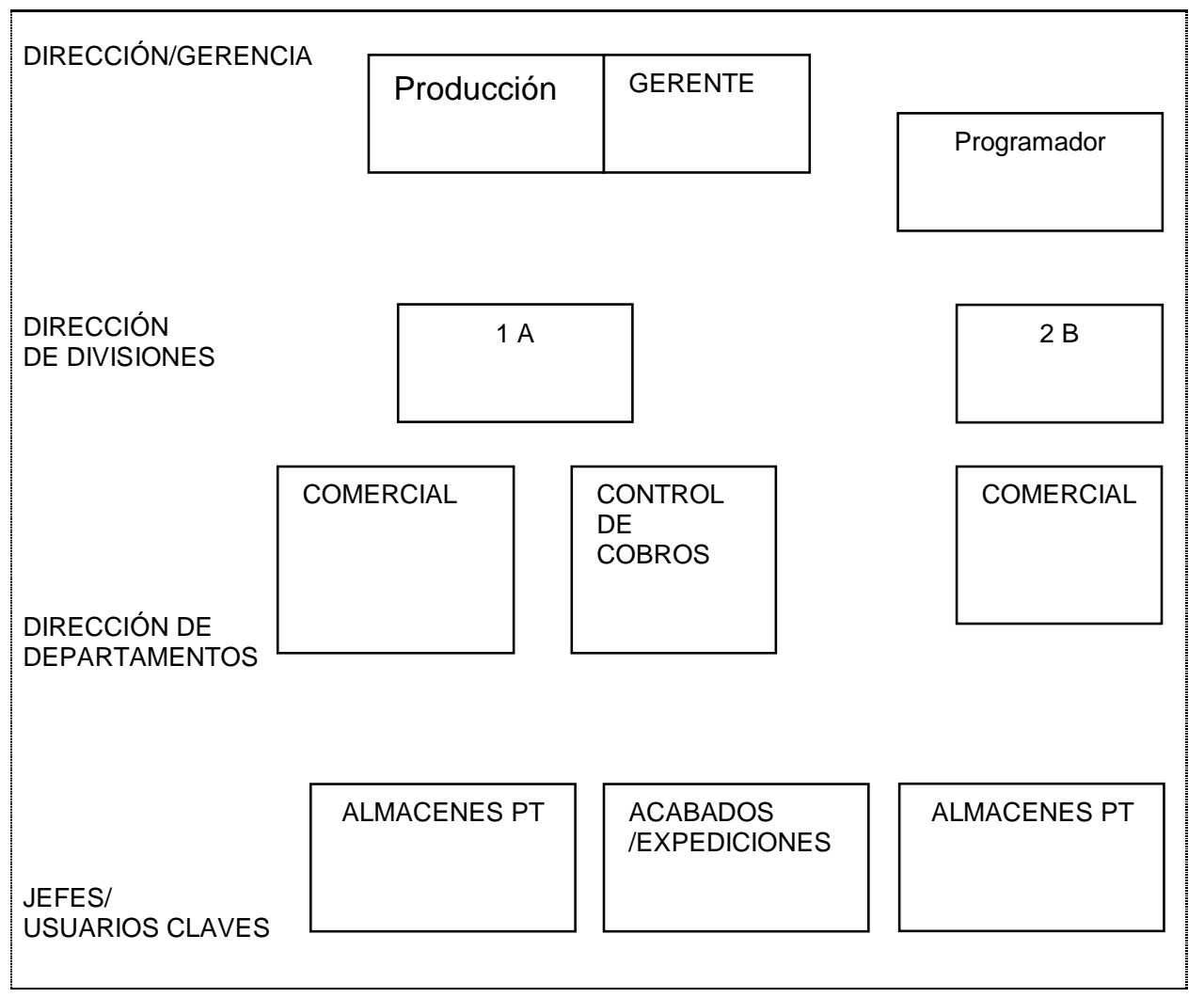




\begin{tabular}{|c|c|c|c|}
\hline $\begin{array}{l}\text { MIEMBROS } \\
\text { G: GERENCIA } \\
\text { E: EQUIPO } \\
1 . \\
2 . \\
3 . \\
4 . \\
5 . \\
6 . \\
7 . \\
8 . \\
9 . \\
10 .\end{array}$ & $\begin{array}{l}\text { DIVISIONES } \\
\begin{array}{ll}\text { 1. } & \mathrm{A} \\
\text { 2. } & \mathrm{B}\end{array}\end{array}$ & $\begin{array}{l}\text { DEPARTAMENTOS } \\
\text { COMERCIAL } \\
\text { FABRICACIÓN } \\
\text { ADMINISTRACION }\end{array}$ & $\begin{array}{l}\text { USUARIOS } \\
\text { CLAVES }\end{array}$ \\
\hline OBSERVACION & & & \\
\hline
\end{tabular}

\begin{tabular}{|c|l|}
\hline FECHA DE ELABORACIÓN & CÓDIGO DEL DOCUMENTO \\
& EQ - 001 \\
\hline PROYECTO & FASE DEL PROYECTO \\
EMPRESA PILOTO & SELECCIÓN DEL EQUIPO DE GESTIÓN DEL PROYECTO \\
\hline ERPIPO DEL PROYECTO & TIPO \\
PILOTO A & Equipo de Integración Empresarial \\
\hline DIRECCIÓN & OBJETIVO \\
& Definición del equipo de gestión de la consultoría. \\
\hline
\end{tabular}

\section{DESCRIPCIÓN DEL EQUIPO}

Equipo interdisciplinar integrado tanto por personal interno, (conocedores de todos los procesos y sistemas de información de la empresa) como externo (expertos en sistemas ERP aplicados al sector textil).

\section{AUTORIDAD Y RESPONSABILIDAD}

Consultoría de selección de empresas de implantación de sistemas ERP. 


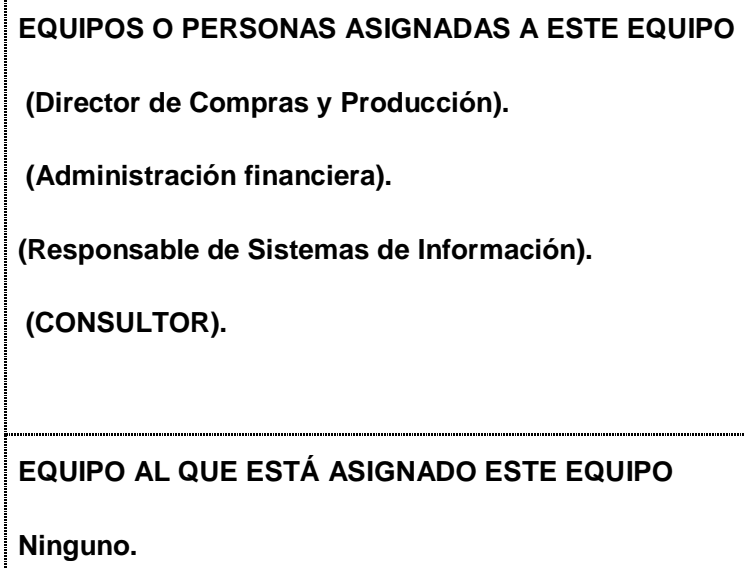

FICHAS PERSONALES:

\begin{tabular}{|l|}
\hline NOMBRE \\
\hline DIRECCIÓN \\
DESCRIPCIÓN DEL TRABAJO \\
Descripción y análisis de los procesos productivos. \\
Supervisión del trabajo de consultoría. \\
\hline PERFIL DE HABILIDADES \\
Conocedor de todos los procesos productivos y de la operativa de la empresa. \\
AUTORIDAD \\
Autoridad sobre todos los miembros del equipo pertenecientes a la empresa piloto A \\
\hline RESPONSABILIDAD \\
Informar sobre objetivos del proyecto, alcance, y proporcionar información necesaria para su \\
Consecución. \\
EQQUIPO O EQUIPOS AL QUE ESTÁ ASIGNADA \\
\hline Piloto A
\end{tabular}




\begin{tabular}{|l|l|l|}
\hline NOMBRE & IDENTIFICADOR \\
\hline DIRECCIÓN & \\
DESCRIPCIÓN DEL TRABAJO \\
Descripción y análisis de los procesos administrativos. \\
PERFIL DE HABILIDADES \\
Conocedora de todos los procesos administrativos de la empresa. \\
AUTORIDAD \\
RESPONSABILIDAD \\
Proporcionar información sobre procesos administrativos. \\
\hline EQUIPO O EQUIPOS AL QUE ESTÁ ASIGNADA \\
\hline
\end{tabular}




\section{ANEXO 5}

\section{DESCRIPCIÓN DE LOS PROCESOS DE NEGOCIO}

Procesos presentes en la empresa piloto:

\begin{tabular}{|l|}
\hline P. Operativos \\
\hline Aprovisionamiento \\
\hline Producción \\
\hline Distribución \\
\hline Ventas \\
\hline Facturación \\
\hline Cobro a clientes \\
\hline Servicio al cliente \\
\hline Captación de clientes \\
\hline Gestión de inventarios y logística \\
\hline Planificación de la producción \\
\hline Pedidos \\
\hline Administración de talleres subcontratados \\
\hline Creación de muestras \\
\hline
\end{tabular}

\begin{tabular}{|l|}
\hline P. de Apoyo \\
\hline Previsiones de demanda \\
\hline Control de producción \\
\hline Calidad \\
\hline Mantenimiento \\
\hline Gestión de muestrarios \\
\hline
\end{tabular}

\begin{tabular}{|l|}
\hline P. de Gestión \\
\hline Contratación/Despido \\
\hline Planificación Estratégica \\
\hline Definición de objetivos \\
\hline Presupuestos \\
\hline Obtención de recursos humanos \\
\hline Obtención de recursos financieros \\
\hline Obtención de recursos de equipamiento \\
\hline Gestión de subcontratas \\
\hline Gestión administrativa \\
\hline
\end{tabular}

\begin{tabular}{|l|}
\hline P. de Información \\
\hline Contabilidad de costes \\
\hline Contabilidad general \\
\hline Nóminas \\
\hline Contabilidad de stocks \\
\hline Preparación de memoria anual \\
\hline Creación de informes \\
\hline Creación de consultas \\
\hline
\end{tabular}

Se han distinguido los siguientes procesos principales:

Elaboración e implementación de la estrategia.

Distribución de productos a clientes.

Producción.

Gestión de calidad. 
Gestión de RRHH.

Gestión de pedidos.

Gestión de stocks.

Aprovisionamiento materias primas.

Gestión servicio-color.

Gestión administrativa de Ventas.

Gestión administrativa de Compras.

Entre ésta lista de procesos, los procesos principales críticos de Producción son:

Aprovisionamiento materias primas.

Fabricación.

Control de subcontratas y Recepción de Producto Acabado.

Gestión servicio-color.

Y los procesos principales de Administración que se analizarán son:

Gestión administrativa de Ventas.

Gestión administrativa de Compras.

Análisis con formato y gráfico del proceso principal operativo de la empresa piloto:

\begin{tabular}{|l|l|}
\hline \multicolumn{1}{|c|}{ Fecha } & Código del Documento \\
& Fase del Proyecto \\
Proyecto & Análisis de necesidades \\
\hline EMPRESA PILOTO & $\begin{array}{l}\text { Tipo } \\
\text { Equipo del Proyecto }\end{array}$ \\
\hline $\begin{array}{l}\text { Autoridad } \\
\text { Director de Compras. }\end{array}$ & $\begin{array}{l}\text { Nombre Principal Operativo. } \\
\text { Aprovisionamiento M.P. }\end{array}$ \\
\hline
\end{tabular}

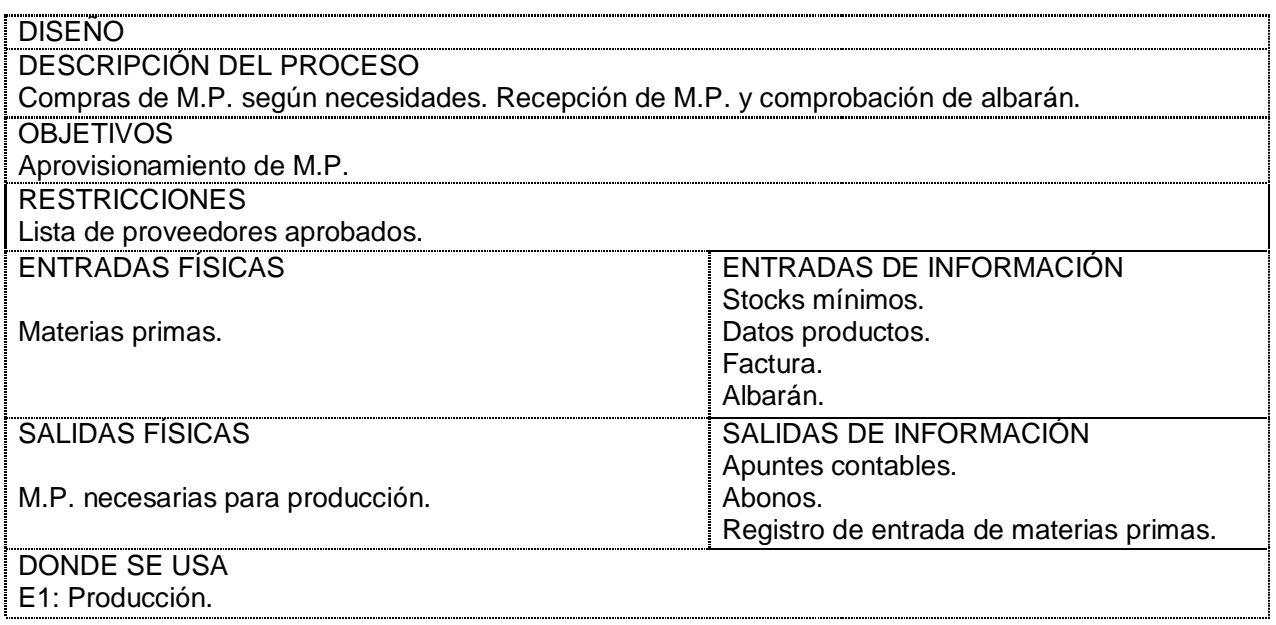


ANEXO 5

\begin{tabular}{l}
\hline COMPRENDE \\
\hline EVENTOS \\
Inventariado mensual de M.P. \\
Entrada de M.P. \\
PARAMETROS \\
No existen en este momento. \\
DIAGRAMA DE FLUJO DEL PROCESO \\
IRÁ ADJUNTO
\end{tabular}




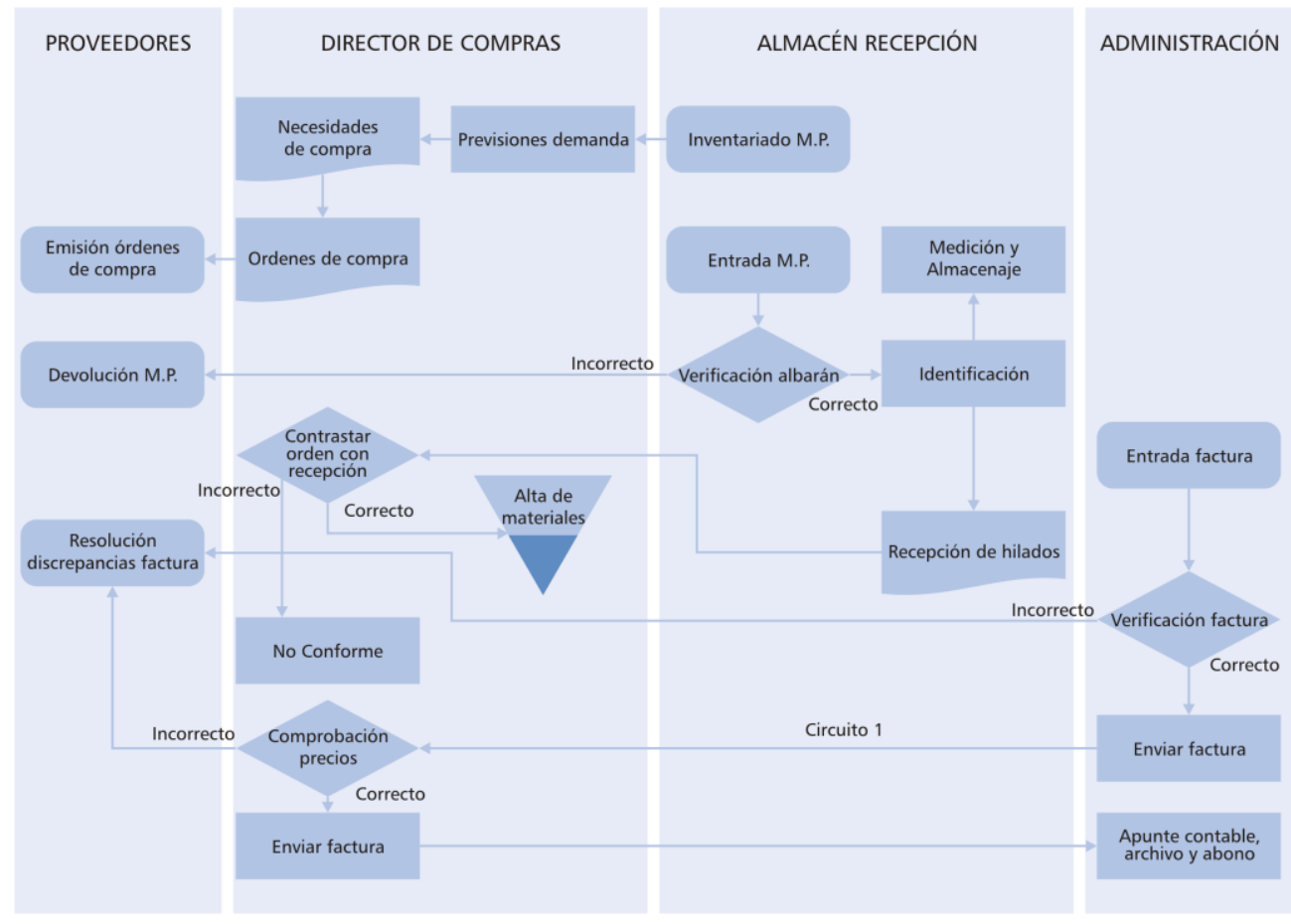

\section{Simbología de los diagramas de flujo:}
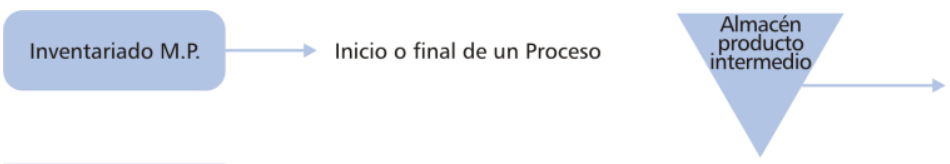

Almacenamiento físico
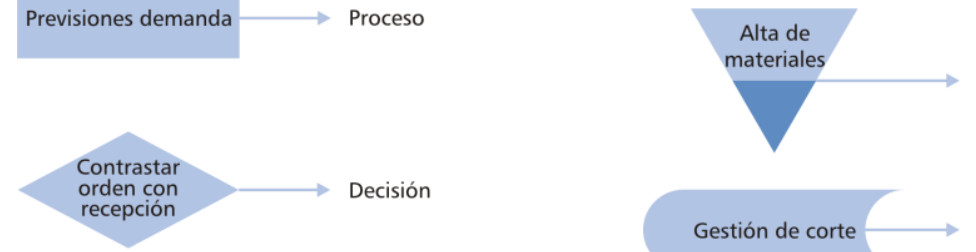

Almacenamiento informático

Gestión de corte

Control de calidad

Necesidades

Documento

Actividad informatizada 


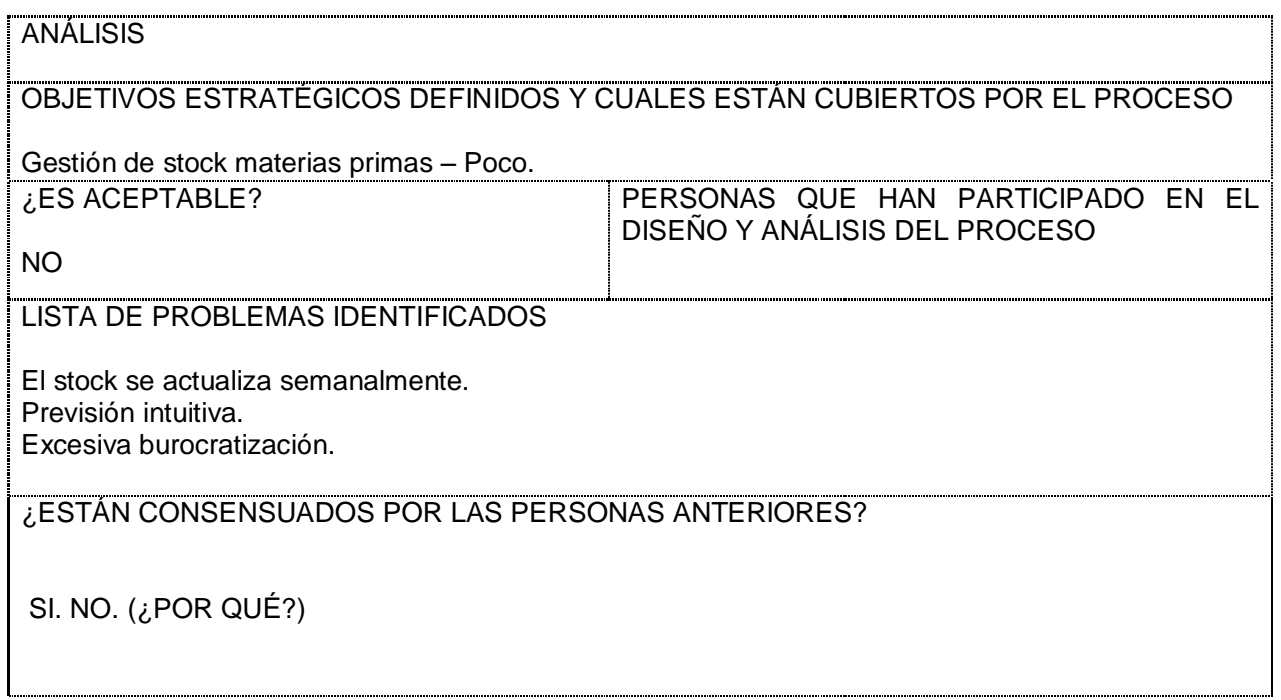




\section{ANEXO 6}

\section{ANÁLISIS DE LOS SISTEMAS DE INFORMACIÓN}

\begin{tabular}{|c|c|c|c|}
\hline \multirow{2}{*}{$\begin{array}{l}\text { EMPRESA PILOTO } \\
\text { Proyecto: } \\
\text { IMPLANTACIÓN }\end{array}$} & \multicolumn{2}{|c|}{$\begin{array}{l}\text { Documento } \\
\text { INVENTARIO DE SISTEMAS } \\
\text { DE INFORMACIÓN }\end{array}$} & $\begin{array}{l}\text { Objetivo: } \\
\text { Identificación Sistemas de } \\
\text { Información: } \\
\text { Hardware/Software }\end{array}$ \\
\hline & & & \multirow[b]{2}{*}{ RESPONSABLE } \\
\hline \multicolumn{2}{|c|}{ EQUIPO INFORMÁTICO } & DEPARTAMENTOS & \\
\hline \multicolumn{2}{|c|}{$\begin{array}{l}\text { Piloto 1a. } \\
\text { Piloto 1b. } \\
\text { Pill 5.0 } \\
\text { Se tienen un conjunto de } 16 \\
\text { ordenadores personales en total. } \\
\text { Ambas redes están "solapadas". } \\
\text { Periféricos: } 8 \text { impresoras. }\end{array}$} & & \\
\hline $\begin{array}{l}\text { APLICACIONES } \\
\text { INFORMÁTICAS }\end{array}$ & & DEPARTAMENTOS & USUARIOS \\
\hline \multicolumn{2}{|l|}{ Procesos Contables } & vo Administrati & \\
\hline \multicolumn{2}{|c|}{ Procesos Comerciales } & vo Administrati & \\
\hline
\end{tabular}

A nivel práctico se analizan principalmente estos elementos:

- Recursos humanos.

- Sistemas informáticos/hardware.

- Parámetros de configuración: lenguajes de desarrollo, ficheros maestros, ejecutables, etc.

- Funcionalidades que proporciona el sistema informático actual en el área administrativa y de producción/operaciones.

- Módulos.

- Procedimientos.

- Requerimientos del sistema de información futuro.

- Conclusiones 


\section{LISTA DE REQUERIMIENTOS A PROVEEDORES DE ERP}

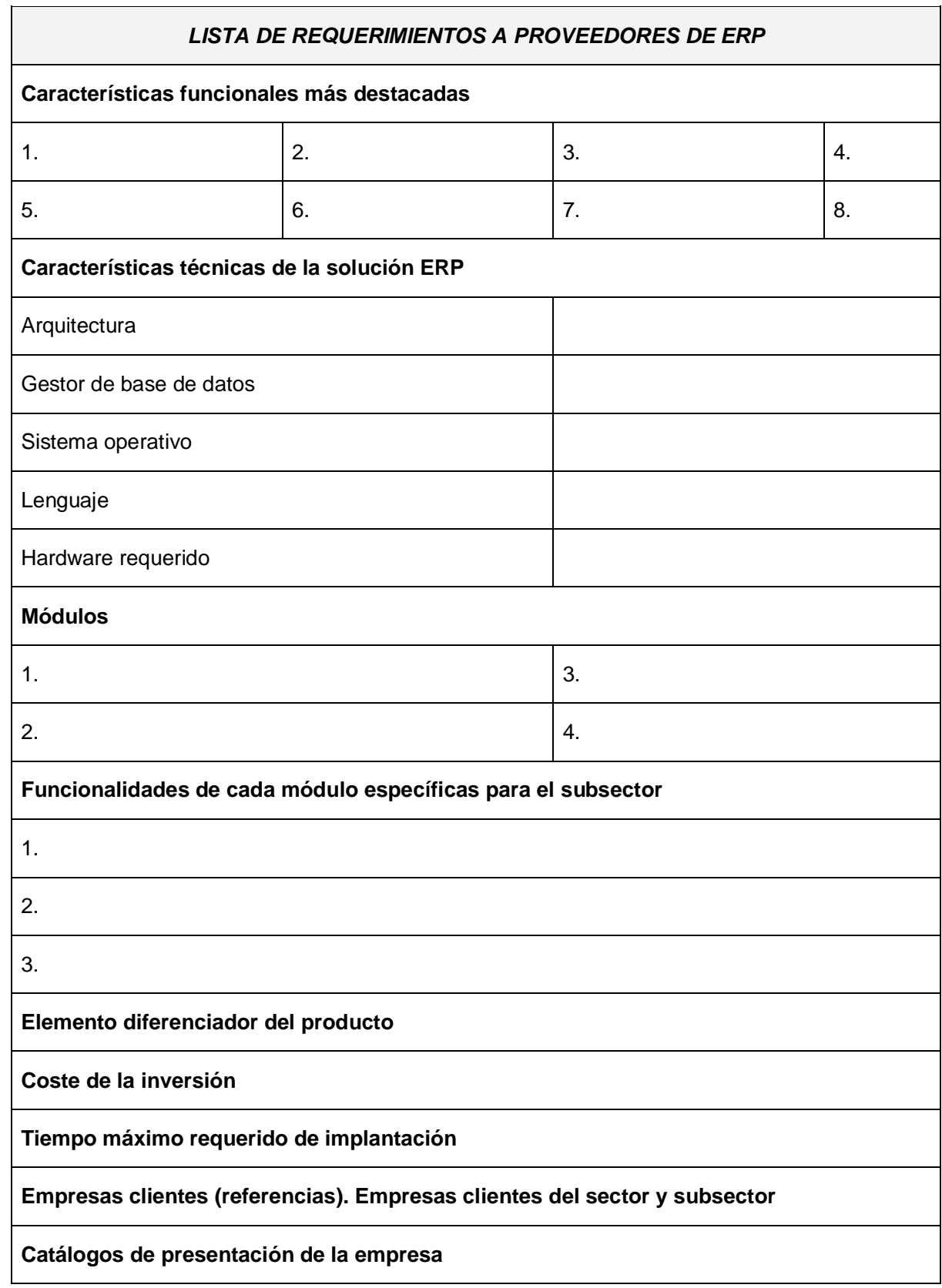




\section{ANEXO 7}

\section{CRITERIOS DE EVALUACIÓN DE LA SOLUCIÓN ERP}

Lista de criterios de valoración de una solución ERP:

\begin{tabular}{|c|c|c|c|}
\hline \multirow[b]{2}{*}{ CRITERIOS } & ERP 1 & ERP 1 & ERP 2 \\
\hline & $\begin{array}{c}\text { Consultora } \\
1\end{array}$ & Consultora 2 & $\begin{array}{c}\text { Consultora } \\
3\end{array}$ \\
\hline \multicolumn{4}{|l|}{ 1.Los criterios de cobertura funcional } \\
\hline \multicolumn{4}{|l|}{ PONDERACIÓN } \\
\hline \multicolumn{4}{|l|}{$\begin{array}{l}\text { Grado de adecuación de la aplicación a las necesidades de la } \\
\text { empresa. }\end{array}$} \\
\hline \multicolumn{4}{|l|}{ Solución de almacén } \\
\hline \multicolumn{4}{|l|}{ Usabilidad por parte del usuario. } \\
\hline \multicolumn{4}{|l|}{ Generación de informes. } \\
\hline \multicolumn{4}{|l|}{ Grado de personalización. } \\
\hline \multicolumn{4}{|l|}{ Flexibilidad, agilidad de parametrización y programación. } \\
\hline VALORACIÓN PARCIAL $\quad X \quad$ PONDERACIÓN & & & \\
\hline \multicolumn{4}{|l|}{ 2. Los criterios de carácter tecnológico } \\
\hline \multicolumn{4}{|l|}{ PONDERACIÓN } \\
\hline \multicolumn{4}{|l|}{ Características de la infraestructura hardware necesaria. } \\
\hline \multicolumn{4}{|l|}{ Modularidad. } \\
\hline \multicolumn{4}{|l|}{ Integración entre módulos y con herramientas ofimáticas externas. } \\
\hline \multicolumn{4}{|l|}{ Herramientas de explotación de la base de datos. } \\
\hline \multicolumn{4}{|l|}{ Seguridad de acceso. } \\
\hline \multicolumn{4}{|l|}{ Protección de datos. } \\
\hline \multicolumn{4}{|l|}{ Conectividad con otros sistemas. } \\
\hline \multicolumn{4}{|l|}{ Entorno de desarrollo } \\
\hline VALORACION PARCIAL $\quad X$ PONDERACIÓN & & & \\
\hline \multicolumn{4}{|l|}{ 3. Los criterios de conocimiento y referencias en el sector } \\
\hline PONDERACIÓN & & & \\
\hline \multicolumn{4}{|l|}{ Experiencia previa en otras empresas del mismo tamaño. } \\
\hline \multicolumn{4}{|l|}{ Experiencia previa en el sector. } \\
\hline \multicolumn{4}{|l|}{ Profesionalidad de los consultores. Experiencia. } \\
\hline \multicolumn{4}{|l|}{ Volumen de rotación del personal: soporte y mantenimiento. } \\
\hline \multicolumn{4}{|l|}{ Referencias. } \\
\hline \multicolumn{4}{|l|}{ Metodología de implantación. } \\
\hline Solvencia económica y financiera del oferente. & & & \\
\hline
\end{tabular}




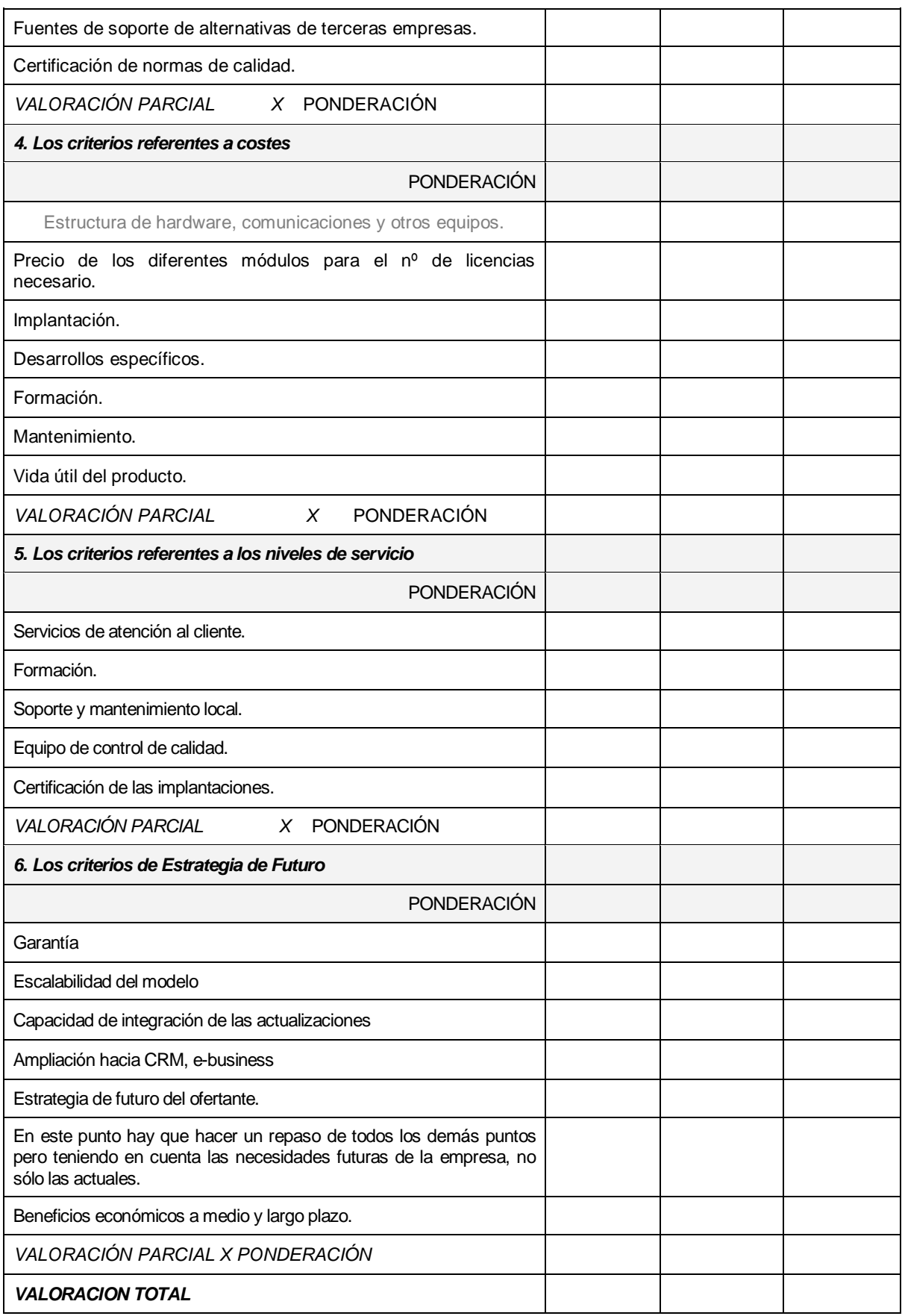


VALORACIÓN PERSONAL

OBSERVACIONES 